\title{
Human Papillomavirus
}

and

\section{Related Diseases Report}

\section{INDIA}

Version posted at www.hpvcentre.net on 10 March 2023 


\section{Copyright and Permissions}

\section{CICO/IARC Information Centre on HPV and Cancer (HPV Information Centre) 2023}

All rights reserved. HPV Information Centre publications can be obtained from the HPV Information Centre Secretariat, Institut Català d'Oncologia, Avda. Gran Via de l'Hospitalet, 199-20308908 L'Hospitalet del Llobregat (Barcelona) Spain. E-mail: hpvcentre@iconcologia.net. Requests for permission to reproduce or translate HPV Information Centre publications - whether for sale or for noncommercial distribution- should be addressed to the HPV Information Centre Secretariat, at the above address. Any digital or printed publication of the information provided in the web site should be accompanied by an acknowledgment of HPV Information Centre as the source.

The designations employed and the presentation of the material in this publication do not imply the expression of any opinion whatsoever on the part the HPV Information Centre concerning the legal status of any country, territory, city or area or of its authorities, or concerning the delimitation of its frontiers or boundaries. Dotted lines on maps represent approximate border lines for which there may not yet be full agreement. The mention of specific companies or of certain manufacturers products does not imply that they are endorsed or recommended the HPV Information Centre in preference to others of a similar nature that are not mentioned. Errors and omissions excepted, the names of proprietary products are distinguished by initial capital letters. All reasonable precautions have been taken by the HPV Information Centre to verify the information contained in this publication. However, the published material is being distributed without warranty of any kind, either expressed or implied. The responsibility for the interpretation and use of the material lies with the reader. In no event shall the HPV Information Centre be liable for damages arising from its use.

\section{Recommended citation:}

Bruni L, Albero G, Serrano B, Mena M, Collado JJ, Gómez D, Muñoz J, Bosch FX, de Sanjosé S. ICO / IARC Information Centre on HPV and Cancer (HPV Information Centre). Human Papillomavirus and Related Diseases in India. Summary Report 10 March 2023. [Date Accessed] 


\section{Executive summary}

Human papillomavirus (HPV) infection is now a well-established cause of cervical cancer and there is growing evidence of HPV being a relevant factor in other anogenital cancers (anus, vulva, vagina and penis) and head and neck cancers. HPV types 16 and 18 are responsible for about $70 \%$ of all cervical cancer cases worldwide. HPV vaccines that prevent against HPV 16 and 18 infection are now available and have the potential to reduce the incidence of cervical and other anogenital cancers.

This report provides key information for India on cervical cancer, other anogenital cancers and head and neck cancers, HPV-related statistics, factors contributing to cervical cancer, cervical cancer screening practices, and HPV vaccine introduction. The report is intended to strengthen the guidance for health policy implementation of primary and secondary cervical cancer prevention strategies in the country. 
Table 1: Key Statistics

\section{Population}

Women at risk for cervical cancer (Female population aged $>=15$ yrs)

511.4 million

Burden of cervical cancer and other HPV-related cancers

Annual number of cervical cancer cases

Annual number of cervical cancer deaths

Crude incidence rates per 100,000 population:

\begin{tabular}{rrr} 
Cervical cancer & Male & Female \\
\hline Anal cancer & - & 18.7 \\
\hline Vulva cancer & 0.43 & 0.35 \\
\hline Vaginal cancer & - & - \\
\hline Penile cancer & 1.49 & 0.52 \\
\hline Oropharyngeal cancer & 2.40 & 0.83 \\
\hline Oral cavity cancer & 14.6 & 0.52 \\
\hline Laryngeal cancer & 4.21 & 4.72 \\
\hline
\end{tabular}

Burden of cervical HPV infection

Prevalence (\%) of HPV 16 and/or HPV 18 among women with:

\begin{tabular}{rr} 
Normal cytology & 5.0 \\
\hline Low-grade cervical lesions (LSIL/CIN-1) & 28.2 \\
\hline High-grade cervical lesions (HSIL/CIN-2/CIN-3/CIS) & \\
\hline Cervical cancer & 62.8 \\
\hline
\end{tabular}

Other factors contributing to cervical cancer

Smoking prevalence (\%) [95\% UI], women

Total fertility rate (live births per women)

Oral contraceptive use (\%)

HIV prevalence (\%) [95\% UI], women (15-49 years)

Sexual behaviour

Percentage of 15-year-old who have had sexual intercourse (men/women)

Range of median age at first sexual intercourse (men/women)

Cervical screening practices and recommendations

Existence of official national recommendations

Starting year of current recommendations 2016

Active invitation to screening

Screening ages (years), primary screening test used, and screening interval or frequency of screen- $30-65$ (VIA, 5 years) ings

\section{HPV vaccine in females}

HPV vaccination programme

Year of introduction

Year of estimation of HPV vaccination coverage

HPV coverage - first dose (\%)

HPV coverage - last dose (\%)

* Please see the specific sections for more information. 


\section{Contents}

Executive summary

1 Introduction 2

2 Demographic and socioeconomic factors 4

3 Burden of HPV related cancers $\quad 5$

$3.1 \mathrm{HPV}$ related cancers incidence . . . . . . . . . . . . . . . . . 5

3.2 HPV related cancers mortality . . . . . . . . . . . . . . . . . . . 7

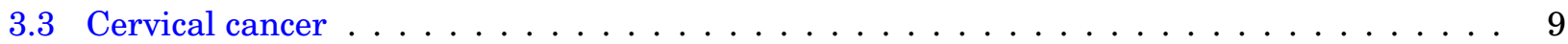

3.3.1 Cervical cancer incidence in India . . . . . . . . . . . . . . . . 9

3.3.2 Cervical cancer incidence by histology in India . . . . . . . . . . . . . . . . . . . . . . . . . . . . . . . .

3.3.3 Cervical cancer mortality in India . . . . . . . . . . . . . . . . . . . . 14

3.3.4 Cervical cancer incidence and mortality comparison in India . . . . . . . . . . . 16

3.4 Anogenital cancers other than the cervix . . . . . . . . . . . . . . . 18

3.4 .1 Anal cancer . . . . . . . . . . . . . . . . . . . 18

3.4.1.1 Anal cancer incidence in India . . . . . . . . . . . . . . . . . . . . . . . . . . . . . . . . . . . . .

3.4.1.2 Anal cancer mortality in India . . . . . . . . . . . . . . . . . 20

3.4.1.3 Anal cancer incidence and mortality comparison in India . . . . . . . . . . 22

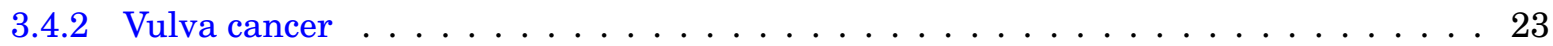

3.4.2.1 Vulva cancer incidence in India . . . . . . . . . . . . . . . . . 23

3.4.2.2 Vulva cancer mortality in India . . . . . . . . . . . . . . . . 25

3.4.2.3 Vulva cancer incidence and mortality comparison in India . . . . . . . . 27

3.4 .3 Vaginal cancer . . . . . . . . . . . . . . . . . . . . . 28

3.4.3.1 Vaginal cancer incidence in India . . . . . . . . . . . . . . . . . . . . . . . . . . . . . .

3.4.3.2 Vaginal cancer mortality in India . . . . . . . . . . . . . . . . . 30

3.4.3.3 Vaginal cancer incidence and mortality comparison in India . . . . . . . . 32

3.4 Penile cancer . . . . . . . . . . . . . . . . . . . . . 33

3.4.4.1 Penile cancer incidence in India . . . . . . . . . . . . . . . . . . . . . . . . . . . . . . . . . . . . . . . . .

3.4.4.2 Penile cancer mortality in India . . . . . . . . . . . . . . . . 35

3.4.4.3 Penile cancer incidence and mortality comparison in India . . . . . . . . . 37

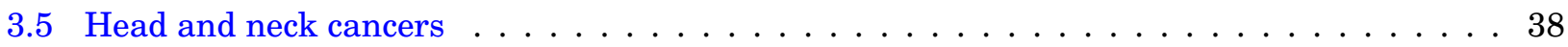

3.5.1 Oropharyngeal cancer . . . . . . . . . . . . . . . . . . 38

3.5.1.1 Oropharyngeal cancer incidence in India . . . . . . . . . . . . . . . . . 38

3.5.1.2 Oropharyngeal cancer mortality in India . . . . . . . . . . . . . . . . . 40

3.5.1.3 Oropharyngeal cancer incidence and mortality comparison in India . . . 42

3.5 .2 Oral cavity cancer . . . . . . . . . . . . . . . . . . . . . 43

3.5.2.1 Oral cavity cancer incidence in India . . . . . . . . . . . . . . . 43

3.5.2.2 Oral cavity cancer incidence and mortality comparison in India . . . . . . 45

3.5.2.3 Oral cavity cancer incidence and mortality comparison in India . . . . . . 47

3.5.3 Laryngeal cancer . . . . . . . . . . . . . . . . . . . . . . 48

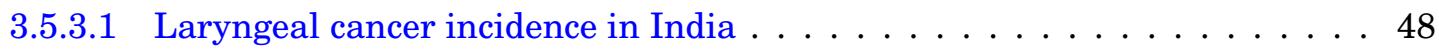

3.5.3.2 Laryngeal cancer incidence and mortality comparison in India . . . . . . 50

3.5.3.3 Laryngeal cancer incidence and mortality comparison in India . . . . . . . 52

4 HPV related statistics

4.1 HPV burden in women with normal cervical cytology, cervical precancerous lesions or invasive cervical cancer . . . . . . . . . . . . . . . . . . . 53

4.1.1 HPV prevalence in women with normal cervical cytology . . . . . . . . . . . . 5 54

4.1.2 HPV type distribution among women with normal cervical cytology, precancerous cervical lesions and cervical cancer . . . . . . . . . . . . . . 56 56

4.1.3 HPV type distribution among HIV+ women with normal cervical cytology . . . . . 66 


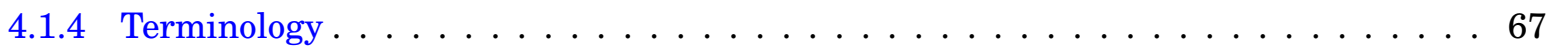

4.2 HPV burden in anogenital cancers other than cervix $\ldots \ldots \ldots \ldots$

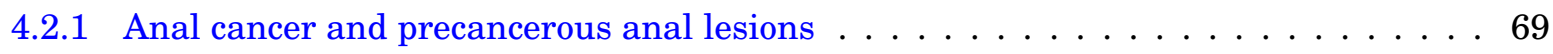

4.2.2 Vulvar cancer and precancerous vulvar lesions . . . . . . . . . . . . . . . . 71

4.2 .3 Vaginal cancer and precancerous vaginal lesions $\ldots \ldots \ldots \ldots \ldots$

4.2.4 Penile cancer and precancerous penile lesions $\ldots \ldots \ldots \ldots \ldots \ldots \ldots$

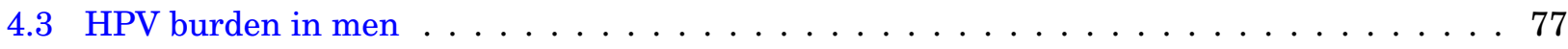

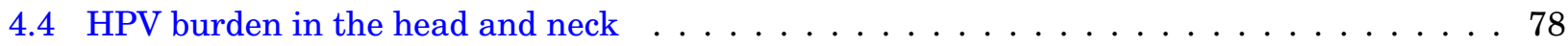

4.4.1 Burden of oral HPV infection in healthy population . . . . . . . . . . . 78

4.4 .2 HPV burden in head and neck cancers . . . . . . . . . . . . . . . . . . 79

$\begin{array}{lll}5 & \text { Factors contributing to cervical cancer } & 81\end{array}$

6 Sexual and reproductive health behaviour indicators $\quad 82$

7 HPV preventive strategies $\quad 85$

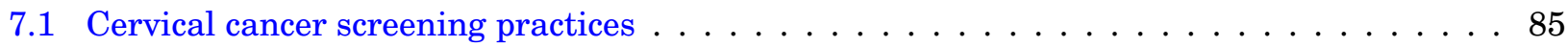

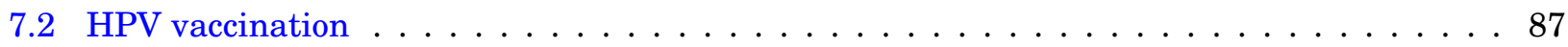

8 Protective factors for cervical cancer $\quad 89$

9 Annex $\quad 90$

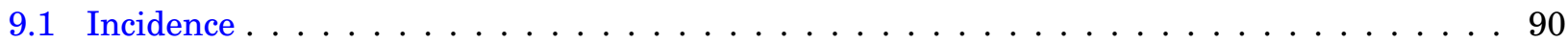

9.1.1 Cervical cancer incidence in India across Southern Asia . . . . . . . . . . . . . . 90

9.1.2 Anal cancer incidence in India across Southern Asia . . . . . . . . . . . . . . . 93

9.1 .3 Vulva cancer incidence in India across Southern Asia . . . . . . . . . . . . . . . 98

9.1.4 Vaginal cancer incidence in India across Southern Asia . . . . . . . . . . . . . . 101

9.1.5 Penile cancer incidence in India across Southern Asia . . . . . . . . . . . . . . . 104

9.1.6 Oropharyngeal cancer incidence in India across Southern Asia . . . . . . . . . . . 107

9.1.7 Oral cavity cancer incidence in India across Southern Asia . . . . . . . . . . . . 112

9.1.8 Laryngeal cancer incidence in India across Southern Asia . . . . . . . . . . . . . . . . 117

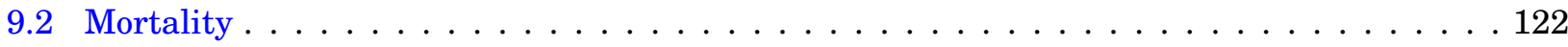

9.2.1 Cervical cancer mortality in India across Southern Asia . . . . . . . . . . . . . . . 122

9.2.2 Anal cancer mortality in India across Southern Asia . . . . . . . . . . . . . . 125

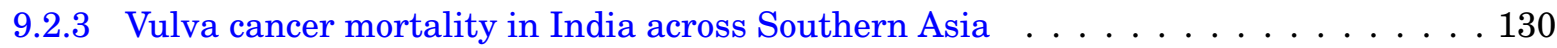

9.2.4 Vaginal cancer mortality in India across Southern Asia . . . . . . . . . . . . . 133

9.2.5 Penile cancer mortality in India across Southern Asia . . . . . . . . . . . . . . . . 136

9.2.6 Oropharyngeal cancer mortality in India across Southern Asia . . . . . . . . . . . 139

9.2.7 Oral cavity cancer mortality in India across Southern Asia . . . . . . . . . . . . 144

9.2.8 Laryngeal cancer mortality in India across Southern Asia . . . . . . . . . . . . . 149

10 Glossary $\quad 154$ 


\section{List of Figures}

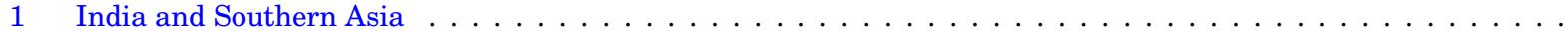

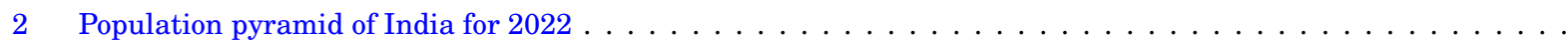

3 Population trends in four selected age groups in India . . . . . . . . . . . . . . . . . . . . .

4 Comparison of HPV related cancers incidence to other cancers in men and women of all ages in India (estimates for 2020)

5 Comparison of HPV related cancers incidence to other cancers among men and women 15-44 years of age in India (estimates for 2020).

6 Comparison of HPV related cancers mortality to other cancers in men and women of all ages in India (estimates

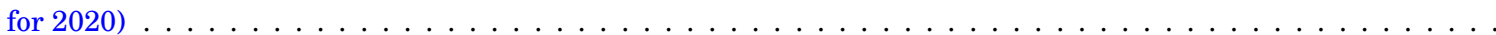

7 Comparison of HPV related cancers mortality to other cancers among men and women 15-44 years of age in India (estimates for 2020).

8 Age-specific incidence rates of cervical cancer in India (estimates for 2020) . . . . . . . . . . . . . . . . . . .

9 Annual number of new cases of cervical cancer in India (estimates for 2020) . . . . . . . . . . . . . . .

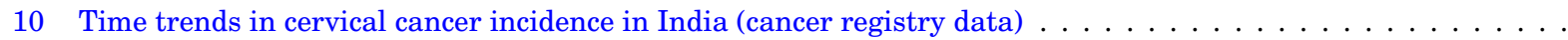

11 Age-specific mortality rates of cervical cancer in India (estimates for 2020) . . . . . . . . . . . . . . . . . .

12 Annual number of deaths of cervical cancer in India (estimates for 2020) . . . . . . . . . . . . . . . . .

13 Comparison of age-specific cervical cancer incidence and mortality rates in India (estimates for 2020) . . . . .

14 Comparison of annual premature deaths and disability from cervical cancer in India to other cancers among women $($ estimates for 2019$) \quad \ldots \ldots \ldots \ldots \ldots \ldots \ldots$

15 Age-specific incidence rates of anal cancer in India (estimates for 2020) . . . . . . . . . . . . . . . . .

16 Annual number of new cases of anal cancer in India (estimates for 2020) . . . . . . . . . . . . . . . . .

17 Age-specific mortality rates of anal cancer in India (estimates for 2020) . . . . . . . . . . . . . . . . . .

18 Annual number of deaths of of anal cancer in India (estimates for 2020) . . . . . . . . . . . . . . . . .

19 Comparison of age-specific anal cancer incidence and mortality rates among men in India (estimates for 2020) .

20 Comparison of age-specific anal cancer incidence and mortality rates among women in India (estimates for 2020)

21 Age-specific incidence rates of vulva cancer in India (estimates for 2020) . . . . . . . . . . . . . . . .

22 Annual number of new cases of vulva cancer in India (estimates for 2020) . . . . . . . . . . . . . . . .

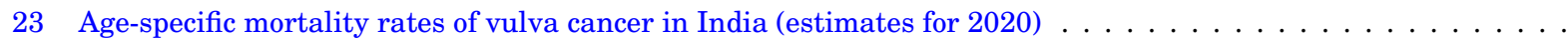
Annual number of deaths of vulva cancer in India (estimates for 2020) . . . . . . . . . . . . . . . . . Comparison of age-specific vulva cancer incidence and mortality rates in India (estimates for 2020) . . . . . . Age-specific incidence rates of vaginal cancer in India (estimates for 2020) . . . . . . . . . . . . . . .

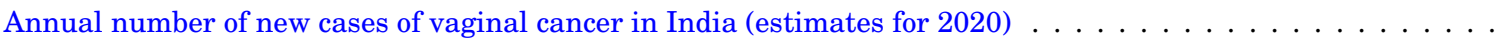

Age-specific mortality rates of vaginal cancer in India (estimates for 2020) . . . . . . . . . . . . . . . .

Annual number of deaths of vaginal cancer in India (estimates for 2020) . . . . . . . . . . . . . . . . .

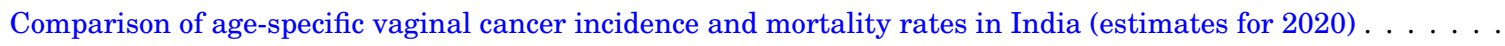

31 Age-specific incidence rates of penile cancer in India (estimates for 2020) . . . . . . . . . . . . . . . . . .

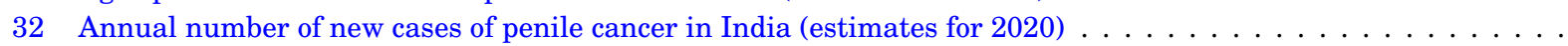

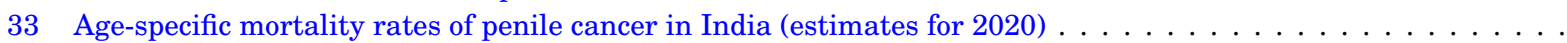

34 Annual number of deaths of penile cancer in India (estimates for 2020) . . . . . . . . . . . . . . . . .

35 Comparison of age-specific penile cancer incidence and mortality rates in India (estimates for 2020) . . . . . .

36 Age-specific incidence rates of oropharyngeal cancer in India (estimates for 2020) . . . . . . . . . . . . . . . .

37 Annual number of new cases of oropharyngeal cancer in India (estimates for 2020) . . . . . . . . . . . . .

38 Age-specific mortality rates of oropharyngeal cancer in India (estimates for 2020) . . . . . . . . . . . . . . . . .

39 Annual number of deaths of oropharyngeal cancer in India (estimates for 2020) . . . . . . . . . . . . . . .

40 Comparison of age-specific oropharyngeal cancer incidence and mortality rates among men in India (estimates for 2020)

41 Comparison of age-specific oropharyngeal cancer incidence and mortality rates among women in India (estimates

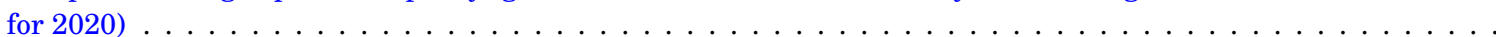

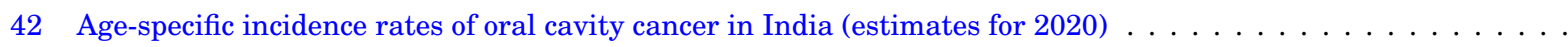

43 Annual number of new cases of oral cavity cancer in India (estimates for 2020) . . . . . . . . . . . . . . .

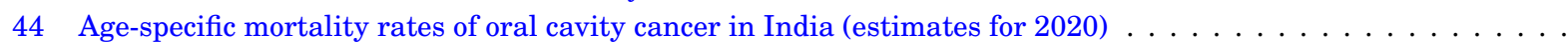

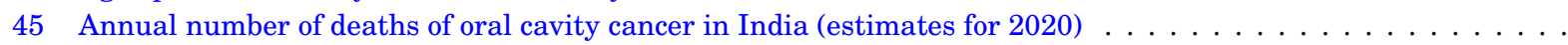

46 Comparison of age-specific oral cavity cancer incidence and mortality rates among men in India (estimates for

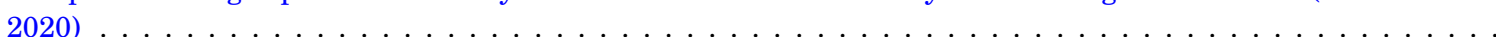

47 Comparison of age-specific oral cavity cancer incidence and mortality rates among women in India (estimates

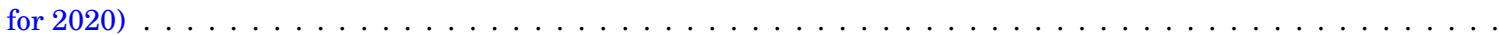

48 Age-specific incidence rates of laryngeal cancer in India (estimates for 2020) . . . . . . . . . . . . . . . .

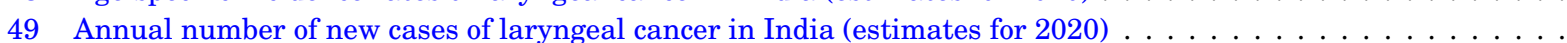

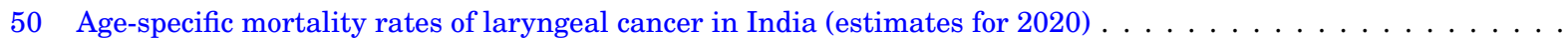

51 Annual number of deaths of of laryngeal cancer in India (estimates for 2020) . . . . . . . . . . . . . . . .

52 Comparison of age-specific laryngeal cancer incidence and mortality rates among men in India (estimates for 2020) 
53 Comparison of age-specific laryngeal cancer incidence and mortality rates among women in India (estimates for

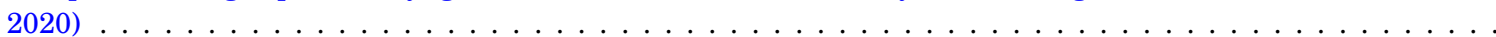

54 Crude age-specific HPV prevalence (\%) and 95\% confidence interval in women with normal cervical cytology in

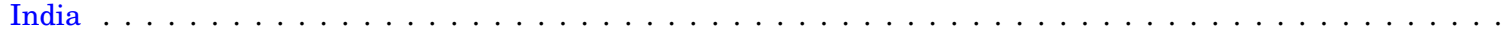

55 HPV prevalence among women with normal cervical cytology in India, by study . . . . . . . . . . . . . . . . . . . . . . . .

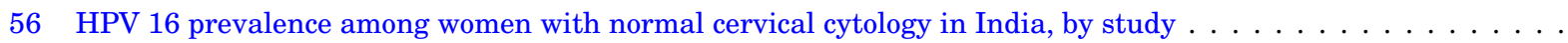

57 HPV 16 prevalence among women with low-grade cervical lesions in India, by study . . . . . . . . . . . . .

58 HPV 16 prevalence among women with high-grade cervical lesions in India, by study . . . . . . . . . . . . .

59 HPV 16 prevalence among women with invasive cervical cancer in India, by study . . . . . . . . . . . . . . .

60 Comparison of the ten most frequent HPV oncogenic types in India among women with and without cervical

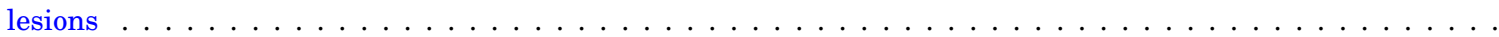

61 Comparison of the ten most frequent HPV oncogenic types in India among women with invasive cervical cancer

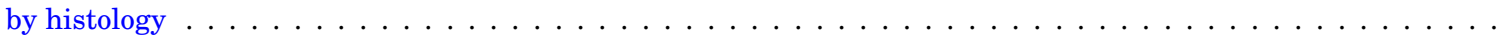

62 Comparison of the ten most frequent HPV types in anal cancer cases in Asia and the World . . . . . . . . .

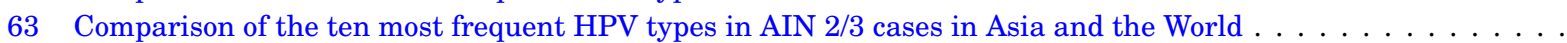

64 Comparison of the ten most frequent HPV types in cases of vulvar cancer in Asia and the World . . . . . . . . .

65 Comparison of the ten most frequent HPV types in VIN $2 / 3$ cases in Asia and the World . . . . . . . . . . . . .

66 Comparison of the ten most frequent HPV types in cases of vaginal cancer in Asia and the World . . . . . . . .

67 Comparison of the ten most frequent HPV types in VaIN $2 / 3$ cases in Asia and the World . . . . . . . . . . . .

68 Comparison of the ten most frequent HPV types in cases of penile cancer in Asia and the World . . . . . . . . .

69 Comparison of the ten most frequent HPV types in PeIN $2 / 3$ cases in Asia and the World . . . . . . . . . . . .

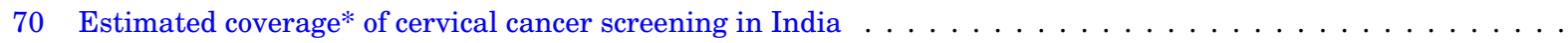

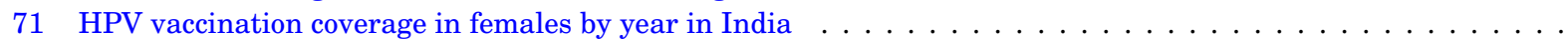

72 HPV vaccination coverage in males by year in India . . . . . . . . . . . . . . . . . . . .

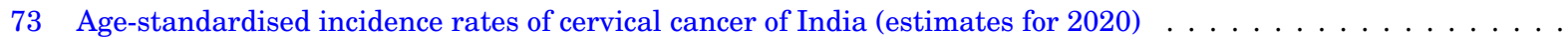

74 Annual number of new cases of cervical cancer by age group in India (estimates for 2020) . . . . . . . . . . . .

75 Comparison of age-specific cervical cancer incidence rates in India, within the region, and the rest of world . . .

76 Age-standardised incidence rates of anal cancer of India (estimates for 2020) . . . . . . . . . . . . . . . . . . .

77 Annual number of new cases of anal cancer among men by age group in India (estimates for 2020) . . . . . .

78 Annual number of new cases of anal cancer among women by age group in India (estimates for 2020) . . . . .

79 Comparison of age-specific anal cancer incidence rates among men by age in India, within the region, and the rest of world . . . . . . . . . . . . . . . . . . . . . . . . . . . . .

80 Comparison of age-specific anal cancer incidence rates among women by age in India, within the region, and the rest of world . . . . . . . . . . . . . . . . . . . . . . . . . . . . .

81 Age-standardised incidence rates of vulva cancer of India (estimates for 2020) . . . . . . . . . . . . . . . .

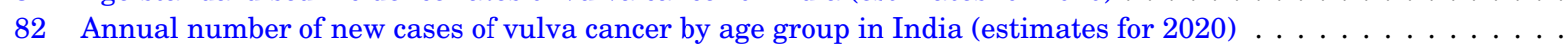

83 Comparison of age-specific vulva cancer incidence rates in India, within the region, and the rest of world . . .

84 Age-standardised incidence rates of vaginal cancer of India (estimates for 2020) . . . . . . . . . . . . . . . . .

85 Annual number of new cases of cervical cancer by age group in India (estimates for 2020) . . . . . . . . . . .

86 Comparison of age-specific vaginal cancer incidence rates in India, within the region, and the rest of world ...

87 Age-standardised incidence rates of penile cancer of India (estimates for 2020) . . . . . . . . . . . . . . . . .

88 Annual number of new cases of penile cancer by age group in India (estimates for 2020 ) . . . . . . . . . . . .

89 Comparison of age-specific penile cancer incidence rates in India, within the region, and the rest of world . . . .

90 Age-standardised incidence rates of oropharyngeal cancer of India (estimates for 2020) . . . . . . . . . . . . . .

91 Annual number of new cases of oropharyngeal cancer among men by age group in India (estimates for 2020) . .

92 Annual number of new cases of oropharyngeal cancer among women by age group in India (estimates for 2020)

93 Comparison of age-specific oropharyngeal cancer incidence rates among men by age in India, within the region,

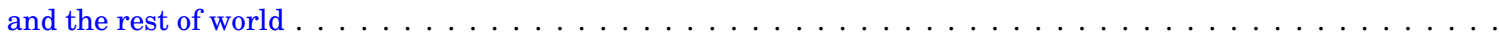

94 Comparison of age-specific oropharyngeal cancer incidence rates among women by age in India, within the

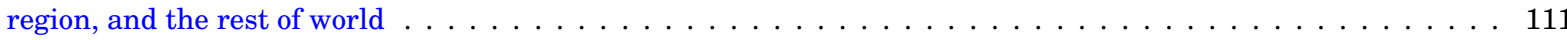

95 Age-standardised incidence rates of oral cavity cancer of India (estimates for 2020) . . . . . . . . . . . . . . . 112

96 Annual number of new cases of oral cavity cancer among men by age group in India (estimates for 2020) . . . . 113

97 Annual number of new cases of oral cavity cancer among women by age group in India (estimates for 2020) . . . 114

98 Comparison of age-specific oral cavity cancer incidence rates among men by age in India, within the region, and

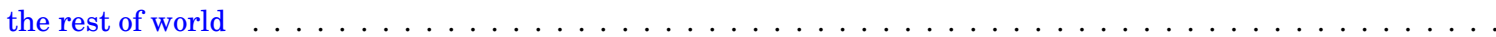

99 Comparison of age-specific oral cavity cancer incidence rates among women by age in India, within the region,

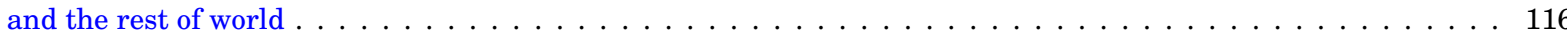

100 Age-standardised incidence rates of laryngeal cancer of India (estimates for 2020$) \ldots \ldots \ldots \ldots$

101 Annual number of new cases of laryngeal cancer among men by age group in India (estimates for 2020) . . . . 118

102 Annual number of new cases of laryngeal cancer among women by age group in India (estimates for 2020) . . . 119

103 Comparison of age-specific laryngeal cancer incidence rates among men by age in India, within the region, and

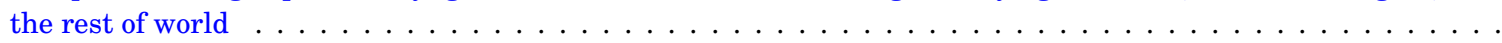

104 Comparison of age-specific laryngeal cancer incidence rates among women by age in India, within the region,

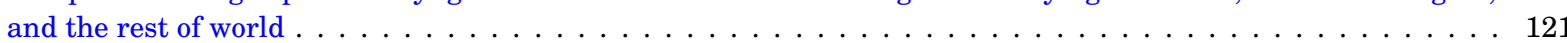

105 Age-standardised mortality rates of cervical cancer of India (estimates for 2020) . . . . . . . . . . . . . . 122 
106 Annual number of deaths of cervical cancer by age group in India (estimates for 2020) . . . . . . . . . . . 123

107 Comparison of age-specific cervical cancer mortality rates in India, within the region, and the rest of world . . . 124

108 Age-standardised mortality rates of anal cancer of India (estimates for 2020) . . . . . . . . . . . . . 125

109 Annual number of deaths of anal cancer among men by age group in India (estimates for 2020) . . . . . . . 126

110 Annual number of deaths of anal cancer among women by age group in India (estimates for 2020) $\quad \ldots \ldots$. . . 127

111 Comparison of age-specific anal cancer mortality rates among men by age in India, within the region, and the rest of world . . . . . . . . . . . . . . . . . . . . . . . . . . . . . . . . . . 128

112 Comparison of age-specific anal cancer mortality rates among women by age in India, within the region, and the rest of world . . . . . . . . . . . . . . . . . . . . . . . . . . . . . . . . . . 129

113 Age-standardised mortality rates of vulva cancer of India (estimates for 2020) . . . . . . . . . . . . . . . . 130

114 Annual number of deaths of vulva cancer by age group in India (estimates for 2020) . . . . . . . . . . . . . 131

115 Comparison of age-specific vulva cancer mortality rates in India, within the region, and the rest of world . . . 132

116 Age-standardised mortality rates of vaginal cancer of India (estimates for 2020) . . . . . . . . . . . . . . . 133

117 Annual number of deaths of cervical cancer by age group in India (estimates for 2020) . . . . . . . . . . . . 134

118 Comparison of age-specific vaginal cancer mortality rates in India, within the region, and the rest of world . . . 135

119 Age-standardised mortality rates of penile cancer of India (estimates for 2020) . . . . . . . . . . . . . . . . 136

120 Annual number of new deaths of penile cancer by age group in India (estimates for 2020) . . . . . . . . . . 137

121 Comparison of age-specific penile cancer mortality rates in India, within the region, and the rest of world . . . 138

122 Age-standardised mortality rates of oropharyngeal cancer of India (estimates for 2020) . . . . . . . . . . . . 139

123 Annual number of deaths of oropharyngeal cancer among men by age group in India (estimates for 2020) . . . 140

124 Annual number of deaths of oropharyngeal cancer among women by age group in India (estimates for 2020) . . 141

125 Comparison of age-specific oropharyngeal cancer mortality rates among men by age in India, within the region, and the rest of world . . . . . . . . . . . . . . . . . . . . . . . . . . . . . . . . . . 142

126 Comparison of age-specific oropharyngeal cancer mortality rates among women by age in India, within the region, and the rest of world . . . . . . . . . . . . . . . . . . . . . . . . . . . . . 143

127 Age-standardised mortality rates of oral cavity cancer of India (estimates for 2020) . . . . . . . . . . . . . . 144

128 Annual number of deaths of oral cavity cancer among men by age group in India (estimates for 2020) . . . . . 145

129 Annual number of deaths of oral cavity cancer among women by age group in India (estimates for 2020) . . . . 146

130 Comparison of age-specific oral cavity cancer mortality rates among men by age in India, within the region, and

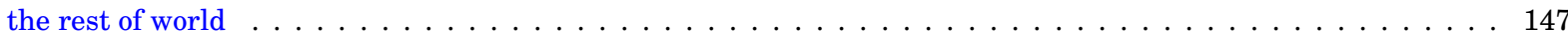

131 Comparison of age-specific oral cavity cancer mortality rates among women by age in India, within the region,

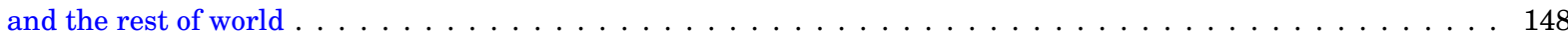

132 Age-standardised mortality rates of laryngeal cancer of India (estimates for 2020) . . . . . . . . . . . . 149

133 Annual number of deaths of laryngeal cancer among men by age group in India (estimates for 2020) . . . . . 150

134 Annual number of deaths of laryngeal cancer among women by age group in India (estimates for 2020) . . . . 151

135 Comparison of age-specific laryngeal cancer mortality rates among men by age in India, within the region, and

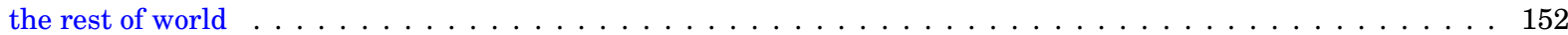

136 Comparison of age-specific laryngeal cancer mortality rates among women by age in India, within the region,

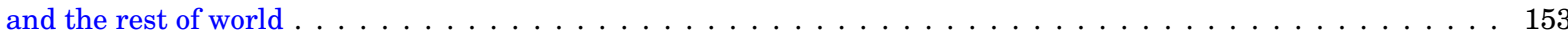




\section{List of Tables}

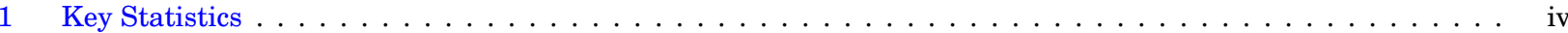

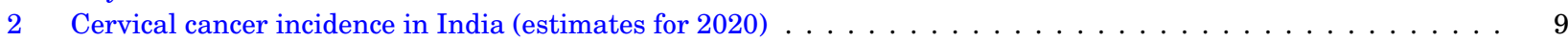

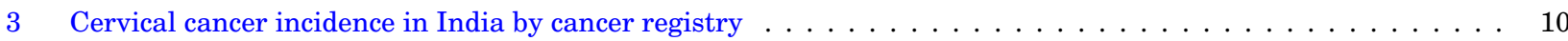

4 Age-standardised incidence rates of cervical cancer in India by histological type and cancer registry $\ldots \ldots \ldots$

5 Cervical cancer mortality in India (estimates for 2020) . . . . . . . . . . . . . . . . . . . . . . . . . 14

6 Premature deaths and disability from cervical cancer in India, Asia and the rest of the world (estimates for 2019$) 16$

7 Anal cancer incidence in India (estimates for 2020) . . . . . . . . . . . . . . . . . . . . . . . 18

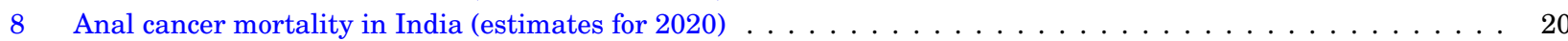

9 Vulva cancer incidence in India (estimates for 2020$) \ldots \ldots \ldots \ldots \ldots \ldots \ldots$

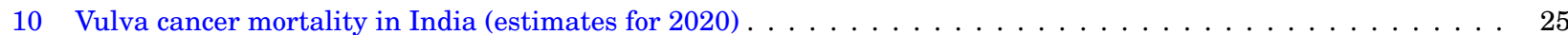

11 Vaginal cancer incidence in India (estimates for 2020$) \ldots \ldots \ldots \ldots$

12 Vaginal cancer mortality in India (estimates for 2020) $\ldots \ldots \ldots \ldots \ldots$

13 Penile cancer incidence in India (estimates for 2020) $\ldots \ldots \ldots \ldots \ldots \ldots$

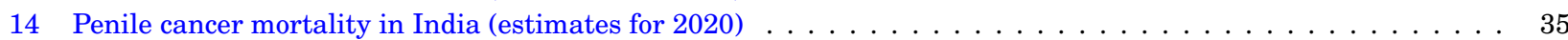

15 Oropharyngeal cancer incidence in India (estimates for 2020) . . . . . . . . . . . . . . . . . . 38

16 Oropharyngeal cancer mortality in India (estimates for 2020) . . . . . . . . . . . . . . . . . . . . . 40

17 Oral cavity cancer incidence in India (estimates for 2020) . . . . . . . . . . . . . . . . . . . . . . 43

18 Oral cavity cancer mortality in India (estimates for 2020$) \ldots \ldots \ldots \ldots \ldots$

19 Laryngeal cancer incidence in India (estimates for 2020) . . . . . . . . . . . . . . . . . . . . . . . . . . 48

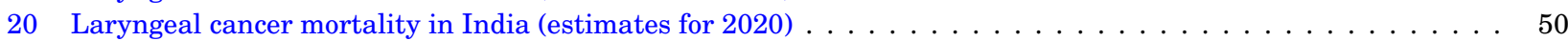

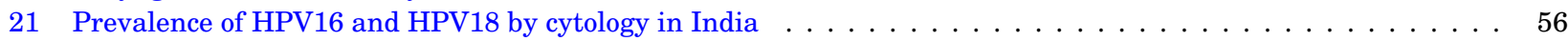

22 Type-specific HPV prevalence in women with normal cervical cytology, precancerous cervical lesions and invasive cervical cancer in India . . . . . . . . . . . . . . . . . . . . . . . . . . . . . . . . . . 63

23 Type-specific HPV prevalence among invasive cervical cancer cases in India by histology . . . . . . . . . . . 65

24 Studies on HPV prevalence among HIV+ women with normal cytology in India . . . . . . . . . . . . . . . . 66

25 Studies on HPV prevalence among anal cancer cases in India (male and female) . . . . . . . . . . . . . . . . 69

26 Studies on HPV prevalence among cases of AIN2/3 in India . . . . . . . . . . . . . . . . . . . . . 69

27 Studies on HPV prevalence among vulvar cancer cases in India . . . . . . . . . . . . . . . . . . . . . . . 71

28 Studies on HPV prevalence among VIN $2 / 3$ cases in India . . . . . . . . . . . . . . . . . . . . . . . 71

29 Studies on HPV prevalence among vaginal cancer cases in India . . . . . . . . . . . . . . . . . . 73

30 Studies on HPV prevalence among VaIN $2 / 3$ cases in India . . . . . . . . . . . . . . . . . . . . . . 73

31 Studies on HPV prevalence among penile cancer cases in India . . . . . . . . . . . . . . . . . . . . . . 75

32 Studies on HPV prevalence among PeIN $2 / 3$ cases in India . . . . . . . . . . . . . . . . . . . 75

33 Studies on HPV prevalence among men in India . . . . . . . . . . . . . . . . . . . . . . . . . . 77

34 Studies on HPV prevalence among men from special subgroups in India . . . . . . . . . . . . . . . . 77

35 Studies on oral HPV prevalence among healthy in India . . . . . . . . . . . . . . . . . 78

36 Studies on HPV prevalence among cases of oral cavity cancer in India . . . . . . . . . . . . . . . . . . . . 79

37 Studies on HPV prevalence among cases of oropharyngeal cancer in India . . . . . . . . . . . . . . . . . . 80

38 Studies on HPV prevalence among cases of hypopharyngeal or laryngeal cancer in India . . . . . . . . . . 80

39 Factors contributing to cervical carcinogenesis (cofactors) in India . . . . . . . . . . . . . . . . . . . . . 81

40 Percentage of 15 -year-olds who have had sexual intercourse in India . . . . . . . . . . . . . . . . . . . . . 82

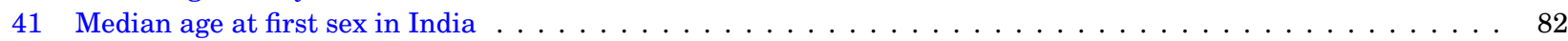

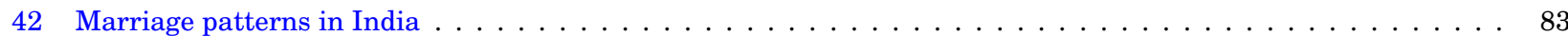

43 Average number of sexual partners in India . . . . . . . . . . . . . . . . . . . . . . 83

44 Lifetime prevalence of anal intercourse among women in India . . . . . . . . . . . . . . . . . . . . . . . . . . . . . . .

45 Main characteristics of cervical cancer screening in India . . . . . . . . . . . . . . . . . . . . . . 85

46 National HPV Immunization programme in India . . . . . . . . . . . . . . . . . . . . . . . . 87

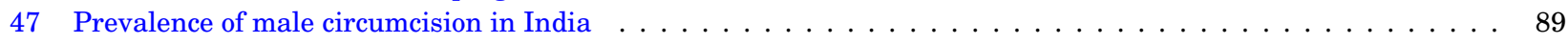

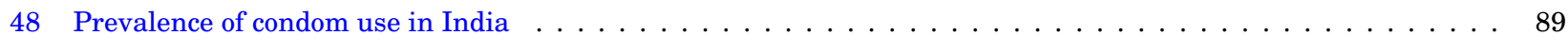

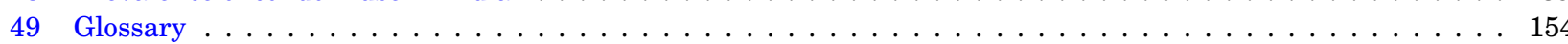




\section{Introduction}

Figure 1: India and Southern Asia

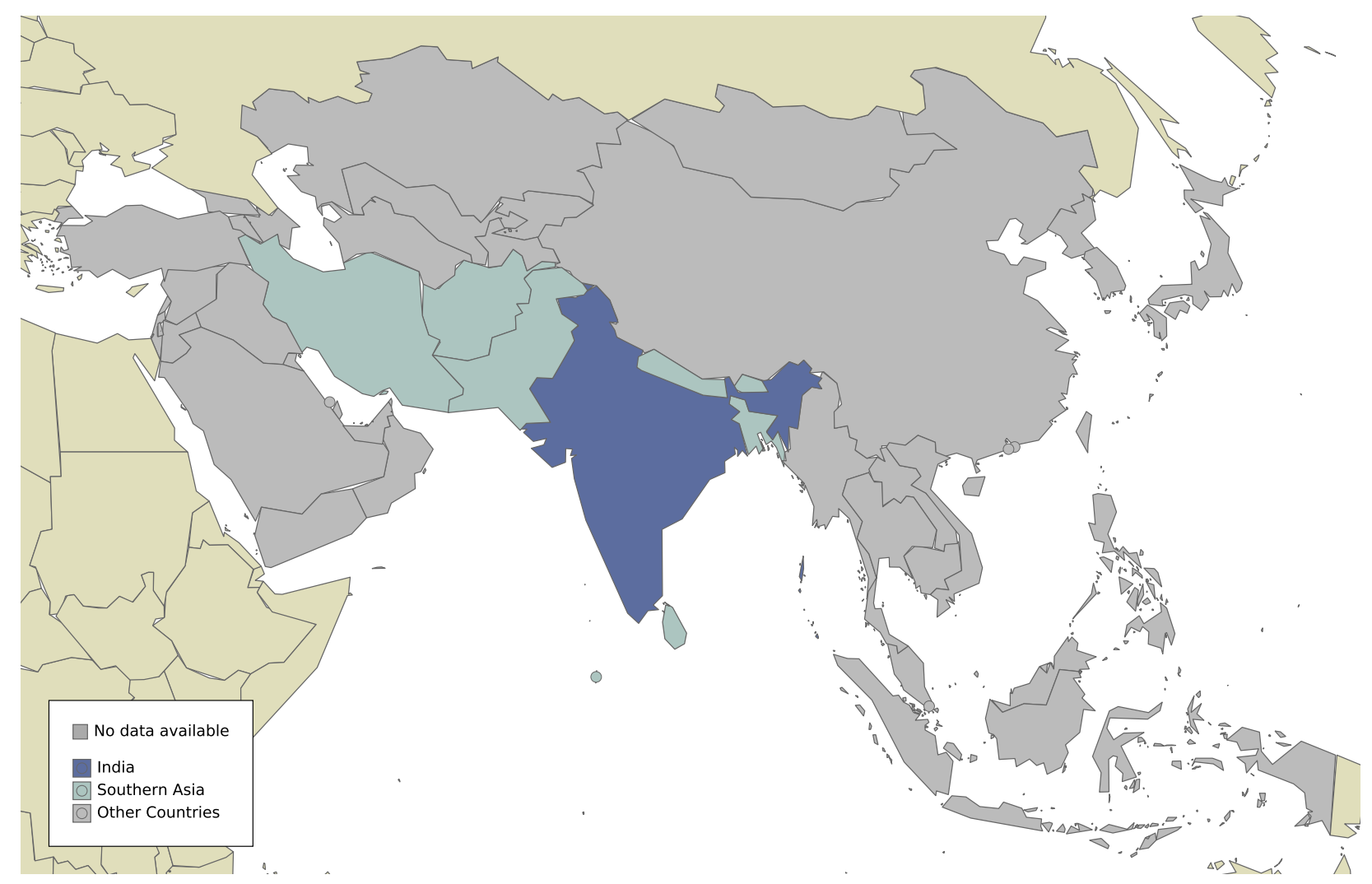

Information Centre aims to compile and centralise updated data and statistics on human papillomavirus (HPV) and related cancers. This report aims to summarise the data available to fully evaluate the burden of disease in India and to facilitate stakeholders and relevant bodies of decision makers to formulate recommendations on the prevention of cervical cancer and other HPV-related cancers. Data include relevant cancer statistic estimates, epidemiological determinants of cervical cancer such as demographics, socioeconomic factors, risk factors, burden of HPV infection in women and men, cervical screening and immunization practices. The report is structured into the following sections:

Section 2, Demographic and socioeconomic factors. This section summarises the socio-demographic profile of India. For analytical purposes, India is classified in the geographical region of Southern Asia (Figure 1, lighter blue), which is composed of the following countries: Bangladesh, Bhutan, Iran (Islamic Republic of), Sri Lanka, Maldives, Nepal, and Pakistan. Throughout the report, India estimates will be complemented with corresponding regional estimates.

Section 3, Burden of HPV related cancers. This section describes the current burden of invasive cervical cancer and other HPV-related cancers in India ith estimates of prevalence, incidence, and mortality rates. Information in other HPV-related cancers includes other anogenital cancers (anus, vulva, vagina, and penis) and head and neck cancers (oral cavity, oropharyngeal, and larynx).

Section 4, HPV related statistics. This section reports on prevalence of HPV and HPV type-specific distribution in India, in women with normal cytology, precancerous lesions and invasive cervical cancer. In addition, the burden of HPV in other anogenital cancers (anus, vulva, vagina, and penis), head and neck cancers (oral cavity, oropharynx, and larynx) and men are presented.

Section 5, Factors contributing to cervical cancer. This section describes factors that can modify 
the natural history of HPV and cervical carcinogenesis such as smoking, parity, oral contraceptive use, and co-infection with HIV.

Section 6, Sexual and reproductive health behaviour indicators. This section presents sexual and reproductive behaviour indicators that may be used as proxy measures of risk for HPV infection and anogenital cancers, such as age at first sexual intercourse, average number of sexual partners, and anal intercourse among others.

Section 7, HPV preventive strategies. This section presents preventive strategies that include basic characteristics and performance of cervical cancer screening status, status of HPV vaccine licensure introduction, and recommendations in national immunisation programmes.

Section 8, Protective factors for cervical cancer. This section presents male circumcision and the use of condoms. 


\section{Demographic and socioeconomic factors}

Figure 2: Population pyramid of India for 2022

\begin{tabular}{|c|c|c|}
\hline $80+$ & $6,290,271$ & $8,481,954$ \\
\hline 75-79 & $7,199,590$ & $8,452,148$ \\
\hline 70-74 & $12,916,917$ & $13,765,252$ \\
\hline $65-69$ & $19,533,210$ & $19,998,116$ \\
\hline $60-64$ & $25,242,364$ & $25,253,906$ \\
\hline $55-59$ & $30,989,422$ & $30,203,908$ \\
\hline $50-54$ & $36,591,296$ & $35,179,384$ \\
\hline $45-49$ & $42,480,204$ & $40,318,696$ \\
\hline $40-44$ & $48,135,628$ & $44,982,596$ \\
\hline $35-39$ & $54,850,356$ & $50,951,708$ \\
\hline $30-34$ & $59,511,440$ & $55,066,720$ \\
\hline $25-29$ & $63,422,572$ & $57,785,720$ \\
\hline $20-24$ & $66,522,944$ & $60,161,728$ \\
\hline $15-19$ & $67,075,532$ & $60,849,484$ \\
\hline $10-14$ & $65,588,624$ & $59,540,076$ \\
\hline 5-9 & $62,901,792$ & $57,482,756$ \\
\hline nder 5 & $59,562,268$ & $55,031,240$ \\
\hline
\end{tabular}

Males $\square$ Females

Data accessed on 30 Jul 2022

Please refer to original source for methods of estimation.

Year of estimate: 2022

Data Sources:

United Nations, Department of Economic and Social Affairs, Population Division (2022). World Population Prospects 2022, Online Edition. [Accessed on July 30, 2022].

Figure 3: Population trends in four selected age groups in India
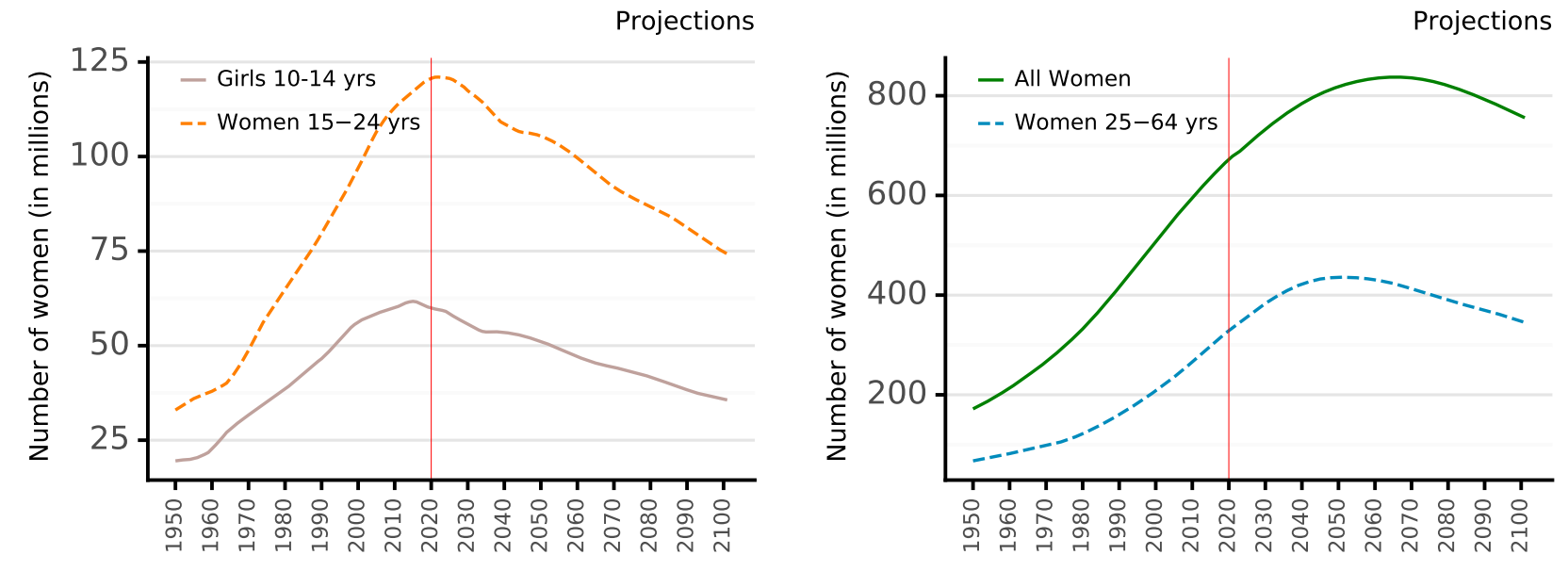

Female population trends in India Number of women by year and age group

Data accessed on 30 Jul 2022

Please refer to original source for methods of estimation.

Year of estimate: 2022

Data Sources:

United Nations, Department of Economic and Social Affairs, Population Division (2022). World Population Prospects 2022, Online Edition. [Accessed on July 30, 2022]. 


\section{Burden of HPV related cancers}

HPV is the cause of almost all cervical cancer cases and is responsible for an important fraction of other anogenital and head and neck cancer. Here, we present the most recent estimations on the burden of HPV-associated cancer.

\subsection{HPV related cancers incidence}

Figure 4: Comparison of HPV related cancers incidence to other cancers in men and women of all ages in India (estimates for 2020)

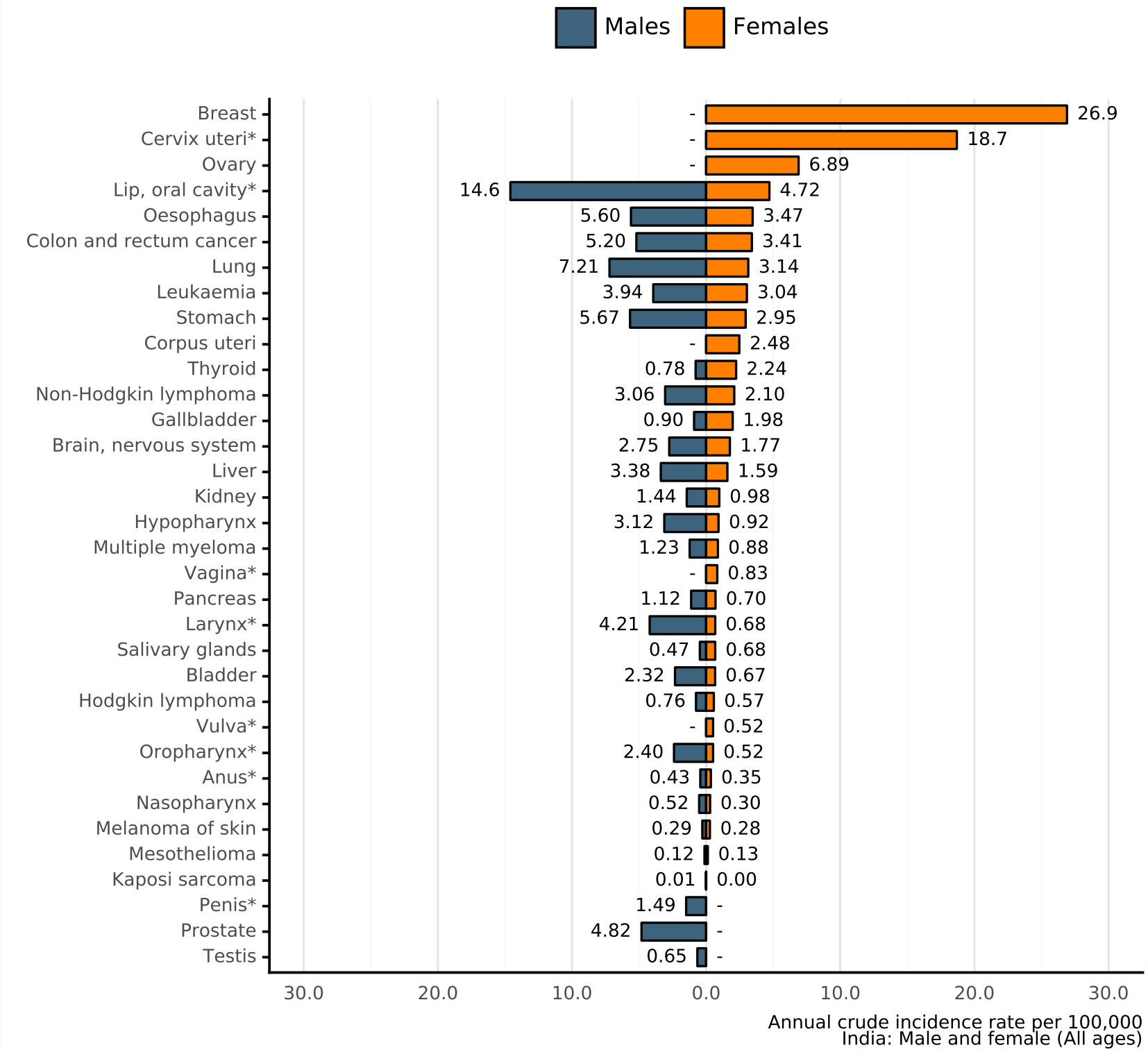

Data accessed on 27 Jan 2021

For more detailed methods of estimation please refer to http://gco.iarc.fr/today/data-sources-methods

Non-melanoma skin cancer is not included

Rates per 100,000 men per year.

Rates per 100,000 women per year.

Data Sources:

Ferlay J, Ervik M, Lam F, Colombet M, Mery L, Piñeros M, Znaor A, Soerjomataram I, Bray F (2020). Global Cancer Observatory: Cancer Today. Lyon, France: International Agency for Research on Cancer. Available from: https ://gco.iarc.fr/today, accessed [27 January 2021]. 
Figure 5: Comparison of HPV related cancers incidence to other cancers among men and women 15-44 years of age in India (estimates for 2020)

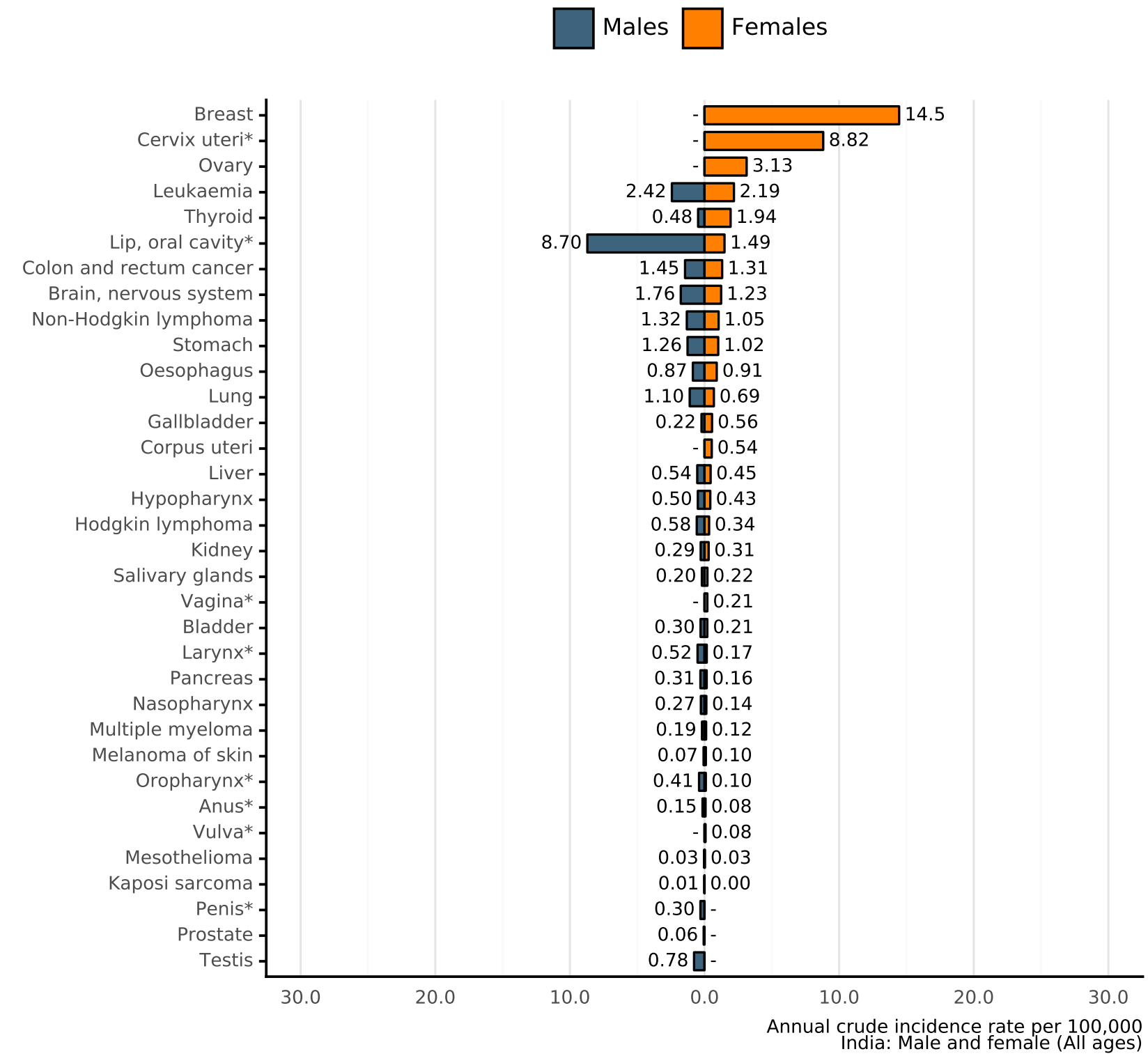

Data accessed on 27 Jan 2021

For more detailed methods of estimation please refer to http://gco.iarc.fr/today/data-sources-methods

Non-melanoma skin cancer is not included

Rates per 100,000 men per year.

Rates per 100,000 women per year.

Data Sources:

Ferlay J, Ervik M, Lam F, Colombet M, Mery L, Piñeros M, Znaor A, Soerjomataram I, Bray F (2020). Global Cancer Observatory: Cancer Today. Lyon, France: International Agency for Research on Cancer. Available from: https ://gco.iarc.fr/today, accessed [27 January 2021]. 


\subsection{HPV related cancers mortality}

Figure 6: Comparison of HPV related cancers mortality to other cancers in men and women of all ages in India (estimates for 2020)

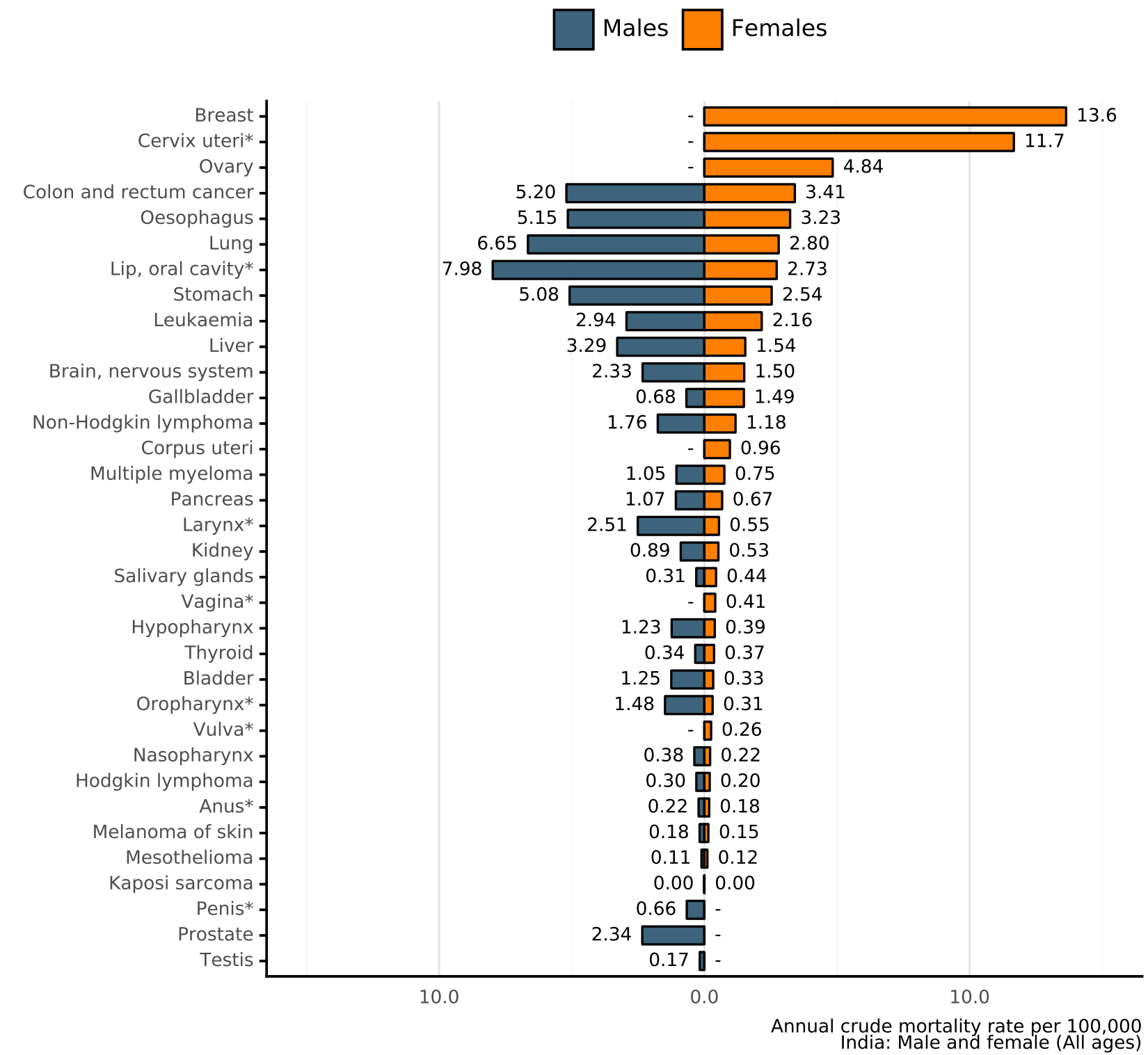

Data accessed on 27 Jan 2021

For more detailed methods of estimation please refer to http://gco.iarc.fr/today/data-sources-methods

Non-melanoma skin cancer is not included

Rates per 100,000 men per year.

Rates per 100,000 women per year.

Data Sources:

Ferlay J, Ervik M, Lam F, Colombet M, Mery L, Piñeros M, Znaor A, Soerjomataram I, Bray F (2020). Global Cancer Observatory: Cancer Today. Lyon, France: International Agency for Research on Cancer. Available from: https ://gco.iarc.fr/today, accessed [27 January 2021]. 
Figure 7: Comparison of HPV related cancers mortality to other cancers among men and women 15-44 years of age in India (estimates for 2020)

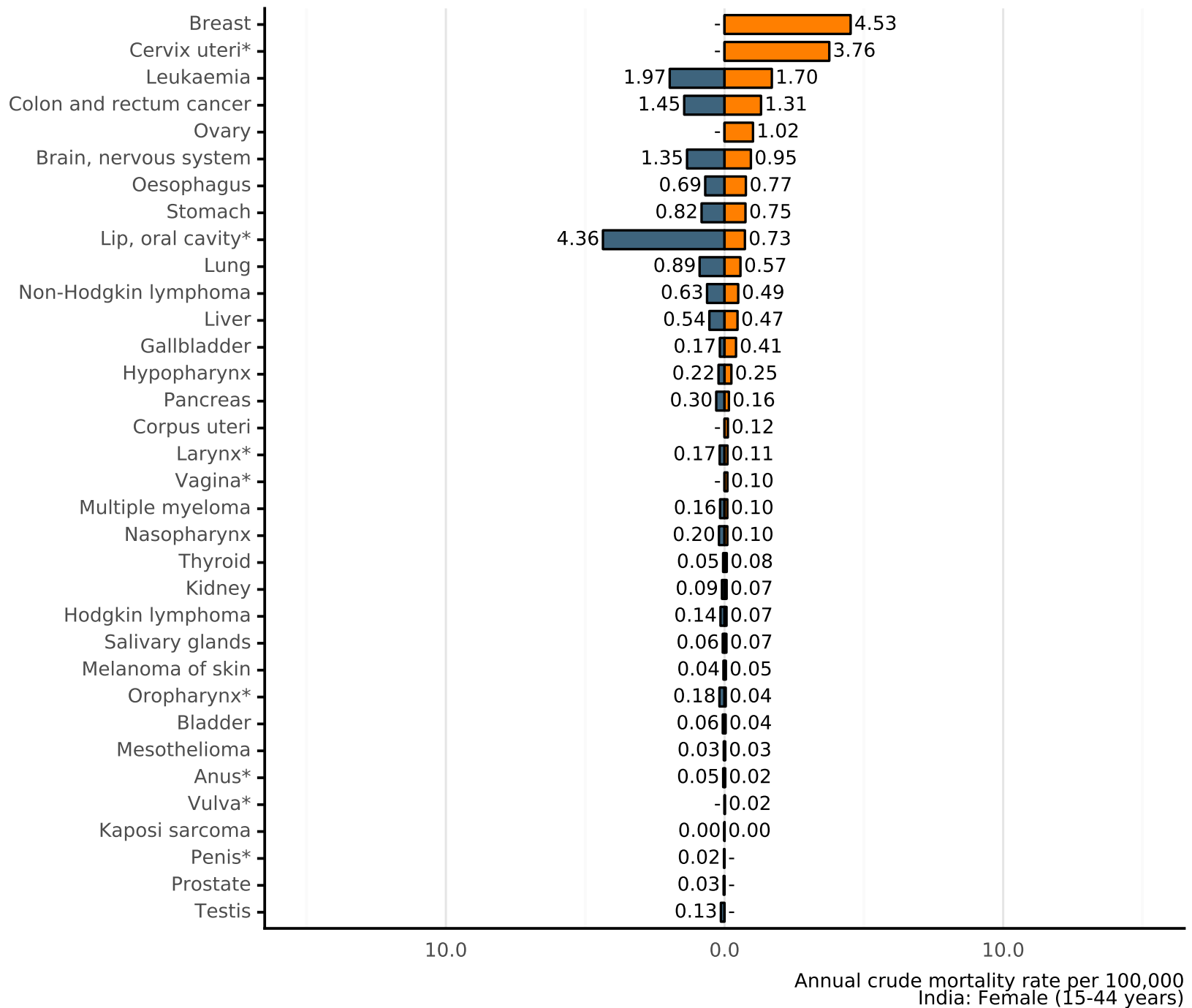

Data accessed on 27 Jan 2021

For more detailed methods of estimation please refer to http://gco.iarc.fr/today/data-sources-methods

Non-melanoma skin cancer is not included

Rates per 100,000 men per year.

Rates per 100,000 women per year.

Data Sources:

Ferlay J, Ervik M, Lam F, Colombet M, Mery L, Piñeros M, Znaor A, Soerjomataram I, Bray F (2020). Global Cancer Observatory: Cancer Today. Lyon, France: International Agency for Research on Cancer. Available from: https ://gco.iarc.fr/today, accessed [27 January 2021]. 


\subsection{Cervical cancer}

Cancer of the cervix uteri is the $4^{\text {th }}$ most common cancer among women worldwide, with an estimated 604,127 new cases and 341,831 deaths in 2020 . Worldwide, mortality rates of cervical cancer are substantially lower than incidence with a ratio of mortality to incidence to 57\% (GLOBOCAN 2020). The majority of cases are squamous cell carcinoma followed by adenocarcinomas. (Vaccine 2006, Vol. 24, Suppl 3; Vaccine 2008, Vol. 26, Suppl 10; Vaccine 2012, Vol. 30, Suppl 5; IARC Monographs 2007, Vol. 90)

This section describes the current burden of invasive cervical cancer in India and in comparison to geographic region, including estimates of the annual number of new cases, deaths, incidence, and mortality rates.

\subsubsection{Cervical cancer incidence in India}

\section{Key Stats.}
About 123,907 new cervical cancer cases are diagnosed annually in India (estimations for 2020).
Cervical cancer ranks* as the $2^{\text {nd }}$ leading cause of female cancer in India.
Cervical cancer is the $2^{\text {nd }}$ most common female cancer in women aged 15 to 44 years in India.

\footnotetext{
* Ranking of cervical cancer incidence to other cancers among all women according to highest incidence rates (ranking 1st) excluding non-melanoma skin cancer. Ranking is based on crude
} incidence rates (actual number of cervical cancer cases). Ranking using age-standardized rate (ASR) may differ

Table 2: Cervical cancer incidence in India (estimates for 2020)

\begin{tabular}{|c|c|c|c|}
\hline Indicator & India & Southern Asia & World \\
\hline $\begin{array}{l}\text { Annual number of new cancer } \\
\text { cases }\end{array}$ & 123,907 & 143,183 & 604,127 \\
\hline $\begin{array}{l}\text { Uncertainty intervals of new } \\
\text { cancer cases [95\% UI] }\end{array}$ & {$[119,237-128,760]$} & {$[883-1,631]$} & {$[582,031-627,062]$} \\
\hline Crude incidence rate ${ }^{b}$ & 18.7 & 15.2 & 15.6 \\
\hline $\begin{array}{l}\text { Age-standardized incidence } \\
\text { rate }^{b}\end{array}$ & 18.0 & 15.4 & 13.3 \\
\hline $\begin{array}{l}\text { Cumulative risk (\%) at } 75 \text { years } \\
\text { old }^{\mathrm{a}}\end{array}$ & 2.01 & 1.72 & 1.39 \\
\hline
\end{tabular}

Data accessed on 27 Jan 2021

For more detailed methods of estimation please refer to http://gco.iarc.fr/today/data-sources-methods

${ }^{a}$ Cumulative risk (incidence) is the probability or risk of individuals getting from the disease during ages $0-74$ years. For cancer, it is expressed as the \% of new born children who would be expected to develop from a particular cancer before the age of 75 if they had the rates of cancer observed in the period in the absence of competing causes.

$b$ Rates per 100,000 women per year.

Data Sources:

Ferlay J, Ervik M, Lam F, Colombet M, Mery L, Piñeros M, Znaor A, Soerjomataram I, Bray F (2020). Global Cancer Observatory: Cancer Today. Lyon, France: International Agency for Research on Cancer. Available from: https ://gco.iarc.fr/today, accessed [27 January 2021]. 
Table 3: Cervical cancer incidence in India by cancer registry

\begin{tabular}{|c|c|c|c|c|}
\hline Cancer registry & Period & $\mathbf{N} \operatorname{cases}^{\mathbf{a}}$ & Crude rate ${ }^{b}$ & $\mathbf{A S R}^{\mathbf{b}}$ \\
\hline Ahmedabad $^{1}$ & 1993-1997 & 799 & 9.1 & 13.4 \\
\hline Bangalore $^{2}$ & $2005-2007$ & 1541 & 15.9 & 20.6 \\
\hline Barshi $^{3}$ & 1988-1992 & 252 & 23.4 & 27.4 \\
\hline Chennai (Madras) ${ }^{4}$ & $1998-2002$ & 2550 & 24.2 & 28 \\
\hline Chennai $^{2}$ & $2003-2007$ & 2145 & 19.4 & 21.4 \\
\hline Delhi $^{1}$ & 1993-1996 & 2983 & 16.7 & 25.8 \\
\hline Karunagappally $^{2}$ & $2003-2007$ & 108 & 9.9 & 8.9 \\
\hline Mumbai (Bombay) $^{4}$ & $1998-2002$ & 3121 & 11.8 & 14.5 \\
\hline Mumbai $^{2}$ & $2003-2007$ & 3388 & 11.7 & 13.5 \\
\hline Nagpur 4 & $1998-2002$ & 741 & 15.2 & 18.4 \\
\hline New Delhi ${ }^{2}$ & $2003-2007$ & 4280 & 12.3 & 17.7 \\
\hline Poona $^{2}$ & $2003-2007$ & 1035 & 10.6 & 13.4 \\
\hline Trivandrum $^{2}$ & $2005-2007$ & 188 & 10.8 & 10 \\
\hline Barshi, Paranda and Bhum ${ }^{2}$ & $2003-2007$ & 214 & 17.1 & 18.7 \\
\hline Bhopal $^{2}$ & 2004-2007 & 426 & 13.5 & 19.5 \\
\hline Dindigul, Ambilikkai $^{2}$ & $2003-2007$ & 1215 & 24.1 & 24.5 \\
\hline Mizoram $^{2}$ & $2003-2007$ & 364 & 15.4 & 19.7 \\
\hline Sikkim State ${ }^{2}$ & $2003-2007$ & 87 & 6.5 & 10.2 \\
\hline Ahmedabad $^{5}$ & $2008-2011$ & 262 & 8.7 & 9.5 \\
\hline Bangalore $^{5}$ & $2008-2012$ & 2741 & 14.5 & 17.5 \\
\hline Barshi, Paranda, and Bhum 5 & $2008-2012$ & 237 & 20.3 & 19 \\
\hline Bhopal $^{5}$ & $2008-2012$ & 564 & 12.5 & 15.7 \\
\hline Cachar $^{5}$ & $2008-2012$ & 373 & 8.9 & 11.2 \\
\hline Chennai $^{5}$ & $2008-2012$ & 2001 & 17.4 & 17.3 \\
\hline Dindigul, Ambilikkai $^{5}$ & $2008-2012$ & 1158 & 21.6 & 20.5 \\
\hline Kamrup Urban District ${ }^{5}$ & 2009-2012 & 231 & 10.2 & 11.5 \\
\hline Kollam $^{5}$ & $2008-2012$ & 642 & 9.3 & 7.4 \\
\hline Mizoram $^{5}$ & $2008-2012$ & 467 & 17.5 & 21.2 \\
\hline Mumbai $^{5}$ & $2008-2012$ & 2924 & 9.7 & 10.4 \\
\hline Poona $^{5}$ & $2008-2011$ & 891 & 8.5 & 10.1 \\
\hline Sikkim State ${ }^{5}$ & $2008-2012$ & 102 & 7.2 & 9.2 \\
\hline Tripura $^{5}$ & $2010-2012$ & 481 & 8.9 & 10.1 \\
\hline Trivandrum 5 & $2008-2012$ & 284 & 9.3 & 7.9 \\
\hline Wardha $^{5}$ & $2010-2012$ & 151 & 7.9 & 7.4 \\
\hline
\end{tabular}

\section{Data accessed on 5 Oct 2018}

Please refer to original source (available at http://ci5.iarc.fr/CI5-XI/Def ault .aspx)

ASR: Age-standardized rate, Standardized rates have been estimated using the direct method and the World population as the reference.

${ }^{a}$ Accumulated number of cases during the period in the population covered by the corresponding registry.

$b$ Rates per 100,000 women per year.

Data Sources:

1 Parkin, D.M., Whelan, S.L., Ferlay, J., Teppo, L., and Thomas, D.B., eds (2002). Cancer Incidence in Five Continents, Vol. VIII. IARC Scientific Publications No. 155, Lyon, IARC.

2 Forman D, Bray F, Brewster DH, Gombe Mbalawa C, Kohler B, Piñeros M, Steliarova-Foucher E, Swaminathan R and Ferlay J eds (2013). Cancer Incidence in Five Continents, Vol. X (electronic version) Lyon, IARC. http://ci5.iarc.fr

3 Parkin, D.M., Whelan, S.L., Ferlay, J., Raymond, L., and Young, J., eds (1997). Cancer Incidence in Five Continents, Vol. VII. IARC Scientific Publications No. 143, Lyon, IARC.

4 Curado. M. P., Edwards, B., Shin. H.R., Storm. H., Ferlay. J., Heanue. M. and Boyle. P., eds (2007). Cancer Incidence in Five Continents, Vol. IX. IARC Scientific Publications No. 160, Lyon, IARC.

5 Bray F, Colombet M, Mery L, Piñeros M, Znaor A, Zanetti R and Ferlay J, editors (2017). Cancer Incidence in Five Continents, Vol. XI (electronic version). Lyon: International Agency for Research on Cancer. Available from: http://ci5.iarc.fr, accessed [05 October 2018]. 
Figure 8: Age-specific incidence rates of cervical cancer in India (estimates for 2020)

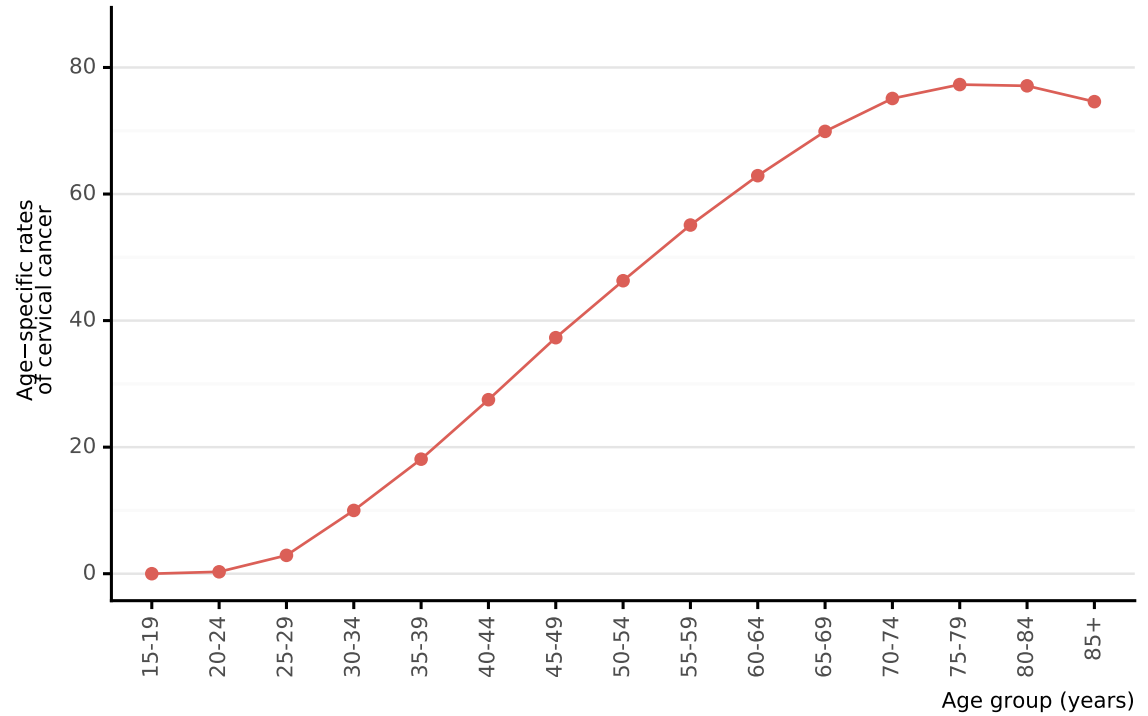

Data accessed on 27 Jan 2021

For more detailed methods of estimation please refer to http://gco.iarc.fr/today/data-sources-methods

${ }^{a}$ Rates per 100,000 women per year.

Data Sources:

Ferlay J, Ervik M, Lam F, Colombet M, Mery L, Piñeros M, Znaor A, Soerjomataram I, Bray F (2020). Global Cancer Observatory: Cancer Today. Lyon, France: International Agency for Research on Cancer. Available from: https ://gco.iarc.fr/today, accessed [27 January 2021].

Figure 9: Annual number of new cases of cervical cancer in India (estimates for 2020)

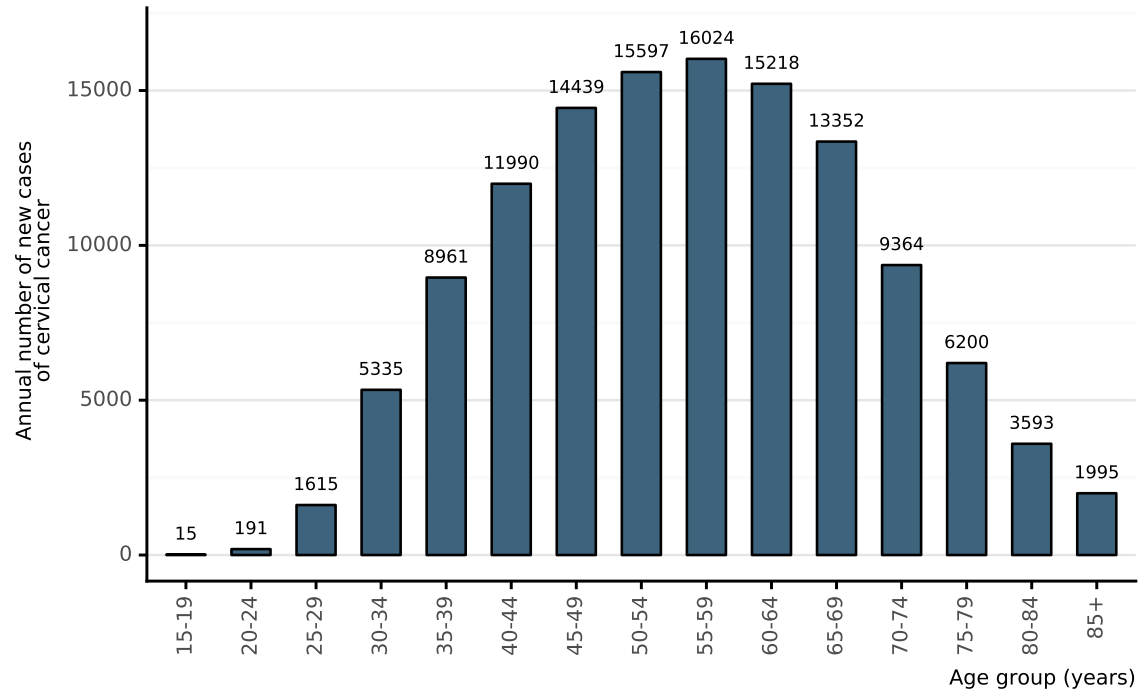

Data accessed on 27 Jan 2021

For more detailed methods of estimation please refer to http://gco.iarc.fr/today/data-sources-methods

Data Sources:

Ferlay J, Ervik M, Lam F, Colombet M, Mery L, Piñeros M, Znaor A, Soerjomataram I, Bray F (2020). Global Cancer Observatory: Cancer Today. Lyon, France: International Agency for Research on Cancer. Available from: https ://gco.iarc.fr/today, accessed [27 January 2021].

- For age-standardised incidence rates of cervical cancer of India (estimates for 2020) please refer to Figure 73

- For annual number of new cases of cervical cancer by age group in India (estimates for 2020) please refer to Figure 74

- For comparison of age-specific cervical cancer incidence rates in India, within the region, and the rest of world please refer to Figure 75 


\subsubsection{Cervical cancer incidence by histology in India}

Table 4: Age-standardised incidence rates of cervical cancer in India by histological type and cancer

\begin{tabular}{|c|c|c|c|c|c|}
\hline \multicolumn{6}{|c|}{ registry } \\
\hline Cancer registry $^{1}$ & Period & Squamo & Adeno & Other & Unspec. \\
\hline Ahmedabad & $2008-2011$ & 8 & 0.6 & 0.2 & 0.2 \\
\hline Bangalore & $2008-2012$ & 12.1 & 0.8 & 0.2 & 3.2 \\
\hline Barshi, Paranda, and Bhum & $2008-2012$ & 15.5 & 1 & 0.2 & 0.1 \\
\hline Bhopal & $2008-2012$ & 13.9 & 0.8 & 0.1 & 0.1 \\
\hline Cachar & $2008-2012$ & 7.9 & 0.1 & - & 2.5 \\
\hline Chennai & $2008-2012$ & 12.8 & 0.5 & 0.2 & 1.4 \\
\hline Dindigul, Ambilikkai & $2008-2012$ & 11 & 0.7 & 0.1 & 4.1 \\
\hline Kamrup Urban District & $2009-2012$ & 9.2 & 0.8 & 0.1 & 0.1 \\
\hline Kollam & $2008-2012$ & 6.1 & 0.6 & 0.1 & 0.2 \\
\hline Mizoram & $2008-2012$ & 15.6 & 1.5 & 0.3 & 0.6 \\
\hline Mumbai & $2008-2012$ & 8.2 & 0.7 & 0.1 & 0.3 \\
\hline Poona & $2008-2011$ & 8.3 & 0.5 & 0 & 0.2 \\
\hline Sikkim State & $2008-2012$ & 7.5 & 0.9 & - & 0.2 \\
\hline Tripura & $2010-2012$ & 8.5 & 0.6 & 0.2 & 0.5 \\
\hline Trivandrum & $2008-2012$ & 5.6 & 0.9 & 0.1 & 0.6 \\
\hline Wardha & $2010-2012$ & 6.2 & 0.2 & 0.1 & 0.1 \\
\hline
\end{tabular}

Data accessed on 5 Oct 2018

Rates per 100,000 women per year.

Standarized rates have been estimated using the direct method and the World population as the references.

Adeno: adenocarcinoma; Other: Other carcinoma; Squamous: Squamous cell carcinoma; Unspec: Unspecified carcinoma;

Data Sources:

1 Bray F, Colombet M, Mery L, Piñeros M, Znaor A, Zanetti R and Ferlay J, editors (2017). Cancer Incidence in Five Continents, Vol. XI (electronic version). Lyon: International Agency for

Research on Cancer. Available from: http://ci5.iarc.fr, accessed [05 October 2018]. 
Figure 10: Time trends in cervical cancer incidence in India (cancer registry data)

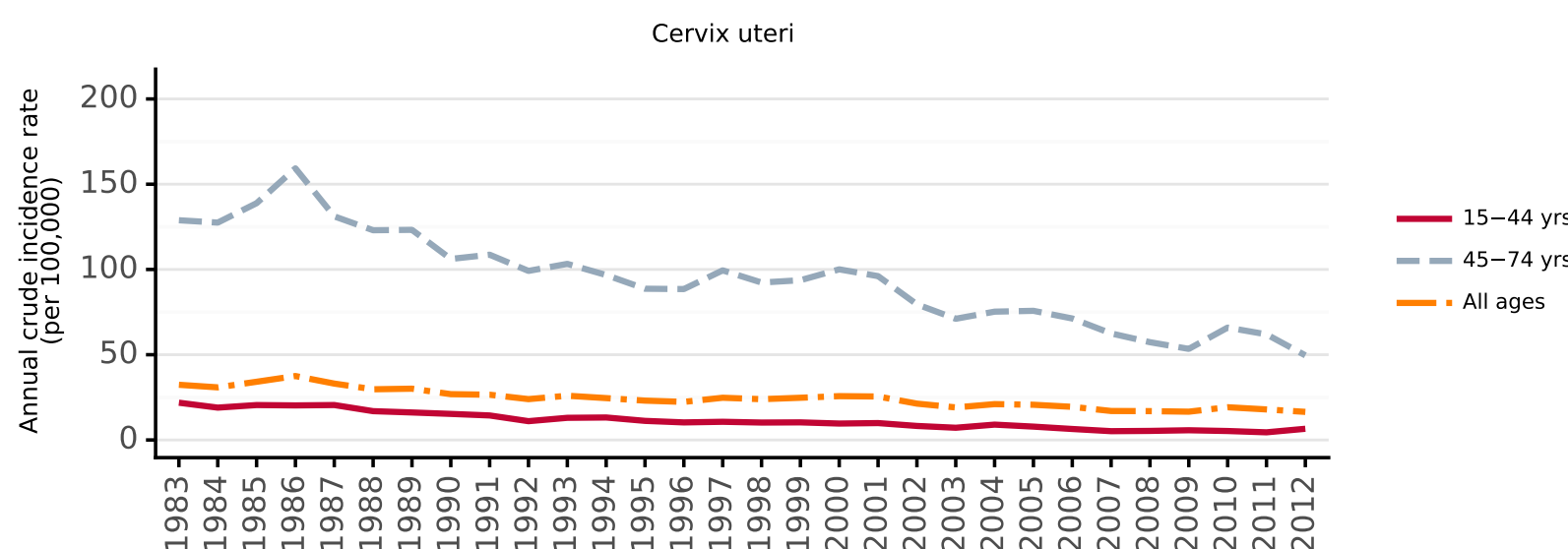

品

Cervix uteri: Squamous cell carcinoma

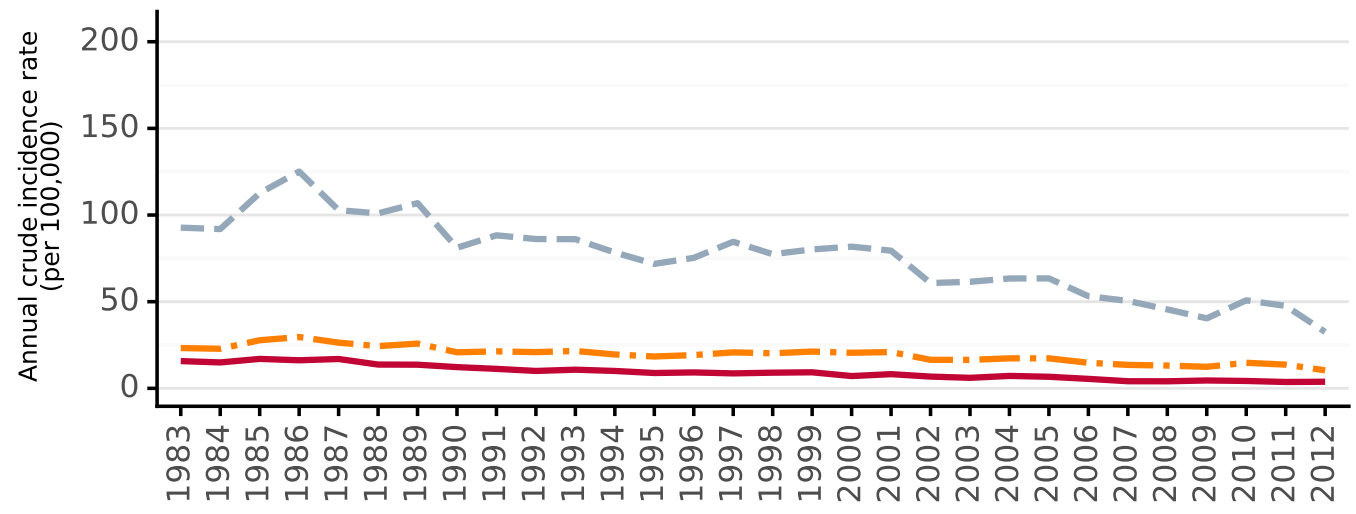

Cervix uteri: Adenocarcinoma

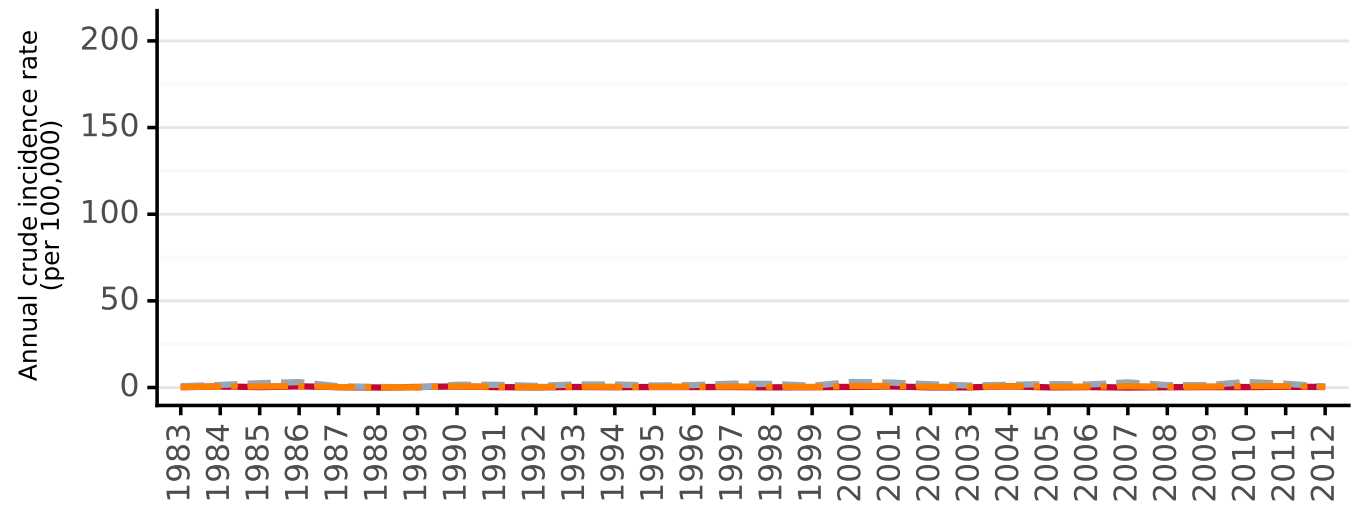

Data accessed on 28 Aug 2018

The following regional cancer registries provided data and contributed to their national estimate: Chennai
${ }^{a}$ Estimated annual percentage change based on the trend variable from the net drift for 20 years, from 1983-2002.

Ferlay J, Colombet M and Bray F. Cancer Incidence in Five Continents, CI5plus: IARC CancerBase No. 9 [Internet]. Lyon, France: International Agency for Research on Cancer; 2018. Available from: http://ci5.iarc.fr

Vaccarella S, Lortet-Tieulent J, Plummer M, Franceschi S, Bray F. Worldwide trends in cervical cancer incidence: Impact of screening against changes in disease risk factors. eur J Cancer 2013;49:3262-73 


\subsubsection{Cervical cancer mortality in India}

Key Stats.

About 77,348 cervical cancer deaths occur annually in India are diagnosed annually (estimations for 2020).

Cervical cancer ranks* as the $2^{\text {nd }}$ leading cause of cancer deaths of female cancer deaths in India.

Cervical cancer is the $2^{\text {nd }}$ leading cause of cancer deaths in women aged 15 to 44 years in India.

* Ranking of cervical cancer incidence to other cancers among all women according to highest incidence rates (ranking 1st) excluding non-melanoma skin cancer. Ranking is based on crude incidence rates (actual number of cervical cancer cases). Ranking using age-standardized rate (ASR) may differ.

Table 5: Cervical cancer mortality in India (estimates for 2020)

\begin{tabular}{|c|c|c|c|}
\hline Indicator & India & Southern Asia & World \\
\hline Annual number of deaths & 77,348 & 89,307 & 341,831 \\
\hline $\begin{array}{l}\text { Uncertainty intervals of mortal- } \\
\text { ity cancer cases }[95 \% \text { UI] }\end{array}$ & {$[74,246-80,580]$} & {$[619-1,095]$} & {$[324,231-360,386]$} \\
\hline Crude mortality rate $^{\mathrm{b}}$ & 11.7 & 9.50 & 8.84 \\
\hline $\begin{array}{l}\text { Age-standardized mortality } \\
\text { rate }^{\text {b }}\end{array}$ & 11.4 & 9.75 & 7.25 \\
\hline $\begin{array}{l}\text { Cumulative risk (\%) at } 75 \text { years } \\
\text { old }^{\text {a }}\end{array}$ & 1.30 & 1.12 & 0.82 \\
\hline
\end{tabular}

Data accessed on 27 Jan 2021

For more detailed methods of estimation please refer to http://gco.iarc.fr/today/data-sources-methods

${ }^{a}$ Cumulative risk (mortality) is the probability or risk of individuals dying from the disease during ages 0-74 years. For cancer, it is expressed as the \% of new born children who would be expected to die from a particular cancer before the age of 75 if they had the rates of cancer observed in the period in the absence of competing causes.

$b$ Rates per 100,000 women per year.

Data Sources:

Data Sources: Research on Cancer. Available from: https ://gco.iarc.fr/today, accessed [27 January 2021]. 
Figure 11: Age-specific mortality rates of cervical cancer in India (estimates for 2020)

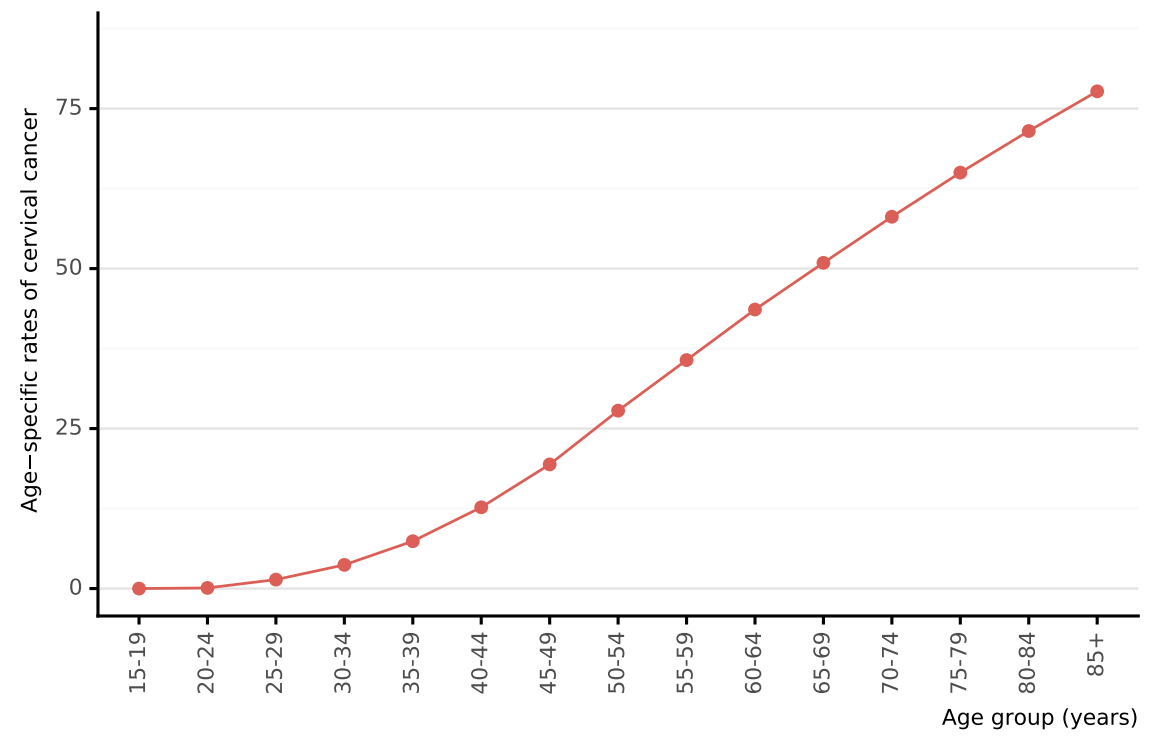

Data accessed on 27 Jan 2021

For more detailed methods of estimation please refer to http://gco.iarc.fr/today/data-sources-methods

$a^{a}$ Rates per 100,000 women per year.

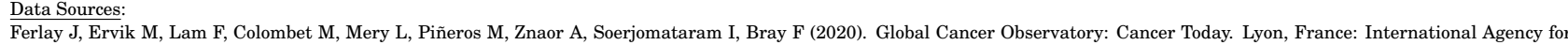
Research on Cancer. Available from: https://gco.iarc.fr/today, accessed [27 January 2021].

Figure 12: Annual number of deaths of cervical cancer in India (estimates for 2020)

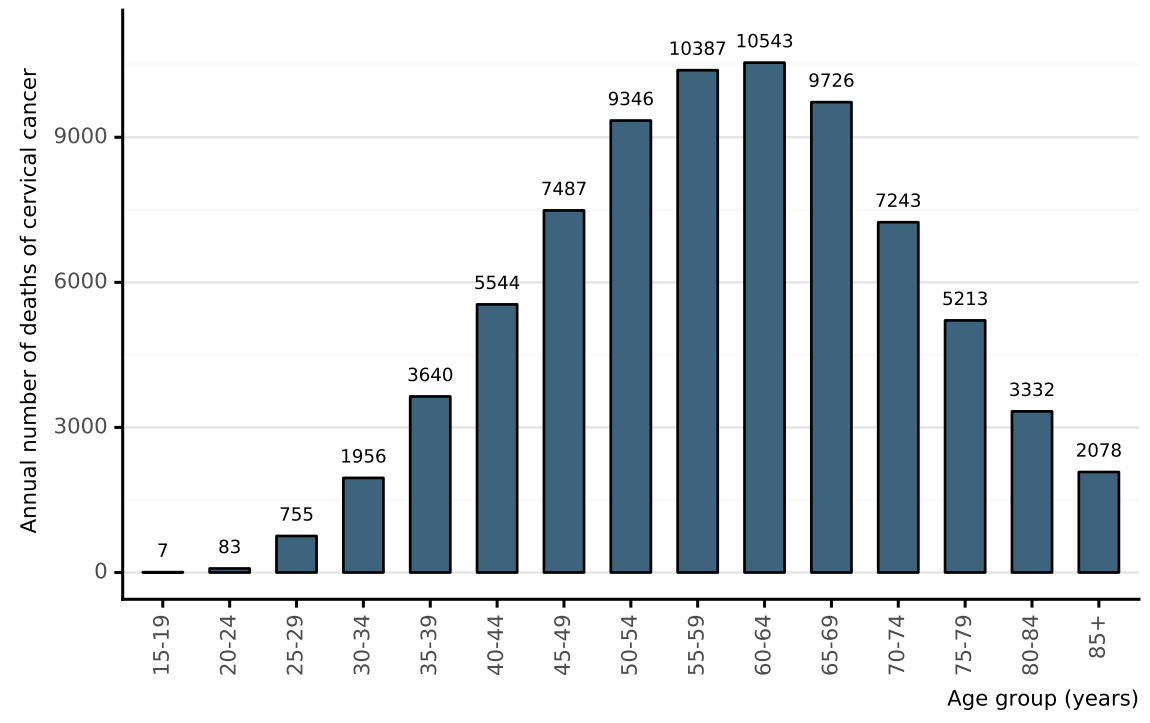

Data accessed on 27 Jan 2021

For more detailed methods of estimation please refer to http://gco.iarc.fr/today/data-sources-methods

Data Sources:

Ferlay J, Ervik M, Lam F, Colombet M, Mery L, Piñeros M, Znaor A, Soerjomataram I, Bray F (2020). Global Cancer Observatory: Cancer Today. Lyon, France: International Agency for Research on Cancer. Available from: https ://gco.iarc.fr/today, accessed [27 January 2021].

- For age-standardised mortality rates of cervical cancer of India (estimates for 2020) please refer to Figure 105

- For annual number of deaths of cervical cancer by age group in India (estimates for 2020) please refer to Figure 106

- For comparison of age-specific cervical cancer mortality rates in India, within the region, and the rest of world please refer to Figure 107 


\subsubsection{Cervical cancer incidence and mortality comparison in India}

Figure 13: Comparison of age-specific cervical cancer incidence and mortality rates in India (estimates for 2020)

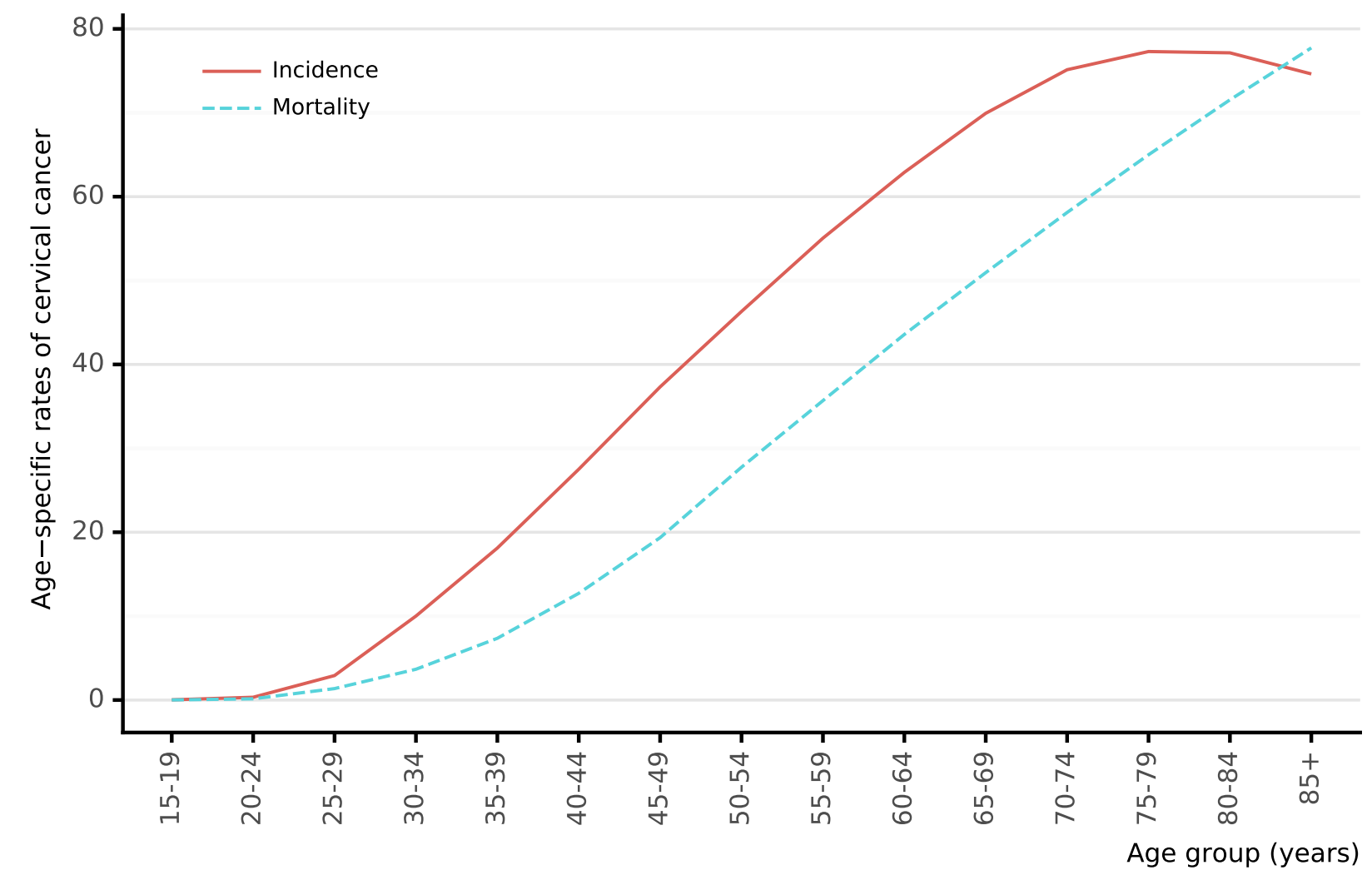

Data accessed on 27 Jan 2021

For more detailed methods of estimation please refer to http://gco.iarc.fr/today/data-sources-methods

$a$ Rates per 100,000 women per year.

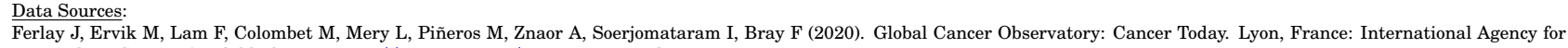
Research on Cancer. Available from: https://gco.iarc.fr/today, accessed [27 January 2021].

Table 6: Premature deaths and disability from cervical cancer in India, Asia and the rest of the world (estimates for 2019)

\begin{tabular}{|c|c|c|c|c|c|c|}
\hline \multirow[b]{2}{*}{ Indicator } & \multicolumn{2}{|c|}{ India } & \multicolumn{2}{|l|}{ Asia } & \multicolumn{2}{|l|}{ World } \\
\hline & Number & Rate & Number & Rate & Number & Rate \\
\hline DALYs $\left(95 \%\right.$ UI) ${ }^{\mathrm{a}}$ & $\begin{array}{c}1,554,489 \\
(1,198,223- \\
2,094,137)\end{array}$ & $\begin{array}{c}229 \\
(177-309)\end{array}$ & $\begin{array}{c}4,693,918 \\
(3,779,579- \\
5,446,237)\end{array}$ & $\begin{array}{c}210 \\
(169-243)\end{array}$ & $\begin{array}{c}8,955,013 \\
(7,547,733-9,978,462)\end{array}$ & $\begin{array}{c}232 \\
(196-259)\end{array}$ \\
\hline YLLs $\left(95 \%\right.$ UI) ${ }^{b}$ & $\begin{array}{c}1,520,063 \\
(1,167,146- \\
2,052,701)\end{array}$ & $\begin{array}{c}224 \\
(172-303)\end{array}$ & $\begin{array}{c}4,565,684 \\
(3,682,645- \\
5,330,317)\end{array}$ & $\begin{array}{c}204 \\
(165-238)\end{array}$ & $\begin{array}{c}8,712,962 \\
(7,365,279-9,728,886)\end{array}$ & $\begin{array}{c}226 \\
(191-252)\end{array}$ \\
\hline YLDs $\left(95 \%\right.$ UI) ${ }^{\mathrm{c}}$ & $\begin{array}{c}34,427 \\
(22,645-50,207)\end{array}$ & $5(3-7)$ & $\begin{array}{c}128,234 \\
(88,980-176,159)\end{array}$ & $6(4-8)$ & $\begin{array}{c}242,051 \\
(171,644-326,024)\end{array}$ & $6(4-8)$ \\
\hline
\end{tabular}

\section{Data accessed on 29 Apr 2021}

Rate per 100,000 women

${ }^{a}$ DALYs (95\% UI): estimated disability adjusted life years (95\% uncertainty interval)

$b$ YLLs (95\% UI): years of life lost (95\% uncertainty interval)

${ }^{c}$ YLDs (95\% UI): estimated years lived with disability (95\% uncertainty interval)

Data Sources:

GBD 2019 Diseases and Injuries Collaborators. Global burden of 369 diseases and injuries in 204 countries and territories, 1990-2019: a systematic analysis for the Global Burden of Disease Study 2019. Lancet. 2020 Oct 17;396(10258):1204-1222 
Figure 14: Comparison of annual premature deaths and disability from cervical cancer in India to other cancers among women (estimates for 2019)

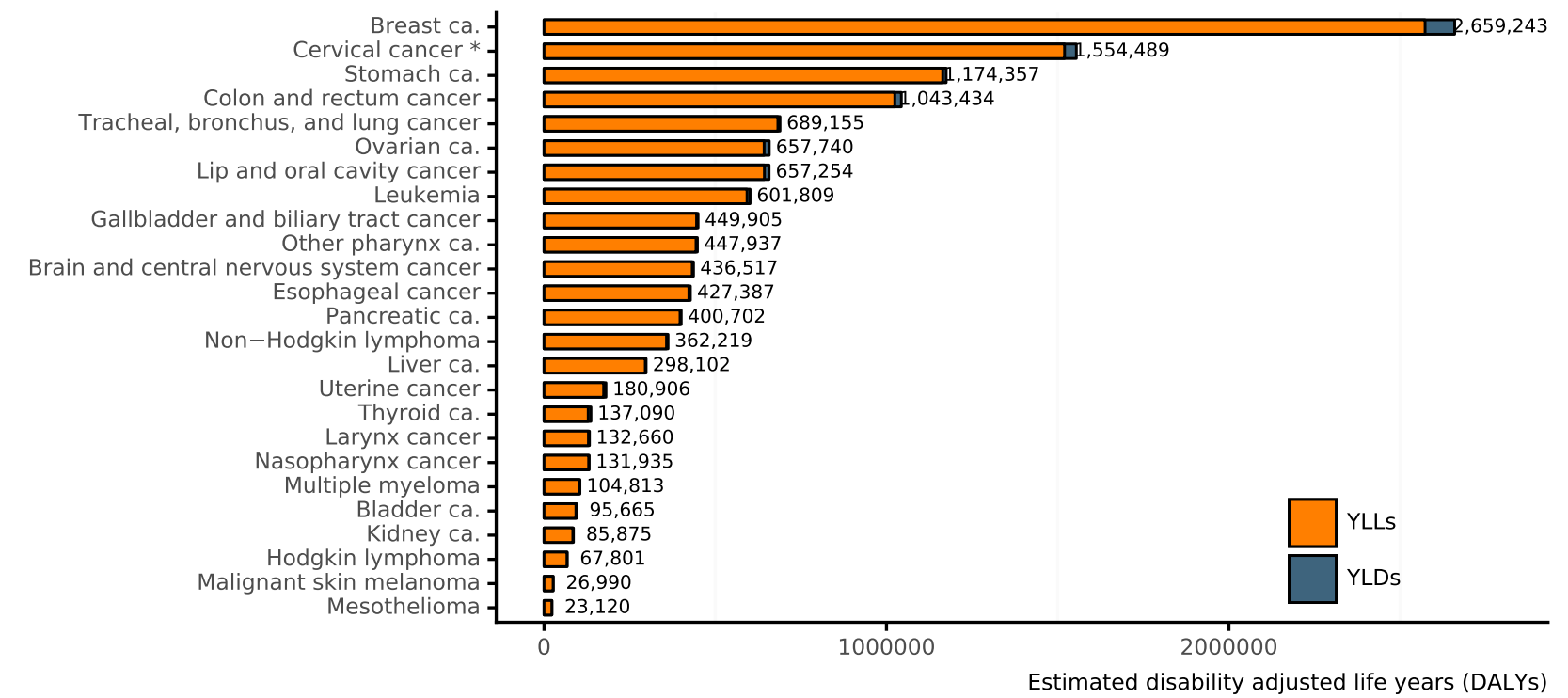

Data accessed on 29 Apr 2021

YLLs: years of life lost

YLDs: years lived with disability

Data Sources:

GBD 2019 Diseases and Injuries Collaborators. Global burden of 369 diseases and injuries in 204 countries and territories, 1990-2019: a systematic analysis for the Global Burden of Disease Study 2019. Lancet. 2020 Oct 17;396(10258):1204-1222 


\subsection{Anogenital cancers other than the cervix}

Data on HPV role in anogenital cancers other than cervix are limited, but there is an increasing body of evidence strongly linking HPV DNA with cancers of anus, vulva, vagina, and penis. Although these cancers are much less frequent compared to cervical cancer, their association with HPV make them potentially preventable and subject to similar preventative strategies as those for cervical cancer. (Vaccine 2006, Vol. 24, Suppl 3; Vaccine 2008, Vol. 26, Suppl 10; Vaccine 2012, Vol. 30, Suppl 5; IARC Monographs 2007, Vol. 90).

\subsubsection{Anal cancer}

Anal cancer is rare in the general population with an average worldwide incidence of 1 per 100,000, but is reported to be increasing in more developed regions. Globally, there are an estimated 29,000 new cases in 2018 every year (de Martel C et al. Lancet Glob Health 2020;8(2):e180-e190). Women have higher incidences of anal cancer than men. Incidence is particularly high among populations of men who have sex with men (MSM), women with history of cervical or vulvar cancer, and immunosuppressed populations, including those who are HIV-infected and patients with a history of organ transplantation. These cancers are predominantly squamous cell carcinoma, adenocarcinomas, or basaloid and cloacogenic carcinomas.

\subsubsection{Anal cancer incidence in India}

Table 7: Anal cancer incidence in India (estimates for 2020)

\begin{tabular}{|c|c|c|c|}
\hline Indicator & India & Southern Asia & World \\
\hline \multicolumn{4}{|l|}{ MEN } \\
\hline Annual number of new cancer cases & 3,111 & 4,068 & 21,706 \\
\hline $\begin{array}{l}\text { Uncertainty intervals of new cancer } \\
\text { cases }[95 \% \text { UI] }\end{array}$ & {$[2,510-3,856]$} & [12-399] & {$[18,432-25,561]$} \\
\hline Crude incidence rate ${ }^{b}$ & 0.43 & 0.41 & 0.55 \\
\hline Age-standardized incidence rate ${ }^{b}$ & 0.46 & 0.45 & 0.49 \\
\hline $\begin{array}{l}\text { Cumulative risk (\%) at } 75 \text { years } \\
\text { old }^{\mathrm{a}}\end{array}$ & 0.05 & 0.05 & 0.06 \\
\hline \multicolumn{4}{|l|}{ WOMEN } \\
\hline Annual number of new cancer cases & 2,341 & 2,801 & 29,159 \\
\hline $\begin{array}{l}\text { Uncertainty intervals of new cancer } \\
\text { cases }[95 \% \text { UI] }\end{array}$ & {$[1,799-3,046]$} & {$[8-209]$} & {$[25,656-33,140]$} \\
\hline Crude incidence rate $^{c}$ & 0.35 & 0.30 & 0.75 \\
\hline Age-standardized incidence rate ${ }^{c}$ & 0.35 & 0.31 & 0.58 \\
\hline $\begin{array}{l}\text { Cumulative risk (\%) at } 75 \text { years } \\
\text { old }^{\mathrm{a}}\end{array}$ & 0.04 & 0.04 & 0.07 \\
\hline
\end{tabular}

\section{Data accessed on 27 Jan 2021}

For more detailed methods of estimation please refer to http://gco.iarc.fr/today/data-sources-methods

${ }^{a}$ Cumulative risk (incidence) is the probability or risk of individuals getting from the disease during ages 0-74 years. For cancer, it is expressed as the \% of new born children who would be expected to develop from a particular cancer before the age of 75 if they had the rates of cancer observed in the period in the absence of competing causes.

$b$ Rates per 100,000 men per year.

${ }^{c}$ Rates per 100,000 women per year.

Data Sources:

Ferlay J, Ervik M, Lam F, Colombet M, Mery L, Piñeros M, Znaor A, Soerjomataram I, Bray F (2020). Global Cancer Observatory: Cancer Today. Lyon, France: International Agency for Research on Cancer. Available from: https ://gco.iarc.fr/today, accessed [27 January 2021]. 
Figure 15: Age-specific incidence rates of anal cancer in India (estimates for 2020)

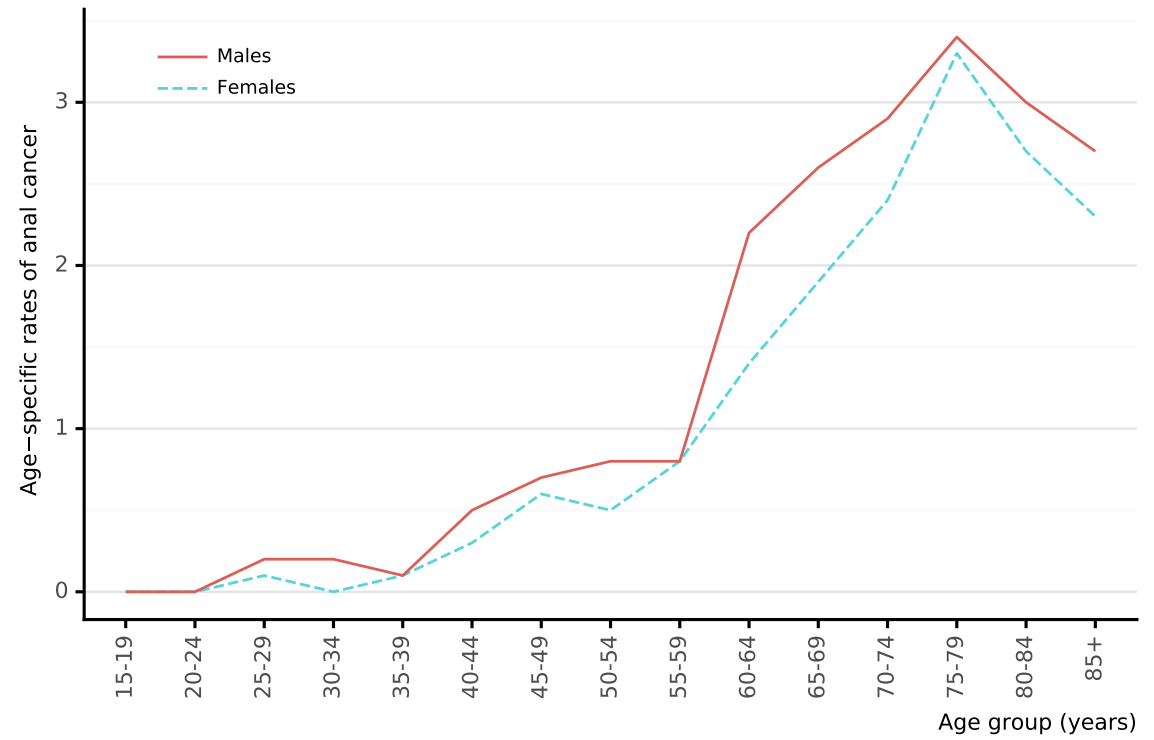

Data accessed on 27 Jan 2021

For more detailed methods of estimation please refer to http://gco.iarc.fr/today/data-sources-methods

${ }^{a}$ Rates per 100,000 men per year.

$b^{b}$ Rates per 100,000 women per year.

Data Sources:

Ferlay J, Ervik M, Lam F, Colombet M, Mery L, Piñeros M, Znaor A, Soerjomataram I, Bray F (2020). Global Cancer Observatory: Cancer Today. Lyon, France: International Agency for Research on Cancer. Available from: https ://gco.iarc.fr/today, accessed [27 January 2021].

Figure 16: Annual number of new cases of anal cancer in India (estimates for 2020)

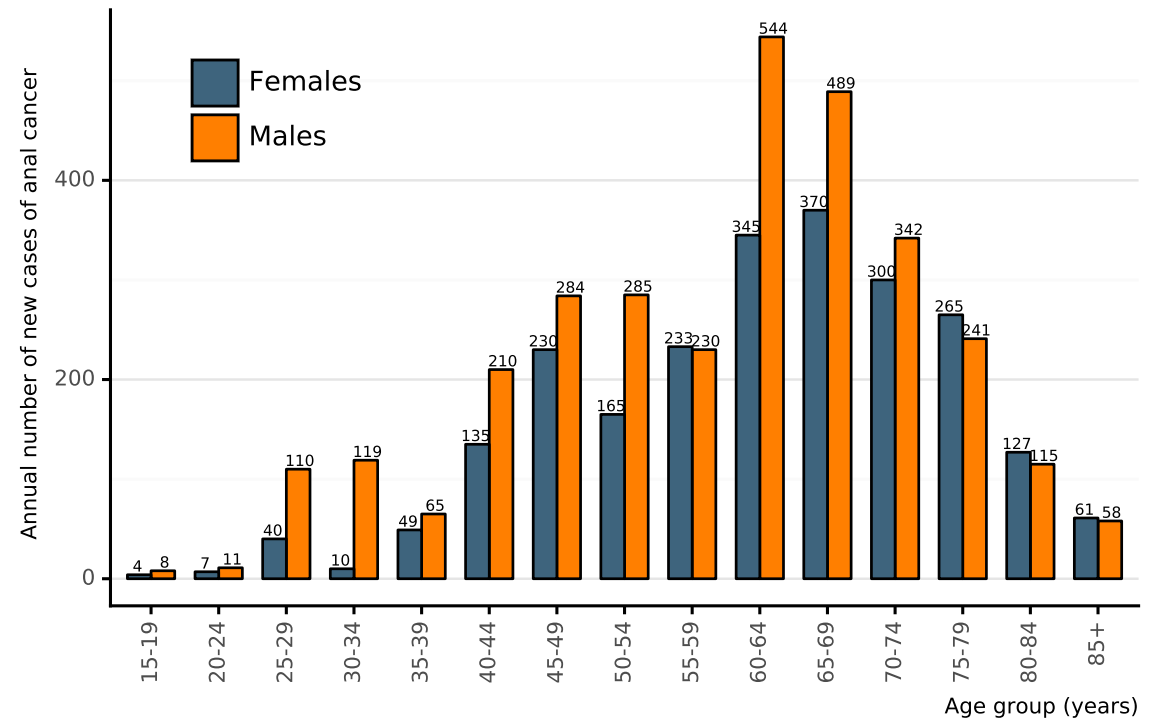

Data accessed on 27 Jan 2021

For more detailed methods of estimation please refer to http://gco.iarc.fr/today/data-sources-methods

Data Sources

Ferlay J, Ervik M, Lam F, Colombet M, Mery L, Piñeros M, Znaor A, Soerjomataram I, Bray F (2020). Global Cancer Observatory: Cancer Today. Lyon, France: International Agency for Research on Cancer. Available from: https ://gco.iarc.fr/today, accessed [27 January 2021]. 


\subsubsection{Anal cancer mortality in India}

Table 8: Anal cancer mortality in India (estimates for 2020)

\begin{tabular}{l|c|c|c} 
Indicator & India & Southern Asia & World \\
MEN & & & 9,416 \\
\hline Annual number of new cancer cases & 1,560 & 2,003 & {$[7,282-12,175]$} \\
\hline $\begin{array}{l}\text { Uncertainty intervals of new cancer } \\
\text { cases [95\% UI] }\end{array}$ & {$[1,241-1,961]$} & {$[8-207]$} & 0.24 \\
\hline Crude incidence rate & & 0.20 & 0.21 \\
\hline Age-standardized incidence rate & 0.22 & 0.22 & 0.02 \\
\hline $\begin{array}{l}\text { Cumulative risk (\%) at 75 years } \\
\text { old }^{\mathrm{b}}\end{array}$ & 0.23 & 0.03 & 9,877 \\
\hline WOMEN & 0.03 & 1,440 & {$[7,795-12,516]$} \\
\hline Annual number of new cancer cases & 1,216 & {$[5-107]$} & 0.26 \\
\hline $\begin{array}{l}\text { Uncertainty intervals of new cancer } \\
\text { cases [95\% UI] }\end{array}$ & {$[919-1,610]$} & 0.15 & 0.19 \\
\hline Crude incidence rate & & 0.16 & 0.02
\end{tabular}

Data accessed on 27 Jan 2021

For more detailed methods of estimation please refer to http://gco.iarc.fr/today/data-sources-method

${ }^{a}$ Cumulative risk (mortality) is the probability or risk of individuals dying from the disease during ages 0-74 years. For cancer, it is expressed as the \% of new born children who would be expected to die from a particular cancer before the age of 75 if they had the rates of cancer observed in the period in the absence of competing causes.

${ }^{b}$ Rates per 100,000 men per year.

${ }^{c}$ Rates per 100,000 women per year.

Data Sources:

Ferlay J, Ervik M, Lam F, Colombet M, Mery L, Piñeros M, Znaor A, Soerjomataram I, Bray F (2020). Global Cancer Observatory: Cancer Today. Lyon, France: International Agency for Research on Cancer. Available from: https ://gco.iarc.fr/today, accessed [27 January 2021]. 
Figure 17: Age-specific mortality rates of anal cancer in India (estimates for 2020)

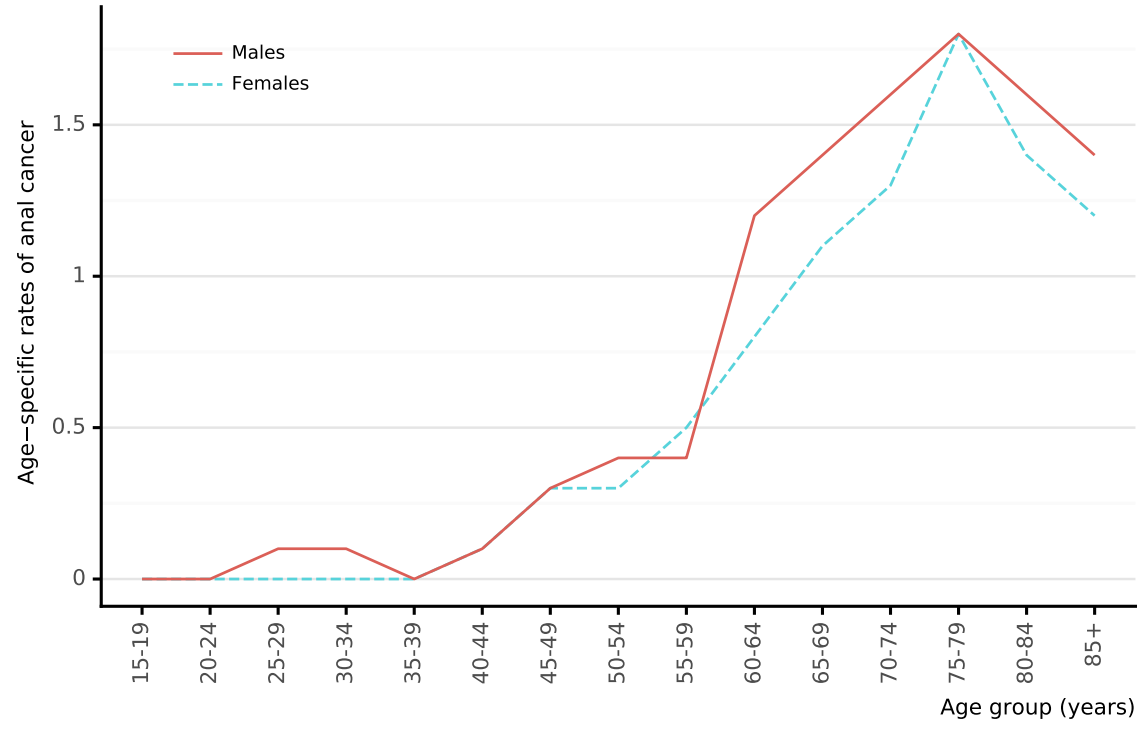

Data accessed on 27 Jan 2021

For more detailed methods of estimation please refer to http://gco.iarc.fr/today/data-sources-methods

${ }^{a}$ Rates per 100,000 men per year.

${ }^{b}$ Rates per 100,000 women per year.

Data Sources:

Ferlay J, Ervik M, Lam F, Colombet M, Mery L, Piñeros M, Znaor A, Soerjomataram I, Bray F (2020). Global Cancer Observatory: Cancer Today. Lyon, France: International Agency for Research on Cancer. Available from: https ://gco.iarc.fr/today, accessed [27 January 2021].

Figure 18: Annual number of deaths of of anal cancer in India (estimates for 2020)

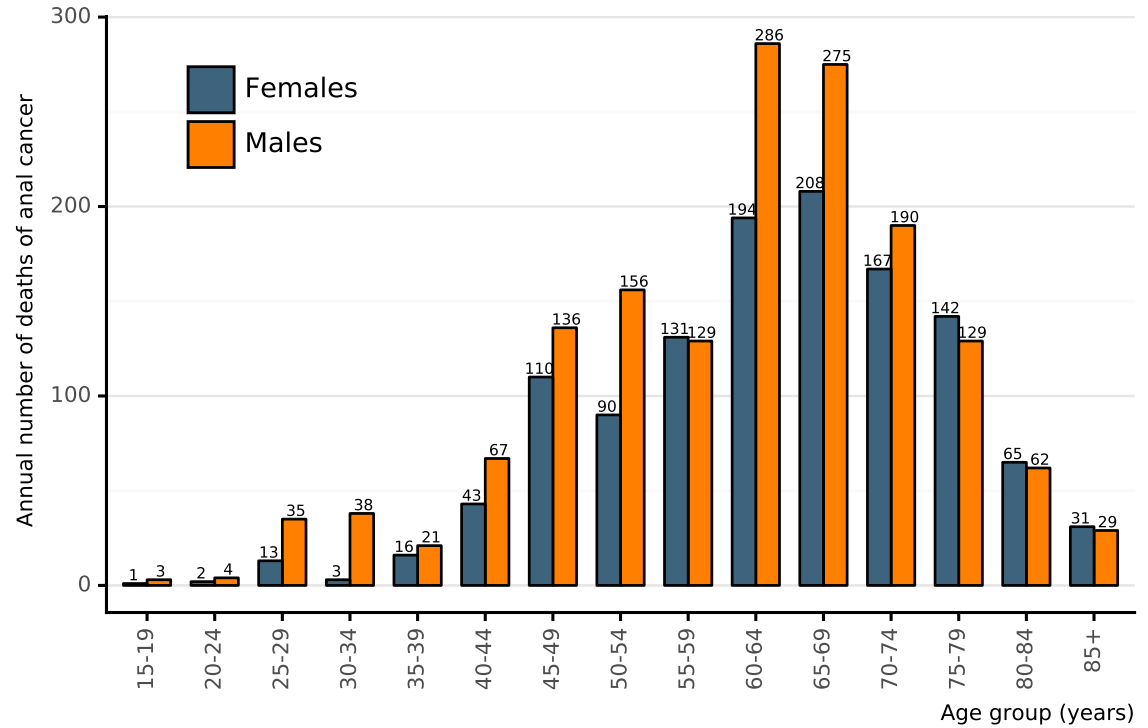

Data accessed on 27 Jan 2021

For more detailed methods of estimation please refer to http://gco.iarc.fr/today/data-sources-methods

Ferlay J, Ervik M, Lam F, Colombet M, Mery L, Piñeros M, Znaor A, Soerjomataram I, Bray F (2020). Global Cancer Observatory: Cancer Today. Lyon, France: International Agency for Research on Cancer. Available from: https ://gco.iarc.fr/today, accessed [27 January 2021]. 


\subsubsection{Anal cancer incidence and mortality comparison in India}

Figure 19: Comparison of age-specific anal cancer incidence and mortality rates among men in India (estimates for 2020)

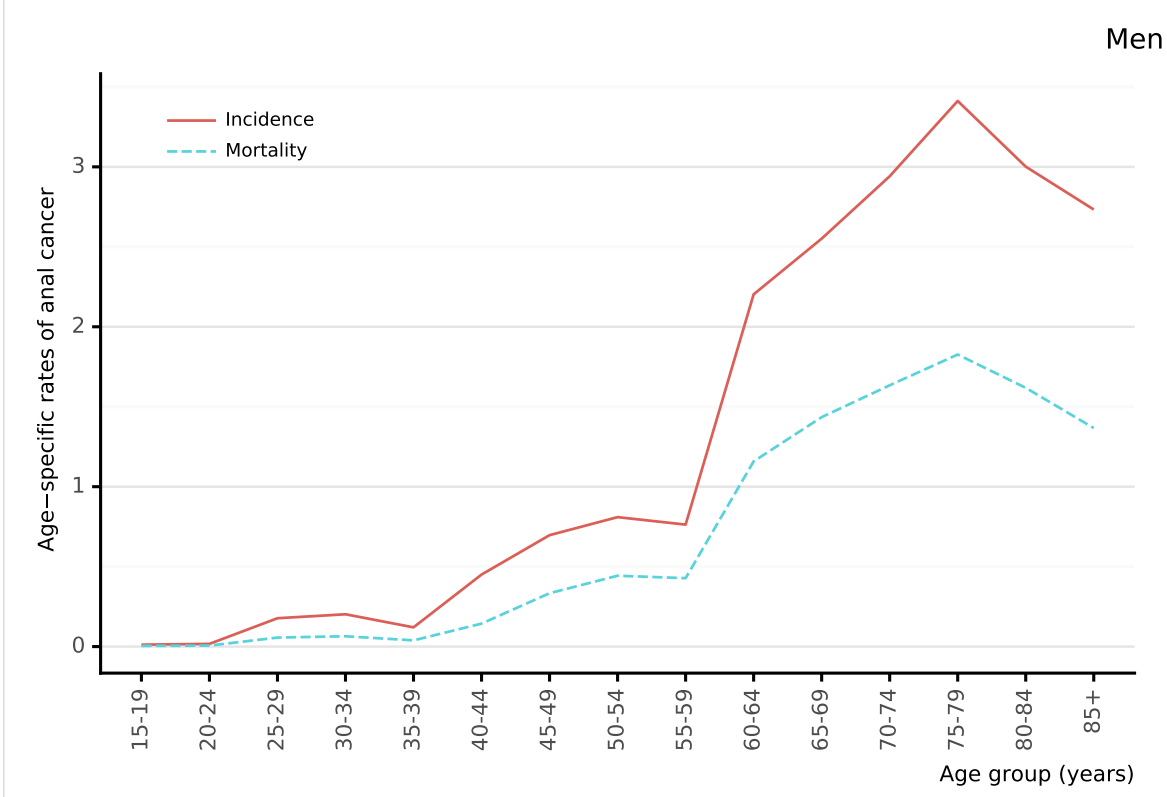

Data accessed on 27 Jan 2021

For more detailed methods of estimation please refer to http://gco.iarc.fr/today/data-sources-methods

${ }^{a}$ Rates per 100,000 men per year.

Data Sources:

Ferlay J, Ervik M, Lam F, Colombet M, Mery L, Piñeros M, Znaor A, Soerjomataram I, Bray F (2020). Global Cancer Observatory: Cancer Today. Lyon, France: International Agency for Research on Cancer. Available from: https://gco.iarc.fr/today, accessed [27 January 2021].

Figure 20: Comparison of age-specific anal cancer incidence and mortality rates among women in India (estimates for 2020)

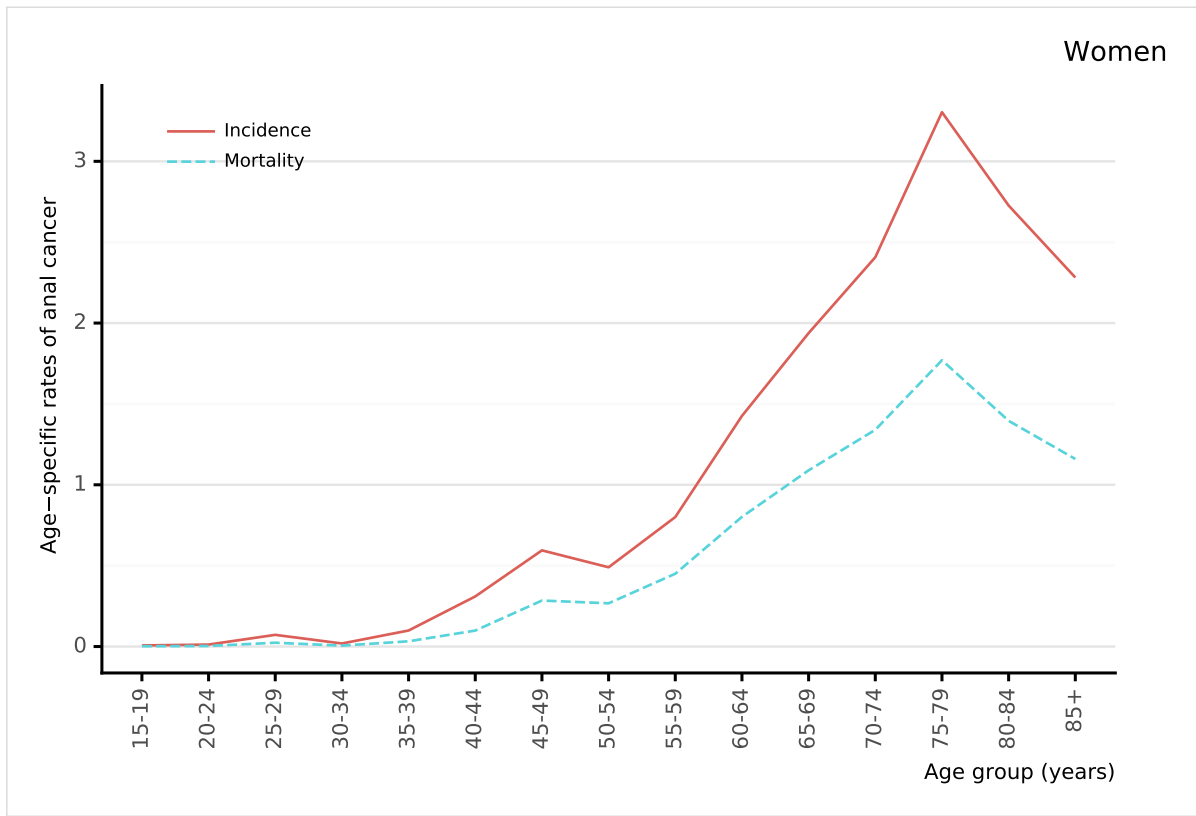

Data accessed on 27 Jan 2021

For more detailed methods of estimation please refer to http://gco.iarc.fr/today/data-sources-methods

${ }^{a}$ Rates per 100,000 women per year.

Data Sources:

Ferlay J, Ervik M, Lam F, Colombet M, Mery L, Piñeros M, Znaor A, Soerjomataram I, Bray F (2020). Global Cancer Observatory: Cancer Today. Lyon, France: International Agency for Research on Cancer. Available from: https ://gco.iarc.fr/today, accessed [27 January 2021]. 


\subsubsection{Vulva cancer}

Cancer of the vulva is rare among women worldwide, with an estimated 44,000 new cases in 2018, representing 6\% of all gynaecologic cancers (de Martel C et al. Lancet Glob Health 2020;8(2):e180e190). Worldwide, about $60 \%$ of all vulvar cancer cases occur in more developed countries. Vulvar cancer has two distinct histological patterns with two different risk factor profiles: (1) basaloid/warty types (2) keratinising types. Basaloid/warty lesions are more common in young women, are very often associated with HPV DNA detection (75-100\%), and have a similar risk factor profile as cervical cancer. Keratinising vulvar carcinomas represent the majority of the vulvar lesions ( $>60 \%)$, they occur more often in older women and are more rarely associated with HPV (IARC Monograph Vol 100B).

\subsubsection{Vulva cancer incidence in India}

Table 9: Vulva cancer incidence in India (estimates for 2020)

\begin{tabular}{l|c|c|c} 
Indicator & India & Southern Asia & World \\
$\begin{array}{l}\text { Annual number of new cancer } \\
\text { cases }\end{array}$ & 3,447 & 4,111 & 45,240 \\
\hline Uncertainty intervals [95\% UI] & {$[2,733-4,347]$} & {$[10-157]$} & {$[40,656-50,342]$} \\
\hline Crude incidence rate & 0.52 & 0.44 & 1.17 \\
\hline $\begin{array}{l}\text { Age-standardized incidence } \\
\text { rate }^{\mathrm{b}}\end{array}$ & 0.51 & 0.46 & 0.85 \\
\hline $\begin{array}{l}\text { Cumulative risk (\%) at 75 years } \\
\text { old }^{\mathrm{a}}\end{array}$ & 0.06 & 0.06 & 0.09 \\
\hline
\end{tabular}

Data accessed on 27 Jan 2021

For more detailed methods of estimation please refer to http://gco.iarc.fr/today/data-sources-methods

${ }^{a}$ Cumulative risk (incidence) is the probability or risk of individuals getting from the disease during ages 0-74 years. For cancer, it is expressed as the \% of new born children who would be expected to develop from a particular cancer before the age of 75 if they had the rates of cancer observed in the period in the absence of competing causes.

$b$ Rates per 100,000 women per year.

Data Sources:

Ferlay J, Ervik M, Lam F, Colombet M, Mery L, Piñeros M, Znaor A, Soerjomataram I, Bray F (2020). Global Cancer Observatory: Cancer Today. Lyon, France: International Agency for Research on Cancer. Available from: https ://gco.iarc.fr/today, accessed [27 January 2021]. 
Figure 21: Age-specific incidence rates of vulva cancer in India (estimates for 2020)

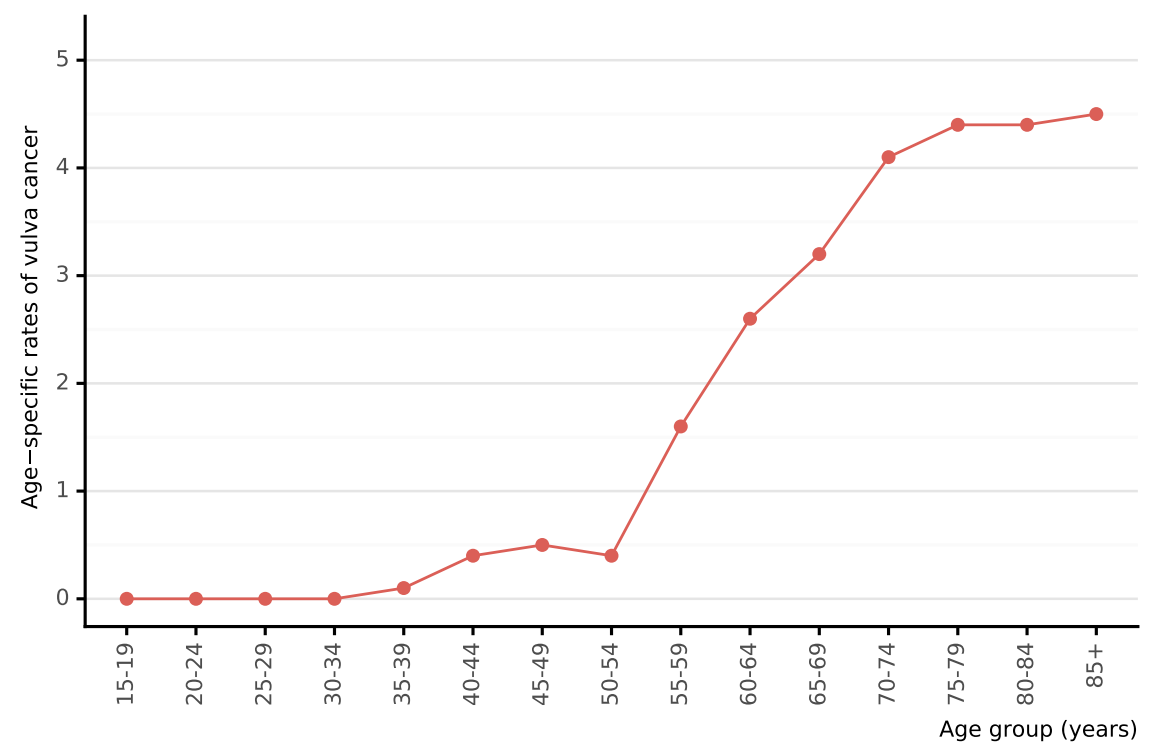

Data accessed on 27 Jan 2021

For more detailed methods of estimation please refer to http://gco.iarc.fr/today/data-sources-methods

${ }^{a}$ Rates per 100,000 women per year.

Ferlay J, Ervik M, Lam F, Colombet M, Mery L, Piñeros M, Znaor A, Soerjomataram I, Bray F (2020). Global Cancer Observatory: Cancer Today. Lyon, France: International Agency for Research on Cancer. Available from: https://gco.iarc.fr/today, accessed [27 January 2021].

Figure 22: Annual number of new cases of vulva cancer in India (estimates for 2020)

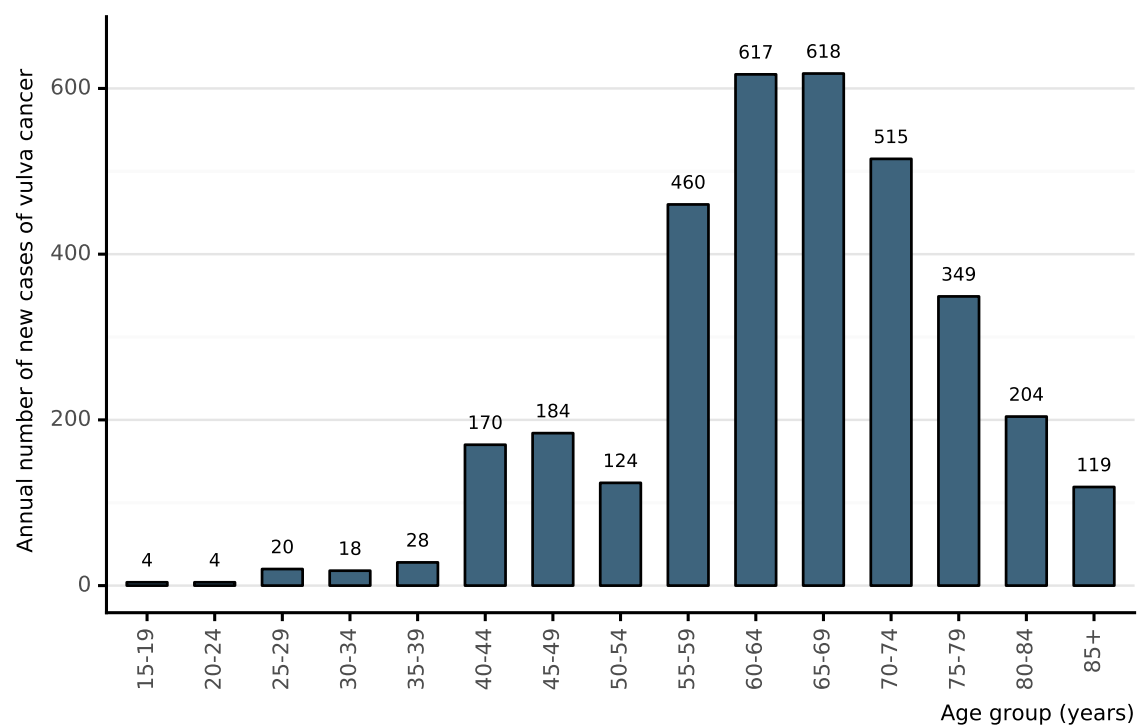

Data accessed on 27 Jan 2021

For more detailed methods of estimation please refer to http://gco.iarc.fr/today/data-sources-methods

Data Sources:

Ferlay J, Ervik M, Lam F, Colombet M, Mery L, Piñeros M, Znaor A, Soerjomataram I, Bray F (2020). Global Cancer Observatory: Cancer Today. Lyon, France: International Agency for Research on Cancer. Available from: https://gco.iarc.fr/today, accessed [27 January 2021]. 


\subsubsection{Vulva cancer mortality in India}

Table 10: Vulva cancer mortality in India (estimates for 2020)

\begin{tabular}{lccc} 
Indicator & India & Southern Asia & World \\
Annual number of deaths & 1,694 & 2,019 & 17,427 \\
\hline Uncertainty intervals [95\% UI] & {$[1,323-2,169]$} & {$[7-88]$} & {$[14,497-20,950]$} \\
\hline $\begin{array}{l}\text { Crude mortality rate } \\
\text { Age-standardized mortality }\end{array}$ & 0.26 & 0.21 & 0.45 \\
rate $^{\mathrm{b}}$ & 0.25 & 0.23 & 0.30 \\
\hline $\begin{array}{l}\text { Cumulative risk (\%) at 75 years } \\
\text { ld }^{\mathrm{a}}\end{array}$ & 0.03 & 0.03 & 0.03
\end{tabular}

Data accessed on 27 Jan 2021

For more detailed methods of estimation please refer to http://gco.iarc.fr/today/data-sources-methods

${ }^{a}$ Cumulative risk (mortality) is the probability or risk of individuals dying from the disease during ages 0-74 years. For cancer, it is expressed as the \% of new born children who would be expected to die from a particular cancer before the age of 75 if they had the rates of cancer observed in the period in the absence of competing causes.

$b^{b}$ Rates per 100,000 women per year.

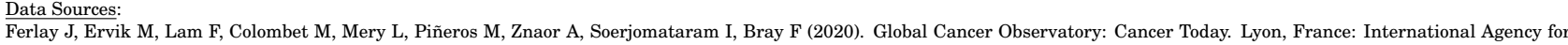
Research on Cancer. Available from: https://gco.iarc.fr/today, accessed [27 January 2021]. 
Figure 23: Age-specific mortality rates of vulva cancer in India (estimates for 2020)

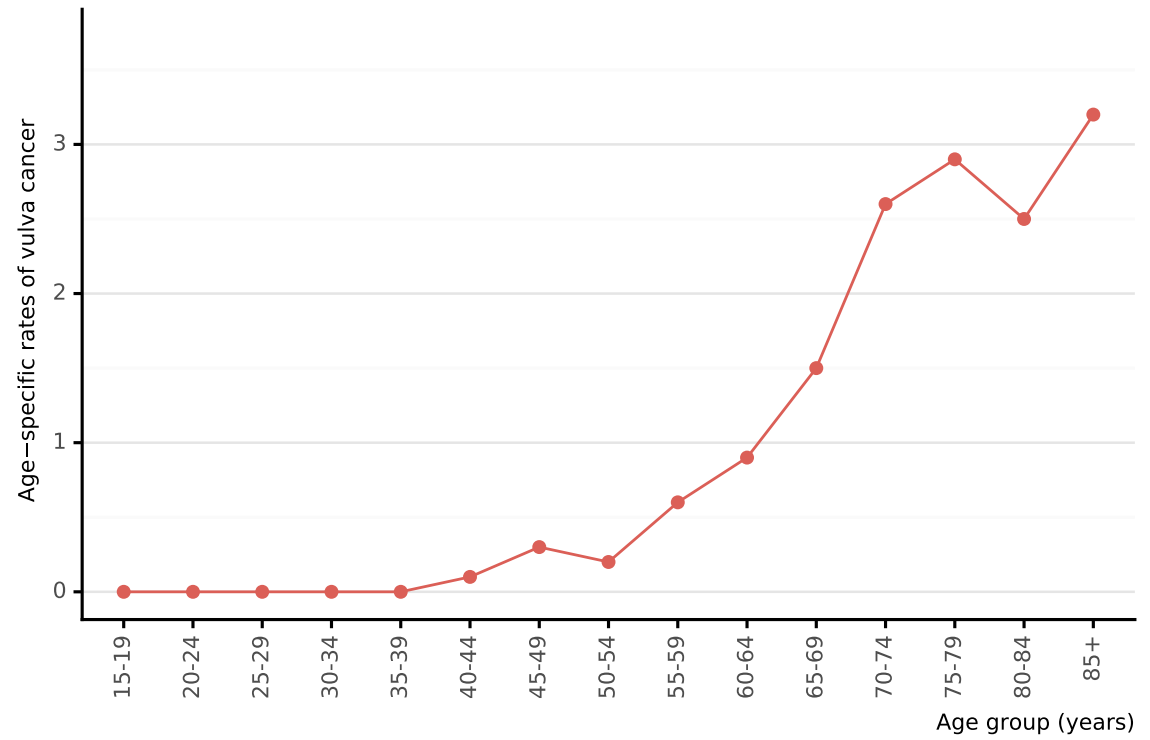

Data accessed on 27 Jan 2021

For more detailed methods of estimation please refer to http://gco.iarc.fr/today/data-sources-methods

${ }^{a}$ Rates per 100,000 women per year.

Ferlay J, Ervik M, Lam F, Colombet M, Mery L, Piñeros M, Znaor A, Soerjomataram I, Bray F (2020). Global Cancer Observatory: Cancer Today. Lyon, France: International Agency for Research on Cancer. Available from: https ://gco.iarc.fr/today, accessed [27 January 2021].

Figure 24: Annual number of deaths of vulva cancer in India (estimates for 2020)

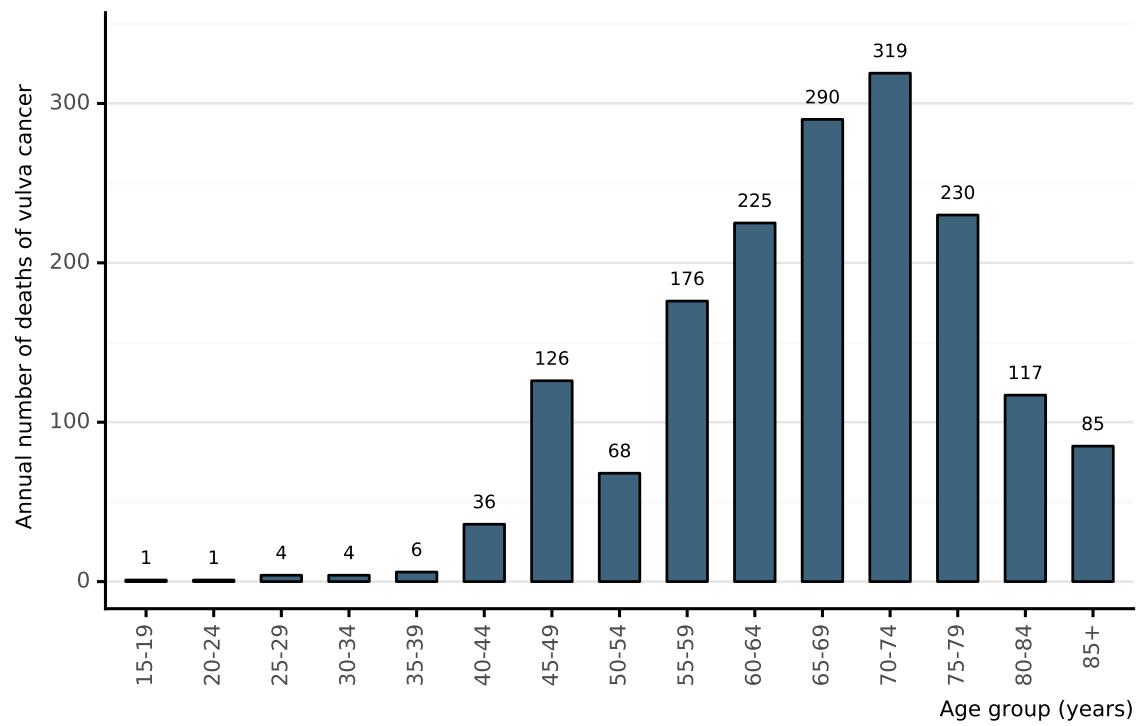

Data accessed on 27 Jan 2021

For more detailed methods of estimation please refer to http://gco.iarc.fr/today/data-sources-methods

$a^{a}$ Rates per 100,000 women per year.

Data Sources:

Ferlay J, Ervik M, Lam F, Colombet M, Mery L, Piñeros M, Znaor A, Soerjomataram I, Bray F (2020). Global Cancer Observatory: Cancer Today. Lyon, France: International Agency for Research on Cancer. Available from: https ://gco.iarc.fr/today, accessed [27 January 2021]. 


\subsubsection{Vulva cancer incidence and mortality comparison in India}

Figure 25: Comparison of age-specific vulva cancer incidence and mortality rates in India (estimates for 2020)

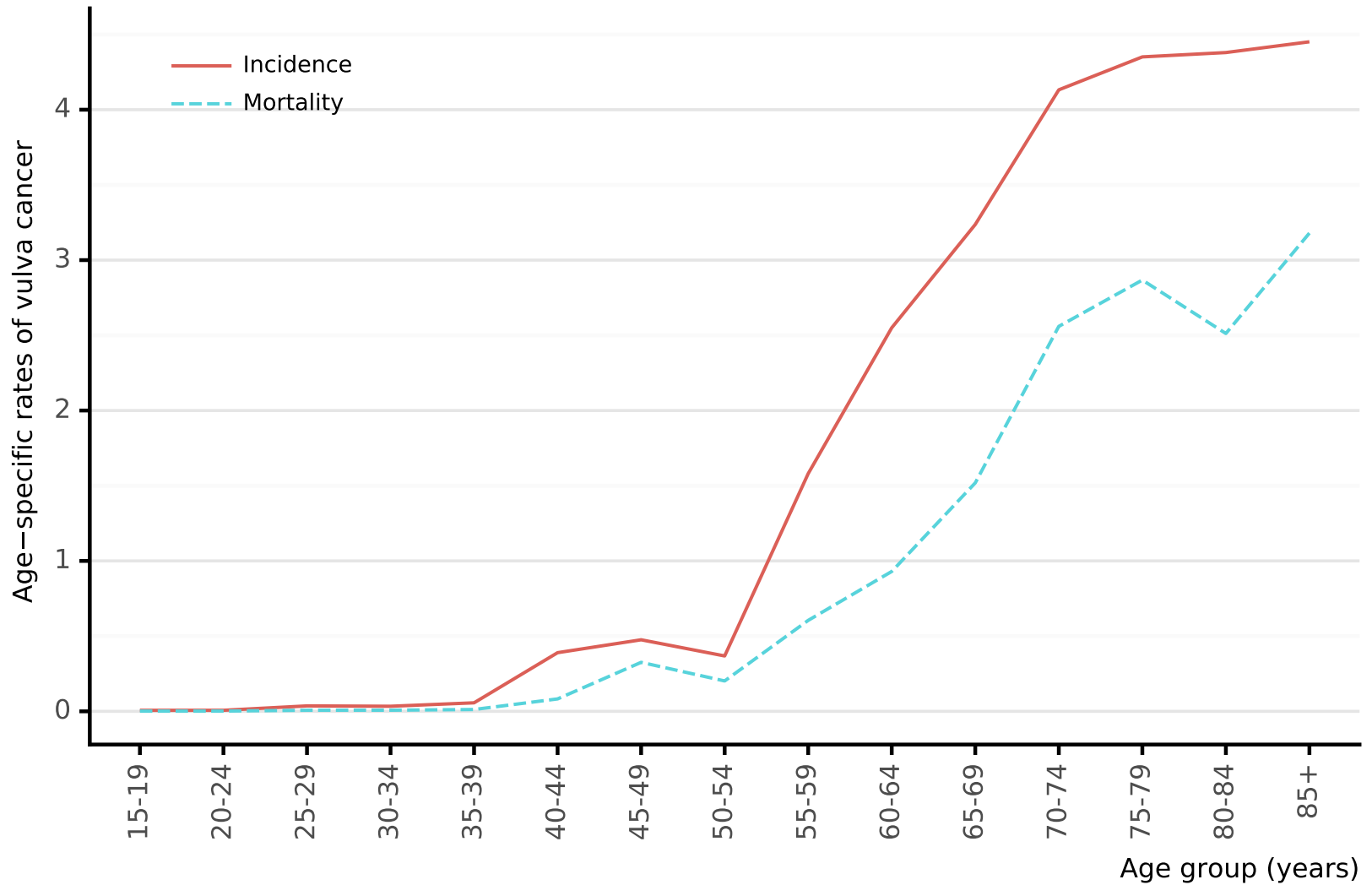

Data accessed on 27 Jan 2021

For more detailed methods of estimation please refer to http://gco.iarc.fr/today/data-sources-methods

${ }^{a}$ Rates per 100,000 women per year.

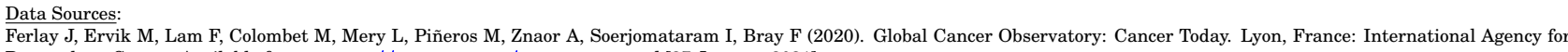
Research on Cancer. Available from: https://gco.iarc.fr/today, accessed [27 January 2021] 


\subsubsection{Vaginal cancer}

Cancer of the vagina is a rare cancer, with an estimated 18,000 new cases in 2018, representing $3 \%$ of all gynaecologic cancers (de Martel C et al. Lancet Glob Health 2020;8(2):e180-e190). Similar to cervical cancer, the majority of vaginal cancer cases (68\%) occur in less developed countries. Most vaginal cancers are squamous cell carcinoma (90\%) generally attributable to HPV, followed by clear cell adenocarcinomas and melanoma. Vaginal cancers are primarily reported in developed countries. Metastatic cervical cancer can be misclassified as cancer of the vagina. Invasive vaginal cancer is diagnosed primarily in old women ( $>=65$ years) and the diagnosis is rare in women under 45 years whereas the peak incidence of carcinoma in situ is observed between ages 55 and 70 (Vaccine 2008, Vol. 26, Suppl 10).

\subsubsection{Vaginal cancer incidence in India}

Table 11: Vaginal cancer incidence in India (estimates for 2020)

\begin{tabular}{l|ccc} 
Indicator & India & Southern Asia & World \\
$\begin{array}{l}\text { Annual number of new cancer } \\
\text { cases }\end{array}$ & 5,518 & 6,216 & 17,908 \\
\hline \begin{tabular}{l} 
Uncertainty intervals [95\% UI] \\
\hline Crude incidence rate
\end{tabular} & {$[4,512-6,748]$} & {$[4-104]$} & {$[14,678-21,848]$} \\
\hline $\begin{array}{l}\text { Age-standardized incidence } \\
\text { rate }\end{array}$ & 0.83 & 0.66 & 0.46 \\
\hline $\begin{array}{l}\text { Cumulative risk (\%) at 75 years } \\
\text { old }^{\mathrm{b}}\end{array}$ & 0.81 & 0.69 & 0.36 \\
\hline
\end{tabular}

Data accessed on 27 Jan 2021

For more detailed methods of estimation please refer to http://gco.iarc.fr/today/data-sources-methods

${ }^{a}$ Cumulative risk (incidence) is the probability or risk of individuals getting from the disease during ages 0-74 years. For cancer, it is expressed as the \% of new born children who would be expected to develop from a particular cancer before the age of 75 if they had the rates of cancer observed in the period in the absence of competing causes.

$b$ Rates per 100,000 women per year.

Data Sources:

Ferlay J, Ervik M, Lam F, Colombet M, Mery L, Piñeros M, Znaor A, Soerjomataram I, Bray F (2020). Global Cancer Observatory: Cancer Today. Lyon, France: International Agency for Research on Cancer. Available from: https ://gco.iarc.fr/today, accessed [27 January 2021]. 
Figure 26: Age-specific incidence rates of vaginal cancer in India (estimates for 2020)

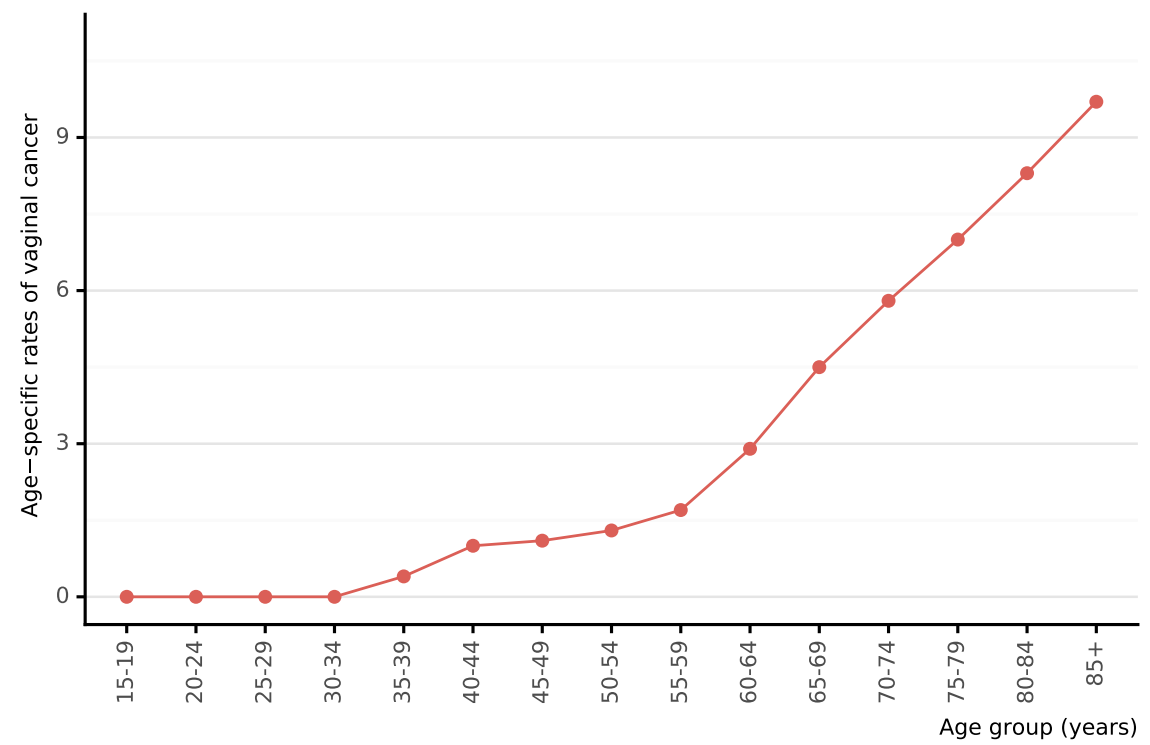

Data accessed on 27 Jan 2021

For more detailed methods of estimation please refer to http://gco.iarc.fr/today/data-sources-methods

${ }^{a}$ Rates per 100,000 women per year.

Ferlay J, Ervik M, Lam F, Colombet M, Mery L, Piñeros M, Znaor A, Soerjomataram I, Bray F (2020). Global Cancer Observatory: Cancer Today. Lyon, France: International Agency for Research on Cancer. Available from: https://gco.iarc.fr/today, accessed [27 January 2021].

Figure 27: Annual number of new cases of vaginal cancer in India (estimates for 2020)

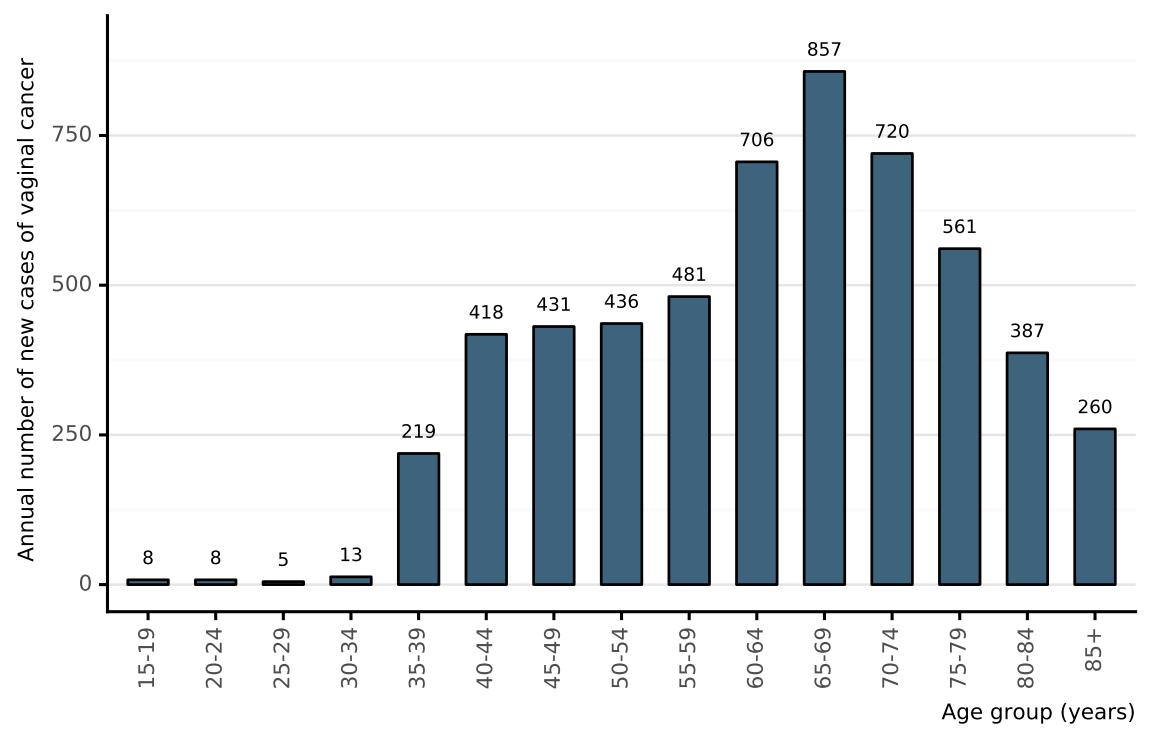

Data accessed on 27 Jan 2021

For more detailed methods of estimation please refer to http://gco.iarc.fr/today/data-sources-methods

Data Sources:

Ferlay J, Ervik M, Lam F, Colombet M, Mery L, Piñeros M, Znaor A, Soerjomataram I, Bray F (2020). Global Cancer Observatory: Cancer Today. Lyon, France: International Agency for Research on Cancer. Available from: https://gco.iarc.fr/today, accessed [27 January 2021]. 


\subsubsection{Vaginal cancer mortality in India}

Table 12: Vaginal cancer mortality in India (estimates for 2020)

\begin{tabular}{lcccc} 
Indicator & India & Southern Asia & World \\
Annual number of deaths & 2,723 & 3,060 & 7,995 \\
\hline $\begin{array}{l}\text { Uncertainty intervals [95\% UI] } \\
\text { Crude mortality rate }\end{array}$ & {$[2,198-3,374]$} & {$[3-69]$} & {$[5,983-10,684]$} \\
\hline $\begin{array}{l}\text { Age-standardized mortality } \\
\text { rate }\end{array}$ & 0.41 & 0.33 & 0.21 \\
\hline $\begin{array}{l}\text { Cumulative risk (\%) at 75 years } \\
\text { old }^{\mathrm{b}}\end{array}$ & 0.40 & 0.34 & 0.16 \\
\hline
\end{tabular}

Data accessed on 27 Jan 2021

For more detailed methods of estimation please refer to http://gco.iarc.fr/today/data-sources-methods

${ }^{a}$ Cumulative risk (mortality) is the probability or risk of individuals dying from the disease during ages 0-74 years. For cancer, it is expressed as the \% of new born children who would be expected to die from a particular cancer before the age of 75 if they had the rates of cancer observed in the period in the absence of competing causes.

${ }^{b}$ Rates per 100,000 women per year.

Data Sources: Research on Cancer. Available from: https://gco.iarc.fr/today, accessed [27 January 2021]. 
Figure 28: Age-specific mortality rates of vaginal cancer in India (estimates for 2020)

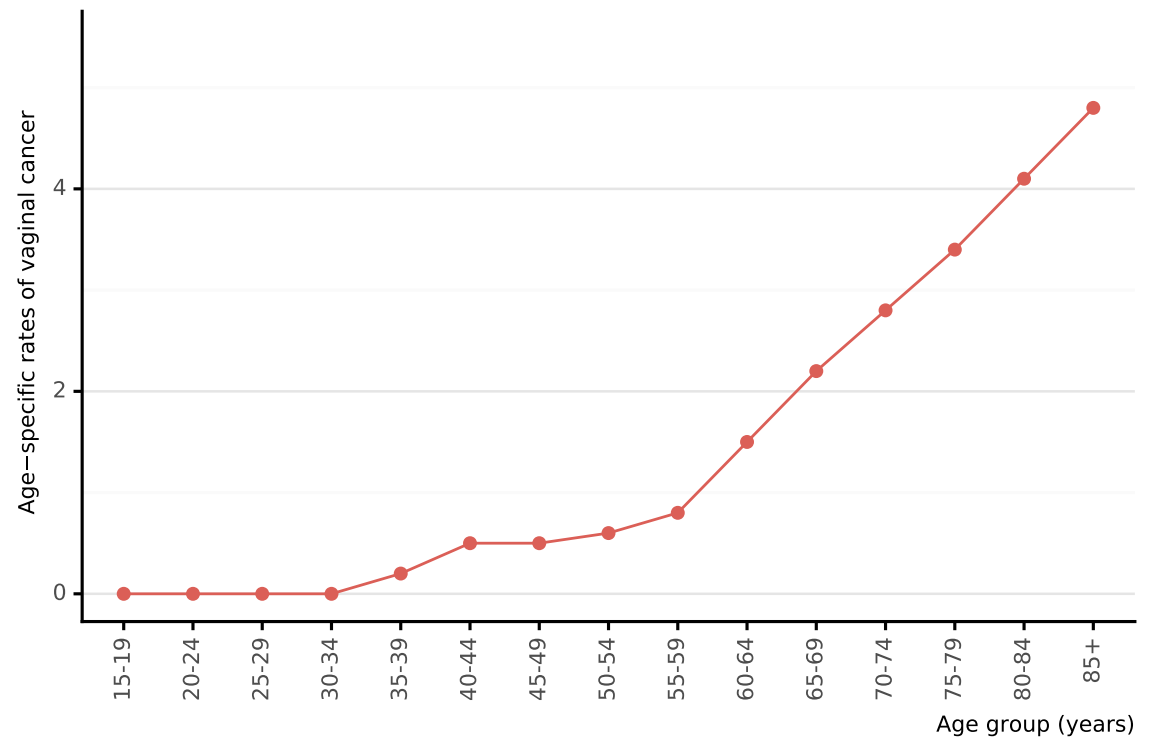

Data accessed on 27 Jan 2021

For more detailed methods of estimation please refer to http://gco.iarc.fr/today/data-sources-methods

${ }^{a}$ Rates per 100,000 women per year.

Data Source:

Ferlay J, Ervik M, Lam F, Colombet M, Mery L, Piñeros M, Znaor A, Soerjomataram I, Bray F (2020). Global Cancer Observatory: Cancer Today. Lyon, France: International Agency for Research on Cancer. Available from: https://gco.iarc.fr/today, accessed [27 January 2021].

Figure 29: Annual number of deaths of vaginal cancer in India (estimates for 2020)

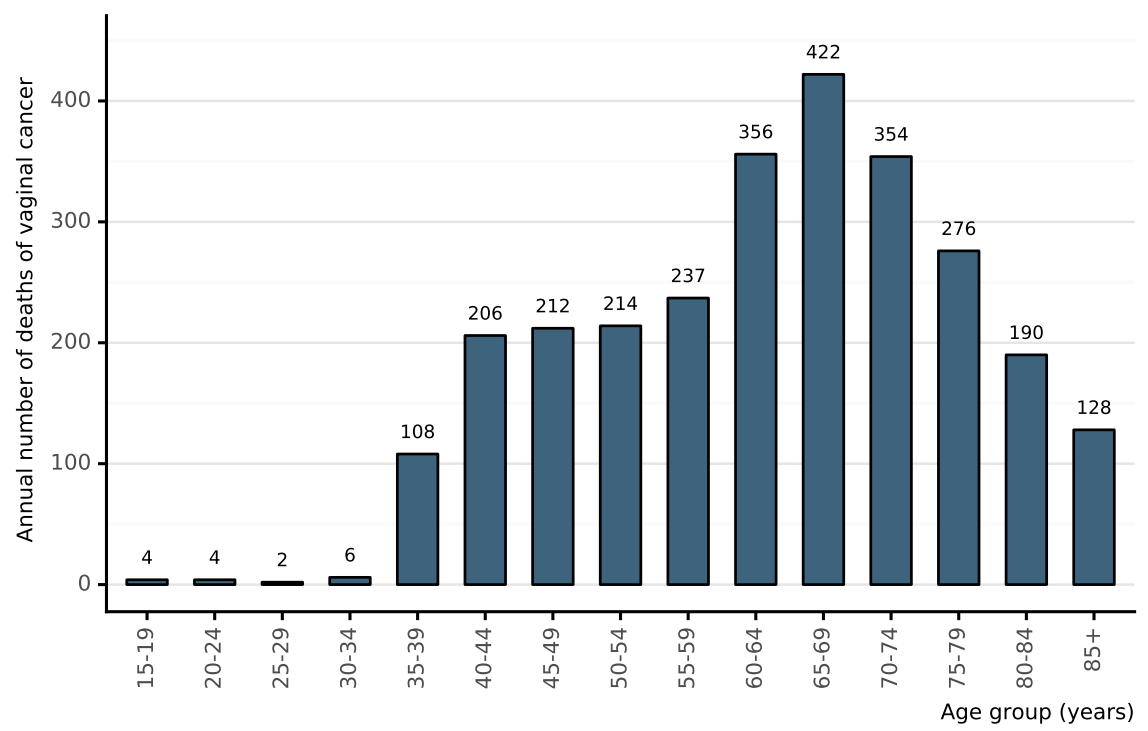

Data accessed on 27 Jan 2021

For more detailed methods of estimation please refer to http://gco.iarc.fr/today/data-sources-methods

Data Sources:

Ferlay J, Ervik M, Lam F, Colombet M, Mery L, Piñeros M, Znaor A, Soerjomataram I, Bray F (2020). Global Cancer Observatory: Cancer Today. Lyon, France: International Agency for Research on Cancer. Available from: https ://gco .iarc.fr/today, accessed [27 January 2021]. 


\subsubsection{Vaginal cancer incidence and mortality comparison in India}

Figure 30: Comparison of age-specific vaginal cancer incidence and mortality rates in India (estimates for 2020)

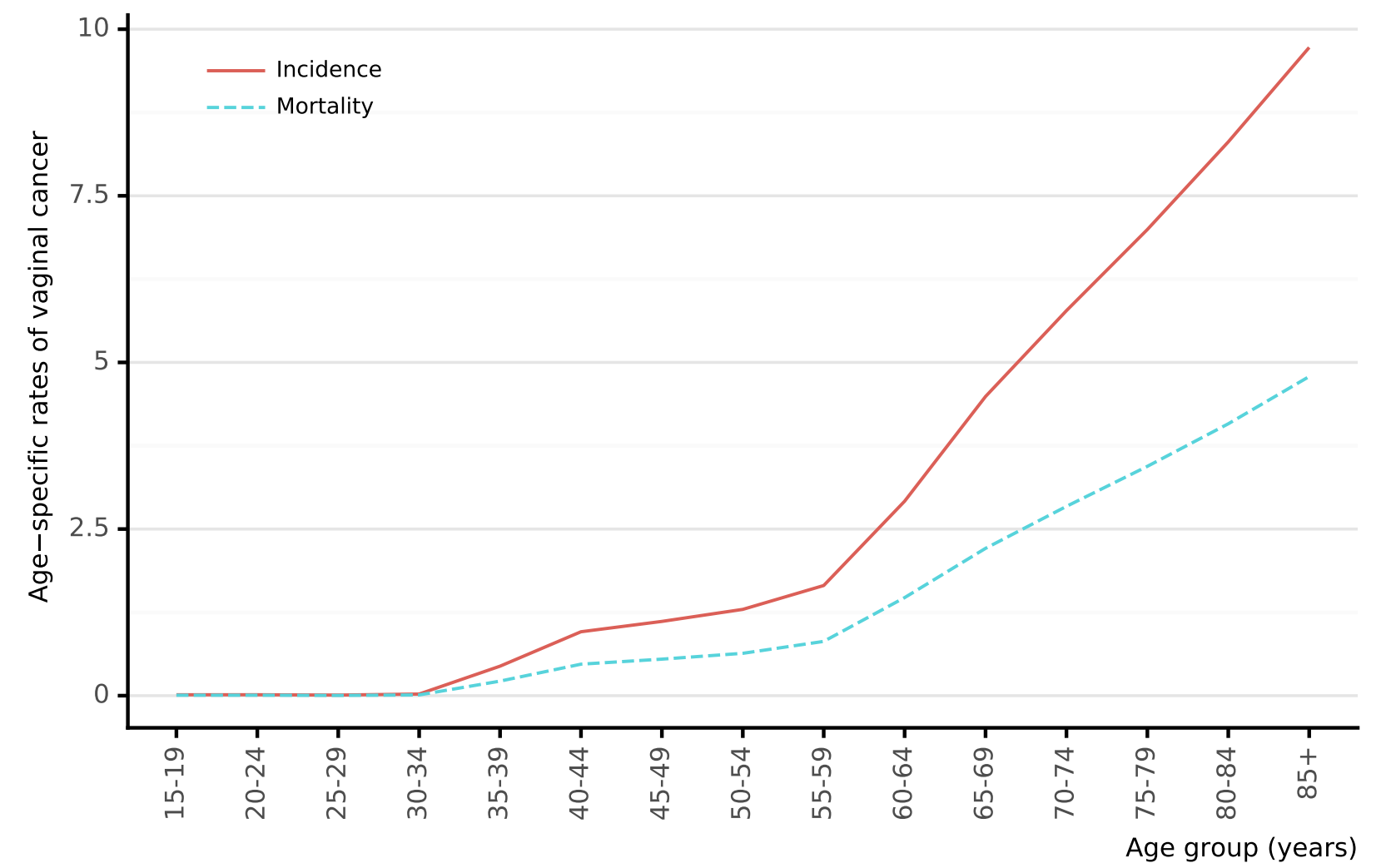

Data accessed on 27 Jan 2021

For more detailed methods of estimation please refer to http://gco.iarc.fr/today/data-sources-methods

${ }^{a}$ Rates per 100,000 women per year.

Ferlay J, Ervik M, Lam F, Colombet M, Mery L, Piñeros M, Znaor A, Soerjomataram I, Bray F (2020). Global Cancer Observatory: Cancer Today. Lyon, France: International Agency for Research on Cancer. Available from: https ://gco.iarc.fr/today, accessed [27 January 2021]. 


\subsubsection{Penile cancer}

The annual burden of penile cancer has been estimated to be 34,000 cases in 2018 worldwide with incidence rates strongly correlating with those of cervical cancer (de Martel C et al. Lancet Glob Health 2020;8(2):e180-e190). Penile cancer is rare and most commonly affects men aged 50-70 years. Incidence rates are higher in less developed countries than in more developed countries, accounting for up to 10\% of male cancers in some parts of Africa, South America and Asia. Precursor cancerous penile lesions $($ PeIN) are rare.

Cancers of the penis are primarily of squamous cell carcinomas (SCC) (95\%) and the most common penile SCC histologic sub-types are keratinising (49\%), mixed warty-basaloid (17\%), verrucous (8\%) warty (6\%), and basaloid (4\%). HPV is most commonly detected in basaloid and warty tumours but is less common in keratinising and verrucous tumours. Approximately $60-100 \%$ of PeIN lesions are HPV DNA positive.

\subsubsection{Penile cancer incidence in India}

Table 13: Penile cancer incidence in India (estimates for 2020)

\begin{tabular}{l|c|c|c} 
Indicator & India & Southern Asia & World \\
$\begin{array}{l}\text { Annual number of new cancer } \\
\text { cases }\end{array}$ & 10,677 & 12,011 & 36,068 \\
\hline Uncertainty intervals [95\% UI] & {$[9,218-12,367]$} & {$[2-71]$} & {$[30,963-42,015]$} \\
\hline Crude incidence rate & 1.49 & 1.20 & 0.92 \\
\hline $\begin{array}{l}\text { Age-standardized incidence } \\
\text { rate }\end{array}$ & 1.61 & 1.35 & 0.80 \\
\hline $\begin{array}{l}\text { Cumulative risk (\%) at 75 years } \\
\text { old }^{\mathrm{b}}\end{array}$ & 0.20 & 0.16 & 0.09 \\
\hline
\end{tabular}

Data accessed on 27 Jan 2021

For more detailed methods of estimation please refer to http://gco.iarc.fr/today/data-sources-methods

${ }^{a}$ Cumulative risk (incidence) is the probability or risk of individuals getting from the disease during ages $0-74$ years. For cancer, it is expressed as the \% of new born children who would be expected to develop from a particular cancer before the age of 75 if they had the rates of cancer observed in the period in the absence of competing causes.

${ }^{b}$ Rates per 100,000 men per year.

Data Sources:

Ferlay J, Ervik M, Lam F, Colombet M, Mery L, Piñeros M, Znaor A, Soerjomataram I, Bray F (2020). Global Cancer Observatory: Cancer Today. Lyon, France: International Agency for Research on Cancer. Available from: https ://gco.iarc.fr/today, accessed [27 January 2021]. 
Figure 31: Age-specific incidence rates of penile cancer in India (estimates for 2020)

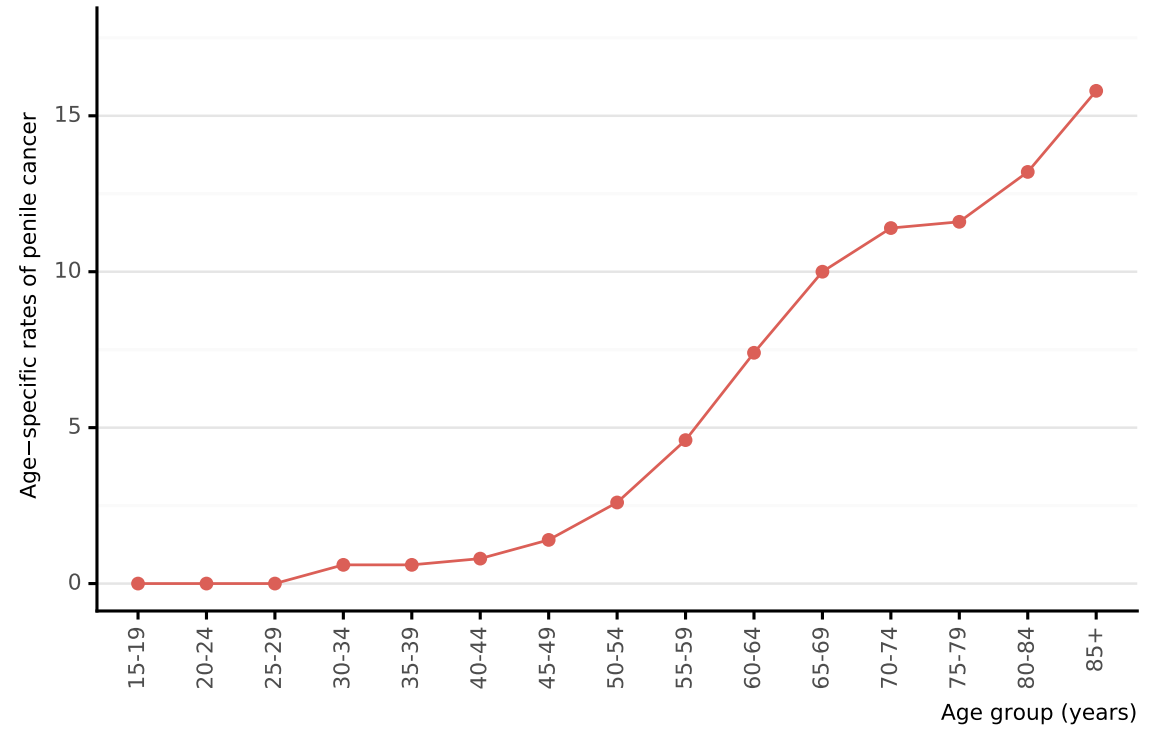

Data accessed on 27 Jan 2021

For more detailed methods of estimation please refer to http://gco.iarc.fr/today/data-sources-methods

$a^{a}$ Rates per 100,000 men per year.

Data Sources: Research on Cancer. Available from: https ://gco.iarc.fr/today, accessed [27 January 2021].

Figure 32: Annual number of new cases of penile cancer in India (estimates for 2020)

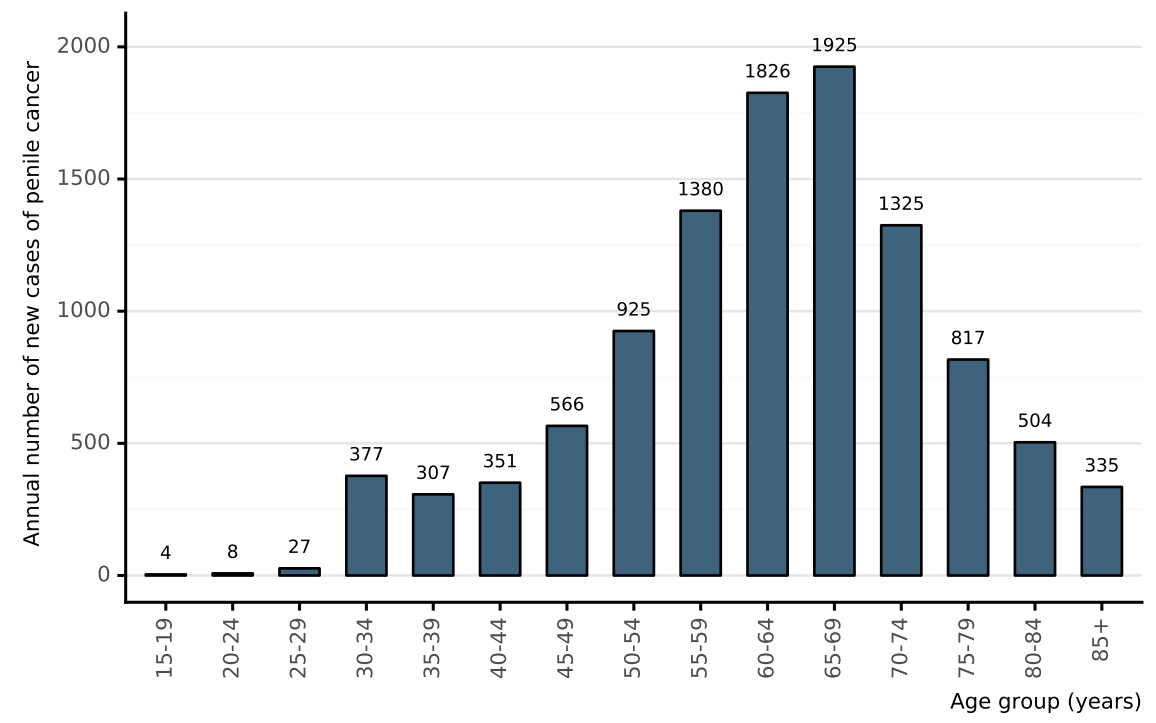

Data accessed on 27 Jan 2021

For more detailed methods of estimation please refer to http://gco.iarc.fr/today/data-sources-methods

Data Sources:

Ferlay J, Ervik M, Lam F, Colombet M, Mery L, Piñeros M, Znaor A, Soerjomataram I, Bray F (2020). Global Cancer Observatory: Cancer Today. Lyon, France: International Agency for Research on Cancer. Available from: https ://gco.iarc.fr/today, accessed [27 January 2021]. 


\subsubsection{Penile cancer mortality in India}

Table 14: Penile cancer mortality in India (estimates for 2020)

\begin{tabular}{lcccc} 
Indicator & India & Southern Asia & World \\
Annual number of deaths & 4,760 & 5,311 & 13,211 \\
\hline $\begin{array}{l}\text { Uncertainty intervals [95\% UI] } \\
\text { Crude mortality rate }^{\mathrm{b}} \text { mortality }\end{array}$ & $0.670-5,567]$ & {$[1-28]$} & {$[10,687-16,332]$} \\
\hline $\begin{array}{l}\text { Age-standardized } \\
\text { rate }^{\mathrm{b}}\end{array}$ & 0.66 & 0.53 & 0.34 \\
\hline $\begin{array}{l}\text { Cumulative risk (\%) at 75 years } \\
\text { old }^{\mathrm{a}}\end{array}$ & 0.08 & 0.60 & 0.29 \\
\hline
\end{tabular}

Data accessed on 27 Jan 2021

For more detailed methods of estimation please refer to http://gco.iarc.fr/today/data-sources-methods

${ }^{a}$ Cumulative risk (mortality) is the probability or risk of individuals dying from the disease during ages 0-74 years. For cancer, it is expressed as the \% of new born children who would be expected to die from a particular cancer before the age of 75 if they had the rates of cancer observed in the period in the absence of competing causes.

$b^{b}$ Rates per 100,000 men per year.

Data Sources:

Ferlay J, Ervik M, Lam F, Colombet M, Mery L, Piñeros M, Znaor A, Soerjomataram I, Bray F (2020). Global Cancer Observatory: Cancer Today. Lyon, France: International Agency for Research on Cancer. Available from: https://gco.iarc.fr/today, accessed [27 January 2021]. 
Figure 33: Age-specific mortality rates of penile cancer in India (estimates for 2020)

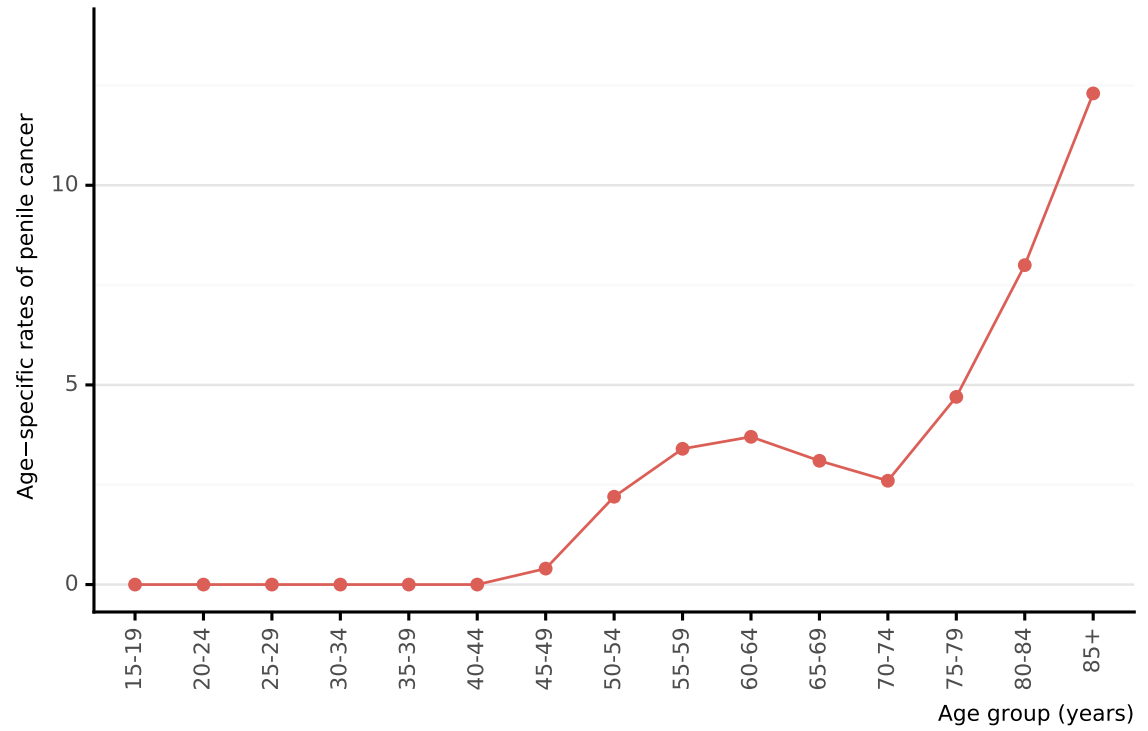

Data accessed on 27 Jan 2021

For more detailed methods of estimation please refer to http://gco.iarc.fr/today/data-sources-methods

${ }^{a}$ Rates per 100,000 men per year.

Data Sources: Research on Cancer. Available from: https://gco.iarc.fr/today, accessed [27 January 2021].

Figure 34: Annual number of deaths of penile cancer in India (estimates for 2020)

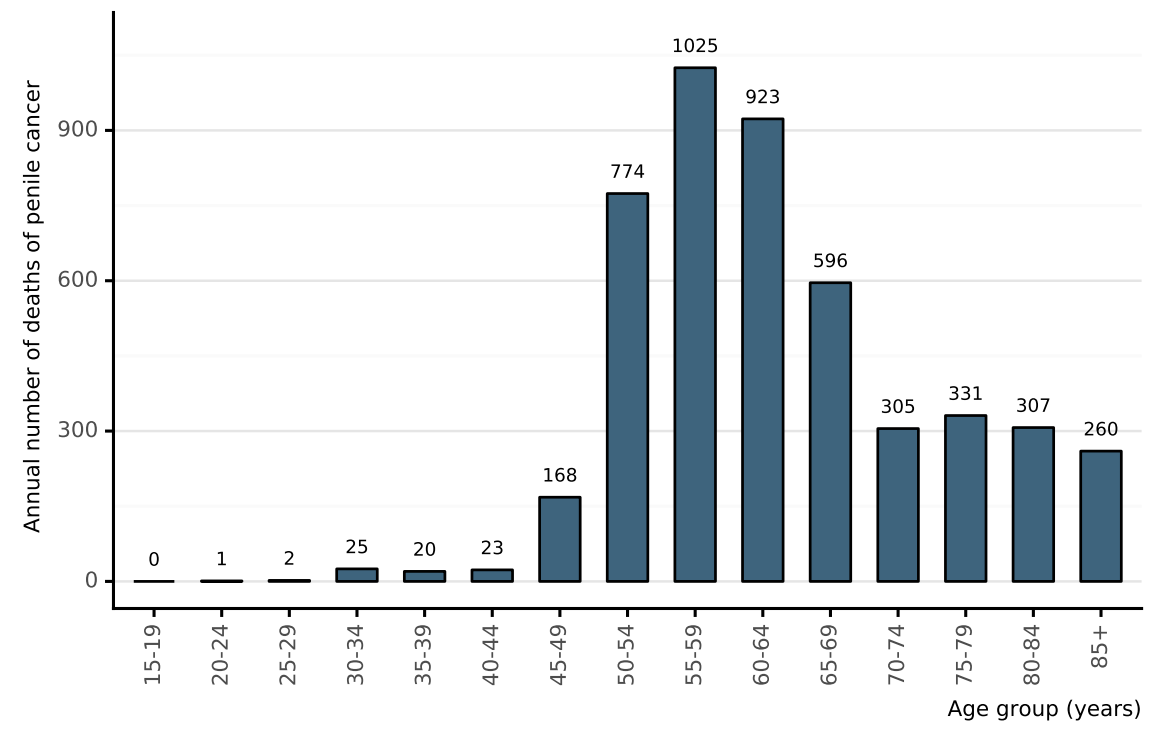

\section{Data accessed on 27 Jan 2021}

For more detailed methods of estimation please refer to http://gco.iarc.fr/today/data-sources-methods

Data Sources:

Ferlay J, Ervik M, Lam F, Colombet M, Mery L, Piñeros M, Znaor A, Soerjomataram I, Bray F (2020). Global Cancer Observatory: Cancer Today. Lyon, France: International Agency for Research on Cancer. Available from: https://gco.iarc.fr/today, accessed [27 January 2021]. 


\subsubsection{Penile cancer incidence and mortality comparison in India}

Figure 35: Comparison of age-specific penile cancer incidence and mortality rates in India (estimates for 2020)

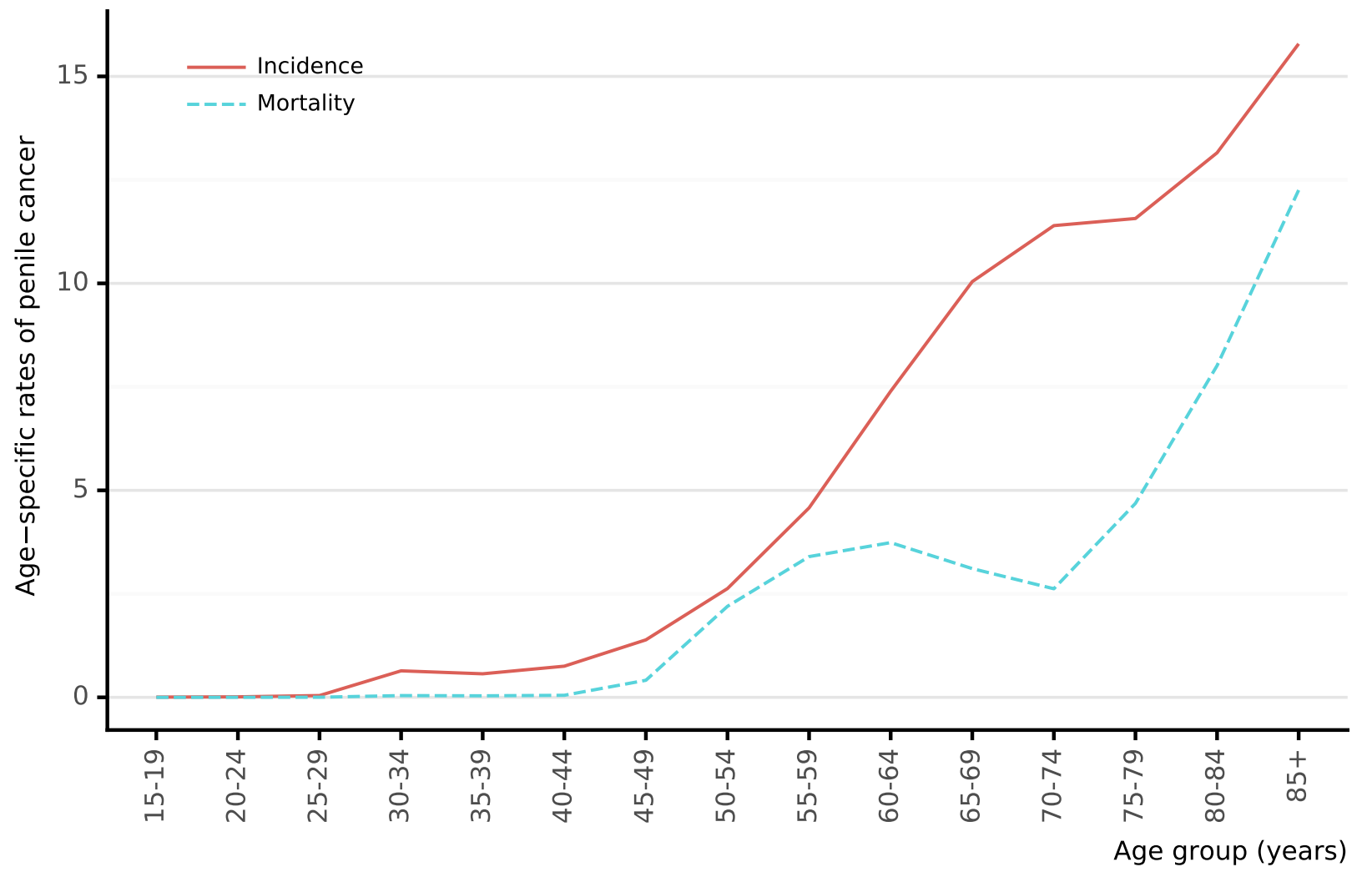

Data accessed on 27 Jan 2021

For more detailed methods of estimation please refer to http://gco.iarc.fr/today/data-sources-methods

${ }^{a}$ Rates per 100,000 men per year.

Data Sources:

Ferlay J, Ervik M, Lam F, Colombet M, Mery L, Piñeros M, Znaor A, Soerjomataram I, Bray F (2020). Global Cancer Observatory: Cancer Today. Lyon, France: International Agency for Research on Cancer. Available from: https://gco.iarc.fr/today, accessed [27 January 2021]. 


\subsection{Head and neck cancers}

The majority of head and neck cancers are associated with high tobacco and alcohol consumption. However, increasing trends in the incidence at specific sites suggest that other aetiological factors are involved, and infection by certain high-risk types of HPV (i.e. HPV16) have been reported to be associated with head and neck cancers, in particular with oropharyngeal cancer. Current evidence suggests that HPV16 is associated with tonsil cancer (including Waldeyer ring cancer), base of tongue cancer and other oropharyngeal cancer sites. Associations with other head and neck cancer sites such as oral cancer are neither strong nor consistent when compared to molecular-epidemiological data on HPV and oropharyngeal cancer. Association with laryngeal cancer is still unclear (IARC Monograph Vol 100B)

\subsubsection{Oropharyngeal cancer}

\subsubsection{Oropharyngeal cancer incidence in India}

Table 15: Oropharyngeal cancer incidence in India (estimates for 2020)

\begin{tabular}{|c|c|c|c|}
\hline Indicator & India & Southern Asia & World \\
\hline \multicolumn{4}{|l|}{ MEN } \\
\hline Annual number of new cancer cases & 17,175 & 21,941 & 79,045 \\
\hline $\begin{array}{l}\text { Uncertainty intervals of new cancer } \\
\text { cases }[95 \% \text { UI] }\end{array}$ & {$[15,687-18,804]$} & {$[40-273]$} & {$[72,769-85,862]$} \\
\hline Crude incidence rate $\mathrm{sa}^{\mathrm{b}}$ & 2.40 & 2.19 & 2.01 \\
\hline $\begin{array}{l}\text { Age-standardized incidence rate } \\
\text { sa }^{\mathrm{b}}\end{array}$ & 2.58 & 2.44 & 1.79 \\
\hline $\begin{array}{l}\text { Cumulative risk (\%) at } 75 \text { years } \\
\text { old }^{\text {a }}\end{array}$ & 0.31 & 0.29 & 0.22 \\
\hline \multicolumn{4}{|l|}{ WOMEN } \\
\hline Annual number of new cancer cases & 3,442 & 4,430 & 19,367 \\
\hline $\begin{array}{l}\text { Uncertainty intervals of new cancer } \\
\text { cases }[95 \% \text { UI] }\end{array}$ & {$[2,797-4,236]$} & [9-234] & {$[16,279-23,041]$} \\
\hline Crude incidence rate $\mathrm{sa}^{\mathrm{c}}$ & 0.52 & 0.47 & 0.50 \\
\hline Age-standardized incidence rate $\mathrm{sa}^{\mathrm{c}}$ & 0.51 & 0.49 & 0.40 \\
\hline $\begin{array}{l}\text { Cumulative risk (\%) at } 75 \text { years } \\
\text { old }^{\text {a }}\end{array}$ & 0.06 & 0.06 & 0.05 \\
\hline
\end{tabular}

Data accessed on 27 Jan 2021

For more detailed methods of estimation please refer to http://gco.iarc.fr/today/data-sources-methods

${ }^{a}$ Cumulative risk (incidence) is the probability or risk of individuals getting from the disease during ages $0-74$ years. For cancer, it is expressed as the \% of new born children who would be expected to develop from a particular cancer before the age of 75 if they had the rates of cancer observed in the period in the absence of competing causes.

$b$ Rates per 100,000 men per year.

$c$ Rates per 100,000 women per year.

Data Sources:

Ferlay J, Ervik M, Lam F, Colombet M, Mery L, Piñeros M, Znaor A, Soerjomataram I, Bray F (2020). Global Cancer Observatory: Cancer Today. Lyon, France: International Agency for Ferlay J, Ervik M, Lam F, Colombet M, Mery L, Piñeros M, Znaor A, Soerjomataram I, Bray F (2020
Research on Cancer. Available from: https://gco.iarc.fr/today, accessed [27 January 2021]. 
Figure 36: Age-specific incidence rates of oropharyngeal cancer in India (estimates for 2020)

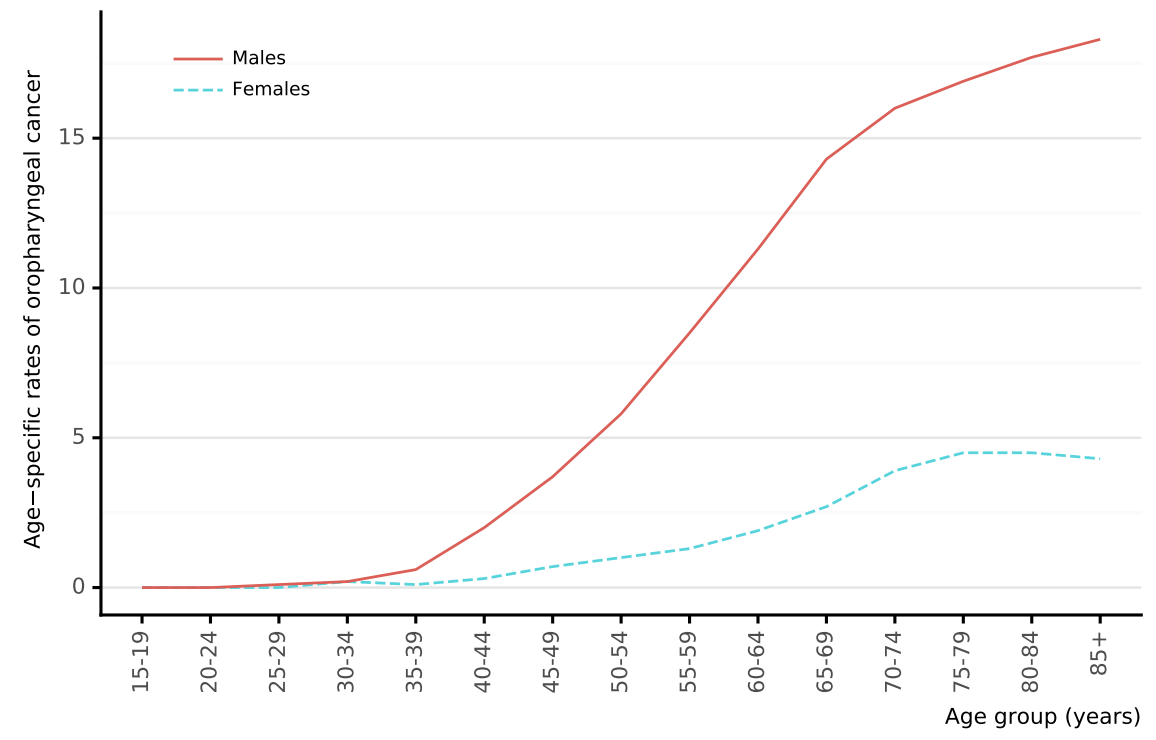

Data accessed on 27 Jan 2021

For more detailed methods of estimation please refer to http://gco.iarc.fr/today/data-sources-methods

${ }^{a}$ Rates per 100,000 men per year.

${ }^{b}$ Rates per 100,000 women per year.

Data Sources:

Ferlay J, Ervik M, Lam F, Colombet M, Mery L, Piñeros M, Znaor A, Soerjomataram I, Bray F (2020). Global Cancer Observatory: Cancer Today. Lyon, France: International Agency for Research on Cancer. Available from: https ://gco.iarc.fr/today, accessed [27 January 2021].

Figure 37: Annual number of new cases of oropharyngeal cancer in India (estimates for 2020)

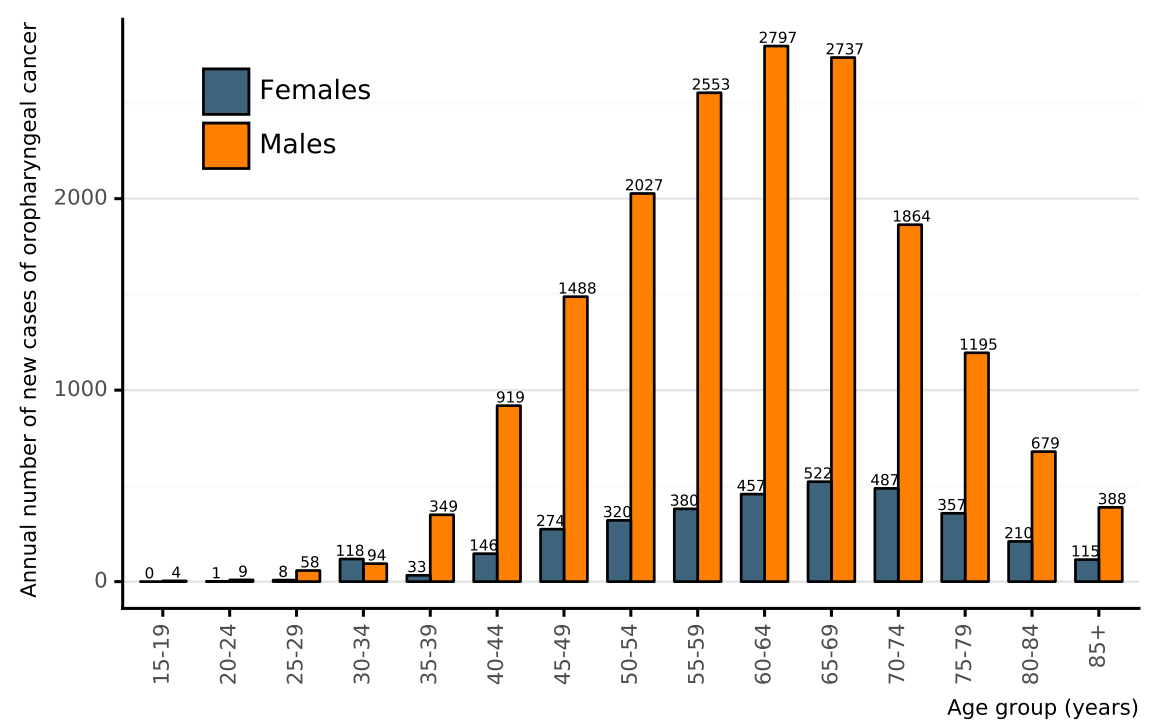

Data accessed on 27 Jan 2021

For more detailed methods of estimation please refer to http://gco.iarc.fr/today/data-sources-methods

Data Sourc dis

Ferlay J, Ervik M, Lam F, Colombet M, Mery L, Piñeros M, Znaor A, Soerjomataram I, Bray F (2020). Global Cancer Observatory: Cancer Today. Lyon, France: International Agency for Research on Cancer. Available from: https://gco.iarc.fr/today, accessed [27 January 2021]. 


\subsubsection{Oropharyngeal cancer mortality in India}

Table 16: Oropharyngeal cancer mortality in India (estimates for 2020)

\begin{tabular}{|c|c|c|c|}
\hline Indicator & India & Southern Asia & World \\
\hline \multicolumn{4}{|l|}{ MEN } \\
\hline Annual number of deaths & 10,637 & 13,474 & 39,590 \\
\hline $\begin{array}{l}\text { Uncertainty intervals of mortality } \\
\text { cancer cases [95\% UI] }\end{array}$ & {$[9,658-11,716]$} & {$[28-167]$} & {$[35,255-44,458]$} \\
\hline Crude mortality rate $\mathrm{sa}^{\mathrm{b}}$ & 1.48 & 1.35 & 1.01 \\
\hline $\begin{array}{l}\text { Age-standardized mortality rate } \\
\text { sa }^{\mathrm{b}}\end{array}$ & 1.60 & 1.51 & 0.89 \\
\hline $\begin{array}{l}\text { Cumulative risk (\%) at } 75 \text { years } \\
\text { old }^{\text {a }}\end{array}$ & 0.20 & 0.19 & 0.11 \\
\hline \multicolumn{4}{|l|}{ WOMEN } \\
\hline Annual number of deaths & 2,066 & 2,665 & 8,553 \\
\hline $\begin{array}{l}\text { Uncertainty intervals of mortality } \\
\text { cancer cases [95\% UI] }\end{array}$ & {$[1,656-2,578]$} & [6-120] & {$[6,684-10,945]$} \\
\hline Crude mortality rate $\mathrm{sa}^{\mathrm{c}}$ & 0.31 & 0.28 & 0.22 \\
\hline Age-standardized mortality rate $\mathrm{sa}^{\mathrm{c}}$ & 0.31 & 0.30 & 0.17 \\
\hline $\begin{array}{l}\text { Cumulative risk (\%) at } 75 \text { years } \\
\text { old }^{\text {a }}\end{array}$ & 0.04 & 0.04 & 0.02 \\
\hline
\end{tabular}

Data accessed on 27 Jan 2021

For more detailed methods of estimation please refer to http://gco.iarc.fr/today/data-sources-methods

${ }^{a}$ Cumulative risk (mortality) is the probability or risk of individuals dying from the disease during ages 0-74 years. For cancer, it is expressed as the \% of new born children who would be expected to die from a particular cancer before the age of 75 if they had the rates of cancer observed in the period in the absence of competing causes.

${ }^{b}$ Rates per 100,000 men per year.

${ }^{c}$ Rates per 100,000 women per year.

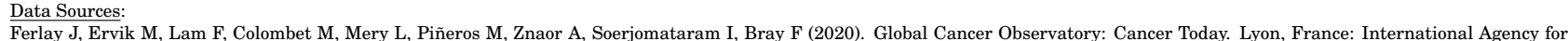
Research on Cancer. Available from: https ://gco.iarc.fr/today, accessed [27 January 2021]. 
Figure 38: Age-specific mortality rates of oropharyngeal cancer in India (estimates for 2020)

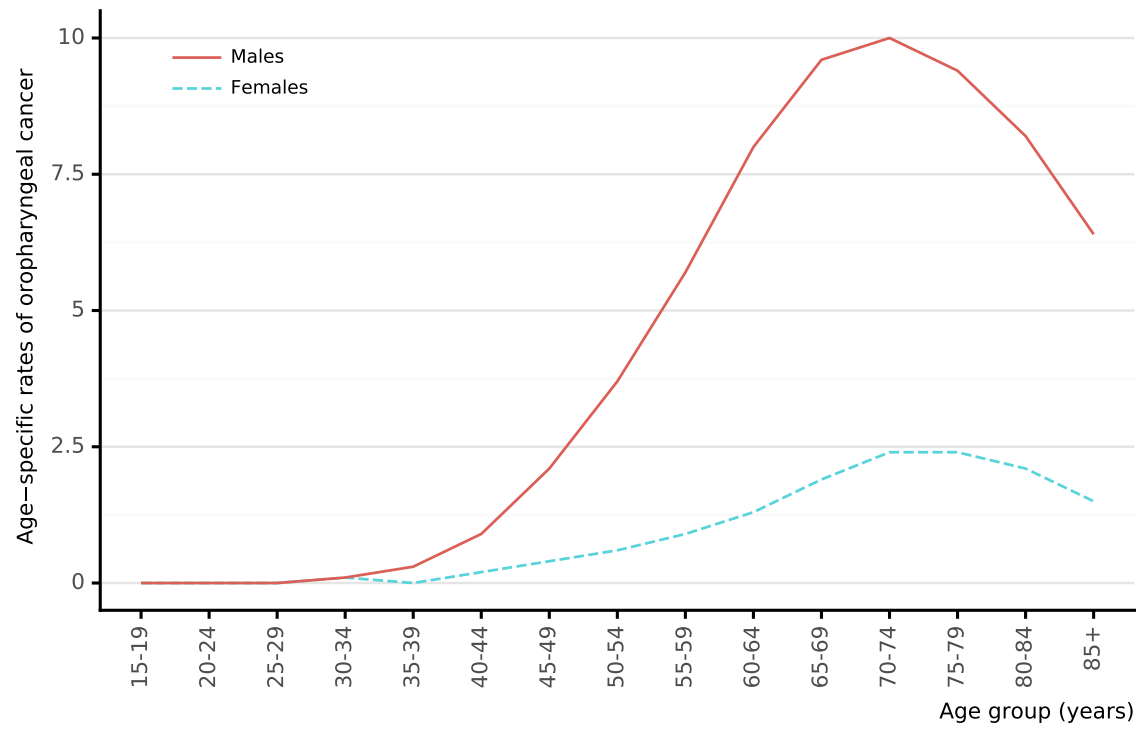

\section{Data accessed on 27 Jan 2021}

For more detailed methods of estimation please refer to http://gco.iarc.fr/today/data-sources-methods

${ }^{a}$ Rates per 100,000 men per year.

${ }^{b}$ Rates per 100,000 women per year.

Data Sources:

Ferlay J, Ervik M, Lam F, Colombet M, Mery L, Piñeros M, Znaor A, Soerjomataram I, Bray F (2020). Global Cancer Observatory: Cancer Today. Lyon, France: International Agency for Research on Cancer. Available from: https ://gco.iarc.fr/today, accessed [27 January 2021].

Figure 39: Annual number of deaths of oropharyngeal cancer in India (estimates for 2020)

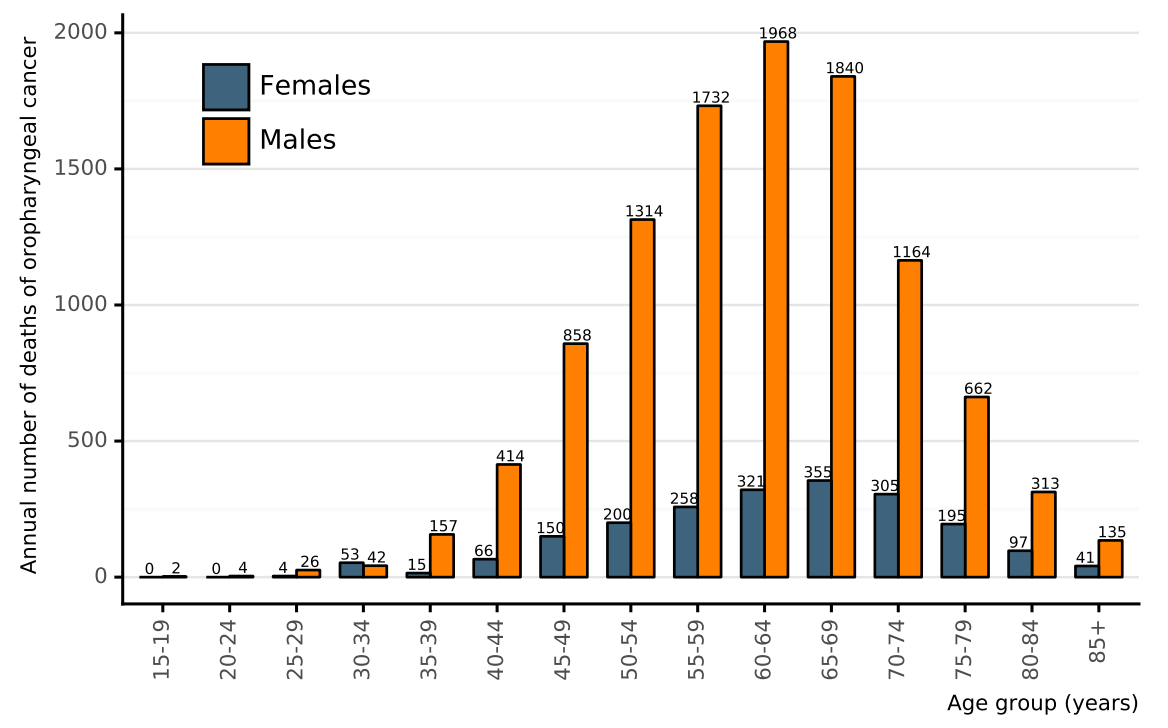

Data accessed on 27 Jan 2021

For more detailed methods of estimation please refer to http://gco.iarc.fr/today/data-sources-methods

Ferlay J, Ervik M, Lam F, Colombet M, Mery L, Piñeros M, Znaor A, Soerjomataram I, Bray F (2020). Global Cancer Observatory: Cancer Today. Lyon, France: International Agency for Research on Cancer. Available from: https ://gco.iarc.fr/today, accessed [27 January 2021]. 


\subsubsection{Oropharyngeal cancer incidence and mortality comparison in India}

Figure 40: Comparison of age-specific oropharyngeal cancer incidence and mortality rates among men in India (estimates for 2020)

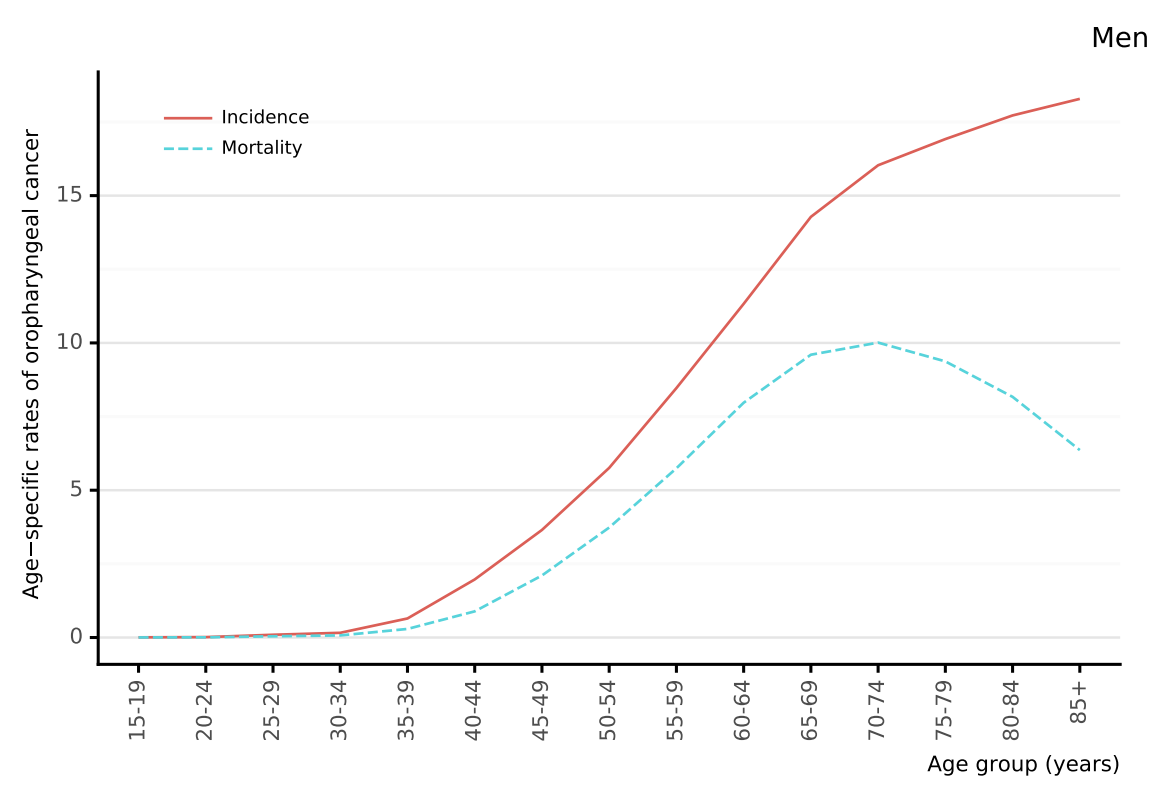

Data accessed on 27 Jan 2021

For more detailed methods of estimation please refer to http://gco.iarc.fr/today/data-sources-methods

${ }^{a}$ Rates per 100,000 men per year.

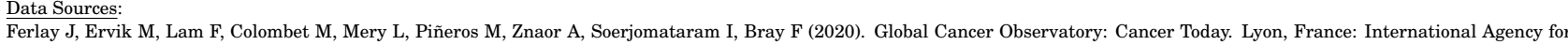
Research on Cancer. Available from: https://gco.iarc.fr/today, accessed [27 January 2021]

Figure 41: Comparison of age-specific oropharyngeal cancer incidence and mortality rates among women in India (estimates for 2020)

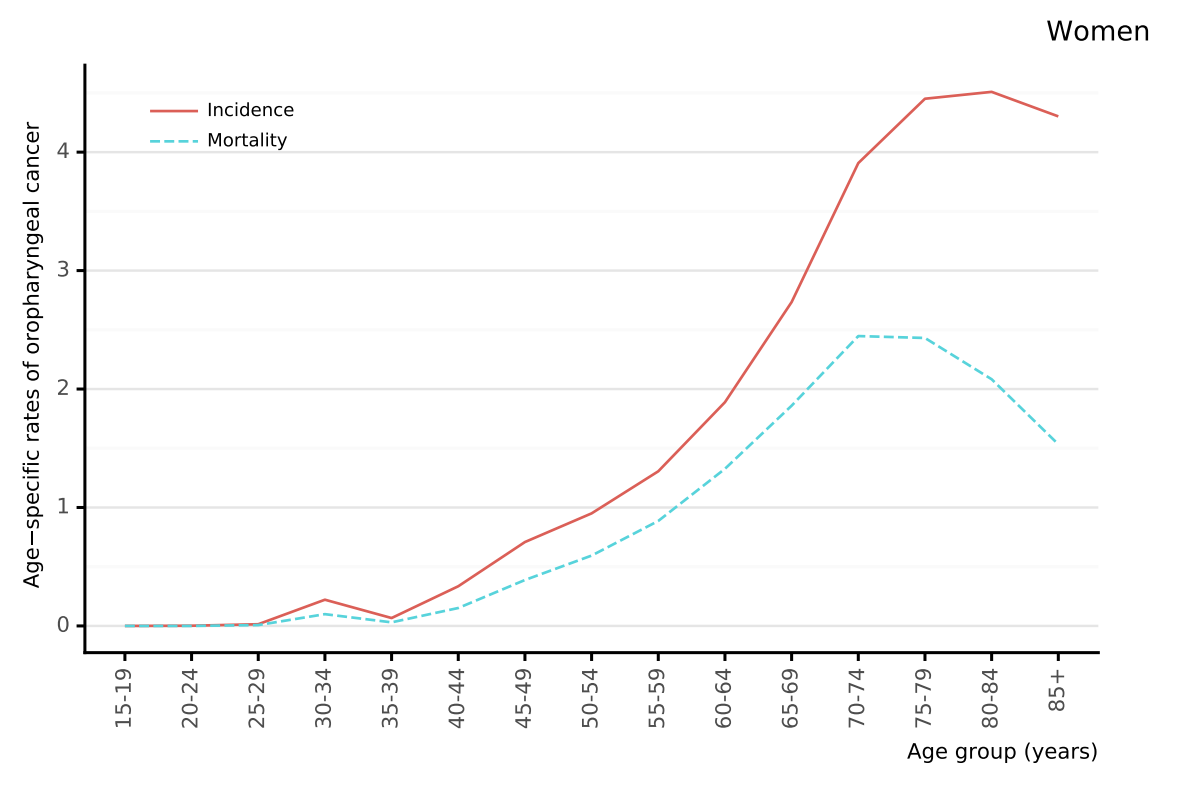

Data accessed on 27 Jan 2021

For more detailed methods of estimation please refer to http://gco.iarc.fr/today/data-sources-methods

${ }^{a}$ Rates per 100,000 women per year.

Data Sources:

Ferlay J, Ervik M, Lam F, Colombet M, Mery L, Piñeros M, Znaor A, Soerjomataram I, Bray F (2020). Global Cancer Observatory: Cancer Today. Lyon, France: International Agency for Research on Cancer. Available from: https ://gco.iarc.fr/today, accessed [27 January 2021]. 


\subsubsection{Oral cavity cancer}

\subsubsection{Oral cavity cancer incidence in India}

Table 17: Oral cavity cancer incidence in India (estimates for 2020)

\begin{tabular}{|c|c|c|c|}
\hline Indicator & India & Southern Asia & World \\
\hline \multicolumn{4}{|l|}{ MEN } \\
\hline Annual number of new cancer cases & 104,661 & 129,467 & 264,211 \\
\hline $\begin{array}{l}\text { Uncertainty intervals of new cancer } \\
\text { cases [95\% UI] }\end{array}$ & {$[100,601-108,885]$} & {$[337-1,134]$} & $\begin{array}{r}{[251,153-} \\
277,948]\end{array}$ \\
\hline Crude incidence rate $\mathrm{sa}^{\mathrm{b}}$ & 14.6 & 12.9 & 6.72 \\
\hline $\begin{array}{l}\text { Age-standardized incidence rate } \\
\mathrm{sa}^{\mathrm{b}}\end{array}$ & 14.8 & 13.6 & 5.96 \\
\hline $\begin{array}{l}\text { Cumulative risk (\%) at } 75 \text { years } \\
\text { old }^{\mathrm{a}}\end{array}$ & 1.63 & 1.51 & 0.68 \\
\hline \multicolumn{4}{|l|}{ WOMEN } \\
\hline Annual number of new cancer cases & 31,268 & 43,148 & 113,502 \\
\hline $\begin{array}{l}\text { Uncertainty intervals of new cancer } \\
\text { cases [95\% UI] }\end{array}$ & {$[29,416-33,236]$} & {$[147-591]$} & $\begin{array}{r}{[105,599-} \\
121,997]\end{array}$ \\
\hline Crude incidence rate $\mathrm{sa}^{\mathrm{c}}$ & 4.72 & 4.59 & 2.94 \\
\hline Age-standardized incidence rate $\mathrm{sa}^{\mathrm{c}}$ & 4.61 & 4.73 & 2.28 \\
\hline $\begin{array}{l}\text { Cumulative risk (\%) at } 75 \text { years } \\
\text { old }^{\mathrm{a}}\end{array}$ & 0.53 & 0.55 & 0.26 \\
\hline
\end{tabular}

Data accessed on 27 Jan 2021

For more detailed methods of estimation please refer to http://gco.iarc.fr/today/data-sources-methods

${ }^{a}$ Cumulative risk (incidence) is the probability or risk of individuals getting from the disease during ages 0-74 years. For cancer, it is expressed as the \% of new born children who would be expected to develop from a particular cancer before the age of 75 if they had the rates of cancer observed in the period in the absence of competing causes.

$b$ Rates per 100,000 men per year.

$c$ Rates per 100,000 women per year.

Data Sources:

Ferlay J, Ervik M, Lam F, Colombet M, Mery L, Piñeros M, Znaor A, Soerjomataram I, Bray F (2020). Global Cancer Observatory: Cancer Today. Lyon, France: International Agency for Research on Cancer. Available from: https ://gco.iarc.fr/today, accessed [27 January 2021]. 
Figure 42: Age-specific incidence rates of oral cavity cancer in India (estimates for 2020)

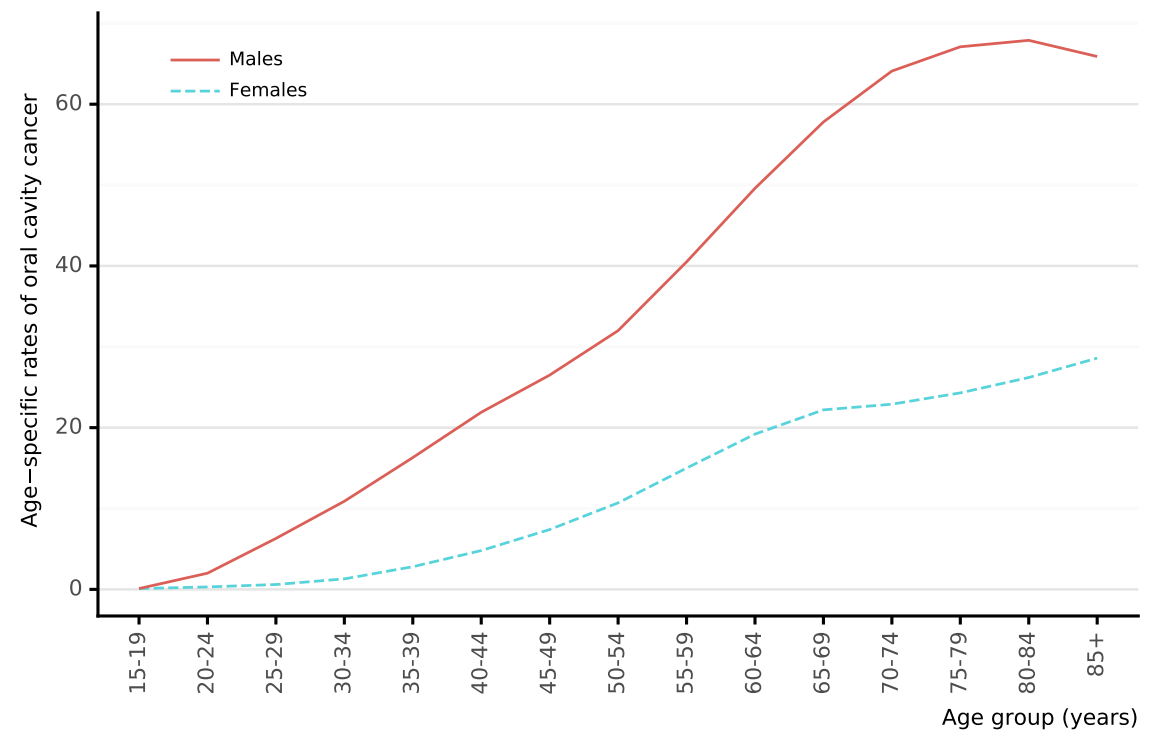

Data accessed on 27 Jan 2021

For more detailed methods of estimation please refer to http://gco.iarc.fr/today/data-sources-methods

$a$ Rates per 100,000 men per year.

$b^{b}$ Rates per 100,000 women per year.

Data Sources:

Ferlay J, Ervik M, Lam F, Colombet M, Mery L, Piñeros M, Znaor A, Soerjomataram I, Bray F (2020). Global Cancer Observatory: Cancer Today. Lyon, France: International Agency for Research on Cancer. Available from: https ://gco.iarc.fr/today, accessed [27 January 2021].

Figure 43: Annual number of new cases of oral cavity cancer in India (estimates for 2020)

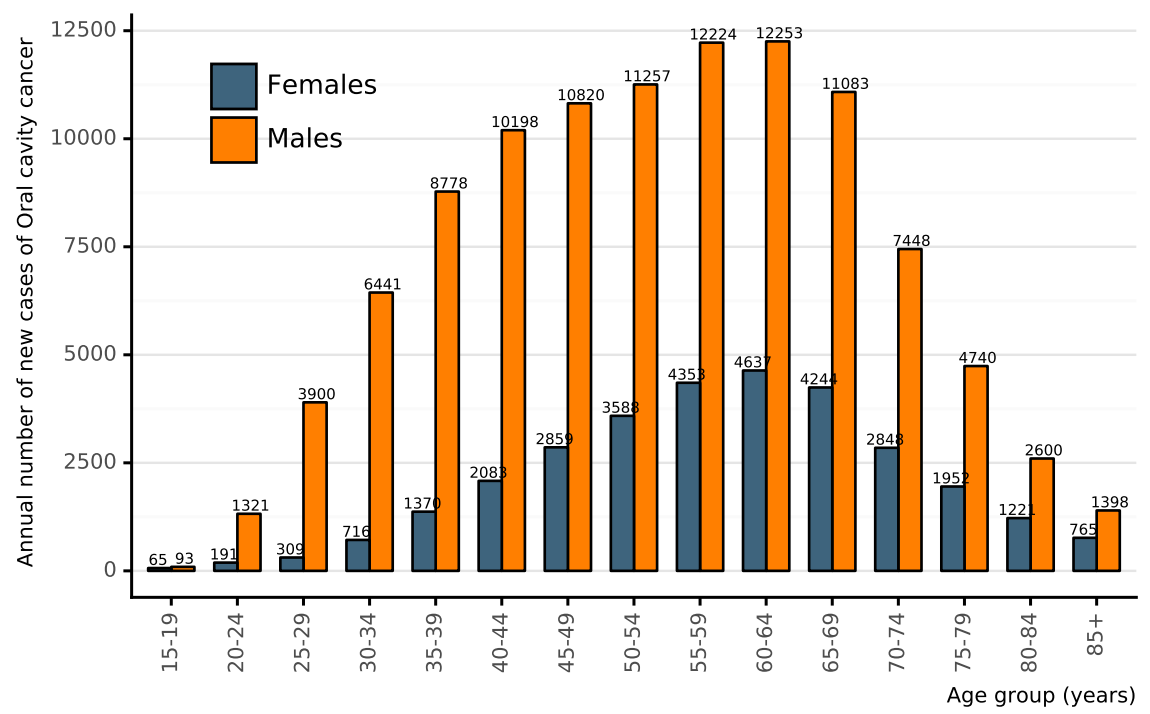

Data accessed on 27 Jan 2021

For more detailed methods of estimation please refer to http://gco.iarc.fr/today/data-sources-methods

Ferlay J, Ervik M, Lam F, Colombet M, Mery L, Piñeros M, Znaor A, Soerjomataram I, Bray F (2020). Global Cancer Observatory: Cancer Today. Lyon, France: International Agency for Research on Cancer. Available from: https ://gco.iarc.fr/today, accessed [27 January 2021]. 


\subsubsection{Oral cavity cancer incidence and mortality comparison in India}

Table 18: Oral cavity cancer mortality in India (estimates for 2020)

\begin{tabular}{|c|c|c|c|}
\hline Indicator & India & Southern Asia & World \\
\hline \multicolumn{4}{|l|}{ MEN } \\
\hline Annual number of deaths & 57,216 & 71,632 & 125,022 \\
\hline $\begin{array}{l}\text { Uncertainty intervals of mortality } \\
\text { cancer cases [95\% UI] }\end{array}$ & {$[54,854-59,680]$} & {$[246-762]$} & $\begin{array}{c}{[116,573-} \\
134,084]\end{array}$ \\
\hline Crude mortality rate $\mathrm{sa}^{\mathrm{b}}$ & 7.98 & 7.16 & 3.18 \\
\hline $\begin{array}{l}\text { Age-standardized mortality rate } \\
\text { sa }^{b}\end{array}$ & 8.12 & 7.58 & 2.82 \\
\hline $\begin{array}{l}\text { Cumulative risk (\%) at } 75 \text { years } \\
\text { old }^{\mathrm{a}}\end{array}$ & 0.92 & 0.86 & 0.32 \\
\hline \multicolumn{4}{|l|}{ WOMEN } \\
\hline Annual number of deaths & 18,074 & 25,299 & 52,735 \\
\hline $\begin{array}{l}\text { Uncertainty intervals of mortality } \\
\text { cancer cases [95\% UI] }\end{array}$ & {$[16,936-19,289]$} & {$[113-411]$} & {$[47,690-58,313]$} \\
\hline Crude mortality rate $\mathrm{sa}^{\mathrm{c}}$ & 2.73 & 2.69 & 1.36 \\
\hline Age-standardized mortality rate $\mathrm{sa}^{\mathrm{c}}$ & 2.68 & 2.79 & 1.04 \\
\hline $\begin{array}{l}\text { Cumulative risk (\%) at } 75 \text { years } \\
\text { old }^{\text {a }}\end{array}$ & 0.32 & 0.33 & 0.12 \\
\hline
\end{tabular}

Data accessed on 27 Jan 2021

For more detailed methods of estimation please refer to http://gco.iarc.fr/today/data-sources-methods

${ }^{a}$ Cumulative risk (mortality) is the probability or risk of individuals dying from the disease during ages 0-74 years. For cancer, it is expressed as the \% of new born children who would be expected to die from a particular cancer before the age of 75 if they had the rates of cancer observed in the period in the absence of competing causes.

${ }^{b}$ Rates per 100,000 men per year.

${ }^{c}$ Rates per 100,000 women per year.

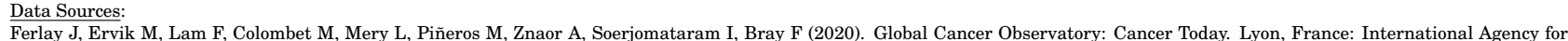
Research on Cancer. Available from: https ://gco.iarc.fr/today, accessed [27 January 2021]. 
Figure 44: Age-specific mortality rates of oral cavity cancer in India (estimates for 2020)

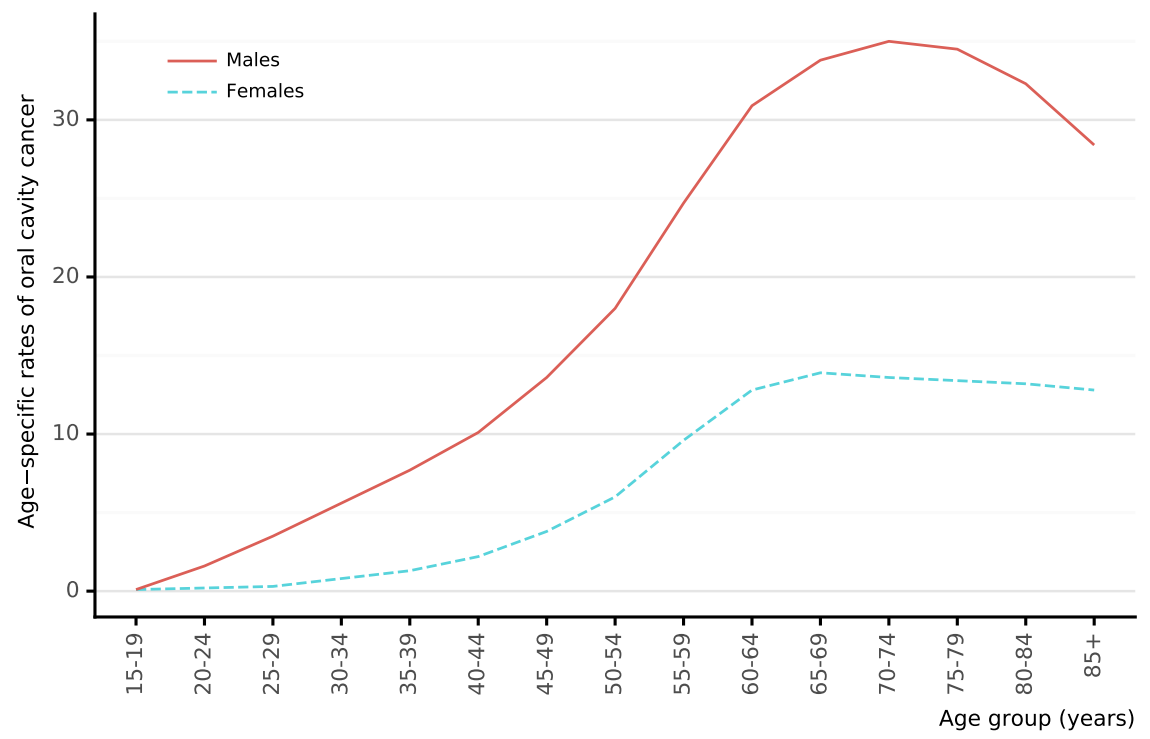

Data accessed on 27 Jan 2021

For more detailed methods of estimation please refer to http://gco.iarc.fr/today/data-sources-methods

${ }^{a}$ Rates per 100,000 men per year.

$b^{b}$ Rates per 100,000 women per year.

Data Sources:

Ferlay J, Ervik M, Lam F, Colombet M, Mery L, Piñeros M, Znaor A, Soerjomataram I, Bray F (2020). Global Cancer Observatory: Cancer Today. Lyon, France: International Agency for Research on Cancer. Available from: https ://gco.iarc.fr/today, accessed [27 January 2021].

Figure 45: Annual number of deaths of oral cavity cancer in India (estimates for 2020)

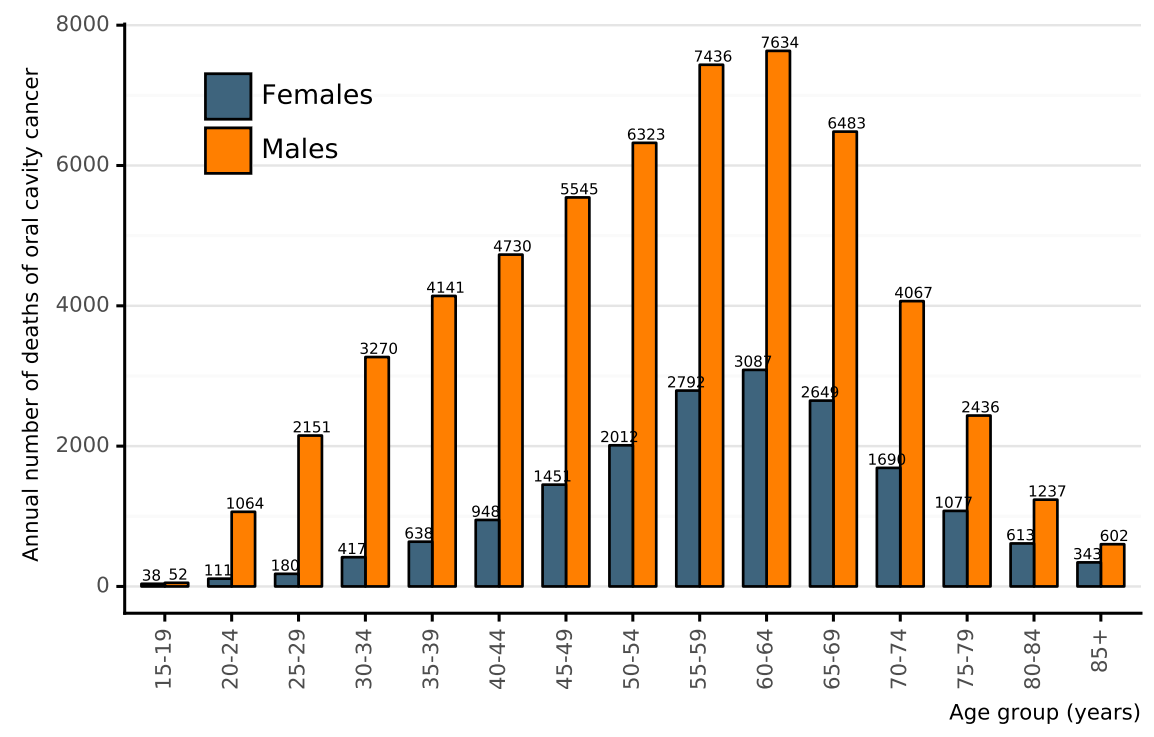

Data accessed on 27 Jan 2021

For more detailed methods of estimation please refer to http://gco.iarc.fr/today/data-sources-methods

Ferlay J, Ervik M, Lam F, Colombet M, Mery L, Piñeros M, Znaor A, Soerjomataram I, Bray F (2020). Global Cancer Observatory: Cancer Today. Lyon, France: International Agency for Research on Cancer. Available from: https ://gco.iarc.fr/today, accessed [27 January 2021]. 


\subsubsection{Oral cavity cancer incidence and mortality comparison in India}

Figure 46: Comparison of age-specific oral cavity cancer incidence and mortality rates among men in India (estimates for 2020)

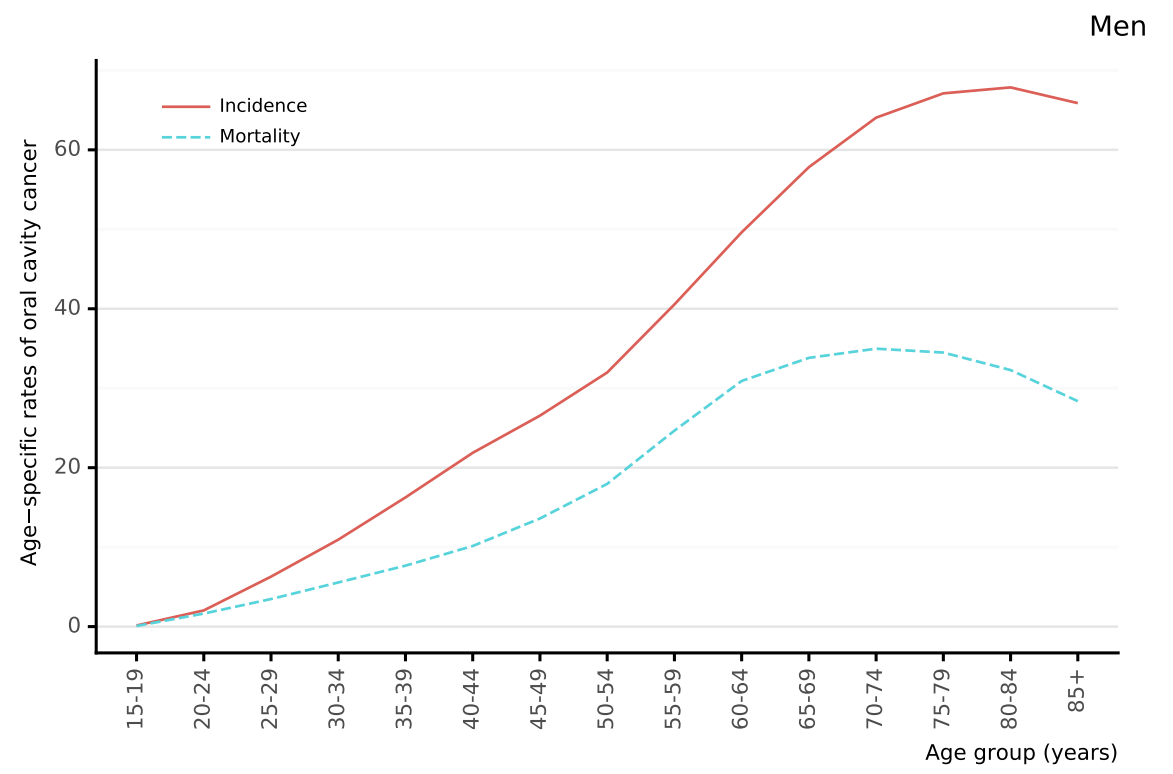

Data accessed on 27 Jan 2021

For more detailed methods of estimation please refer to http://gco.iarc.fr/today/data-sources-methods

${ }^{a}$ Rates per 100,000 men per year.

Derlay J, Ervik M, Lam F, Colombet M, Mery L, Piñeros M, Znaor A, Soerjomataram I, Bray F (2020). Global Cancer Observatory: Cancer Today. Lyon, France: International Agency for Research on Cancer. Available from: https : / gco. iarc.fr/today, accessed [27 January 2021].

Figure 47: Comparison of age-specific oral cavity cancer incidence and mortality rates among women in India (estimates for 2020)

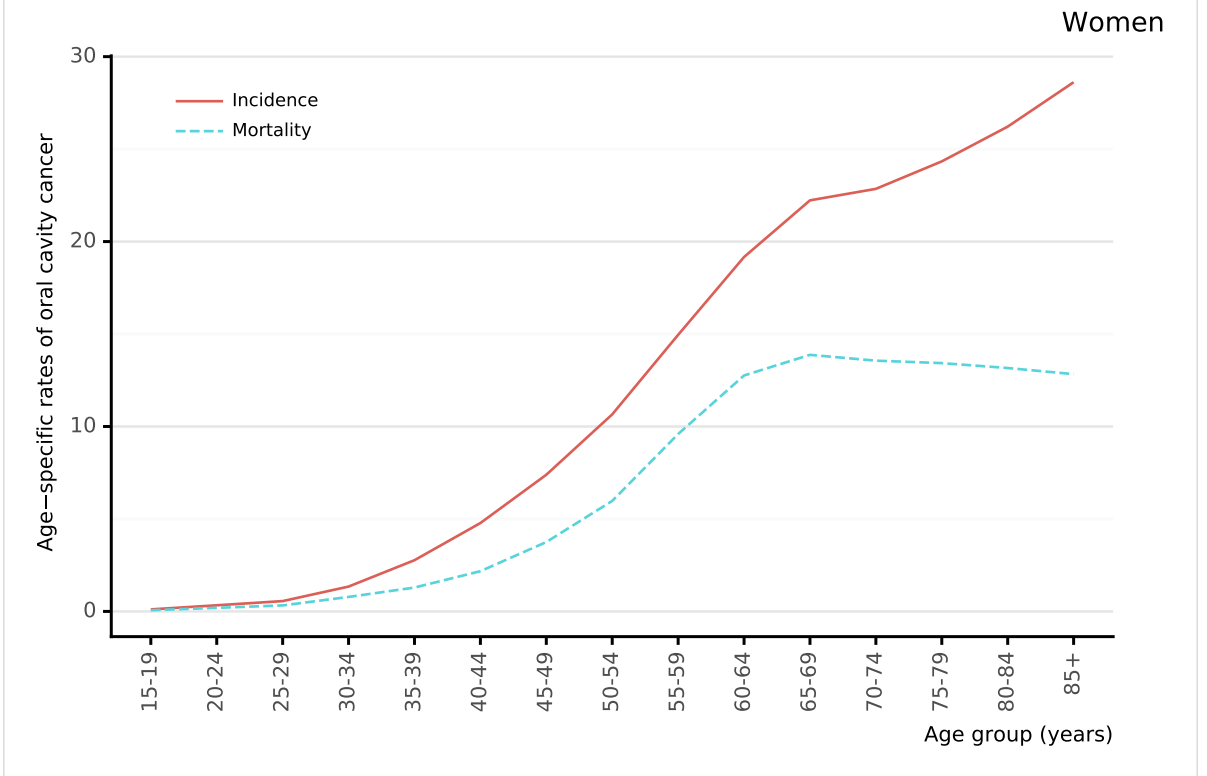

Data accessed on 27 Jan 2021

For more detailed methods of estimation please refer to http://gco.iarc.fr/today/data-sources-methods ${ }^{a}$ Rates per 100,000 women per year.

Ferlay J, Ervik M, Lam F, Colombet M, Mery L, Piñeros M, Znaor A, Soerjomataram I, Bray F (2020). Global Cancer Observatory: Cancer Today. Lyon, France: International Agency for Research on Cancer. Available from: https://gco.iarc.fr/today, accessed [27 January 2021] 


\subsubsection{Laryngeal cancer}

\subsubsection{Laryngeal cancer incidence in India}

Table 19: Laryngeal cancer incidence in India (estimates for 2020)

\begin{tabular}{|c|c|c|c|}
\hline Indicator & India & Southern Asia & World \\
\hline \multicolumn{4}{|l|}{ MEN } \\
\hline Annual number of new cancer cases & 30,180 & 41,582 & 160,265 \\
\hline $\begin{array}{l}\text { Uncertainty intervals of new cancer } \\
\text { cases [95\% UI] }\end{array}$ & {$[28,277-32,211]$} & {$[81-516]$} & $\begin{array}{l}{[150,633-} \\
170,513]\end{array}$ \\
\hline Crude incidence rate $\mathrm{sa}^{\mathrm{b}}$ & 4.21 & 4.15 & 4.08 \\
\hline $\begin{array}{l}\text { Age-standardized incidence rate } \\
\text { sa }^{b}\end{array}$ & 4.55 & 4.67 & 3.59 \\
\hline $\begin{array}{l}\text { Cumulative risk (\%) at } 75 \text { years } \\
\text { old }^{\text {a }}\end{array}$ & 0.56 & 0.58 & 0.45 \\
\hline \multicolumn{4}{|l|}{ WOMEN } \\
\hline Annual number of new cancer cases & 4,507 & 6,681 & 24,350 \\
\hline $\begin{array}{l}\text { Uncertainty intervals of new cancer } \\
\text { cases [95\% UI] }\end{array}$ & {$[3,773-5,384]$} & {$[12-177]$} & {$[20,845-28,444]$} \\
\hline Crude incidence rate $\mathrm{sa}^{\mathrm{c}}$ & 0.68 & 0.71 & 0.63 \\
\hline Age-standardized incidence rate $\mathrm{sa}^{\mathrm{c}}$ & 0.67 & 0.74 & 0.49 \\
\hline $\begin{array}{l}\text { Cumulative risk (\%) at } 75 \text { years } \\
\text { old }^{\mathrm{a}}\end{array}$ & 0.08 & 0.09 & 0.06 \\
\hline
\end{tabular}

Data accessed on 27 Jan 2021

For more detailed methods of estimation please refer to http://gco.iarc.fr/today/data-sources-methods

${ }^{a}$ Cumulative risk (incidence) is the probability or risk of individuals getting from the disease during ages 0-74 years. For cancer, it is expressed as the \% of new born children who would be expected to develop from a particular cancer before the age of 75 if they had the rates of cancer observed in the period in the absence of competing causes.

$b$ Rates per 100,000 men per year.

$c$ Rates per 100,000 women per year.

Data Sources:

Ferlay J, Ervik M, Lam F, Colombet M, Mery L, Piñeros M, Znaor A, Soerjomataram I, Bray F (2020). Global Cancer Observatory: Cancer Today. Lyon, France: International Agency for Research on Cancer. Available from: https ://gco.iarc.fr/today, accessed [27 January 2021]. 
Figure 48: Age-specific incidence rates of laryngeal cancer in India (estimates for 2020)

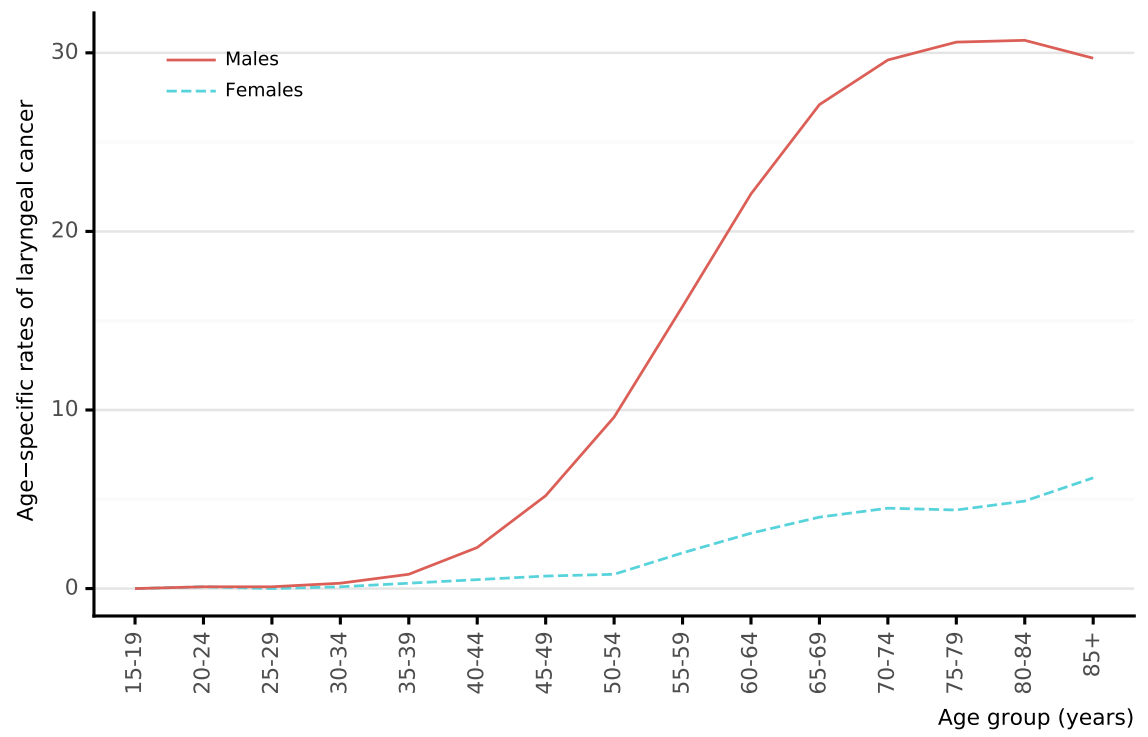

Data accessed on 27 Jan 2021

For more detailed methods of estimation please refer to http://gco.iarc.fr/today/data-sources-methods

${ }^{a}$ Rates per 100,000 men per year.

${ }^{b}$ Rates per 100,000 women per year.

Data Sources:

Ferlay J, Ervik M, Lam F, Colombet M, Mery L, Piñeros M, Znaor A, Soerjomataram I, Bray F (2020). Global Cancer Observatory: Cancer Today. Lyon, France: International Agency for Research on Cancer. Available from: https ://gco.iarc.fr/today, accessed [27 January 2021].

Figure 49: Annual number of new cases of laryngeal cancer in India (estimates for 2020)

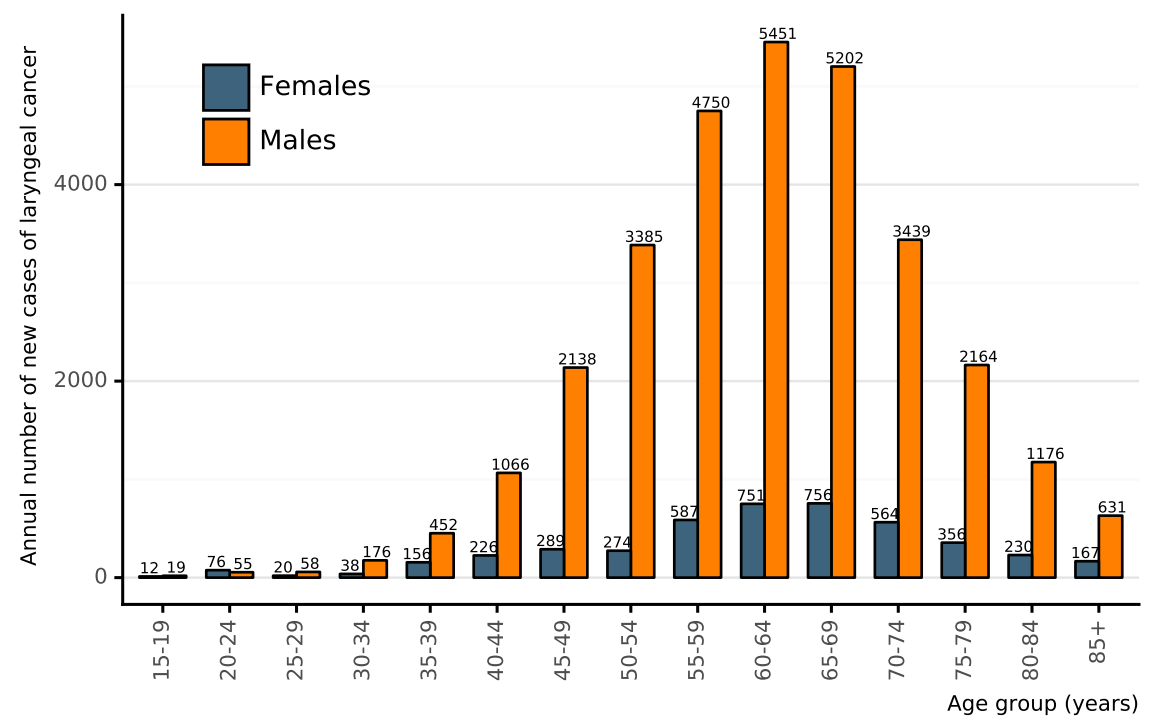

Data accessed on 27 Jan 2021

For more detailed methods of estimation please refer to http://gco.iarc.fr/today/data-sources-methods

Data $S$

Ferlay J, Ervik M, Lam F, Colombet M, Mery L, Piñeros M, Znaor A, Soerjomataram I, Bray F (2020). Global Cancer Observatory: Cancer Today. Lyon, France: International Agency for Research on Cancer. Available from: https://gco.iarc.fr/today, accessed [27 January 2021]. 


\subsubsection{Laryngeal cancer incidence and mortality comparison in India}

Table 20: Laryngeal cancer mortality in India (estimates for 2020)

\begin{tabular}{|c|c|c|c|}
\hline Indicator & India & Southern Asia & World \\
\hline \multicolumn{4}{|l|}{ MEN } \\
\hline Annual number of deaths & 18,002 & 25,077 & 85,351 \\
\hline $\begin{array}{l}\text { Uncertainty intervals of mortality } \\
\text { cancer cases [95\% UI] }\end{array}$ & {$[16,795-19,296]$} & {$[65-367]$} & {$[78,895-92,335]$} \\
\hline Crude mortality rate $\mathrm{sa}^{\mathrm{b}}$ & 2.51 & 2.51 & 2.17 \\
\hline $\begin{array}{l}\text { Age-standardized mortality rate } \\
\text { sa }^{\text {b }}\end{array}$ & 2.74 & 2.86 & 1.89 \\
\hline $\begin{array}{l}\text { Cumulative risk (\%) at } 75 \text { years } \\
\text { old }^{\mathrm{a}}\end{array}$ & 0.36 & 0.37 & 0.23 \\
\hline \multicolumn{4}{|l|}{ WOMEN } \\
\hline Annual number of deaths & 3,658 & 5,311 & 14,489 \\
\hline $\begin{array}{l}\text { Uncertainty intervals of mortality } \\
\text { cancer cases [95\% UI] }\end{array}$ & {$[3,026-4,421]$} & {$[11-127]$} & {$[11,902-17,639]$} \\
\hline Crude mortality rate $\mathrm{sa}^{\mathrm{c}}$ & 0.55 & 0.57 & 0.37 \\
\hline Age-standardized mortality rate $\mathrm{sa}^{\mathrm{c}}$ & 0.55 & 0.59 & 0.28 \\
\hline $\begin{array}{l}\text { Cumulative risk (\%) at } 75 \text { years } \\
\text { old }^{\text {a }}\end{array}$ & 0.07 & 0.07 & 0.03 \\
\hline
\end{tabular}

Data accessed on 27 Jan 2021

For more detailed methods of estimation please refer to http://gco.iarc.fr/today/data-sources-methods

${ }^{a}$ Cumulative risk (mortality) is the probability or risk of individuals dying from the disease during ages 0-74 years. For cancer, it is expressed as the \% of new born children who would be expected to die from a particular cancer before the age of 75 if they had the rates of cancer observed in the period in the absence of competing causes.

${ }^{b}$ Rates per 100,000 men per year.

${ }^{c}$ Rates per 100,000 women per year.

Data Sources:

Ferlay J, Ervik M, Lam F, Colombet M, Mery L, Piñeros M, Znaor A, Soerjomataram I, Bray F (2020). Global Cancer Observatory: Cancer Today. Lyon, France: International Agency for Research on Cancer. Available from: https ://gco.iarc.fr/today, accessed [27 January 2021]. 
Figure 50: Age-specific mortality rates of laryngeal cancer in India (estimates for 2020)

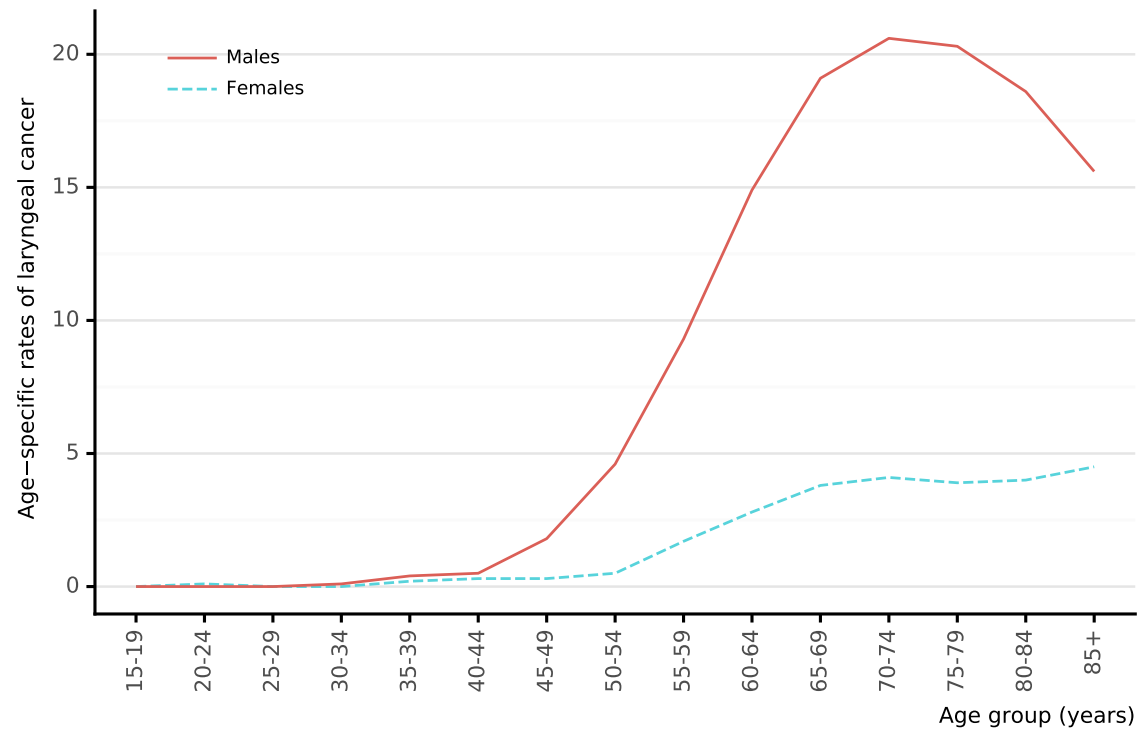

Data accessed on 27 Jan 2021

For more detailed methods of estimation please refer to http://gco.iarc.fr/today/data-sources-methods

${ }^{a}$ Rates per 100,000 men per year.

$b$ Rates per 100,000 women per year.

Data Sources:

Ferlay J, Ervik M, Lam F, Colombet M, Mery L, Piñeros M, Znaor A, Soerjomataram I, Bray F (2020). Global Cancer Observatory: Cancer Today. Lyon, France: International Agency for Research on Cancer. Available from: https ://gco.iarc.fr/today, accessed [27 January 2021].

Figure 51: Annual number of deaths of of laryngeal cancer in India (estimates for 2020)

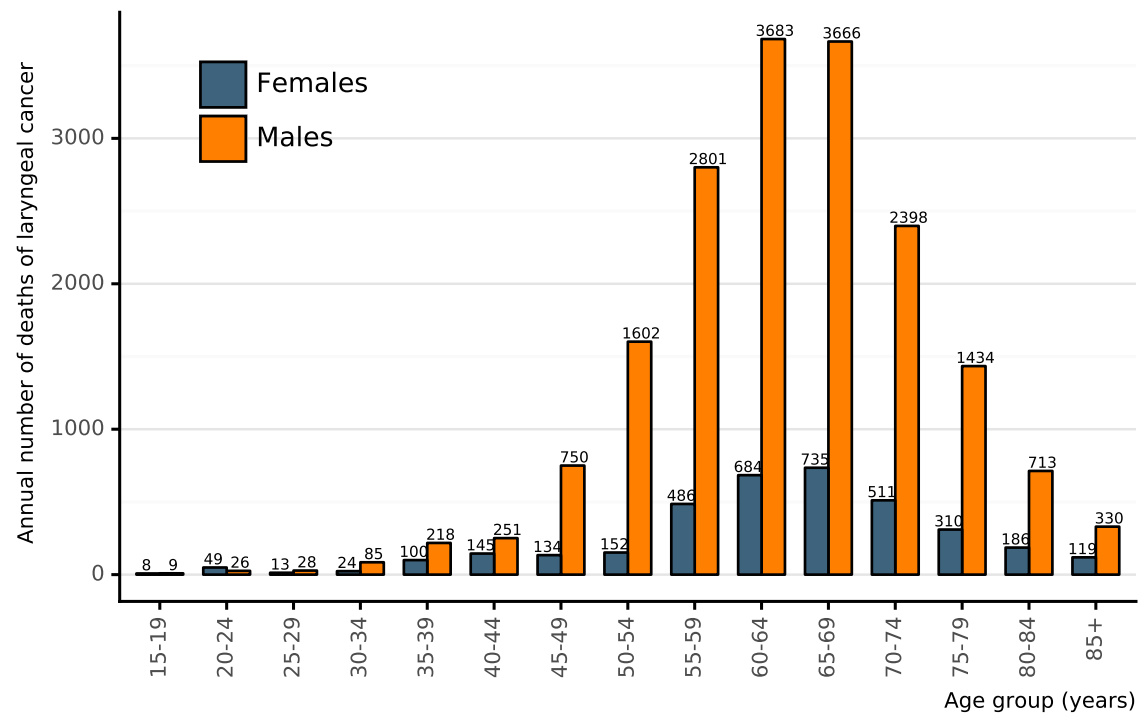

Data accessed on 27 Jan 2021

For more detailed methods of estimation please refer to http://gco.iarc.fr/today/data-sources-methods

Data

Ferlay J, Ervik M, Lam F, Colombet M, Mery L, Piñeros M, Znaor A, Soerjomataram I, Bray F (2020). Global Cancer Observatory: Cancer Today. Lyon, France: International Agency for Research on Cancer. Available from: https://gco.iarc.fr/today, accessed [27 January 2021]. 


\subsubsection{Laryngeal cancer incidence and mortality comparison in India}

Figure 52: Comparison of age-specific laryngeal cancer incidence and mortality rates among men in India (estimates for 2020)

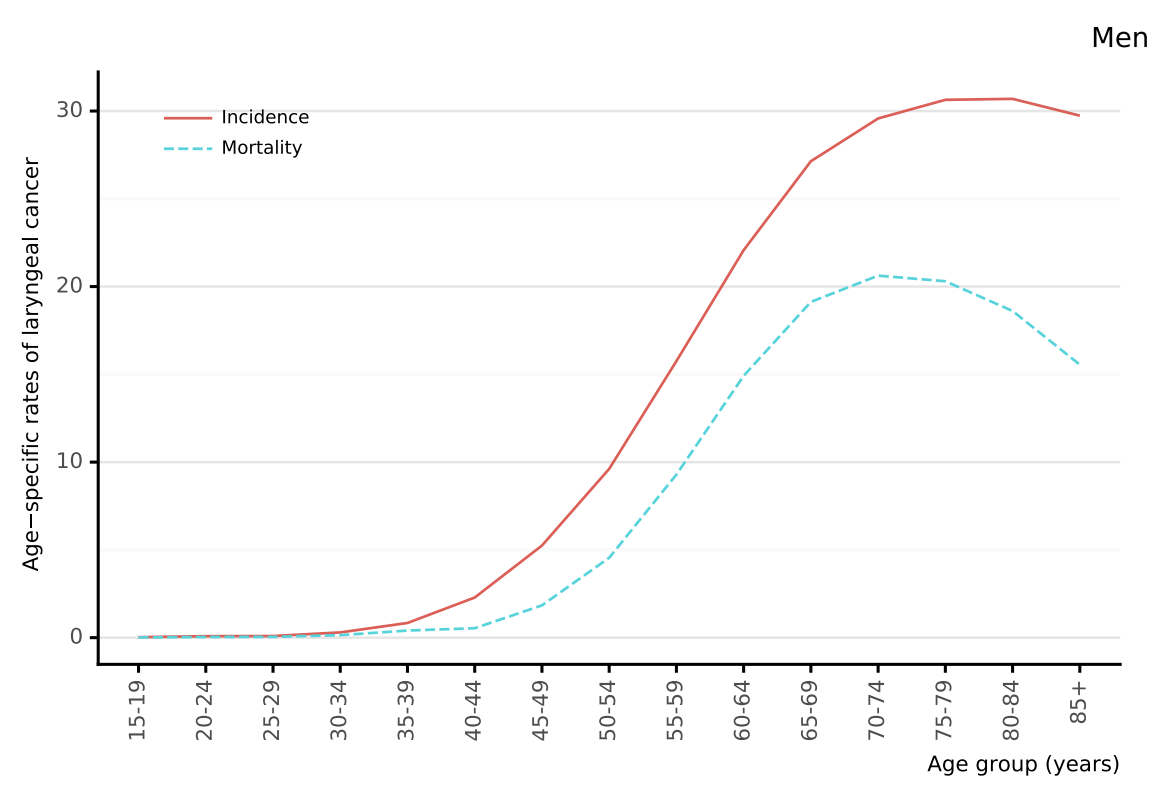

Data accessed on 27 Jan 2021

For more detailed methods of estimation please refer to http://gco.iarc.fr/today/data-sources-methods

${ }^{a}$ Rates per 100,000 men per year.

Data Sources:

Ferlay J, Ervik M, Lam F, Colombet M, Mery L, Piñeros M, Znaor A, Soerjomataram I, Bray F (2020). Global Cancer Observatory: Cancer Today. Lyon, France: International Agency for Research on Cancer. Available from: https://gco.iarc.fr/today, accessed [27 January 2021]

Figure 53: Comparison of age-specific laryngeal cancer incidence and mortality rates among women in India (estimates for 2020)

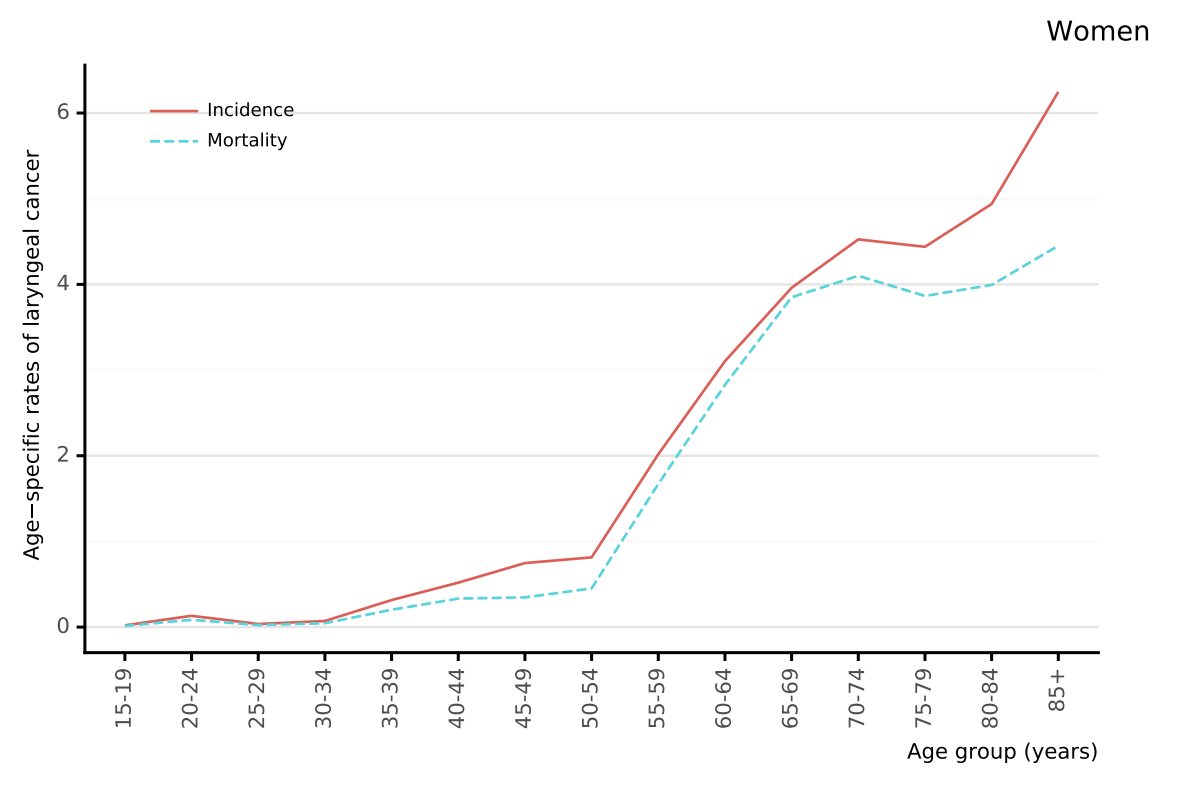

Data accessed on 27 Jan 2021

For more detailed methods of estimation please refer to http://gco.iarc.fr/today/data-sources-methods

${ }^{a}$ Rates per 100,000 women per year.

Data Sources:

Ferlay J, Ervik M, Lam F, Colombet M, Mery L, Piñeros M, Znaor A, Soerjomataram I, Bray F (2020). Global Cancer Observatory: Cancer Today. Lyon, France: International Agency for Research on Cancer. Available from: https ://gco.iarc.fr/today, accessed [27 January 2021]. 


\section{HPV related statistics}

HPV infection is commonly found in the anogenital tract of men and women with and without clinical lesions. The aetiological role of HPV infection among women with cervical cancer is well-established, and there is growing evidence of its central role in other anogenital sites. HPV is also responsible for other diseases such as recurrent juvenile respiratory papillomatosis and genital warts, both mainly caused by HPV types 6 and 11 (Lacey CJ, Vaccine 2006; 24(S3):35). For this section, the methodologies used to compile the information on HPV burden are derived from systematic reviews and meta-analyses of the literature. Due to the limitations of HPV DNA detection methods and study designs used, these data should be interpreted with caution and used only as a guide to assess the burden of HPV infection within the population. (Vaccine 2006, Vol. 24, Suppl 3; Vaccine 2008, Vol. 26, Suppl 10; Vaccine 2012,Vol. 30, Suppl 5; IARC Monographs 2007, Vol. 90).

\subsection{HPV burden in women with normal cervical cytology, cervical precancerous lesions or invasive cervical cancer}

The statistics shown in this section focus on HPV infection in the cervix uteri. HPV cervical infection results in cervical morphological lesions ranging from normalcy (cytologically normal women) to different stages of precancerous lesions (CIN-1, CIN-2, CIN-3/CIS) and invasive cervical cancer. HPV infection is measured by HPV DNA detection in cervical cells (fresh tissue, paraffin embedded or exfoliated cells). The prevalence of HPV increases with lesion severity. HPV causes virtually $100 \%$ of cervical cancer cases, and an underestimation of HPV prevalence in cervical cancer is most likely due to the limitations of study methodologies. Worldwide, HPV16 and 18 (the two vaccine-preventable types) contribute to over $70 \%$ of all cervical cancer cases, between $41 \%$ and $67 \%$ of high-grade cervical lesions and 16-32\% of low-grade cervical lesions. After HPV16/18, the six most common HPV types are the same in all world regions, namely $31,33,35,45,52$ and 58 ; these account for an additional $20 \%$ of cervical cancers worldwide (Clifford G, Vaccine 2006;24(S3):26).

\section{Methods: Prevalence and type distribution of human papillomavirus in cervical carcinoma, low-grade cervical lesions, high-grade cervical lesions and normal cytology: systematic re- view and meta-analysis}

A systematic review of the literature was conducted regarding the worldwide HPV-prevalence and type distribution for cervical carcinoma, low-grade cervical lesions, high-grade cervical lesions and normal cytology from 1990 to 'data as of' indicated in each section. The search terms for the review were 'HPV' AND cerv* using Pubmed. There were no limits in publication language. References cited in selected articles were also investigated. Inclusion criteria were: HPV DNA detection by means of PCR or $\mathrm{HC} 2$, a minimum of 20 cases for cervical carcinoma, 20 cases for low-grade cervical lesions, 20 cases for highgrade cervical lesions and 100 cases for normal cytology and a detailed description of HPV DNA detection and genotyping techniques used. The number of cases tested and HPV positive extracted for each study were pooled to estimate the prevalence of HPV DNA and the HPV type distribution globally and by geographical region. Binomial 95\% confidence intervals were calculated for each HPV prevalence. For more details refer to the methods document. 


\subsubsection{HPV prevalence in women with normal cervical cytology}

Figure 54: Crude age-specific HPV prevalence (\%) and 95\% confidence interval in women with normal cervical cytology in India

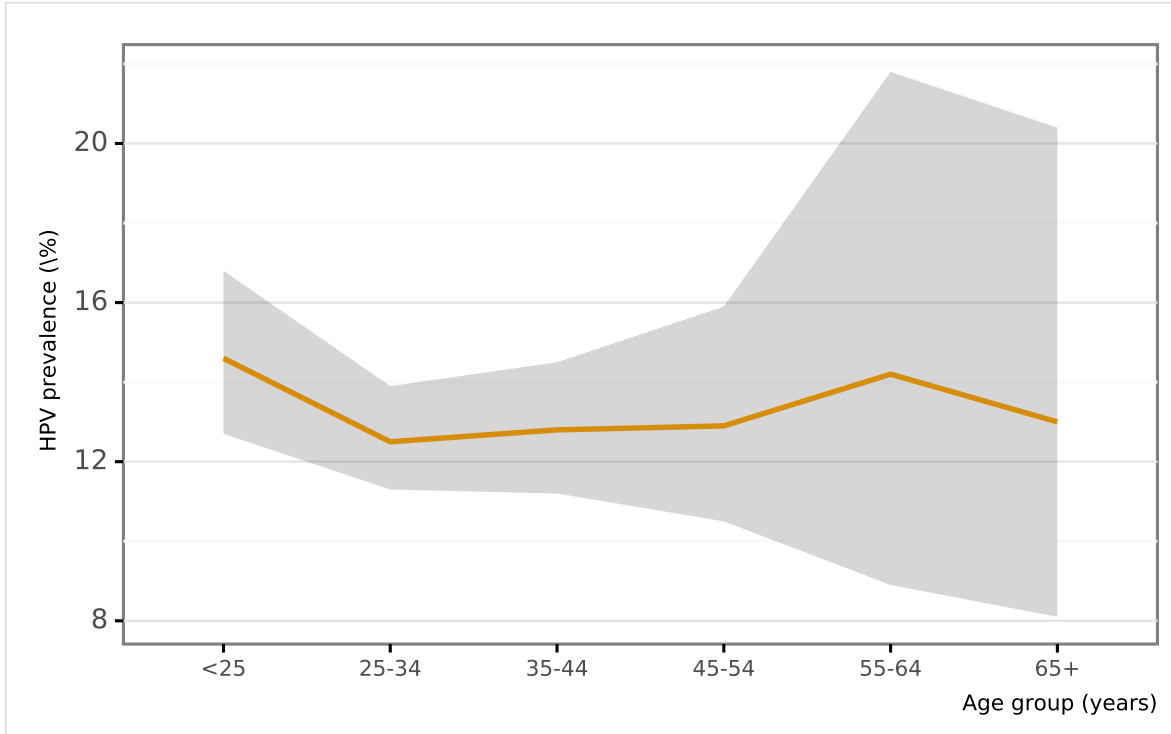

Data updated on 30 Jun 2015 (data as of 30 Jun 2014)

Data Sources:

Aggarwal R, Indian J Cancer 2006; 43: 110 | Arora R, Eur J Obstet Gynecol Reprod Biol 2005; 121: 104 । Bhatla N, Int J Gynecol Pathol 2008; $27: 426$ । Franceschi S, Br J Cancer 2005; 92: 601 । Gupta S, Cytopathology 2009; 20: 249 । Kerkar SC, Sex Reprod Healthc 2011; 2: 7 । Laikangbam P, Int J Gynecol Cancer 2007; 17: 107

Based on systematic reviews and meta-analysis performed by ICO. The ICO HPV Information Centre has updated data until June 2014. Reference publications: 1) Bruni L, J Infect Dis 2010; 202: 1789. 2) De Sanjosé S, Lancet Infect Dis 2007; 7: 453 
Figure 55: HPV prevalence among women with normal cervical cytology in India, by study

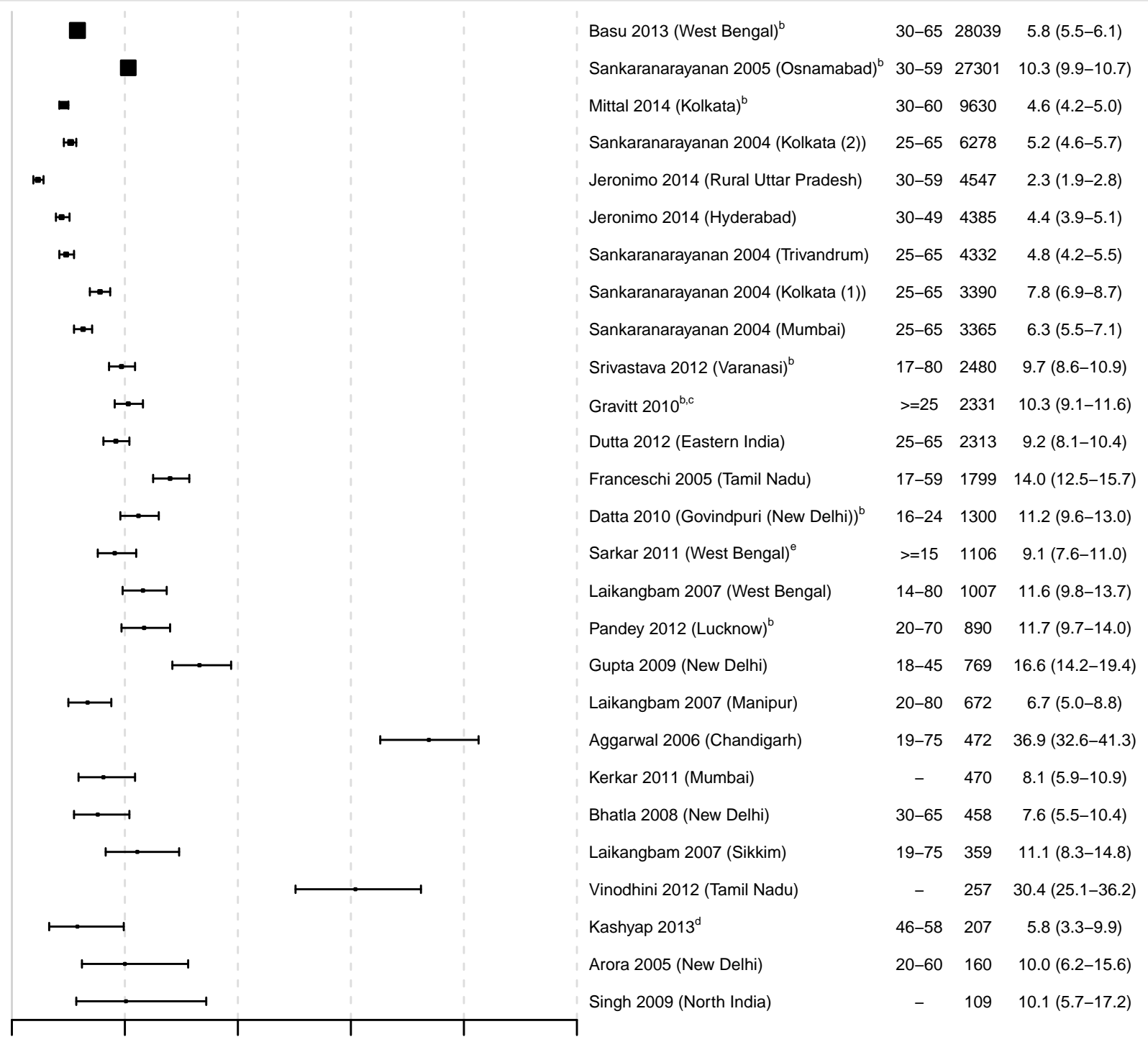

Data updated on 30 Jun 2015 (data as of 30 Jun 2014)

The samples for HPV testing come from cervical specimens (fresh/fixed biopsies or exfoliated cells)

${ }^{a}$ Number of women tested

$b$ Women from the general population, including some with cytological cervical abnormalities

${ }^{c}$ Medchal Mandal (Andhra Pradesh)

${ }^{d}$ Few HPV types tested: 16 only

${ }^{e}$ Few HPV types tested: 16,18 only

Data Sources:

Aggarwal R, Indian J Cancer 2006; 43: 110 । Arora R, Eur J Obstet Gynecol Reprod Biol 2005; 121: 104 । Basu P, Int J Cancer 2013; $132: 1693$ । Bhatla N, Int J Gynecol Pathol 2008; 27: 426 I Datta P, Cancer Epidemiol 2010; 34: 157 । Dutta S, Int J Gynecol Pathol 2012; 31: 178 I Franceschi S, Br J Cancer 2005; 92: 601 । Gravitt PE, PLoS ONE 2010; 5: e13711 । Gupta S, Cytopathology 2009; 20: 249 । Jeronimo J, Int J Gynecol Cancer 2014; 24: 576 । Kashyap V, J Cytol 2013; 30 : 190 I Kerkar SC, Sex Reprod Healthc 2011; 2: 7 । Laikangbam P, Int J Gynecol Cancer 2007; 17: 107 । Mittal S, Int J Gynaecol Obstet 2014; 126: 227 I Pandey S, Asian Pac J Cancer Prev 2012; 13: 2643 | Sankaranarayanan R, Int J Cancer 2004; 112: 341 । Sankaranarayanan R, Int J Cancer 2005; 116: 617 । Sarkar K, BMC Infect Dis 2011; 11: 72 । Singh A, Int J Gynecol Cancer 2009; 19: 1642 I Srivastava S, J Biosci 2012; 37: 63 | Vinodhini K, Int J Gynaecol Obstet 2012; 119: 253

Based on systematic reviews and meta-analysis performed by ICO. The ICO HPV Information Centre has updated data until June 2014. Reference publications: 1) Bruni L, J Infect Dis 2010; 202: 1789. 2) De Sanjosé S, Lancet Infect Dis 2007; 7: 453 


\subsubsection{HPV type distribution among women with normal cervical cytology, precancerous cer- vical lesions and cervical cancer}

Table 21: Prevalence of HPV16 and HPV18 by cytology in India

\begin{tabular}{|c|c|c|}
\hline & No. tested & $\begin{array}{c}\text { HPV 16/18 } \\
\text { Prevalence \% (95\% } \\
\text { CI) }\end{array}$ \\
\hline Normal cytology ${ }^{1,2}$ & 8845 & $5.0(4.6-5.5)$ \\
\hline Low-grade lesions $^{3,4}$ & 177 & $28.2(22.1-35.3)$ \\
\hline High-grade lesions ${ }^{5,6}$ & 253 & $62.8(56.7-68.6)$ \\
\hline Cervical cancer ${ }^{7,8}$ & 2006 & $83.2(81.5-84.8)$ \\
\hline
\end{tabular}

Data updated on 19 May 2017 (data as of 30 Jun 2015 / 30 Nov 2014)

The samples for HPV testing come from cervical specimens (fresh/fixed biopsies or exfoliated cells)

$a$ Number of women tested

$b$ 95\% Confidence Interval

Data Sources:

${ }^{1}$ Aggarwal R, Indian J Cancer 2006; 43: 110 I Arora R, Eur J Obstet Gynecol Reprod Biol 2005; 121: 104 I Bhatla N, Int J Gynecol Pathol $2008 ; 27: 426$ । Dutta S, Int J Gynecol Pathol 2012; 31: 178 | Franceschi S, Br J Cancer 2005; 92: 601 । Gupta S, Cytopathology 2009; 20: 249 | Kerkar SC, Sex Reprod Healthc 2011; 2: 7 । Laikangbam P, Int J Gynecol Cancer 2007; 17: 107 I Singh A, Int J Gynecol Cancer 2009; 19: 1642 I Vinodhini K, Int J Gynaecol Obstet 2012; 119: 253

2 Based on systematic reviews and meta-analysis performed by ICO. The ICO HPV Information Centre has updated data until November 2014. Reference publications: 1) Bruni L, J Infect Dis 2010; 202: 1789. 2) De Sanjosé $\mathrm{S}$, Lancet Infect Dis 2007; 7: 453

3 Contributing studies: Berlin Grace VM, Indian J Cancer 2009; 46: 203 । Franceschi S, Br J Cancer 2005; 92: 601 । Nagpal JK, Eur J Clin Invest 2002; $32: 943$ । Nair P, Pathol Oncol Res 1999; 5: 95 । Singh M, Tumour Biol 2009; 30: 276

4 Based on meta-analysis performed by IARC's Infections and Cancer Epidemiology Group up to November 2011, the ICO HPV Information Centre has updated data until June 2015. Reference publications: 1) Guan P, Int J Cancer 2012;131:2349 2) Clifford GM, Cancer Epidemiol Biomarkers Prev 2005;14:1157

5 Contributing studies: Deodhar K, J Med Virol 2012; 84: 1054 । Franceschi S, Br J Cancer 2005; 92: 601 । Nagpal JK, Eur J Clin Invest 2002; 32: 943 । Singh M, Tumour Biol 2009; 30: 276

6 Based on meta-analysis performed by IARC's Infections and Cancer Epidemiology Group up to November 2011, the ICO HPV Information Centre has updated data until June 2015. Reference publications: 1) Guan P, Int J Cancer 2012;131:2349 2) Smith JS, Int J Cancer 2007;121:621 3) Clifford GM, Br J Cancer 2003;89:101.

${ }^{7}$ Contributing studies: Basu P, Asian Pac J Cancer Prev 2009; 10: 27 । Bhatla N, Int J Gynecol Pathol 2006; 25: 398 I Deodhar K, J Med Virol 2012; 84: 1054 । Franceschi S, Int J Cancer 2003; 107: 127 | Gheit T, Vaccine 2009; 27: 636 | Munagala R, Int J Oncol 2009; 34: 263 | Munirajan AK, Gynecol Oncol 1998; 69: 205 | Munjal K, Int J Gynecol Pathol 2014; 33: 531 | 2003; 107: 127 Iheit I, Vaccine 2009, 27: 636 I Munagala R, Int J Oncol 2009; 34: 263 I Munirajan AK, Gynecol Oncol 1998; 69: 205 I Munjal K, Int J Gynecol Pathol 2014; 33: 531 I A, Int J Gynecol Cancer 2006; 16: 1591 I Peedicayil A, J Low Genit Tract Dis 2009; 13: 102 I Serrano B, Cancer Epidemiol 2014 I Sowjanya AP, BMC Infect Dis 2005; 5: 116

A, Int J Gynecol Cancer 2006; 16: 1591 I Peedicayil A, J Low Genit Tract Dis 2009; 13: 102 I Serrano B, Cancer Epidemiol 2014 I Sowjanya AP, BMC Infect Dis 2005; 5: 116
8 Based on meta-analysis performed by IARC's Infections and Cancer Epidemiology Group up to November 2011, the ICO HPV Information Centre has updated data until June 2015. Reference publications: 1) Guan P, Int J Cancer 2012;131:2349 2) Li N, Int J Cancer 2011;128:927 3) Smith JS, Int J Cancer 2007;121:621 4) Clifford GM, Br J Cancer 2003;88:63 5) Clifford GM, Br J Cancer 2003;89:101.

Figure 56: HPV 16 prevalence among women with normal cervical cytology in India, by study

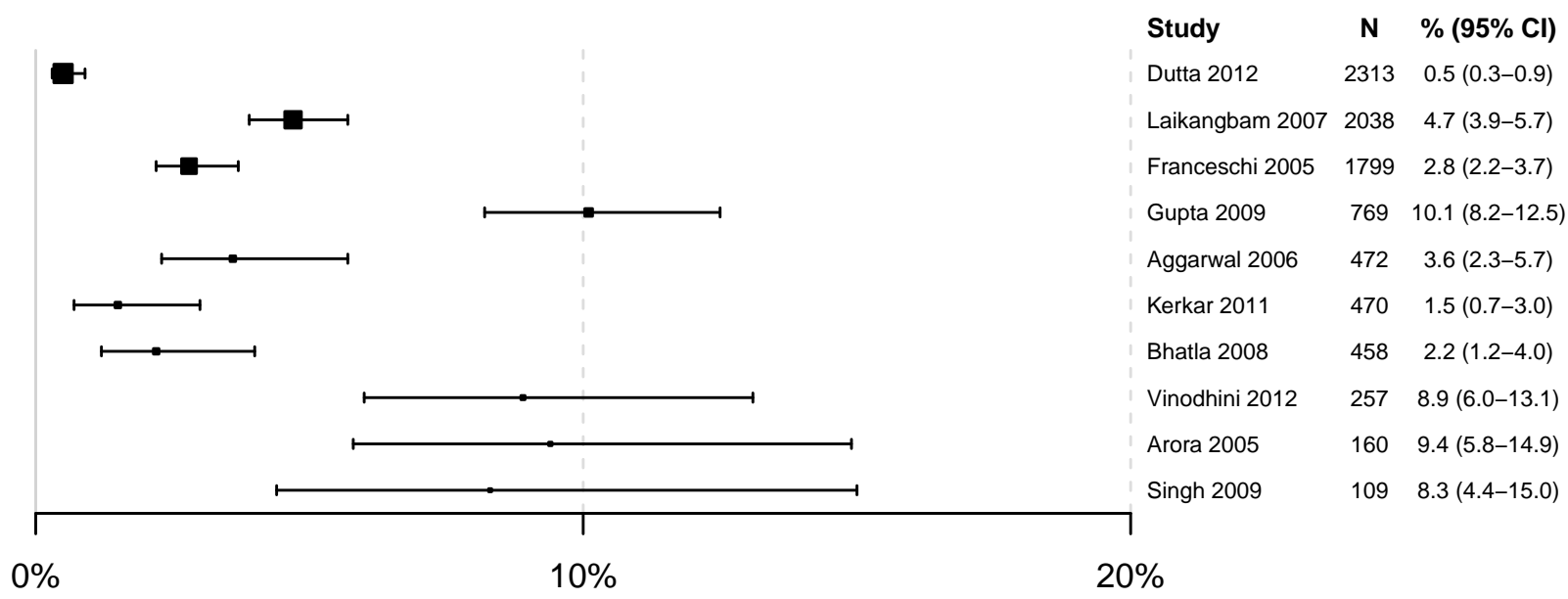

Data updated on 30 Jun 2015 (data as of 30 Jun 2014)

The samples for HPV testing come from cervical specimens (fresh/fixed biopsies or exfoliated cells)

$a$ Number of women tested

Data Sources:

Aggarwal R, Indian J Cancer 2006; 43: 110 | Arora R, Eur J Obstet Gynecol Reprod Biol 2005; $121: 104$ | Bhatla N, Int J Gynecol Pathol 2008; $27: 426$ । Dutta S, Int J Gynecol Pathol 2012; 31: 178 | Franceschi S, Br J Cancer 2005; 92: 601 | Gupta S, Cytopathology 2009; 20: 249 | Kerkar SC, Sex Reprod Healthc 2011; 2: 7 | Laikangbam P, Int J Gynecol Cancer 2007; 17: 107 I Singh A, Int J Gynecol Cancer 2009; 19: 1642 I Vinodhini K, Int J Gynaecol Obstet 2012; 119: 253

Based on systematic reviews and meta-analysis performed by ICO. The ICO HPV Information Centre has updated data until June 2014. Reference publications: 1) Bruni L, J Infect Dis 2010; 202: 1789. 2) De Sanjosé S, Lancet Infect Dis 2007; 7: 453 
Figure 57: HPV 16 prevalence among women with low-grade cervical lesions in India, by study

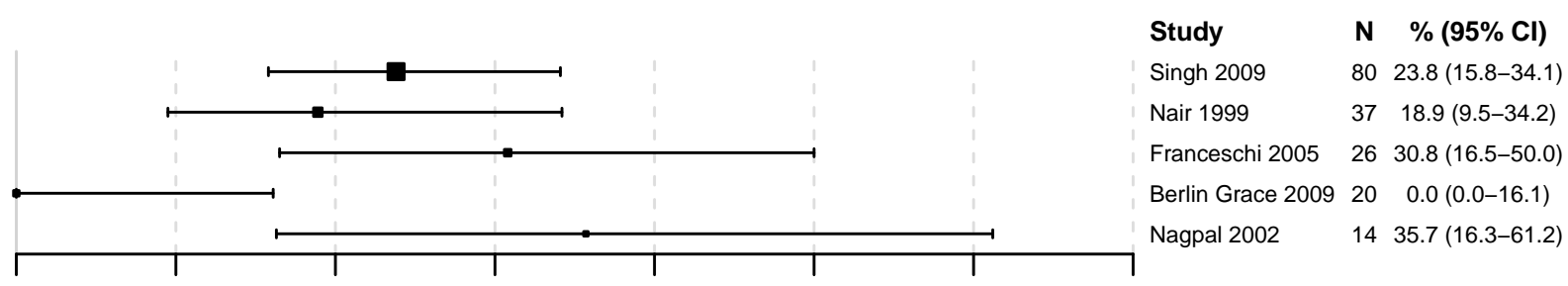

$\begin{array}{lllllll}0 \% & 10 \% & 20 \% & 30 \% & 40 \% & 50 \% & 60 \%\end{array}$

\section{Data updated on 27 Jan 2017 (data as of 30 Jun 2015)}

The samples for HPV testing come from cervical specimens (fresh/fixed biopsies or exfoliated cells)

${ }^{a}$ Number of women tested

Berlin Grace VM, Indian J Cancer 2009; 46: 203 । Franceschi S, Br J Cancer 2005; 92: 601 । Nagpal JK, Eur J Clin Invest 2002; 32: 943 । Nair P, Pathol Oncol Res 1999; 5: 95 । Singh M, Tumour Biol 2009; 30: 276

Based on meta-analysis performed by IARC's Infections and Cancer Epidemiology Group up to November 2011, the ICO HPV Information Centre has updated data until June 2015. Reference publications: 1) Guan P, Int J Cancer 2012;131:2349 2) Clifford GM, Cancer Epidemiol Biomarkers Prev 2005;14:1157

Figure 58: HPV 16 prevalence among women with high-grade cervical lesions in India, by study

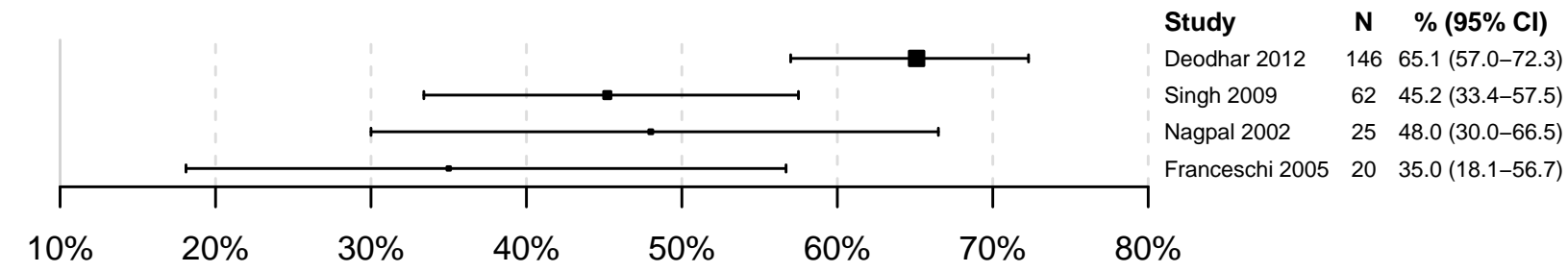

Data updated on 27 Jan 2017 (data as of 30 Jun 2015)

The samples for HPV testing come from cervical specimens (fresh/fixed biopsies or exfoliated cells) ${ }^{a}$ Number of women tested

Data Sources:

Deodhar K, J Med Virol 2012; 84: 1054 । Franceschi S, Br J Cancer 2005; 92: 601 । Nagpal JK, Eur J Clin Invest 2002; 32: 943 I Singh M, Tumour Biol 2009; $30: 276$

Based on meta-analysis performed by IARC's Infections and Cancer Epidemiology Group up to November 2011, the ICO HPV Information Centre has updated data until June 2015. Reference publications: 1) Guan P, Int J Cancer 2012;131:2349 2) Smith JS, Int J Cancer 2007;121:621 3) Clifford GM, Br J Cancer 2003;89:101. 
Figure 59: HPV 16 prevalence among women with invasive cervical cancer in India, by study

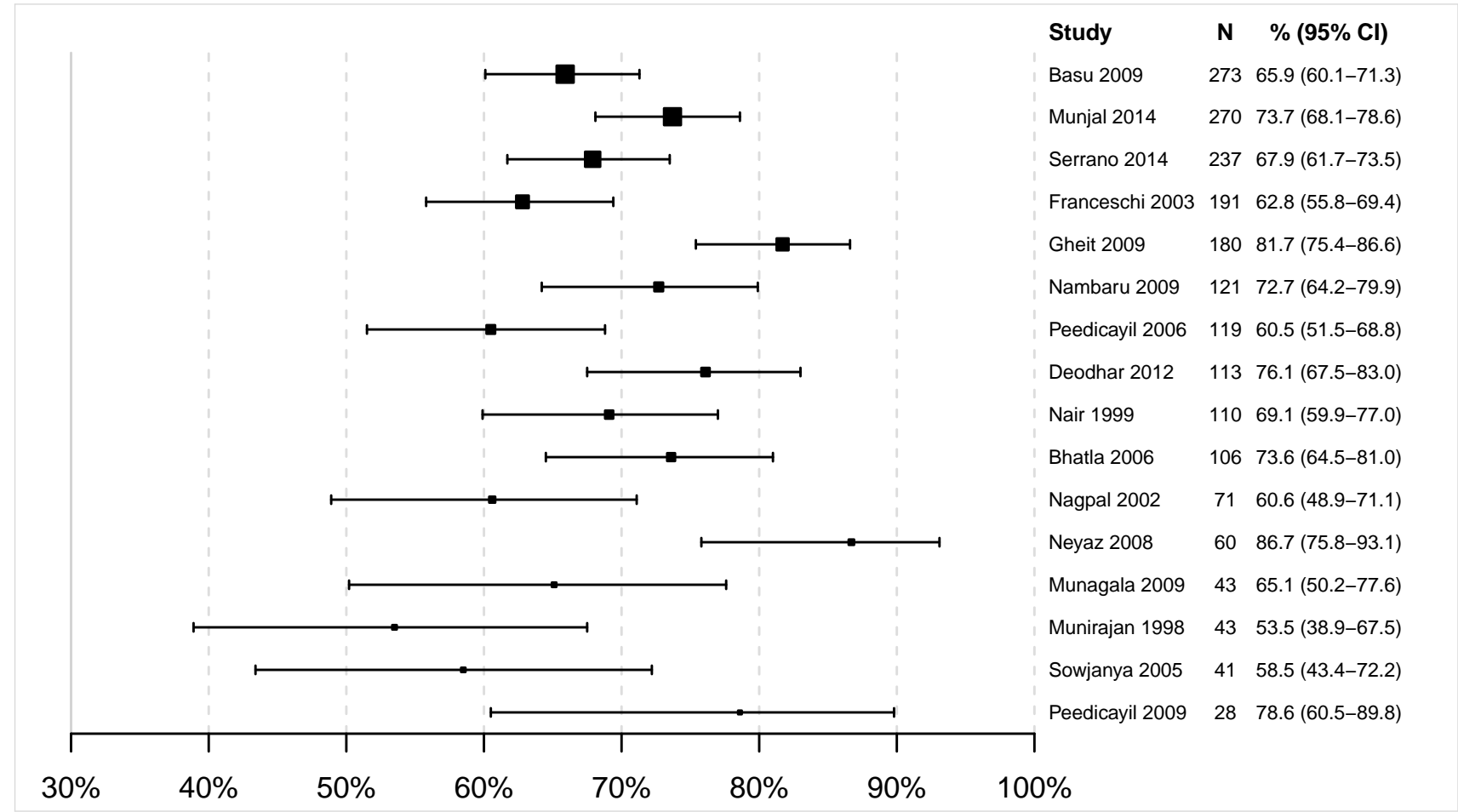

Data updated on 19 May 2017 (data as of 30 Jun 2015)

The samples for HPV testing come from cervical specimens (fresh/fixed biopsies or exfoliated cells)

${ }^{a}$ Number of women tested

Data Sources:

Basu P, Asian Pac J Cancer Prev 2009; 10: 27 । Bhatla N, Int J Gynecol Pathol 2006; 25: 398 । Deodhar K, J Med Virol 2012; 84: 1054 । Franceschi S, Int J Cancer 2003; 107: 127 । Gheit T, Vaccine 2009; 27: 636 । Munagala R, Int J Oncol 2009; 34: 263 । Munirajan AK, Gynecol Oncol 1998; 69: 205 I Munjal K, Int J Gynecol Pathol 2014; 33: 531 I Nagpal JK, Eur J Clin Invest 2002; 32: 943 I Nair P, Pathol Oncol Res 1999; 5: 95 । Nambaru L, Asian Pac J Cancer Prev 2009; 10: 355 । Neyaz MK, Biomarkers 2008; 13: 597 । Peedicayil A, Int J Gynecol Cancer 2006; 16: 1591 I Peedicayil A, J Low Genit Tract Dis 2009; 13: 102 | Serrano B, Cancer Epidemiol 2014 I Sowjanya AP, BMC Infect Dis 2005; 5: 116

Based on meta-analysis performed by IARC's Infections and Cancer Epidemiology Group up to November 2011, the ICO HPV Information Centre has updated data until June 2015. Reference publications: 1) Guan P, Int J Cancer 2012;131:2349 2) Li N, Int J Cancer 2011;128:927 3) Smith JS, Int J Cancer 2007;121:621 4) Clifford GM, Br J Cancer 2003;88:63 5) Clifford GM, Br J Cancer 2003;89:101. 
Figure 60: Comparison of the ten most frequent HPV oncogenic types in India among women with and without cervical lesions

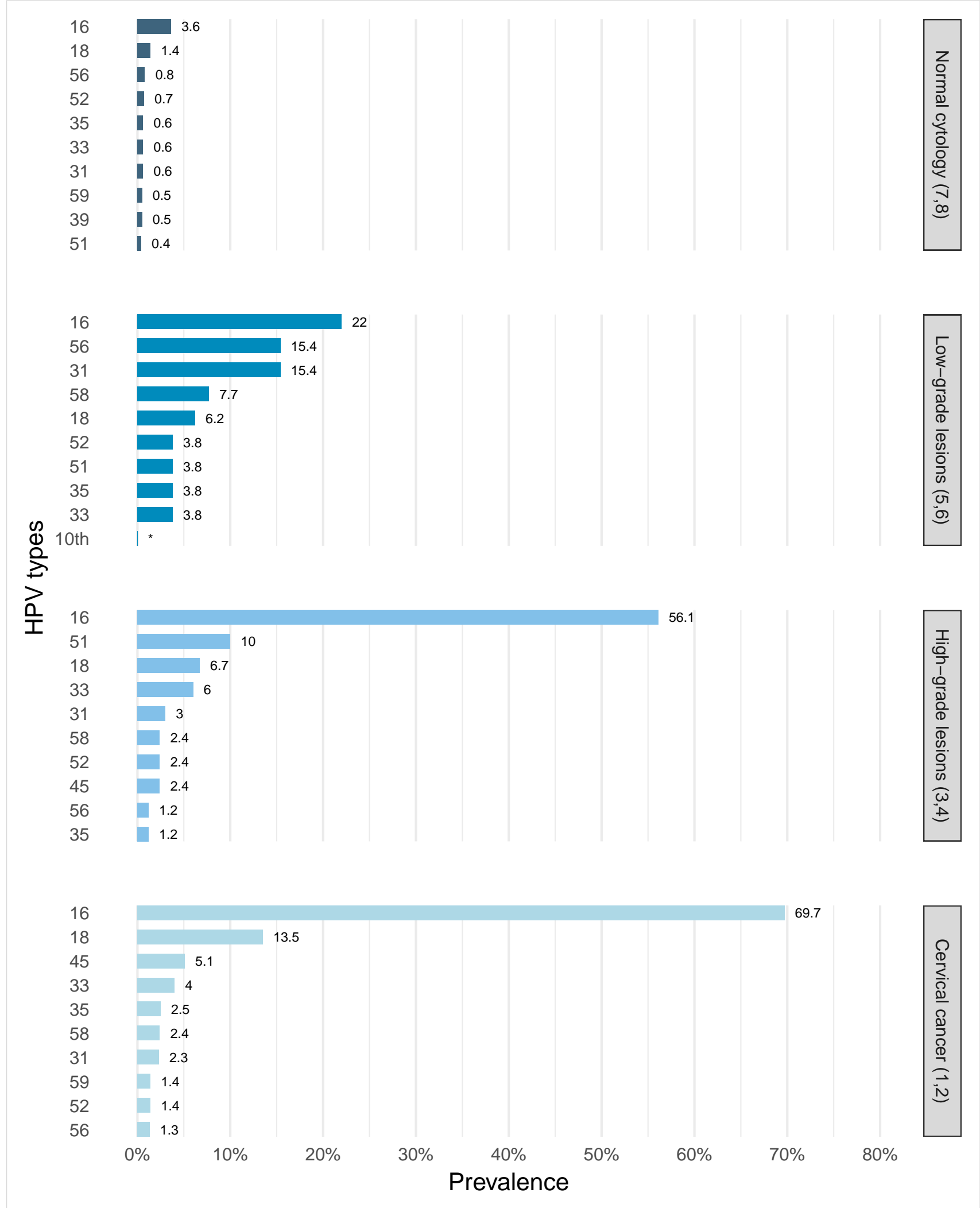

\section{Data updated on 30 Jun 2015 (data as of 30 Jun 2015)}

Data Sources:

${ }^{1}$ Contributing studies: Basu P, Asian Pac J Cancer Prev 2009; 10: 27 । Bhatla N, Int J Gynecol Pathol 2006; 25: 398 । Deodhar K, J Med Virol 2012; $84: 1054$ । Franceschi S, Int J Cancer 2003; 107: 127 | Gheit T, Vaccine 2009; 27: 636 । Munagala R, Int J Oncol 2009; 34: 263 । Munirajan AK, Gynecol Oncol 1998; 69: 205 | Munjal K, Int J Gynecol Pathol 2014; 33: 531 I Nagpal JK, Eur J Clin Invest 2002; 32: 943 I Nair P, Pathol Oncol Res 1999; 5: 95 I Nambaru L, Asian Pac J Cancer Prev 2009; 10: 355 I Neyaz MK, Biomarkers 2008; 13: 597 I Peedicayil A, Int J Gynecol Cancer 2006; 16: 1591 । Peedicayil A, J Low Genit Tract Dis 2009; 13: 102 I Serrano B, Cancer Epidemiol 2014 I Sowjanya AP, BMC Infect Dis 2005; 5: 116

2 Based on meta-analysis performed by IARC's Infections and Cancer Epidemiology Group up to November 2011, the ICO HPV Information Centre has updated data until June 2015. Reference publications: 1) Guan P, Int J Cancer 2012;131:2349 2) Li N, Int J Cancer 2011;128:927 3) Smith JS, Int J Cancer 2007;121:621 4) Clifford GM, Br J Cancer 2003;88:63 5) Clifford Reference publications: 1) Guan P, Int J Cancer 2012;131:2349 2) Li N, Int J Cancer 2011;128:927 3) Smith JS, Int J Cancer 2007;121:621 4) Clifford GM, Br J Cancer 2003;88:63 5) Clifford

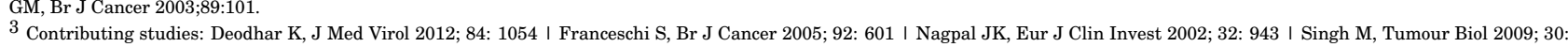


276

4 Based on meta-analysis performed by IARC's Infections and Cancer Epidemiology Group up to November 2011, the ICO HPV Information Centre has updated data until June 2015. Reference publications: 1) Guan P, Int J Cancer 2012;131:2349 2) Smith JS, Int J Cancer 2007;121:621 3) Clifford GM, Br J Cancer 2003;89:101.

5 Contributing studies: Berlin Grace VM, Indian J Cancer 2009; 46: 203 । Franceschi S, Br J Cancer 2005; 92: 601 । Nagpal JK, Eur J Clin Invest 2002; $32: 943$ । Nair P, Pathol Oncol Res 1999; 5: 95 । Singh M, Tumour Biol 2009; 30: 276

6 Based on meta-analysis performed by IARC's Infections and Cancer Epidemiology Group up to November 2011, the ICO HPV Information Centre has updated data until June 2015. Reference publications: 1) Guan P, Int J Cancer 2012;131:2349 2) Clifford GM, Cancer Epidemiol Biomarkers Prev 2005;14:1157

7 Aggarwal R, Indian J Cancer 2006; 43: 110 | Arora R, Eur J Obstet Gynecol Reprod Biol 2005; 121: 104 । Bhatla N, Int J Gynecol Pathol 2008; 27: 426 I Dutta S, Int J Gynecol Pathol 2012; 31: 178 । Franceschi S, Br J Cancer 2005; 92: 601 | Gupta S, Cytopathology 2009; 20: 249 I Kerkar SC, Sex Reprod Healthc 2011; 2: 7 । Laikangbam P, Int J Gynecol Cancer 2007; 17: 107 I Singh A, Int J Gynecol Cancer 2009; 19: 1642 I Vinodhini K, Int J Gynaecol Obstet 2012; 119: 253

8 Based on systematic reviews and meta-analysis performed by ICO. The ICO HPV Information Centre has updated data until November 2014. Reference publications: 1) Bruni L, J Infect Dis 2010; 202: 1789. 2) De Sanjosé S, Lancet Infect Dis 2007; 7: 453 
Figure 61: Comparison of the ten most frequent HPV oncogenic types in India among women with invasive cervical cancer by histology

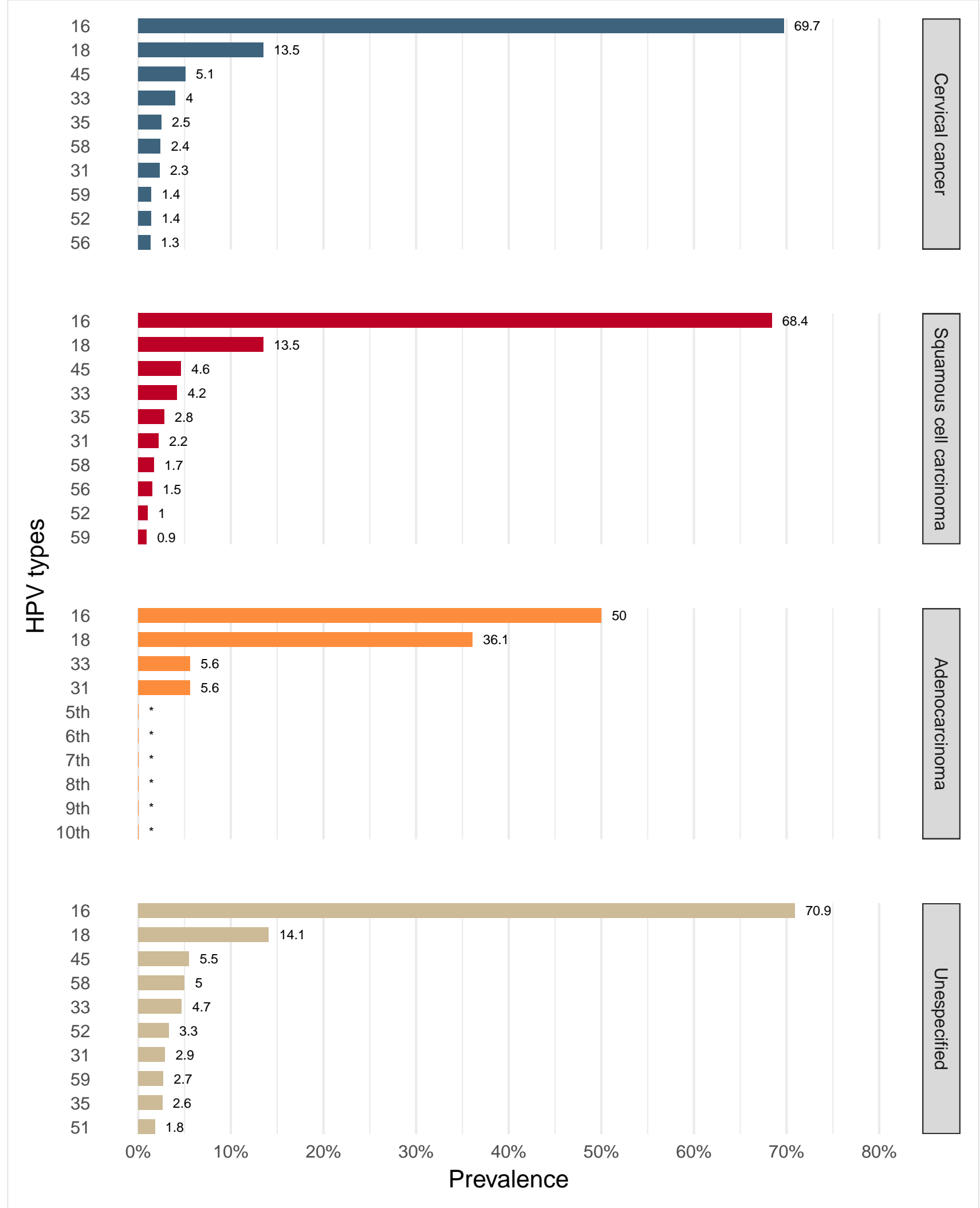

\section{Data updated on 30 Jun 2015 (data as of 30 Jun 2015)}

* No data available. No more types than shown were tested or were positive

Data Sources:

${ }^{1}$ Contributing studies: Basu P, Asian Pac J Cancer Prev 2009; 10: 27 । Bhatla N, Int J Gynecol Pathol 2006; 25: 398 । Deodhar K, J Med Virol 2012; 84: 1054 I Franceschi S, Int J Cancer 2003; 107: 127 | Gheit T, Vaccine 2009; 27: 636 । Munagala R, Int J Oncol 2009; 34: 263 । Munirajan AK, Gynecol Oncol 1998; 69: 205 । Munjal K, Int J Gynecol Pathol 2014; 33: 531 । Nagpal JK, Eur J Clin Invest 2002; 32: 943 I Nair P, Pathol Oncol Res 1999; 5: 95 । Nambaru L, Asian Pac J Cancer Prev 2009; 10: 355 । Neyaz MK, Biomarkers 2008; 13: 597 । Peedicayil A, Int J Gynecol Cancer 2006; 16: 1591 I Peedicayil A, J Low Genit Tract Dis 2009; 13: 102 I Serrano B, Cancer Epidemiol 2014 I Sowjanya AP, BMC Infect Dis 2005; 5: 116

2 Based on meta-analysis performed by IARC's Infections and Cancer Epidemiology Group up to November 2011, the ICO HPV Information Centre has updated data until June 2014. Reference publications: 1) Guan P, Int J Cancer 2012;131:2349 2) Li N, Int J Cancer 2011;128:927 3) Smith JS, Int J Cancer 2007;121:621 4) Clifford GM, Br J Cancer 2003;88:63 5) Clifford GM, Br J Cancer 2003;89:101. 
3 Based on meta-analysis performed by IARC's Infections and Cancer Epidemiology Group up to November 2011, the ICO HPV Information Centre has updated data until June 2015. Reference publications: 1) Guan P, Int J Cancer 2012;131:2349 2) Li N, Int J Cancer 2011;128:927 3) Smith JS, Int J Cancer 2007;121:621 4) Clifford GM, Br J Cancer 2003;88:63 5) Clifford GM, Br J Cancer 2003;89:101. 
Table 22: Type-specific HPV prevalence in women with normal cervical cytology, precancerous cervical lesions and invasive cervical cancer in India

\begin{tabular}{|c|c|c|c|c|c|c|c|c|}
\hline \multirow[b]{2}{*}{$\begin{array}{l}\text { HPV } \\
\text { Type }\end{array}$} & \multicolumn{2}{|c|}{ Normal cytology ${ }^{1,2}$} & \multicolumn{2}{|c|}{ Low-grade lesions ${ }^{3,4}$} & \multicolumn{2}{|c|}{ High-grade lesions ${ }^{5,6}$} & \multicolumn{2}{|c|}{ Cervical cancer ${ }^{7,8}$} \\
\hline & $\begin{array}{l}\text { No. } \\
\text { tested }\end{array}$ & $\begin{array}{l}\text { HPV Prev \% } \\
\text { (95\% CI) }\end{array}$ & $\begin{array}{l}\text { No. } \\
\text { tested }\end{array}$ & $\begin{array}{l}\text { HPV Prev \% } \\
\text { (95\% CI })\end{array}$ & $\begin{array}{l}\text { No. } \\
\text { tested }\end{array}$ & $\begin{array}{c}\text { HPV Prev \% } \\
\text { (95\% CI) }\end{array}$ & $\begin{array}{l}\text { No. } \\
\text { tested }\end{array}$ & $\begin{array}{l}\text { HPV Prev \% } \\
\text { (95\% CI })\end{array}$ \\
\hline \multicolumn{9}{|c|}{ ONCOGENIC HPV TYPES } \\
\hline \multicolumn{9}{|c|}{ High-risk HPV types } \\
\hline 16 & 8845 & $3.6(3.2-4.0)$ & 177 & $22.0(16.6-28.7)$ & 253 & $56.1(50.0-62.1)$ & 2006 & $69.7(67.7-71.7)$ \\
\hline 18 & 8845 & $1.4(1.1-1.6)$ & 177 & $6.2(3.5-10.8)$ & 253 & $6.7(4.2-10.5)$ & 2006 & $13.5(12.1-15.1)$ \\
\hline 31 & 2366 & $0.6(0.4-1.0)$ & 26 & $15.4(6.2-33.5)$ & 166 & $3.0(1.3-6.9)$ & 1644 & $2.3(1.7-3.2)$ \\
\hline 33 & 2366 & $0.6(0.4-1.0)$ & 26 & $3.8(0.7-18.9)$ & 166 & $6.0(3.3-10.7)$ & 1616 & $4.0(3.2-5.1)$ \\
\hline 35 & 2366 & $0.6(0.4-1.0)$ & 26 & $3.8(0.7-18.9)$ & 166 & $1.2(0.3-4.3)$ & 1573 & $2.5(1.8-3.4)$ \\
\hline 39 & 2366 & $0.5(0.3-0.9)$ & 26 & $0.0(0.0-12.9)$ & 166 & $0.6(0.1-3.3)$ & 1411 & $0.7(0.4-1.3)$ \\
\hline 45 & 2366 & $0.3(0.1-0.6)$ & 26 & $0.0(0.0-12.9)$ & 166 & $2.4(0.9-6.0)$ & 1573 & $5.1(4.1-6.3)$ \\
\hline 51 & 2366 & $0.4(0.2-0.7)$ & 26 & $3.8(0.7-18.9)$ & 20 & $10.0(2.8-30.1)$ & 1417 & $0.6(0.3-1.2)$ \\
\hline 52 & 2366 & $0.7(0.4-1.1)$ & 26 & $3.8(0.7-18.9)$ & 166 & $2.4(0.9-6.0)$ & 1497 & $1.4(0.9-2.1)$ \\
\hline 56 & 2366 & $0.8(0.5-1.3)$ & 26 & $15.4(6.2-33.5)$ & 166 & $1.2(0.3-4.3)$ & 1532 & $1.3(0.8-2.0)$ \\
\hline 58 & 2366 & $0.3(0.1-0.6)$ & 26 & $7.7(2.1-24.1)$ & 166 & $2.4(0.9-6.0)$ & 1616 & $2.4(1.8-3.3)$ \\
\hline 59 & 2366 & $0.5(0.3-0.9)$ & 26 & $0.0(0.0-12.9)$ & 166 & $0.0(0.0-2.3)$ & 1454 & $1.4(0.9-2.1)$ \\
\hline \multicolumn{9}{|c|}{ Probable/possible carcinogen } \\
\hline 26 & 2366 & $0.0(0.0-0.2)$ & 26 & $0.0(0.0-12.9)$ & 166 & $0.0(0.0-2.3)$ & 1530 & $0.1(0.0-0.4)$ \\
\hline 30 & 1799 & $0.2(0.1-0.5)$ & 26 & $0.0(0.0-12.9)$ & 20 & $0.0(0.0-16.1)$ & 780 & $0.0(0.0-0.5)$ \\
\hline 34 & 2366 & $0.0(0.0-0.2)$ & 26 & $0.0(0.0-12.9)$ & 20 & $0.0(0.0-16.1)$ & 971 & $0.0(0.0-0.4)$ \\
\hline 53 & 2366 & $0.2(0.1-0.5)$ & 26 & $0.0(0.0-12.9)$ & 166 & $0.0(0.0-2.3)$ & 1530 & $0.3(0.1-0.7)$ \\
\hline 66 & 2366 & $0.5(0.3-0.8)$ & 26 & $0.0(0.0-12.9)$ & 20 & $0.0(0.0-16.1)$ & 1341 & $0.4(0.2-1.0)$ \\
\hline 67 & 2366 & $0.1(0.0-0.4)$ & 26 & $7.7(2.1-24.1)$ & 20 & $0.0(0.0-16.1)$ & 927 & $0.3(0.1-0.9)$ \\
\hline 68 & 2366 & $0.0(0.0-0.2)$ & 26 & $0.0(0.0-12.9)$ & 166 & $0.6(0.1-3.3)$ & 1454 & $0.4(0.2-0.9)$ \\
\hline 69 & 2366 & $0.0(0.0-0.2)$ & 26 & $0.0(0.0-12.9)$ & 20 & $0.0(0.0-16.1)$ & 927 & $0.1(0.0-0.6)$ \\
\hline 70 & 2366 & $0.3(0.1-0.6)$ & 26 & $0.0(0.0-12.9)$ & 166 & $0.6(0.1-3.3)$ & 1411 & $0.0(0.0-0.3)$ \\
\hline 73 & 2366 & $0.2(0.1-0.4)$ & 26 & $0.0(0.0-12.9)$ & 166 & $0.0(0.0-2.3)$ & 1411 & $0.7(0.4-1.3)$ \\
\hline 82 & 2366 & $0.2(0.1-0.4)$ & 26 & $0.0(0.0-12.9)$ & 166 & $1.8(0.6-5.2)$ & 1530 & $0.2(0.1-0.6)$ \\
\hline 85 & - & - & 26 & $0.0(0.0-12.9)$ & 20 & $0.0(0.0-16.1)$ & - & - \\
\hline 97 & - & - & - & - & - & - & 270 & $0.0(0.0-1.4)$ \\
\hline \multicolumn{9}{|c|}{ LOW RISK HPV TYPES } \\
\hline 6 & 3862 & $1.1(0.8-1.4)$ & 83 & $15.7(9.4-25.0)$ & 20 & $0.0(0.0-16.1)$ & 1271 & $0.1(0.0-0.4)$ \\
\hline 11 & 3862 & $0.5(0.3-0.7)$ & 83 & $15.7(9.4-25.0)$ & 20 & $0.0(0.0-16.1)$ & 1228 & $0.2(0.0-0.6)$ \\
\hline 32 & 1799 & $0.2(0.1-0.5)$ & - & - & - & - & 543 & $0.0(0.0-0.7)$ \\
\hline 40 & 2366 & $0.3(0.1-0.6)$ & - & - & - & - & 927 & $0.0(0.0-0.4)$ \\
\hline 42 & 2366 & $1.6(1.2-2.2)$ & - & - & - & - & 1046 & $0.1(0.0-0.5)$ \\
\hline 43 & 1799 & $0.2(0.1-0.5)$ & - & - & - & - & 780 & $0.0(0.0-0.5)$ \\
\hline 44 & 2366 & $0.2(0.1-0.4)$ & - & - & - & - & 780 & $0.0(0.0-0.5)$ \\
\hline 54 & 2366 & $0.2(0.1-0.5)$ & - & - & - & - & 927 & $0.1(0.0-0.6)$ \\
\hline 55 & - & - & - & - & - & - & - & - \\
\hline 57 & 2257 & $0.0(0.0-0.2)$ & - & - & - & - & 649 & $0.0(0.0-0.6)$ \\
\hline 61 & 2366 & $0.0(0.0-0.2)$ & - & - & - & - & 1046 & $0.2(0.1-0.7)$ \\
\hline 62 & 567 & $0.7(0.3-1.8)$ & - & - & - & - & 809 & $0.5(0.2-1.3)$ \\
\hline 64 & - & - & - & - & - & - & - & - \\
\hline 71 & 2366 & $0.0(0.0-0.2)$ & - & - & - & - & 690 & $0.0(0.0-0.6)$ \\
\hline 72 & 2366 & $0.1(0.0-0.3)$ & - & - & - & - & 690 & $0.0(0.0-0.6)$ \\
\hline 74 & - & - & - & - & - & - & 821 & $0.0(0.0-0.5)$ \\
\hline 81 & 1908 & $0.4(0.2-0.8)$ & - & - & - & - & 703 & $0.1(0.0-0.8)$ \\
\hline 83 & 2366 & $0.0(0.0-0.2)$ & - & - & - & - & 690 & $0.0(0.0-0.6)$ \\
\hline 84 & 2366 & $0.2(0.1-0.5)$ & - & - & - & - & 690 & $0.1(0.0-0.8)$ \\
\hline 86 & 1799 & $0.1(0.0-0.4)$ & - & - & - & - & - & - \\
\hline 87 & - & - & - & - & - & - & - & - \\
\hline 89 & 1908 & $0.2(0.1-0.5)$ & - & - & - & - & 690 & $0.0(0.0-0.6)$ \\
\hline 90 & 1799 & $1.0(0.6-1.6)$ & - & - & - & - & 543 & $0.0(0.0-0.7)$ \\
\hline 91 & - & - & - & - & - & - & 780 & $0.0(0.0-0.5)$ \\
\hline
\end{tabular}

\section{Data updated on 30 Jun 2015 (data as of 30 Jun 2015 / 30 Nov 2014)}

The samples for HPV testing come from cervical specimens (fresh/fixed biopsies or exfoliated cells)

Data Sources:

${ }^{1}$ Aggarwal R, Indian J Cancer 2006; 43: 110 । Arora R, Eur J Obstet Gynecol Reprod Biol 2005; 121: 104 I Bhatla N, Int J Gynecol Pathol 2008; 27 : 426 I Dutta S, Int J Gynecol Pathol 2012; 31: 178 । Franceschi S, Br J Cancer 2005; 92: 601 । Gupta S, Cytopathology 2009; 20: 249 | Kerkar SC, Sex Reprod Healthc 2011; 2: 7 । Laikangbam P, Int J Gynecol Cancer 2007; 17: 107 I Singh A, Int J Gynecol Cancer 2009; 19: 1642 । Vinodhini K, Int J Gynaecol Obstet 2012; 119: 253

2 Based on systematic reviews and meta-analysis performed by ICO. The ICO HPV Information Centre has updated data until November 2014. Reference publications: 1) Bruni L, J Infect Dis 2010; 202: 1789. 2) De Sanjosé S, Lancet Infect Dis 2007; 7: 453

${ }^{3}$ Contributing studies: Berlin Grace VM, Indian J Cancer 2009; 46: 203 । Franceschi S, Br J Cancer 2005; 92: 601 । Nagpal JK, Eur J Clin Invest 2002; $32: 943$ । Nair P, Pathol Oncol Res 1999; 5: 95 । Singh M, Tumour Biol 2009; 30: 276

4 Based on meta-analysis performed by IARC's Infections and Cancer Epidemiology Group up to November 2011, the ICO HPV Information Centre has updated data until June 2015. Reference publications: 1) Guan P, Int J Cancer 2012;131:2349 2) Clifford GM, Cancer Epidemiol Biomarkers Prev 2005;14:1157

5 Contributing studies: Deodhar K, J Med Virol 2012; 84: 1054 । Franceschi S, Br J Cancer 2005; 92: 601 I Nagpal JK, Eur J Clin Invest 2002; 32: 943 । Singh M, Tumour Biol 2009; 30: 
276

6 Based on meta-analysis performed by IARC's Infections and Cancer Epidemiology Group up to November 2011, the ICO HPV Information Centre has updated data until June 2015. Reference publications: 1) Guan P, Int J Cancer 2012;131:2349 2) Smith JS, Int J Cancer 2007;121:621 3) Clifford GM, Br J Cancer 2003;89:101.

7 Contributing studies: Basu P, Asian Pac J Cancer Prev 2009; 10: 27 । Bhatla N, Int J Gynecol Pathol 2006; 25: 398 । Deodhar K, J Med Virol 2012; 84: 1054 । Franceschi S, Int J Cancer 2003; 107: 127 | Gheit T, Vaccine 2009; 27: 636 । Munagala R, Int J Oncol 2009; 34: 263 । Munirajan AK, Gynecol Oncol 1998; 69: 205 | Munjal K, Int J Gynecol Pathol 2014; 33: 531 Nagpal JK, Eur J Clin Invest 2002; 32: 943 I Nair P, Pathol Oncol Res 1999; 5: 95 I Nambaru L, Asian Pac J Cancer Prev 2009; 10: 355 I Neyaz MK, Biomarkers 2008; 13: 597 I Peedicayil A, Int J Gynecol Cancer 2006; 16: 1591 I Peedicayil A, J Low Genit Tract Dis 2009; 13: 102 I Serrano B, Cancer Epidemiol 2014 I Sowjanya AP, BMC Infect Dis 2005; 5: 116

8 Based on meta-analysis performed by IARC's Infections and Cancer Epidemiology Group up to November 2011, the ICO HPV Information Centre has updated data until June 2015. Reference publications: 1) Guan P, Int J Cancer 2012;131:2349 2) Li N, Int J Cancer 2011;128:927 3) Smith JS, Int J Cancer 2007;121:621 4) Clifford GM, Br J Cancer 2003;88:63 5) Clifford GM, Br J Cancer 2003;89:101. 
Table 23: Type-specific HPV prevalence among invasive cervical cancer cases in India by histology

\begin{tabular}{|c|c|c|c|c|c|c|c|c|}
\hline \multirow[b]{2}{*}{$\begin{array}{l}\text { HPV } \\
\text { Type }\end{array}$} & \multicolumn{2}{|c|}{ Any Histology } & \multicolumn{2}{|c|}{ Squamous cell carcinoma } & \multicolumn{2}{|c|}{ Adenocarcinoma } & \multicolumn{2}{|c|}{ Unespecified } \\
\hline & $\begin{array}{l}\text { No. } \\
\text { tested }\end{array}$ & $\begin{array}{c}\text { HPV Prev \% } \\
\text { (95\% CI) }\end{array}$ & $\begin{array}{l}\text { No. } \\
\text { tested }\end{array}$ & $\begin{array}{l}\text { HPV Prev \% } \\
\text { (95\% CI) }\end{array}$ & $\begin{array}{c}\text { No. } \\
\text { tested }\end{array}$ & $\begin{array}{c}\text { HPV Prev \% } \\
\text { (95\% CI) }\end{array}$ & $\begin{array}{c}\text { No. } \\
\text { tested }\end{array}$ & $\begin{array}{c}\text { HPV Prev \% } \\
\text { (95\% CI) }\end{array}$ \\
\hline \multicolumn{9}{|c|}{ ONCOGENIC HPV TYPES } \\
\hline \multicolumn{9}{|c|}{ High-risk HPV types } \\
\hline 16 & 2006 & $69.7(67.7-71.7)$ & 1730 & $68.4(66.2-70.6)$ & 36 & $50.0(34.5-65.5)$ & 633 & $70.9(67.3-74.3)$ \\
\hline 18 & 2006 & $13.5(12.1-15.1)$ & 1730 & $13.5(12.0-15.2)$ & 36 & $36.1(22.5-52.4)$ & 633 & $14.1(11.6-17.0)$ \\
\hline 31 & 1644 & $2.3(1.7-3.2)$ & 1549 & $2.2(1.6-3.1)$ & 36 & $5.6(1.5-18.1)$ & 452 & $2.9(1.7-4.9)$ \\
\hline 33 & 1616 & $4.0(3.2-5.1)$ & 1549 & $4.2(3.3-5.3)$ & 36 & $5.6(1.5-18.1)$ & 424 & $4.7(3.1-7.2)$ \\
\hline 35 & 1573 & $2.5(1.8-3.4)$ & 1271 & $2.8(2.1-3.9)$ & 36 & $0.0(0.0-9.6)$ & 381 & $2.6(1.4-4.8)$ \\
\hline 39 & 1411 & $0.7(0.4-1.3)$ & 1271 & $0.7(0.4-1.3)$ & 36 & $0.0(0.0-9.6)$ & 219 & $0.5(0.1-2.5)$ \\
\hline 45 & 1573 & $5.1(4.1-6.3)$ & 1549 & $4.6(3.6-5.7)$ & 36 & $0.0(0.0-9.6)$ & 381 & $5.5(3.6-8.3)$ \\
\hline 51 & 1417 & $0.6(0.3-1.2)$ & 1271 & $0.6(0.3-1.1)$ & 36 & $0.0(0.0-9.6)$ & 225 & $1.8(0.7-4.5)$ \\
\hline 52 & 1497 & $1.4(0.9-2.1)$ & 1549 & $1.0(0.6-1.7)$ & 36 & $0.0(0.0-9.6)$ & 305 & $3.3(1.8-5.9)$ \\
\hline 56 & 1532 & $1.3(0.8-2.0)$ & 1508 & $1.5(1.0-2.2)$ & 36 & $0.0(0.0-9.6)$ & 381 & $1.0(0.4-2.7)$ \\
\hline 58 & 1616 & $2.4(1.8-3.3)$ & 1549 & $1.7(1.1-2.4)$ & 36 & $0.0(0.0-9.6)$ & 424 & $5.0(3.3-7.5)$ \\
\hline 59 & 1454 & $1.4(0.9-2.1)$ & 1549 & $0.9(0.5-1.5)$ & 36 & $0.0(0.0-9.6)$ & 262 & $2.7(1.3-5.4)$ \\
\hline \multicolumn{9}{|c|}{ Probable/possible carcinogen } \\
\hline 26 & 1530 & $0.1(0.0-0.4)$ & - & - & - & - & - & - \\
\hline 30 & 780 & $0.0(0.0-0.5)$ & 769 & $0.0(0.0-0.5)$ & 11 & $0.0(0.0-25.9)$ & - & - \\
\hline 34 & 971 & $0.0(0.0-0.4)$ & 948 & $0.0(0.0-0.4)$ & 23 & $0.0(0.0-14.3)$ & - & - \\
\hline 53 & 1530 & $0.3(0.1-0.7)$ & - & - & - & - & - & - \\
\hline 66 & 1341 & $0.4(0.2-1.0)$ & 1271 & $0.4(0.2-0.9)$ & 36 & $0.0(0.0-9.6)$ & 149 & $0.7(0.1-3.7)$ \\
\hline 67 & 927 & $0.3(0.1-0.9)$ & 1190 & $0.3(0.1-0.9)$ & 24 & $0.0(0.0-13.8)$ & 106 & $0.0(0.0-3.5)$ \\
\hline 68 & 1454 & $0.4(0.2-0.9)$ & 1271 & $0.2(0.1-0.7)$ & 36 & $0.0(0.0-9.6)$ & 262 & $1.1(0.4-3.3)$ \\
\hline 69 & 927 & $0.1(0.0-0.6)$ & - & - & - & - & - & - \\
\hline 70 & 1411 & $0.0(0.0-0.3)$ & - & - & - & - & - & - \\
\hline 73 & 1411 & $0.7(0.4-1.3)$ & - & - & - & - & - & - \\
\hline 82 & 1530 & $0.2(0.1-0.6)$ & 1271 & $0.2(0.0-0.6)$ & 36 & $0.0(0.0-9.6)$ & 338 & $0.6(0.2-2.1)$ \\
\hline 85 & - & - & - & - & - & - & - & - \\
\hline 97 & 270 & $0.0(0.0-1.4)$ & 270 & $0.0(0.0-1.4)$ & - & - & - & - \\
\hline LOW R & HPV 7 & & & & & & & \\
\hline
\end{tabular}

\begin{tabular}{ccccccccc}
\hline 6 & 1271 & $0.1(0.0-0.4)$ & - & - & - & - & - \\
\hline 11 \\
\hline 32
\end{tabular}

\section{Data updated on 19 May 2017 (data as of 30 Jun 2015)}

The samples for HPV testing come from cervical specimens (fresh/fixed biopsies or exfoliated cells)

$a$ Number of women tested

b $95 \%$ Confidence Interval

Data Sources:

Contributing studies: Basu P, Asian Pac J Cancer Prev 2009; 10: 27 । Bhatla N, Int J Gynecol Pathol 2006; 25: 398 । Deodhar K, J Med Virol 2012; $84:$ 1054 । Franceschi S, Int J Cancer 2003; 107: 127 | Gheit T, Vaccine 2009; 27: 636 । Munagala R, Int J Oncol 2009; 34: 263 । Munirajan AK, Gynecol Oncol 1998; 69: 205 | Munjal K, Int J Gynecol Pathol 2014; 33: 531 I Nagpal JK, Eur J Clin Invest 2002; 32: 943 I Nair P, Pathol Oncol Res 1999; 5: 95 I Nambaru L, Asian Pac J Cancer Prev 2009; 10: 355 I Neyaz MK, Biomarkers 2008; 13: 597 I Peedicayil A, Int J Gynecol Cancer 2006; 16: 1591 I Peedicayil A, J Low Genit Tract Dis 2009; 13: 102 I Serrano B, Cancer Epidemiol 2014 I Sowjanya AP, BMC Infect Dis 2005; 5: 116

Based on meta-analysis performed by IARC's Infections and Cancer Epidemiology Group up to November 2011, the ICO HPV Information Centre has updated data until June 2015. Reference publications: 1) Guan P, Int J Cancer 2012;131:2349 2) Li N, Int J Cancer 2011;128:927 3) Smith JS, Int J Cancer 2007;121:621 4) Clifford GM, Br J Cancer 2003;88:63 5) Clifford GM, Br J Cancer 2003;89:101. 


\subsubsection{HPV type distribution among HIV+ women with normal cervical cytology}

Table 24: Studies on HPV prevalence among HIV+ women with normal cytology in India

\begin{tabular}{|c|c|c|c|c|c|} 
Study & $\begin{array}{c}\text { HPV detection method and } \\
\text { targeted HPV types }\end{array}$ & $\begin{array}{c}\text { No. } \\
\text { Tested }^{\mathbf{a}}\end{array}$ & $\%$ & $(95 \% \text { CI })^{\mathbf{b}}$ & $\begin{array}{c}\text { Prevalence of } 5 \text { most } \\
\text { frequent HPVs, HPV } \\
\text { type (\%) }\end{array}$ \\
\hline- & - & - & - & - &
\end{tabular}

Data updated on 31 Dec 2011 (data as of 31 Dec 2011)

DBH: Dot Blot Hybridization; EIA: Enzyme ImmunoAssay; HC2: Hybrid Capture 2; PCR: Polymerase Chain Reaction; TS: Type Specific

$a$ Number of women tested

$b$ 95\% Confidence Interval

Data Sources:

Systematic review and meta-analysis were performed by the ICO HPV Information Centre up to December 2011. Selected studies had to include at least 20 HIV positive women who had both normal cervical cytology and HPV test results (PCR or HC2). 


\subsubsection{Terminology}

\section{Cytologically normal women}

No abnormal cells are observed on the surface of their cervix upon cytology.

\section{Cervical Intraepithelial Neoplasia (CIN) / Squamous Intraepithelial Lesions (SIL)}

SIL and CIN are two commonly used terms to describe precancerous lesions or the abnormal growth of squamous cells observed in the cervix. SIL is an abnormal result derived from cervical cytological screening or Pap smear testing. CIN is a histological diagnosis made upon analysis of cervical tissue obtained by biopsy or surgical excision. The condition is graded as CIN 1,2 or 3, according to the thickness of the abnormal epithelium (1/3, 2/3 or the entire thickness).

\section{Low-grade cervical lesions (LSIL/CIN-1)}

Low-grade cervical lesions are defined by early changes in size, shape, and number of abnormal cells formed on the surface of the cervix and may be referred to as mild dysplasia, LSIL, or CIN-1.

\section{High-grade cervical lesions (HSIL/ CIN-2 / CIN-3 / CIS)}

High-grade cervical lesions are defined by a large number of precancerous cells on the surface of the cervix that are distinctly different from normal cells. They have the potential to become cancerous cells and invade deeper tissues of the cervix. These lesions may be referred to as moderate or severe dysplasia, HSIL, CIN-2, CIN-3 or cervical carcinoma in situ (CIS).

\section{Carcinoma in situ (CIS)}

Preinvasive malignancy limited to the epithelium without invasion of the basement membrane. CIN 3 encompasses the squamous carcinoma in situ.

\section{Invasive cervical cancer (ICC) / Cervical cancer}

If the high-grade precancerous cells invade the basement membrane is called ICC. ICC stages range from stage I (cancer is in the cervix or uterus only) to stage IV (the cancer has spread to distant organs, such as the liver).

\section{Invasive squamous cell carcinoma}

Invasive carcinoma composed of cells resembling those of squamous epithelium.

\section{Adenocarcinoma}

Invasive tumour with glandular and squamous elements intermingled. 


\subsection{HPV burden in anogenital cancers other than cervix}

Methods: Prevalence and type distribution of human papillomavirus in carcinoma of the vulva, vagina, anus and penis: systematic review and meta-analysis

A systematic review of the literature was conducted on the worldwide HPV-prevalence and type distribution for anogenital carcinomas other than cervix from January 1986 to 'data as of' indicated in each section. The search terms for the review were 'HPV' AND (anus OR anal) OR (penile) OR vagin* OR vulv* using Pubmed. There were no limits in publication language. References cited in selected articles were also investigated. Inclusion criteria were: HPV DNA detection by means of PCR, a minimum of 10 cases by lesion and a detailed description of HPV DNA detection and genotyping techniques used. The number of cases tested and HPV positive cases were extracted for each study to estimate the prevalence of HPV DNA and the HPV type distribution. Binomial 95\% confidence intervals were calculated for each HPV prevalence. 


\subsubsection{Anal cancer and precancerous anal lesions}

Anal cancer is similar to cervical cancer with respect to overall HPV DNA positivity, with approximately $100 \%$ of anal squamous cell carcinoma cases associated with HPV infection worldwide (de Martel C et al. Lancet Glob Health 2020;8(2):e180-e190). HPV16 is the most common type detected, representing $73 \%$ of all HPV-positive tumours. HPV18 is the second most common type detected and is found in approximately $5 \%$ of cases. HPV DNA is also detected in the majority of precancerous anal lesions (AIN) (91.5\% in AIN1 and 93.9\% in AIN2/3) (De Vuyst $\mathrm{H}$ et al. Int J Cancer 2009; 124: 1626-36). In this section, the burden of HPV among cases of anal cancers and precancerous anal lesions in India are presented.

Table 25: Studies on HPV prevalence among anal cancer cases in India (male and female)

\begin{tabular}{|c|c|c|c|c|c|}
\hline \multirow[b]{2}{*}{ Study ${ }^{b}$} & \multirow[b]{2}{*}{$\begin{array}{l}\text { HPV detection method and } \\
\text { targeted HPV types }\end{array}$} & \multicolumn{3}{|c|}{ HPV Prevalence } & \multirow[b]{2}{*}{$\begin{array}{c}\text { Prevalence of } 5 \text { most } \\
\text { frequent HPVs, HPV } \\
\text { type }(\%)\end{array}$} \\
\hline & & $\begin{array}{l}\text { No. } \\
\text { Tested }\end{array}$ & $\%$ & $(95 \% \mathrm{CI})^{\mathrm{a}}$ & \\
\hline Alemany 2015 & $\begin{array}{c}\text { PCR-SPF10, EIA, (HPV 6, 11, 16, } \\
\text { 18, 26, 30, 31, 33, 34, 35, 39, 40, 42, } \\
43,44,45,51,52,53,54,56,58,59, \\
61,66,67,68,69,70,73,74,82,83, \\
87,89,91)\end{array}$ & 52 & 80.8 & $(68.1-89.2)$ & $\begin{array}{l}\text { HPV } 16 \text { (67.3), HPV } 18 \\
\text { (3.8), HPV 35 (3.8), HPV } 56 \\
\text { (1.9), HPV 58 (1.9) }\end{array}$ \\
\hline
\end{tabular}

\section{Data updated on 30 Jun 2015 (data as of 30 Jun 2015)}

DBH: Dot Blot Hybridization; EIA: Enzyme ImmunoAssay; HC2: Hybrid Capture 2; ISH: In Situ Hybridization; LBA: Line-Blot Assay; LiPA: Line Probe Assay; PCR: Polymerase Chain Reaction; RFLP: Restriction Fragment Length Polymorphism; RLBH: Reverse Line Blot Hybridization; RT-PCR: Real Time Polymerase Chain Reaction; SBH: Southern Blot Hybridization; SPF: Short Primer Fragment; TS: Type Specific;

$a$
$b$ I5\% Confidence Interval

$b$ Includes cases from Bangladesh, India and South Korea

Data Sources:

Alemany L, Int J Cancer 2015; 136: 98

Based on systematic reviews (up to 2008) performed by ICO for the IARC Monograph on the Evaluation of Carcinogenic Risks to Humans volume 100B and IARC's Infections and Cancer Epidemiology Group. The ICO HPV Information Centre has updated data until June 2015. Reference publications: 1) Bouvard V, Lancet Oncol 2009;10:321 2) De Vuyst H, Int J Cancer $2009 ; 124: 1626$

Table 26: Studies on HPV prevalence among cases of AIN2/3 in India

\begin{tabular}{|l|c|c|c|c|c|} 
Study & $\begin{array}{c}\text { HPV detection method and } \\
\text { targeted HPV types }\end{array}$ & $\begin{array}{c}\text { No. } \\
\text { Tested }\end{array}$ & $\%$ & $(\mathbf{9 5 \%} \text { CI) })^{\mathbf{a}}$ & $\begin{array}{c}\text { Prevalence of } 5 \text { most } \\
\text { frequent HPVs, HPV } \\
\text { type (\%) }\end{array}$ \\
\hline No data available & - & - & - & - &
\end{tabular}

\section{Data updated on 30 Jun 2015 (data as of 30 Jun 2015)}

DBH: Dot Blot Hybridization; EIA: Enzyme ImmunoAssay; HC2: Hybrid Capture 2; ISH: In Situ Hybridization; LBA: Line-Blot Assay; LiPA: Line Probe Assay; PCR: Polymerase Chain Reaction; RFLP: Restriction Fragment Length Polymorphism; RLBH: Reverse Line Blot Hybridization; RT-PCR: Real Time Polymerase Chain Reaction; SBH: Southern Blot Hybridization; SPF: Short Primer Fragment; TS: Type Specific;

AIN 2/3: Anal intraepithelial neoplasia of grade $2 / 3$

a $95 \%$ Confidence Interval

Data Sources:

Based on systematic reviews (up to 2008) performed by ICO for the IARC Monograph on the Evaluation of Carcinogenic Risks to Humans volume 100B and IARC's Infections and Cancer Epidemiology Group. The ICO HPV Information Centre has updated data until June 2015. Reference publications: 1) Bouvard V, Lancet Oncol 2009;10:321 2) De Vuyst H, Int J Cancer 2009;124:1626 
Figure 62: Comparison of the ten most frequent HPV types in anal cancer cases in Asia and the World
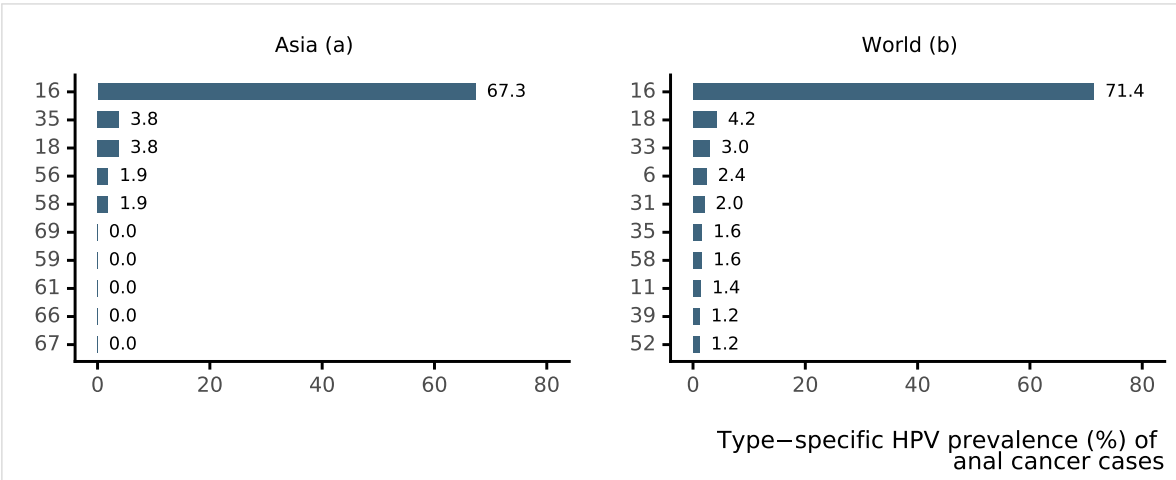

Data updated on 9 Feb 2017 (data as of 30 Jun 2014)

a Includes cases from Bangladesh,India and South Korea

b Includes cases from Europe (Bosnia-Herzegovina, Czech Republic, France, Germany, Poland, Portugal, Slovenia, Spain and United Kingdom); America (Chile, Colombia, Ecuador, Guatemala, Honduras, Mexico, Paraguay and United States); Africa (Mali, Nigeria and Senegal); Asia (Bangladesh,India and South Korea)

Data Sources:

Data from Alemany L, Int J Cancer 2015; 136: 98. This study has gathered the largest international series of anal cancer cases and precancerous lesions worldwide using a standard protocol with a highly sensitive HPV DNA detection assay.

Figure 63: Comparison of the ten most frequent HPV types in AIN 2/3 cases in Asia and the World

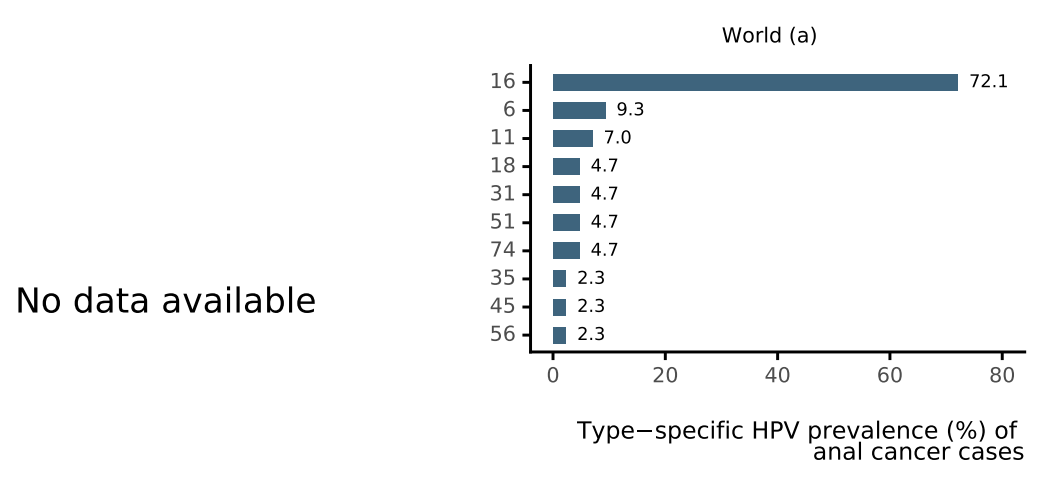

\section{Data updated on 7 Feb 2017 (data as of 30 Jun 2014)}

AIN 2/3: Anal intraepithelial neoplasia of grade 2/3

a Includes cases from Europe (Bosnia-Herzegovina, Czech Republic, France, Germany, Poland, Portugal, Slovenia, Spain and United Kingdom); America (Chile, Colombia, Ecuador, Guatemala, Honduras, Mexico, Paraguay)

Data Sources:

Data from Alemany L, Int J Cancer 2015; 136: 98. This study has gathered the largest international series of anal cancer cases and precancerous lesions worldwide using a standard protocol with a highly sensitive HPV DNA detection assay. 


\subsubsection{Vulvar cancer and precancerous vulvar lesions}

HPV attribution for vulvar cancer is $48 \%$ among age 15-54 years, $28 \%$ among age $55-64$ years, and $15 \%$ among age 65+ worldwide (de Martel C et al. Lancet Glob Health 2020;8(2):e180-e190). Vulvar cancer has two distinct histological patterns with two different risk factor profiles: (1) basaloid/warty types (2) keratinising types. Basaloid/warty lesions are more common in young women, are frequently found adjacent to VIN, are very often associated with HPV DNA detection (86\%), and have a similar risk factor profile as cervical cancer. Keratinising vulvar carcinomas represent the majority of the vulvar lesions $(>60 \%)$. These lesions develop from non HPV-related chronic vulvar dermatoses, especially lichen sclerosus and/or squamous hyperplasia, their immediate cancer precursor lesion is differentiated VIN, they occur more often in older women, and are rarely associated with HPV (6\%) or with any of the other risk factors typical of cervical cancer. HPV prevalence is frequently detected among cases of high-grade VIN (VIN2/3) (85.3\%). HPV 16 is the most common type detected followed by HPV 33 (De Vuyst H et al. Int J Cancer 2009; 124: 1626-36). In this section, the HPV burden among cases of vulvar cancer cases and precancerous vulvar lesions in India are presented.

Table 27: Studies on HPV prevalence among vulvar cancer cases in India

\begin{tabular}{|c|c|c|c|c|c|}
\hline \multirow[b]{2}{*}{ Study ${ }^{b}$} & \multirow[b]{2}{*}{$\begin{array}{l}\text { HPV detection method and } \\
\text { targeted HPV types }\end{array}$} & \multicolumn{3}{|c|}{ HPV Prevalence } & \multirow[b]{2}{*}{$\begin{array}{c}\text { Prevalence of } 5 \text { most } \\
\text { frequent HPVs, HPV } \\
\text { type }(\%)\end{array}$} \\
\hline & & $\begin{array}{l}\text { No. } \\
\text { Tested }\end{array}$ & $\%$ & $(95 \% \mathrm{CI})^{\mathrm{a}}$ & \\
\hline de Sanjosé 2013 & $\begin{array}{c}\text { PCR-SPF10, EIA, (HPV 6, 11, 16, } \\
\text { 18, 26, 30, 31, 33, 34, 35, 39, 40, 42, } \\
43,44,45,51,52,53,54,56,58,59, \\
61,66,67,68,69,70,73,74,82,83, \\
87,89,91)\end{array}$ & 188 & 28.7 & $(22.7-35.6)$ & $\begin{array}{l}\text { HPV } 16 \text { (18.1), HPV } 18 \\
\text { (1.6), HPV } 44 \text { (1.6), HPV } 45 \\
\text { (1.1), HPV } 52 \text { (1.1) }\end{array}$ \\
\hline
\end{tabular}

\section{Data updated on 30 Jun 2015 (data as of 30 Jun 2015)}

DBH: Dot Blot Hybridization; EIA: Enzyme ImmunoAssay; HC2: Hybrid Capture 2; ISH: In Situ Hybridization; LBA: Line-Blot Assay; LiPA: Line Probe Assay; PCR: Polymerase Chain Reaction; RFLP: Restriction Fragment Length Polymorphism; RLBH: Reverse Line Blot Hybridization; RT-PCR: Real Time Polymerase Chain Reaction; SBH: Southern Blot Hybridization; SPF: Short Primer Fragment; TS: Type Specific;

a $95 \%$ Confidence Interval

$b$ Includes cases from Bangladesh, India, Israel, South Korea, Kuwait, Lebanon, Philippines, Taiwan and Turkey Data Sources:

Data Sources:

Based on systematic reviews (up to 2008) performed by ICO for the IARC Monograph on the Evaluation of Carcinogenic Risks to Humans volume 100B and IARC's Infections and Cancer Epidemiology Group. The ICO HPV Information Centre has updated data until June 2015. Reference publications: 1) Bouvard V, Lancet Oncol 2009;10:321 2) De Vuyst H, Int J Cancer 2009;124:1626

Table 28: Studies on HPV prevalence among VIN 2/3 cases in India

\begin{tabular}{|c|c|c|c|c|c|}
\hline \multirow[b]{2}{*}{ Study ${ }^{b}$} & \multicolumn{5}{|c|}{ HPV Prevalence } \\
\hline & $\begin{array}{l}\text { HPV detection method and } \\
\text { targeted HPV types }\end{array}$ & $\begin{array}{l}\text { No. } \\
\text { Tested }\end{array}$ & $\%$ & $(95 \% \mathrm{CI})^{\mathrm{a}}$ & $\begin{array}{c}\text { Prevalence of } 5 \text { most } \\
\text { frequent HPVs, HPV } \\
\text { type }(\%)\end{array}$ \\
\hline de Sanjosé 2013 & $\begin{array}{c}\text { PCR-SPF10, EIA, (HPV 6, 11, 16, } \\
18,26,30,31,33,34,35,39,40,42, \\
43,44,45,51,52,53,54,56,58,59, \\
61,66,67,68,69,70,73,74,82,83, \\
87,89,91)\end{array}$ & 20 & 100 & $(83.9-100.0)$ & $\begin{array}{l}\text { HPV } 16(80.0) \text {, HPV } 18 \\
\text { (5.0), HPV } 33(5.0) \text {, HPV } 35 \\
(5.0), \text { HPV } 54(5.0)\end{array}$ \\
\hline
\end{tabular}

\section{Data updated on 30 Jun 2015 (data as of 30 Jun 2015)}

DBH: Dot Blot Hybridization; EIA: Enzyme ImmunoAssay; HC2: Hybrid Capture 2; ISH: In Situ Hybridization; LBA: Line-Blot Assay; LiPA: Line Probe Assay; PCR: Polymerase Chain Reaction; RFLP: Restriction Fragment Length Polymorphism; RLBH: Reverse Line Blot Hybridization; RT-PCR: Real Time Polymerase Chain Reaction; SBH: Southern Blot Hybridization; SPF: Short Primer Fragment; TS: Type Specific;

VIN 2/3: Vulvar intraepithelial neoplasia of grade $2 / 3$

a $95 \%$ Confidence Interval

$b$ Includes cases from Bangladesh, India, Israel, South Korea, Kuwait, Lebanon, Philippines, Taiwan and Turkey

Data Sources:

de Sanjosé S, Eur J Cancer 2013; 49: 3450

Based on systematic reviews (up to 2008) performed by ICO for the IARC Monograph on the Evaluation of Carcinogenic Risks to Humans volume 100B and IARC's Infections and Cancer Epidemiology Group. The ICO HPV Information Centre has updated data until June 2015. Reference publications: 1) Bouvard V, Lancet Oncol 2009;10:321 2) De Vuyst H, Int J Cancer $2009 ; 124: 1626$ 
Figure 64: Comparison of the ten most frequent HPV types in cases of vulvar cancer in Asia and the World

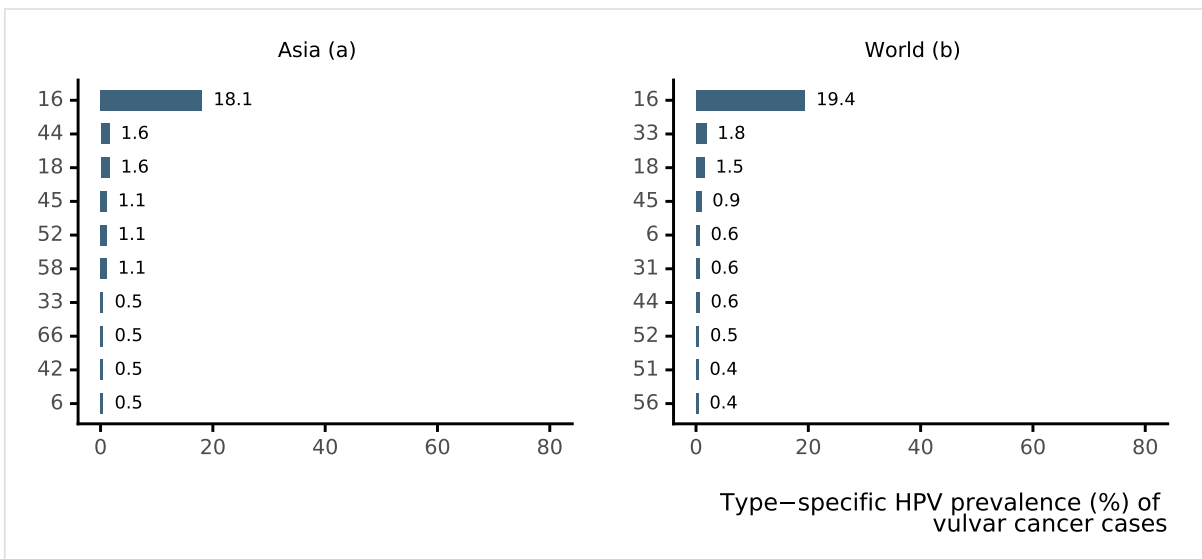

\section{Data updated on 30 Jun 2015 (data as of 30 Jun 2015)}

a Includes cases from Bangladesh, India, Israel, South Korea, Kuwait, Lebanon, Philippines, Taiwan and Turkey.

b Includes cases from America (Argentina, Brazil, Chile, Colombia, Ecuador, Guatemala, Honduras, Mexico, Paraguay, Uruguay, United States of America and Venezuela); Africa (Mali, Mozambique, Nigeria, and Senegal); Oceania (Australia and New Zealand); Europe (Austria, Belarus, Bosnia-Herzegovina, Czech Republic, France, Germany, Greece, Italy, Poland, Portugal, Spain and United Kingdom); and in Asia (Bangladesh, India, Israel, South Korea, Kuwait, Lebanon, Philippines, Taiwan and Turkey)

Data Sources:

Data from de Sanjosé S, Eur J Cancer 2013; 49: 3450. This study has gathered the largest international series of vulva cancer cases and precancerous lesions worldwide using a standard protocol with a highly sensitive HPV DNA detection assay.

Figure 65: Comparison of the ten most frequent HPV types in VIN 2/3 cases in Asia and the World
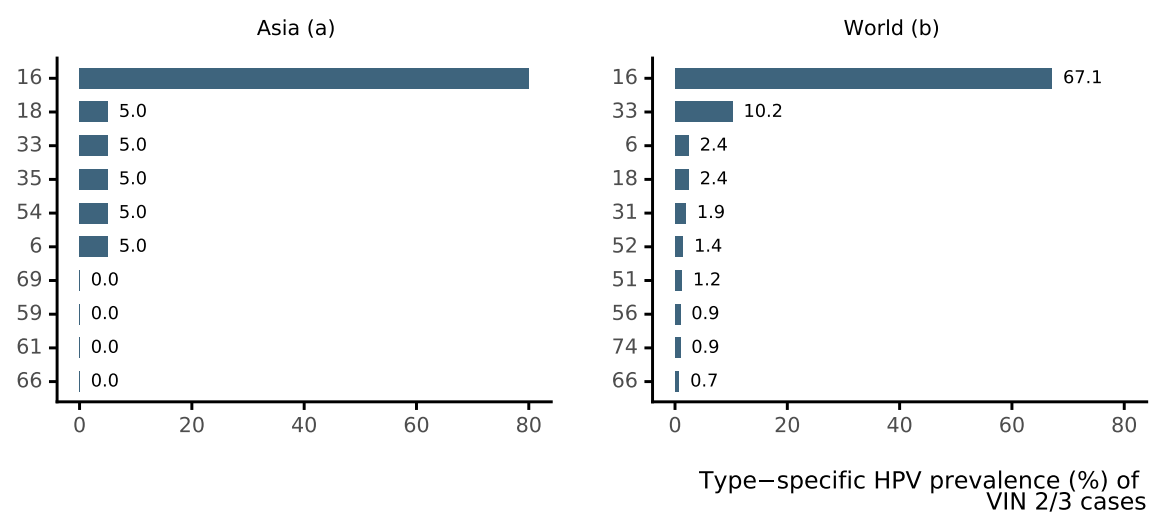

Data updated on 30 Jun 2014 (data as of 30 Jun 2014)

VIN 2/3: Vulvar intraepithelial neoplasia of grade 2/3

a Includes cases from Bangladesh, India, Israel, South Korea, Kuwait, Lebanon, Philippines, Taiwan and Turkey.

b Includes cases from America (Argentina, Brazil, Chile, Colombia, Ecuador, Guatemala, Honduras, Mexico, Paraguay, Uruguay and Venezuela); Oceania (Australia and New Zealand); Europe (Austria, Belarus, Bosnia-Herzegovina, Czech Republic, France, Germany, Greece, Italy, Poland, Portugal, Spain and United Kingdom); and in Asia (Bangladesh, India, Israel, South Korea, Kuwait, Lebanon, Philippines, Taiwan and Turkey)

Korea, Kuwait,

Data Sources: protocol with a highly sensitive HPV DNA detection assay. 


\subsubsection{Vaginal cancer and precancerous vaginal lesions}

Vaginal and cervical cancers share similar risk factors and it is generally accepted that both carcinomas share the same aetiology of HPV infection although there is limited evidence available. Women with vaginal cancer are more likely to have a history of other ano-genital cancers, particularly of the cervix, and these two carcinomas are frequently diagnosed simultaneously. HPV DNA is detected among 78\% of invasive vaginal carcinomas and $91 \%$ of high-grade vaginal neoplasias (VaIN2/3). HPV16 is the most common type in high-grade vaginal neoplasias and it is detected in at least 78\% of HPV-positive carcinomas (de Martel C et al. Lancet Glob Health 2020;8(2):e180-e190; De Vuyst H et al. Int J Cancer 2009; 124:1626-36). In this section, the HPV burden among cases of vaginal cancer cases and precancerous vaginal lesions in India are presented.

Table 29: Studies on HPV prevalence among vaginal cancer cases in India

\begin{tabular}{|c|c|c|c|c|c|}
\hline \multirow[b]{2}{*}{ Study ${ }^{b}$} & \multicolumn{4}{|c|}{ HPV Prevalence } & \multirow[b]{2}{*}{$\begin{array}{c}\text { Prevalence of } 5 \text { most } \\
\text { frequent HPVs, HPV } \\
\text { type }(\%)\end{array}$} \\
\hline & $\begin{array}{l}\text { HPV detection method and } \\
\text { targeted HPV types }\end{array}$ & $\begin{array}{l}\text { No. } \\
\text { Tested }\end{array}$ & $\%$ & $(95 \% \mathrm{CI})^{\mathrm{a}}$ & \\
\hline Alemany 2014 & $\begin{array}{c}\text { PCR-SPF10, EIA, (HPV 6, 11, 16, } \\
\text { 18, } 26,30,31,33,35,39,42,45,51 \text {, } \\
52,53,56,58,59,66,67,68,69,73 \text {, } \\
82 \text { ) }\end{array}$ & 46 & 71.7 & $(57.5-82.7)$ & $\begin{array}{l}\text { HPV } 16 \text { (41.3), HPV } 33 \\
\text { (4.3), HPV 68 (4.3), HPV } 18 \\
\text { (2.2), HPV } 26(2.2)\end{array}$ \\
\hline
\end{tabular}

Data updated on 30 Jun 2015 (data as of 30 Jun 2015)

DBH: Dot Blot Hybridization; EIA: Enzyme ImmunoAssay; HC2: Hybrid Capture 2; ISH: In Situ Hybridization; LBA: Line-Blot Assay; LiPA: Line Probe Assay; PCR: Polymerase Chain Reaction; RFLP: Restriction Fragment Length Polymorphism; RLBH: Reverse Line Blot Hybridization; RT-PCR: Real Time Polymerase Chain Reaction; SBH: Southern Blot Hybridization; SPF: Short Primer Fragment; TS: Type Specific;

a $95 \%$ Confidence Interval

$b$ Includes cases from Australia, Bangladesh, India, Israel, South Korea, Kuwait, Philippines, Taiwan and Turkey

Data Sources:

Data Sources:

Alemany L, Eur J Cancer 2014; 50: 2846
Based on systematic reviews (up to 2008) performed by ICO for the IARC Monograph on the Evaluation of Carcinogenic Risks to Humans volume 100B and IARC's Infections and Cancer Epidemiology Group. The ICO HPV Information Centre has updated data until June 2015. Reference publications: 1) Bouvard V, Lancet Oncol 2009;10:321 2) De Vuyst H, Int J Cancer 2009;124:1626

Table 30: Studies on HPV prevalence among VaIN 2/3 cases in India

\begin{tabular}{|c|c|c|c|c|c|}
\hline \multirow[b]{2}{*}{ Study } & \multirow[b]{2}{*}{$\begin{array}{l}\text { HPV detection method and } \\
\text { targeted HPV types }\end{array}$} & \multicolumn{3}{|c|}{ HPV Prevalence } & \multirow[b]{2}{*}{$\begin{array}{c}\text { Prevalence of } 5 \text { most } \\
\text { frequent HPVs, HPV } \\
\text { type }(\%)\end{array}$} \\
\hline & & $\begin{array}{l}\text { No. } \\
\text { Tested }\end{array}$ & $\%$ & $(95 \% \mathrm{CI})^{\mathrm{a}}$ & \\
\hline Alemany 2014 & $\begin{array}{c}\text { PCR-SPF10, EIA, (HPV 6, 11, 16, } \\
18,26,30,31,33,35,39,42,45,51, \\
52,53,56,58,59,66,67,68,69,73, \\
82,89)\end{array}$ & 13 & 100 & $(77.2-100.0)$ & $\begin{array}{l}\text { HPV } 16 \text { (53.8), HPV } 52 \\
\text { (15.4), HPV 59 (15.4), HPV } \\
45 \text { (7.7), HPV } 73(7.7)\end{array}$ \\
\hline
\end{tabular}

\section{Data updated on 30 Jun 2015 (data as of 30 Jun 2015)}

DBH: Dot Blot Hybridization; EIA: Enzyme ImmunoAssay; HC2: Hybrid Capture 2; ISH: In Situ Hybridization; LBA: Line-Blot Assay; LiPA: Line Probe Assay; PCR: Polymerase Chain Reaction; RFLP: Restriction Fragment Length Polymorphism; RLBH: Reverse Line Blot Hybridization; RT-PCR: Real Time Polymerase Chain Reaction; SBH: Southern Blot Hybridization; SPF: Short Primer Fragment; TS: Type Specific;

VAIN 2/3: Vaginal intraepithelial neoplasia of grade $2 / 3$

a 95\% Confidence Interval

Data Sources:

Alemany L, Eur J Cancer 2014; 50: 2846

Based on systematic reviews (up to 2008) performed by ICO for the IARC Monograph on the Evaluation of Carcinogenic Risks to Humans volume 100B and IARC's Infections and Cancer Epidemiology Group. The ICO HPV Information Centre has updated data until June 2015. Reference publications: 1) Bouvard V, Lancet Oncol 2009;10:321 2) De Vuyst H, Int J Cancer 2009;124:1626 
Figure 66: Comparison of the ten most frequent HPV types in cases of vaginal cancer in Asia and the World

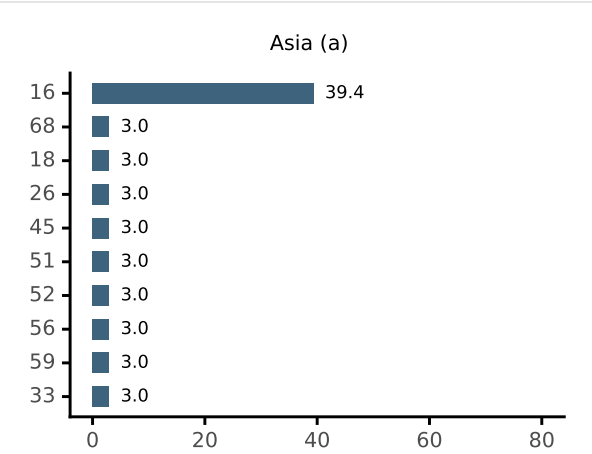

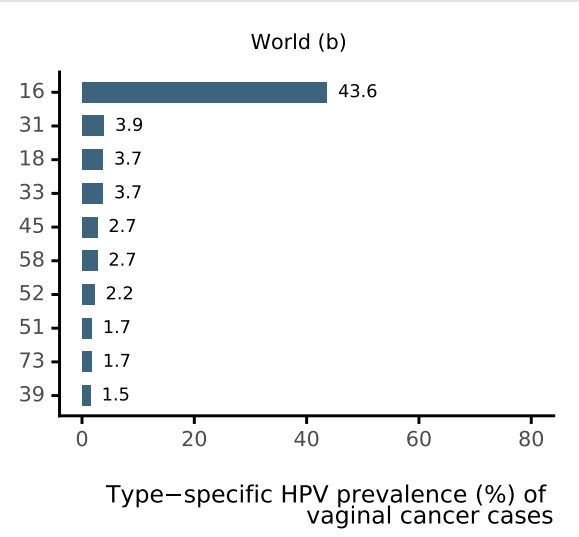

\section{Data updated on 30 Jun 2015 (data as of 30 Jun 2015)}

a Includes cases from Bangladesh, India, Israel, South Korea, Kuwait, Philippines, Taiwan and Turkey

b Includes cases from Europe (Austria, Belarus, Czech Republic, France, Germany, Greece, Poland, Spain and United Kingdom); America (Argentina, Brazil, Chile, Colombia, Ecuador, Guatemala, Mexico, Paraguay, Uruguay, United states of America and Venezuela); Africa (Mozambique, Nigeria); Asia (Bangladesh, India, Israel, South Korea, Kuwait, Philippines, Taiwan and Turkey); and Oceania (Australia)

Data Sources:

Data from Alemany L, Eur J Cancer 2014; 50: 2846. This study has gathered the largest international series of vaginal cancer cases and precancerous lesions worldwide using a standard protocol with a highly sensitive HPV DNA detection assay.

Figure 67: Comparison of the ten most frequent HPV types in VaIN 2/3 cases in Asia and the World
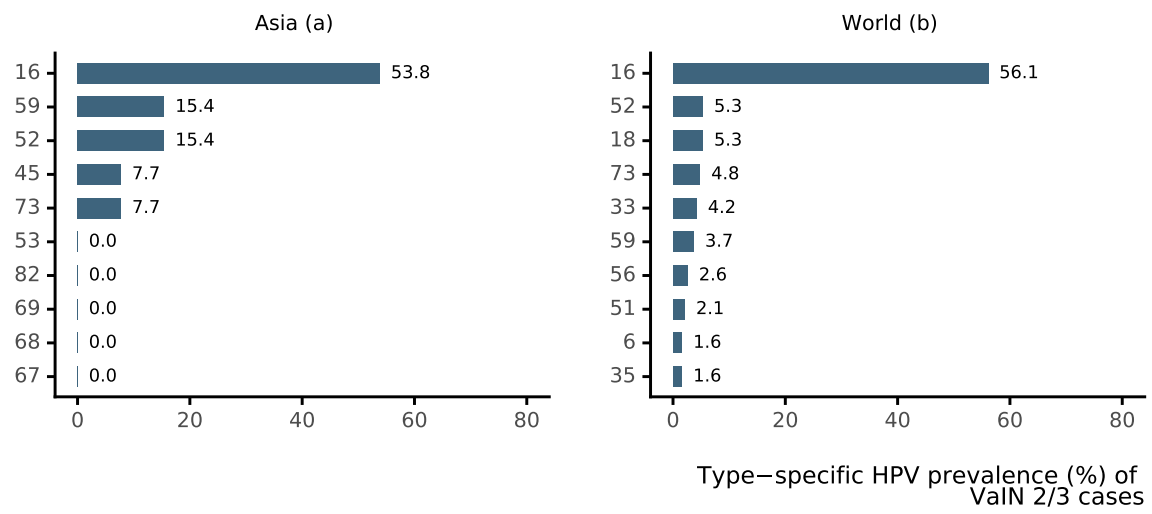

Data updated on 30 Jun 2014 (data as of 30 Jun 2014)

VAIN 2/3: Vaginal intraepithelial neoplasia of grade $2 / 3$

a Includes cases from Australia, Bangladesh, India, Israel, South Korea, Kuwait, Philippines, Taiwan and Turkey.

b Includes cases from Europe (Austria, Belarus, Czech Republic, France, Germany, Greece, Poland, Spain and United Kingdom); America (Argentina, Brazil, Chile, Colombia, Ecuador, Guatemala, Mexico, Paraguay, Uruguay, United states of America and Venezuela); Asia (Bangladesh, India, Israel, South Korea, Kuwait, Philippines, Taiwan and Turkey); and Oceania (Australia)

Data Sources:

Data from Alemany L, Eur J Cancer 2014; 50: 2846. This study has gathered the largest international series of vaginal cancer cases and precancerous lesions worldwide using a standard protocol with a highly sensitive HPV DNA detection assay. 


\subsubsection{Penile cancer and precancerous penile lesions}

HPV DNA is detectable in approximately $51 \%$ of all penile cancers (de Martel C et al. Lancet Glob Health 2020;8(2):e180-e190). Among HPV-related penile tumours, HPV16 is the most common type detected, followed by HPV18 and HPV types 6/11 (Miralles C et al. J Clin Pathol 2009;62:870-8). Over 95\% of invasive penile cancers are SCC and the most common penile SCC histologic sub-types are keratinising (49\%), mixed warty-basaloid (17\%), verrucous (8\%), warty (6\%), and basaloid (4\%). HPV is commonly detected in basaloid and warty tumours but is less common in keratinising and verrucous tumours. In this section, the HPV burden among cases of penile cancer cases and precancerous penile lesions in India are presented.

Table 31: Studies on HPV prevalence among penile cancer cases in India

\begin{tabular}{|l|c|c|c|c|c|} 
Study & $\begin{array}{c}\text { HPV detection method and } \\
\text { targeted HPV types }\end{array}$ & $\begin{array}{c}\text { No. } \\
\text { Tested }\end{array}$ & $\%$ & $(\mathbf{9 5 \%} \text { CI) })^{\mathbf{a}}$ & $\begin{array}{c}\text { Prevalence of } 5 \text { most } \\
\text { frequent HPVs, HPV } \\
\text { type (\%) }\end{array}$ \\
\hline No data available & - & - & - & - & \\
\hline
\end{tabular}

Data updated on 5 Mar 2015 (data as of 30 Jun 2014)

DBH: Dot Blot Hybridization; EIA: Enzyme ImmunoAssay; HC2: Hybrid Capture 2; ISH: In Situ Hybridization; LBA: Line-Blot Assay; LiPA: Line Probe Assay; PCR: Polymerase Chain Reaction; RFLP: Restriction Fragment Length Polymorphism; RLBH: Reverse Line Blot Hybridization; RT-PCR: Real Time Polymerase Chain Reaction; SBH: Southern Blot Hybridization; SPF: Short Primer Fragment; TS: Type Specific;

a $95 \%$ Confidence Interval

Data Sources:

The ICO HPV Information Centre has updated data until June 2014. Reference publications (up to 2008): 1) Bouvard V, Lancet Oncol 2009;10:321 2) Miralles-Guri C,J Clin Pathol 2009;62:870

Table 32: Studies on HPV prevalence among PeIN 2/3 cases in India

\begin{tabular}{|l|c|c|c|c|c|} 
Study & $\begin{array}{c}\text { HPV detection method and } \\
\text { targeted HPV types }\end{array}$ & $\begin{array}{c}\text { No. } \\
\text { Tested }\end{array}$ & $\%$ & $(\mathbf{9 5 \%} \text { CI) })^{\mathbf{a}}$ & $\begin{array}{c}\text { Prevalence of } 5 \text { most } \\
\text { frequent HPVs, HPV } \\
\text { type (\%) }\end{array}$ \\
\hline No data available & - & - & - & - & \\
\hline
\end{tabular}

Data updated on 10 Feb 2015 (data as of 30 Jun 2014)

PeIN 2/3: Penile intraepithelial neoplasia of grade 2/3

DBH: Dot Blot Hybridization; EIA: Enzyme ImmunoAssay; HC2: Hybrid Capture 2; ISH: In Situ Hybridization; LBA: Line-Blot Assay; LiPA: Line Probe Assay; PCR: Polymerase Chain Reaction; RFLP: Restriction Fragment Length Polymorphism; RLBH: Reverse Line Blot Hybridization; RT-PCR: Real Time Polymerase Chain Reaction; SBH: Southern Blot Hybridization; SPF: Short Primer Fragment; TS: Type Specific;

a $95 \%$ Confidence Interval

Data Sources:

The ICO HPV Information Centre has updated data until June 2014. Reference publication (up to 2008): Bouvard V, Lancet Oncol 2009;10:321 
Figure 68: Comparison of the ten most frequent HPV types in cases of penile cancer in Asia and the World

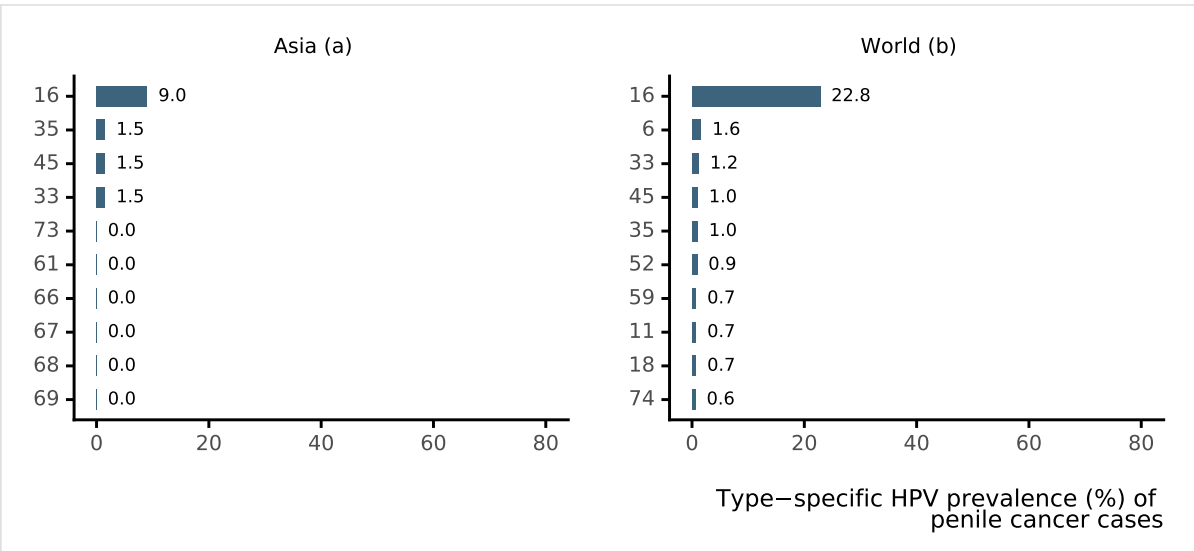

\section{Data updated on 9 Feb 2017 (data as of 30 Jun 2015)}

a Includes cases from Bangladesh, India, South Korea, Lebanon, Philippinesy

b Includes cases from Australia, Bangladesh, India, South Korea, Lebanon, Philippines, Chile, Colombia, Ecuador, Guatemala, Honduras, Mexico, Paraguay, Venezuela and United States, Mozambique, Nigeria, Senegal, Czech Republic, France, Greece, Poland, Portugal, Spain and United Kingdom.

Data Sources:

Alemany L, Eur Urol 2016; 69: 953

Figure 69: Comparison of the ten most frequent HPV types in PeIN 2/3 cases in Asia and the World

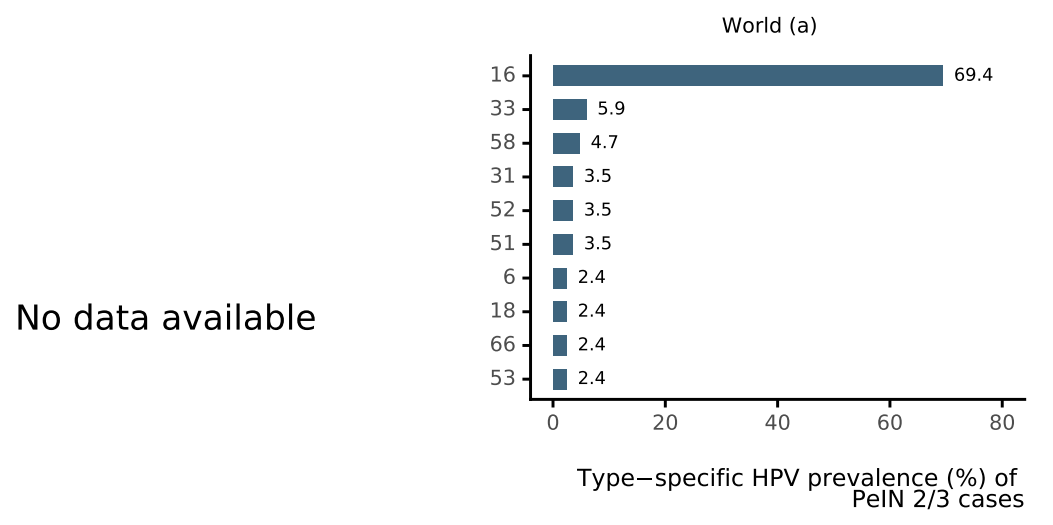

\section{Data updated on 9 Feb 2017 (data as of 30 Jun 2015)}

PeIN 2/3: Penile intraepithelial neoplasia of grade 2/3

a Includes cases from Australia, Bangladesh, India, South Korea, Lebanon, Philippines, Chile, Colombia, Ecuador, Guatemala, Honduras, Mexico, Paraguay, Venezuela, Mozambique, Nigeria, Senegal, Czech Republic, France, Greece, Poland, Portugal, Spain and United Kingdom.

Data Sources:

Balaram P, Int J Cancer 1995; 61: 450 । Bhattacharya N, J Oral Pathol Med 2009; 38: 759 । Chaudhary AK, Virol J 2010; 7: 253 । D’Costa J, Oral Oncol 1998; 34: 413 । Herrero R, J Natl Cancer Inst 2003; 95: 1772 । Laprise C, Int J Cancer 2016; 138: 912 । Mishra A, Int J Cancer 2006; 119: 2840 । Sebastian P, J Oral Pathol Med 2014; 43: 593

Based on systematic reviews and meta-analysis performed by ICO. Reference publications: 1) Ndiaye C, Lancet Oncol 2014; 15: 1319 2) Kreimer AR, Cancer Epidemiol Biomarkers Prev 2005; 14: 467 


\subsection{HPV burden in men}

The information to date regarding anogenital HPV infection is primarily derived from cross-sectional studies of selected populations such as general population, university students, military recruits, and studies that examined husbands of control women, as well as from prospective studies. Special subgroups include mainly studies that examined STD (sexually transmitted diseases) clinic attendees, MSM (men who have sex with men), HIV positive men, and partners of women with HPV lesions, CIN (cervical intraepithelial neoplasia), cervical cancer or cervical carcinoma in situ. Globally, prevalence of external genital HPV infection in men is higher than cervical HPV infection in women, but persistence is less likely. As with genital HPV prevalence, high numbers of sexual partners increase the acquisition of oncogenic HPV infections (Vaccine 2012, Vol. 30, Suppl 5). In this section, the HPV burden among men in India is presented.

\section{Methods}

HPV burden in men was based on published systematic reviews and meta-analyses (Dunne EF, J Infect Dis 2006; 194: 1044, Smith JS, J Adolesc Health 2011; 48: 540, Olesen TB, Sex Transm Infect 2014; 90: 455, and Hebnes JB, J Sex Med 2014; 11: 2630) up to October 31, 2015. The search terms for the review were human papillomavirus, men, polymerase chain reaction (PCR), hybrid capture (HC), and viral DNA. References cited in selected articles were also investigated. Inclusion criteria were: HPV DNA detection by means of PCR or HC (ISH if data are not available for the country), and a detailed description of HPV DNA detection and genotyping techniques used. The number of cases tested and HPV positive cases were extracted for each study to estimate the anogenital prevalence of HPV DNA. Binomial 95\% confidence intervals were calculated for each anogenital HPV prevalence.

Table 33: Studies on HPV prevalence among men in India

\begin{tabular}{|c|c|c|c|c|c|c|c|}
\hline \multirow[b]{2}{*}{ Study } & \multirow[b]{2}{*}{$\begin{array}{c}\text { Anatomic } \\
\text { sites samples }\end{array}$} & \multirow[b]{2}{*}{$\begin{array}{l}\text { HPV detection } \\
\text { method }\end{array}$} & \multirow[b]{2}{*}{ Population } & \multirow[b]{2}{*}{$\begin{array}{c}\text { Age } \\
\text { (years) }\end{array}$} & \multirow[b]{2}{*}{$\begin{array}{c}\text { No. } \\
\text { Tested }\end{array}$} & \multicolumn{2}{|c|}{ HPV Prevalence } \\
\hline & & & & & & $\%$ & $(95 \% \mathrm{CI})^{\mathrm{a}}$ \\
\hline Gupta 2006 & $\begin{array}{c}\text { Coronal sulcus, } \\
\text { distal and } \\
\text { intrameatal } \\
\text { urethra and } \\
\text { glans }\end{array}$ & $\begin{array}{c}\text { PCR-L1 and TS } \\
16,18\end{array}$ & $\begin{array}{l}\text { Partners of women } \\
\text { with normal cytology }\end{array}$ & $\begin{array}{c}\text { Mean } \\
46.9\end{array}$ & 30 & 26.7 & $(12.3-45.9)$ \\
\hline
\end{tabular}

Data updated on 31 Oct 2015 (data as of 31 Oct 2015)

HC2: Hybrid Capture 2; ISH: In Situ Hybridization; PCR: Polymerase Chain Reaction; RT-PCR: Real Time Polymerase Chain Reaction; SPF: Short Primer Fragment; TS: Type Specific; MSM: Men who have sex with men; MSW:Men who have sex with women; STD: sexually transmitted diseases

a $95 \%$ Confidence Interval

Data Sources:

Gupta A, J Clin Virol 2006; 37: 190

Based on published systematic reviews, the ICO HPV Information Centre has updated data until October 2015. Reference publications: 1) Dunne EF, J Infect Dis 2006; 194: 1044 2) Smith JS, J Adolesc Health 2011; 48: 540 3) Olesen TB, Sex Transm Infect 2014; 90: 455 4) Hebnes JB, J Sex Med 2014; 11: 2630.

Table 34: Studies on HPV prevalence among men from special subgroups in India

\begin{tabular}{|c|c|c|c|c|c|c|c|}
\hline \multirow[b]{2}{*}{ Study } & \multirow[b]{2}{*}{$\begin{array}{c}\text { Anatomic } \\
\text { sites samples }\end{array}$} & \multirow[b]{2}{*}{$\begin{array}{l}\text { HPV detection } \\
\text { method }\end{array}$} & \multirow[b]{2}{*}{ Population } & \multirow[b]{2}{*}{$\begin{array}{c}\text { Age } \\
\text { (years) }\end{array}$} & \multirow[b]{2}{*}{$\begin{array}{l}\text { No. } \\
\text { Tested }\end{array}$} & \multicolumn{2}{|c|}{ HPV Prevalence } \\
\hline & & & & & & $\%$ & $(95 \% \mathrm{CI})^{\mathbf{a}}$ \\
\hline Gupta 2006 & $\begin{array}{l}\text { Coronal sulcus, } \\
\text { distal and } \\
\text { intrameatal } \\
\text { urethra and } \\
\text { glans }\end{array}$ & $\begin{array}{c}\text { PCR-L1 and TS } \\
16,18\end{array}$ & $\begin{array}{l}\text { Partners of women } \\
\text { with cervical cancer }\end{array}$ & $\begin{array}{c}\text { Mean } \\
46.4\end{array}$ & 30 & 66.7 & $(47.2-82.7)$ \\
\hline
\end{tabular}

Data updated on 31 Oct 2015 (data as of 31 Oct 2015)

DBH: Dot Blot Hybridization; EIA: Enzyme ImmunoAssay; HC2: Hybrid Capture 2; LiPA: Line Probe Assay; PCR: Polymerase Chain Reaction; RFLP: Restriction Fragment Length Polymorphism; RLH: Reverse Line Hybridisation; RT-PCR: Real Time Polymerase Chain Reaction; SPF: Short Primer Fragment; TS: Type Specific; MSM: Men who have sex with men; MSW:Men who have sex with women; STD: sexually transmitted diseases

a $95 \%$ Confidence Interval

Data Sources:

Data Sources:

Based on published systematic reviews, the ICO HPV Information Centre has updated data until October 2015. Reference publications: 1) Dunne EF, J Infect Dis 2006; 194: 1044 2) Smith Based on published systematic reviews, the ICO HPV Information Centre has updated data until October 2015. Reference
JS, J Adolesc Health 2011; 48: 540 3) Olesen TB, Sex Transm Infect 2014; 90: 455 4) Hebnes JB, J Sex Med 2014; 11: 2630. 


\subsection{HPV burden in the head and neck}

The last evaluation of the International Agency for Research in Cancer (IARC) on the carcinogenicity of HPV in humans concluded that (a) there is enough evidence for the carcinogenicity of HPV type 16 in the oral cavity, oropharynx (including tonsil cancer, base of tongue cancer and other oropharyngeal cancer sites), and (b) limited evidence for laryngeal cancer (IARC Monograph Vol 100B). There is increasing evidence that HPV-related oropharyngeal cancers constitute an epidemiological, molecular and clinical distinct form as compared to non HPV-related ones. Some studies indicate that the most likely explanation for the origin of this distinct form of head and neck cancers associated with HPV is a sexually acquired oral HPV infection that is not cleared, persists and evolves into a neoplastic lesion. Around $30 \%$ of oropharyngeal cancers (which mainly comprises the tonsils and base of tongue sites) are caused by HPV with HPV16 being the most frequent type (de Martel C et al. Int J Cancer 2017;141(4):664670). Attributable fraction varies greatly worldwide, being highest in more developed countries (60\% in Republic of Korea, 51\% in North America, 50\% in Eastern Europe, 46\% in Japan, $42 \%$ in North-Western Europe, $41 \%$ in Australia/New Zealand, 24\% in South Europe, 23\% in China, 22\% in India, and 13\% in elsewhere) (de Martel C et al. Lancet Glob Health 2020;8(2):e180-e190). In this section, the HPV burden in the head and neck in India is presented.

\subsubsection{Burden of oral HPV infection in healthy population}

Table 35: Studies on oral HPV prevalence among healthy in India

\begin{tabular}{|c|c|c|c|c|c|c|c|c|c|}
\hline Study & $\begin{array}{c}\text { Specimen } \\
\text { collection } \\
\text { method / } \\
\text { anatomic site }\end{array}$ & $\begin{array}{c}\text { HPV } \\
\text { detec- } \\
\text { tion } \\
\text { method }^{a}\end{array}$ & Population & $\begin{array}{c}\% \\
\text { males }\end{array}$ & $\begin{array}{c}\text { Age } \\
(\text { years) }\end{array}$ & $\begin{array}{l}\text { No. } \\
\text { tested }^{c}\end{array}$ & $\begin{array}{c}\text { HPV } \\
\text { prevalence \% } \\
(95 \% \mathrm{CI})\end{array}$ & $\begin{array}{c}\text { High-Risk } \\
\text { HPV } \\
\text { prevalence \% } \\
(95 \% \mathrm{CI})\end{array}$ & $\begin{array}{c}5 \text { most } \\
\text { frequent } \\
\text { HPVs, } \\
\text { HPV } \\
\text { type }(\mathbf{n})^{d}\end{array}$ \\
\hline $\begin{array}{l}\text { Herrero } \\
2003\end{array}$ & $\begin{array}{c}\text { Brush/swab \& } \\
\text { oral rinse \& } \\
\text { gargle / Oral } \\
\text { mucosa and } \\
\text { throat }\end{array}$ & $\begin{array}{l}\text { PCR- } \\
\text { GP5+/6+ }\end{array}$ & $\begin{array}{c}\text { Age- } \\
\text { matched } \\
\text { controls }\end{array}$ & 56.9 & $17-78$ & 364 & $4.1(2.5-6.7)$ & - & 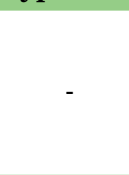 \\
\hline $\begin{array}{l}\text { Koppikar } \\
2005\end{array}$ & $\begin{array}{l}\text { Oral rinse / Oral } \\
\text { mucosa }\end{array}$ & $\begin{array}{l}\text { PCR- } \\
\text { CP } \\
\text { FAP }\end{array}$ & $\begin{array}{c}\text { Age- } \\
\text { matched } \\
\text { controls }\end{array}$ & 80 & - & 102 & $0(0.0-3.6)$ & $0(0.0-3.6)$ & $\begin{array}{c}\text { HPV20 } \\
(2) ; 12(1) ; \\
48 \text { (1); } 23 \\
\text { (1) }\end{array}$ \\
\hline
\end{tabular}

Data updated on 19 Oct 2021 (data as of 19 May 2015)

(95\% CI): 95\% Confidence Interval

$a$ TS: type-specific; RT-PCR: real-time PCR; qPCR: quantitative PCR

$b$ NS: not specified

$c$ number of cases tested for HPV DNA

$d$ number of cases positive for the specific HPV-type

Data Sources:

Herrero R, J Natl Cancer Inst 2003;95(23):1772-83 I Koppikar P, Int J Cancer 2005;113(6):946-50

Systematic review and meta-analysis was performed by ICO HPV Information Centre until May 19, 2015. Reference publication: Mena M et al. J Infect Dis 2019;219(10):1574-1585. 


\subsubsection{HPV burden in head and neck cancers}

Table 36: Studies on HPV prevalence among cases of oral cavity cancer in India

\begin{tabular}{|c|c|c|c|c|c|}
\hline \multirow[b]{2}{*}{ Study } & \multirow[b]{2}{*}{$\begin{array}{l}\text { HPV detection method and } \\
\text { targeted HPV types }\end{array}$} & \multirow[b]{2}{*}{$\begin{array}{l}\text { No. } \\
\text { Tested }\end{array}$} & \multicolumn{2}{|c|}{ HPV Prevalence } & \multirow[b]{2}{*}{$\begin{array}{c}\text { Prevalence of } 5 \text { most } \\
\text { frequent HPVs, HPV type } \\
(\%)\end{array}$} \\
\hline & & & $\%$ & $(95 \% \mathrm{CI})^{\mathbf{a}}$ & \\
\hline \multicolumn{6}{|l|}{ MEN } \\
\hline Balaram 1995 & $\begin{array}{l}\text { MY09/MY11 (L1). GP5+/GP6+ } \\
\text { (L1)/GP17+/GP18+(L1). Y1/Y2 and } \\
\text { TS-PCR for 6/11/16/18 Sequencing }\end{array}$ & 50 & 74 & $(60.4-84.1)$ & - \\
\hline Chaudhary 2010 & $\begin{array}{c}\text { MY09/MY11 (L1) Amplification with } \\
\text { TS primers (16) }\end{array}$ & 146 & 33.6 & $(26.4-41.6)$ & HPV 16 (33.6) \\
\hline D’Costa 1998 & $\begin{array}{c}\text { MY09/MY11 (L1) SBH (6. 11. 16. } 18 . \\
33)\end{array}$ & 71 & 12.7 & $(6.8-22.4)$ & HPV $16(12.7)$ \\
\hline Herrero 2003 & $\begin{array}{l}\text { GP5+/GP6+ (L1) Hybridization with } \\
\text { EIA oligonucleotide probes (2. 6. } 11 . \\
\text { 16. 18. } 31.33 .35 .39 .40 .42 .43 .44 . \\
\text { 45. 51. 52. 56. 58. 59.66.68) }\end{array}$ & 127 & 4.7 & $(2.2-9.9)$ & $\begin{array}{c}\text { HPV } 16(3.9) \text { HPV } 18(0.8) \\
\text { HPV } 35(0.8)\end{array}$ \\
\hline Laprise 2016 & $\begin{array}{l}\text { PCR-PGMY09/11, LBA (HPV 6, 11, } 16, \\
\text { 18, } 26,31,33,35,39,40,42,44,51 \\
\text { 53, 54, 56, 58, 59, 61, 62, 66, 67, 68, } \\
\text { 69, 70, 71, 72, 73, 81, 82, 83, 84, 89) }\end{array}$ & 196 & 0 & - & - \\
\hline \multicolumn{6}{|l|}{ WOMEN } \\
\hline Balaram 1995 & $\begin{array}{c}\text { MY09/MY11 (L1). GP5+/GP6+ } \\
\text { (L1)/GP17+/GP18+ (L1). Y1/Y2 and } \\
\text { TS-PCR for 6/11/16/18 Sequencing }\end{array}$ & 41 & 68.3 & $(53.0-80.4)$ & - \\
\hline Chaudhary 2010 & $\begin{array}{l}\text { MY09/MY11 (L1) Amplification with } \\
\text { TS primers (16) }\end{array}$ & 76 & 30.3 & $(21.1-41.3)$ & HPV 16 (30.3) \\
\hline D’Costa 1998 & $\begin{array}{c}\text { MY09/MY11 (L1) SBH (6. 11. 16. } 18 . \\
33)\end{array}$ & 5 & 20 & $(3.6-62.4)$ & - \\
\hline Herrero 2003 & $\begin{array}{l}\text { GP5+/GP6+ (L1) Hybridization with } \\
\text { EIA oligonucleotide probes (2. 6. } 11 . \\
\text { 16. 18. } 31.33 .35 .39 .40 .42 .43 .44 . \\
\text { 45. 51. 52. 56.58.59.66.68) }\end{array}$ & 135 & 1.5 & $(0.4-5.2)$ & HPV 16 (1.5) HPV 18 (0.7) \\
\hline Laprise 2016 & $\begin{array}{c}\text { PCR-PGMY09/11, LBA (HPV } 6,11,16 \\
\text { 18, } 26,31,33,35,39,40,42,44,51 \\
53,54,56,58,59,61,62,66,67,68 \\
69,70,71,72,73,81,82,83,84,89)\end{array}$ & 154 & 0 & - & - \\
\hline \multicolumn{6}{|c|}{ BOTH OR UNSPECIFIED } \\
\hline Balaram 1995 & $\begin{array}{c}\text { MY09/MY11 (L1). GP5+/GP6+ } \\
\text { (L1)/GP17+/GP18+ (L1). Y1/Y2 and } \\
\text { TS-PCR for 6/11/16/18 Sequencing }\end{array}$ & 91 & 73.6 & $(63.7-81.6)$ & $\begin{array}{l}\text { HPV } 18(47.3) \text { HPV } 16(41.8) \\
\text { HPV } 11(19.8) \text { HPV } 6(14.3)\end{array}$ \\
\hline Bhattacharya 2009 & $\begin{array}{l}\text { MY09/MY11 (L1) Amplification with } \\
\text { TS primers (16. 18) }\end{array}$ & 193 & 62.2 & $(55.2-68.7)$ & HPV 16 (60.1) HPV $18(5.2)$ \\
\hline Chaudhary 2010 & $\begin{array}{l}\text { MY09/MY11 (L1) Amplification with } \\
\text { TS primers (16) }\end{array}$ & 222 & 32.4 & $(26.6-38.8)$ & HPV 16 (32.4) \\
\hline D'Costa 1998 & $\begin{array}{c}\text { MY09/MY11 (L1) SBH (6. 11. 16. } 18 . \\
\text { 33) }\end{array}$ & 99 & 15.2 & $(9.4-23.5)$ & HPV 16 (15.2) \\
\hline Herrero 2003 & $\begin{array}{l}\text { GP5+/GP6+ (L1) Hybridization with } \\
\text { EIA oligonucleotide probes (2. 6. } 11 . \\
\text { 16. 18. } 31.33 .35 .39 .40 .42 .43 .44 . \\
\text { 45. 51. 52.56.58.59.66. 68) }\end{array}$ & 262 & 3.1 & $(1.6-5.9)$ & $\begin{array}{c}\text { HPV } 16(2.7) \text { HPV } 18(0.8) \\
\text { HPV } 35(0.4)\end{array}$ \\
\hline Laprise 2016 & $\begin{array}{l}\text { PCR-PGMY09/11, LBA (HPV } 6,11,16, \\
\text { 18, } 26,31,33,35,39,40,42,44,51 \\
53,54,56,58,59,61,62,66,67,68 \\
69,70,71,72,73,81,82,83,84,89)\end{array}$ & 350 & 0 & - & - \\
\hline Mishra 2006 & $\begin{array}{l}\text { MY09/MY11 (L1) Amplification with } \\
\text { TS primers (16. 18) }\end{array}$ & 66 & 27.3 & $(18.0-39.0)$ & HPV 16 (27.3) \\
\hline Sebastian 2014 & $\begin{array}{c}\text { PCR, LBA (HPV 6, 11, 16, 18, 26, 31, } \\
33,34,35,39,40,42,44,45,51,52 \\
53,54,56,58,59,61,62,66,67,68 \\
69,70,71,72,73,81,82,83,84)\end{array}$ & 22 & 0 & - & - \\
\hline
\end{tabular}

Data updated on 9 May 2016 (data as of 31 Dec 2015)

DBH: Dot Blot Hybridization; EIA: Enzyme ImmunoAssay; HC2: Hybrid Capture 2; ISH: In Situ Hybridization; LBA: Line-Blot Assay; LiPA: Line Probe Assay; PCR: Polymerase Chain Reaction; RFLP: Restriction Fragment Length Polymorphism; RLBH: Reverse Line Blot Hybridization; RT-PCR: Real Time Polymerase Chain Reaction; SBH: Southern Blot Hybridization; SPF: Short Primer Fragment; TS: Type Specific;

SPF: Short Primer Fragment;

Only for European countries

Data Sources:

Balaram P. Int J Cancer 1995; 61: 450 | Bhattacharya N, J Oral Pathol Med 2009; 38: 759 | Chaudhary AK, Virol J 2010; 7: 253 | D’Costa J, Oral Oncol 1998; $34: 413$ । Herrero R, J Nat Cancer Inst 2003; 95: 1772 । Laprise C, Int J Cancer 2016; 138: 912 I Mishra A, Int J Cancer 2006; 119: 2840 । Sebastian P, J Oral Pathol Med 2014; 43: 593

Based on systematic reviews and meta-analysis performed by ICO. Reference publications: 1) Ndiaye C, Lancet Oncol 2014; 15: 1319 2) Kreimer AR, Cancer Epidemiol Biomarkers Prev 2005; 14: 467 
Table 37: Studies on HPV prevalence among cases of oropharyngeal cancer in India

\begin{tabular}{|c|c|c|c|c|c|}
\hline \multirow[b]{2}{*}{ Study } & \multirow[b]{2}{*}{$\begin{array}{l}\text { HPV detection method and } \\
\text { targeted HPV types }\end{array}$} & \multirow[b]{2}{*}{$\begin{array}{l}\text { No. } \\
\text { Tested }\end{array}$} & \multicolumn{2}{|c|}{ HPV Prevalence } & \multirow[b]{2}{*}{$\begin{array}{c}\text { Prevalence of } 5 \text { most } \\
\text { frequent HPVs, HPV type } \\
(\%)\end{array}$} \\
\hline & & & $\%$ & $(95 \% \mathrm{CI})^{\mathrm{a}}$ & \\
\hline \multicolumn{6}{|r|}{$x^{2}(5)$} \\
\hline No data available & - & - & - & - & - \\
\hline \multicolumn{6}{|l|}{ WOMEN } \\
\hline No data available & - & - & - & - & - \\
\hline \multicolumn{6}{|c|}{ BOTH OR UNSPECIFIED } \\
\hline No data available & - & - & - & - & - \\
\hline
\end{tabular}

\section{Data updated on 9 May 2016 (data as of 31 Dec 2015)}

DBH: Dot Blot Hybridization; EIA: Enzyme ImmunoAssay; HC2: Hybrid Capture 2; ISH: In Situ Hybridization; LBA: Line-Blot Assay; LiPA: Line Probe Assay; PCR: Polymerase Chain Reaction; RFLP: Restriction Fragment Length Polymorphism; RLBH: Reverse Line Blot Hybridization; RT-PCR: Real Time Polymerase Chain Reaction; SBH: Southern Blot Hybridization; SPF: Short Primer Fragment; TS: Type Specific

Only for European countries
$a$ 95\% Confidence Interval

Data Sources:

Based on systematic reviews and meta-analysis performed by ICO. Reference publications: 1) Ndiaye C, Lancet Oncol 2014; 15: 1319 2) Kreimer AR, Cancer Epidemiol Biomarkers Prev 2005; 14: 467

Table 38: Studies on HPV prevalence among cases of hypopharyngeal or laryngeal cancer in India

\begin{tabular}{|c|c|c|c|c|c|}
\hline \multirow[b]{2}{*}{ Study } & \multirow[b]{2}{*}{$\begin{array}{l}\text { HPV detection method and } \\
\text { targeted HPV types }\end{array}$} & \multirow[b]{2}{*}{$\begin{array}{l}\text { No. } \\
\text { Tested }\end{array}$} & \multicolumn{2}{|c|}{ HPV Prevalence } & \multirow[b]{2}{*}{$\begin{array}{c}\text { Prevalence of } 5 \text { most } \\
\text { frequent HPVs, HPV type } \\
(\%)\end{array}$} \\
\hline & & & $\%$ & $(95 \% \mathrm{CI})^{\mathrm{a}}$ & \\
\hline \multicolumn{6}{|l|}{ MEN } \\
\hline No data available & - & - & - & - & - \\
\hline \multicolumn{6}{|l|}{ WOMEN } \\
\hline No data available & - & - & - & - & - \\
\hline \multicolumn{6}{|c|}{ BOTH OR UNSPECIFIED } \\
\hline Jacob 2002 & $\begin{array}{l}\text { TS-PCR E1 for } 6 / 11 / 18 \text { and L1 for } 16 \\
\text { SBH with TS probes (6. } 11.16 .18)\end{array}$ & 44 & 34.1 & $(21.9-48.9)$ & HPV 16 (34.1) \\
\hline
\end{tabular}

\section{Data updated on 9 May 2016 (data as of 31 Dec 2015)}

DBH: Dot Blot Hybridization; EIA: Enzyme ImmunoAssay; HC2: Hybrid Capture 2; ISH: In Situ Hybridization; LBA: Line-Blot Assay; LiPA: Line Probe Assay; PCR: Polymerase Chain Reaction; RFLP: Restriction Fragment Length Polymorphism; RLBH: Reverse Line Blot Hybridization; RT-PCR: Real Time Polymerase Chain Reaction; SBH: Southern Blot Hybridization; SPF: Short Primer Fragment; TS: Type Specific

Only for European countries

a $95 \%$ Confidence Interval

Data Sources:

Jacob SE, J Surg Oncol 2002; 79: 142

Based on systematic reviews and meta-analysis performed by ICO. Reference publications: 1) Ndiaye C, Lancet Oncol 2014; 15: 1319 2) Kreimer AR, Cancer Epidemiol Biomarkers Prev 2005; 14: 467 


\section{Factors contributing to cervical cancer}

HPV is a necessary cause of cervical cancer, but it is not a sufficient cause. Other cofactors are necessary for progression from cervical HPV infection to cancer. Tobacco smoking, high parity, long-term hormonal contraceptive use, and co-infection with HIV have been identified as established cofactors. Co-infection with Chlamydia trachomatis and herpes simplex virus type-2, immunosuppression, and certain dietary deficiencies are other probable cofactors. Genetic and immunological host factors and viral factors other than type, such as variants of type, viral load and viral integration, are likely to be important but have not been clearly identified. (Muñoz N, Vaccine 2006; 24(S3): 1-10). In this section, the prevalence of smoking, parity (fertility), oral contraceptive use, and HIV in India are presented.

Table 39: Factors contributing to cervical carcinogenesis (cofactors) in India

\begin{tabular}{|c|c|c|c|c|}
\hline & MALE & FEMALE & TOTAL \\
\hline \multicolumn{5}{|l|}{ Smoking } \\
\hline \multirow{2}{*}{$\begin{array}{l}\text { Smoking of any tobacco adjusted } \\
\text { prevalence }(\%)[95 \% \text { UI] }\end{array}$} & Current $^{\mathrm{a}}$ & $20[14.9-26.1]$ & $1.7[1.3-2.2]$ & $11.1[8.3-14.5]$ \\
\hline & Daily $^{b}$ & $17.5[13-22.4]$ & $1.4[1-1.9]$ & $\begin{array}{c}9.69999999999999 \\
{[7.2-12.5]}\end{array}$ \\
\hline \multirow{2}{*}{$\begin{array}{l}\text { Cigarette smoking adjusted } \\
\text { prevalence (\%) [95\% UI] }\end{array}$} & Current $^{\mathrm{c}}$ & 20 [14.9-26.1] & $1.7[1.3-2.2]$ & $11.1[8.3-14.5]$ \\
\hline & Daily $^{\mathrm{d}}$ & $17.5[13-22.4]$ & $1.4[1-1.9]$ & $\begin{array}{c}9.69999999999999 \\
{[7.2-12.5]}\end{array}$ \\
\hline
\end{tabular}

Parity

Total fertility rate per woman

Age-specific fertility rate (per 1000 women)

\begin{tabular}{l|c|c|c} 
& - & 2.3 & - \\
\hline $15-19$ yrs & - & - & - \\
\hline $20-24$ yrs & - & - & - \\
\hline $25-29$ yrs & - & - & - \\
\hline $30-34$ yrs & - & - & - \\
\hline $35-39$ yrs & - & - & - \\
\hline $40-44$ yrs & - & - & - \\
\hline $45-49$ yrs & - & - & \\
\hline
\end{tabular}

\section{Hormonal contraception}

Oral contraceptive use (\%) among women who are married or in union

Injectable contraception use (\%) among women who are married or in union

Implant contraceptive use (\%) among women who are married or in union

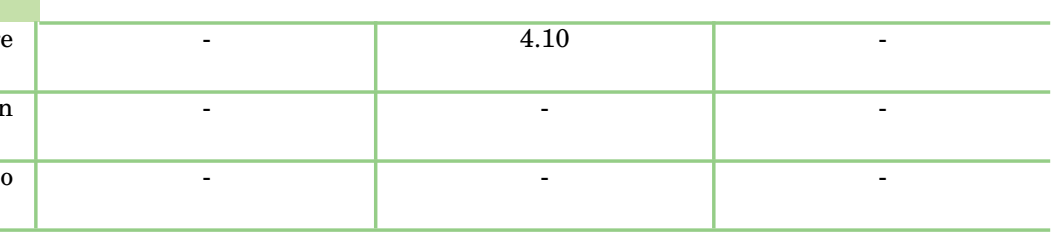

\section{HIV}

Estimated percent of adults aged 15-49 who are living with HIV [95\% UI]

Estimated percent of young adults aged 15-24 who are living with HIV [95\% UI]

HIV prevalence (\%) among sex workers

HIV prevalence (\%) among men who have sex with men $^{1}$

Estimated number of people living with HIV [95\% UI]

Estimated number of adults (15+ yrs) living with HIV [95\% UI]

Estimated number of AIDS-related deaths [95\% UI]

\begin{tabular}{|c|c|c|}
\hline - [-] & - [-] & $-[-]$ \\
\hline$-[-]$ & - [-] & $-[-]$ \\
\hline - & 1.6 & 1.6 \\
\hline 2.7 & - & 2.7 \\
\hline - & - & $-[-]$ \\
\hline$-[-]$ & $-[-]$ & $-[-]$ \\
\hline- & - & $-[-]$ \\
\hline
\end{tabular}

\section{Data accessed on 12 Nov 2019}

Crude adjusted prevalence (\%) estimates of tabacco use among people aged >> 15 years by country, for the year 2016 .

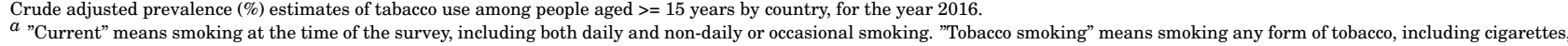
$a$ "Current" means smoking at the time of the survey, including both daily and non-daily or
cigars, pipes, or any other smoked tobacco products and excluding smokeless products.

$b$ "Daily" means smoking every day at the time of the survey. "Tobacco smoking" means smoking any form of tobacco, including cigarettes, cigars, pipes, or any other smoked tobacco products and excluding smokeless products.

$c$ "Current" means smoking at the time of the survey, including both daily and non-daily or occasional smoking.

$d$ "Daily" means smoking every day at the time of the survey.

Year of estimate: 2016

Data Sources:

WHO global report on trends in prevalence of tobacco use 2000-2025, third edition. Geneva: World Health Organization; 2019. Available at https://www .who.int/publications/i/ WHO global report on trends in prevalence of tobacco use 2000-2025, third edition. Geneva: World Health

United Nations, Department of Economic and Social Affairs, Population Division (2019). World Contraceptive Use 2019 (POP/DB/CP/Rev2019). https://www.un.org/en/development/ Unsa/population/publications/dataset/contraception/wcu2019. asp. Available at: [Accessed on November 18, 2019].

UNAIDS database [internet]. Available at: http://aidsinfo.unaids .org/ [Accessed on November 21, 2019]

${ }^{1}$ HIV Sentinel Surveillance 2016-17 


\section{Sexual and reproductive health behaviour indicators}

Sexual intercourse is the primary route of transmission of genital HPV infection. Information about sexual and reproductive health behaviours is essential to the design of effective preventive strategies against anogenital cancers. In this section, we describe sexual and reproductive health indicators that may be used as proxy measures of risk for HPV infection and anogenital cancers. Several studies have reported that earlier sexual debut is a risk factor for HPV infection, although the reason for this relationship is still unclear. In this section, information on sexual and reproductive health behaviour in India are presented.

Table 40: Percentage of 15-year-olds who have had sexual intercourse in India

\begin{tabular}{|c|c|c|}
\hline Indicator & Male & Female \\
\hline Percentage of 15-year-old subjects who report sexual intercourse & 2.7 & 8.0 \\
\hline
\end{tabular}

Data accessed on 16 Mar 2017

Please refer to original source for methods of estimation

Percentage of all 15- to 19-year-olds who report having had sex before the age of 15 years.

Year of estimation: 2005-2006

Data Sources:

ICF International, 2015. The DHS (Demographic and Health Surveys) Program STATcompiler. Funded by USAID. http://www . statcompiler.com. Accessed on March 162017.

Table 41: Median age at first sex in India

\begin{tabular}{|c|c|c|c|c|c|c|c|c|}
\hline \multirow[b]{2}{*}{ Study } & \multirow[b]{2}{*}{ Year/period } & \multirow[b]{2}{*}{$\begin{array}{c}\text { Birth } \\
\text { cohort } \mathbf{N}\end{array}$} & \multicolumn{2}{|r|}{ MALE } & \multicolumn{2}{|c|}{ FEMALE } & \multicolumn{2}{|c|}{ TOTAL } \\
\hline & & & $\mathbf{N}$ & $\begin{array}{l}\text { Median age } \\
\text { at first sex }\end{array}$ & $\mathbf{N}$ & $\begin{array}{l}\text { Median age } \\
\text { at first sex }\end{array}$ & $\mathbf{N}$ & $\begin{array}{l}\text { Median age } \\
\text { at first sex }\end{array}$ \\
\hline India DHS 2005-06 & 2006 & - & - & - & - & 17.8 & - & - \\
\hline
\end{tabular}

Data accessed on 16 Mar 2017

Please refer to original source for methods of estimation

Median age at first sexual intercourse for women aged 20-49; Median age at first sexual intercourse for men aged 20-49(54,59).

Data Sources:

ICF International, 2015. The DHS (Demographic and Health Surveys) Program STATcompiler. Funded by USAID. http://www . statcompiler. com. Accessed on March 162017. 
Table 42: Marriage patterns in India

\begin{tabular}{|c|c|c|c|}
\hline Indicator & & Male & Female \\
\hline Average age at first marriage ${ }^{1}$ & & 24.9 & 20.7 \\
\hline \multirow{13}{*}{ Age-specific $\%$ of ever married ${ }^{2}$} & $15-19$ years & 2.73 & 16.38 \\
\hline & 20-24 years & 24.7 & 67.23 \\
\hline & $25-29$ years & 63.9 & 91.5 \\
\hline & $30-34$ years & 88.3 & 97.5 \\
\hline & $35-39$ years & 95.8 & 98.7 \\
\hline & 40-44 years & 97.7 & 98.9 \\
\hline & $45-49$ years & 98.15 & 99.1 \\
\hline & $50-54$ years & 98.52 & 98.92 \\
\hline & $55-59$ years & 98.67 & 99.03 \\
\hline & $60-64$ years & 98.64 & 98.93 \\
\hline & $65-69$ years & 99.01 & 98.8 \\
\hline & 70-74 years & 98.79 & 98.99 \\
\hline & +75 & 98.6 & 98.86 \\
\hline
\end{tabular}

Data accessed on 20 Feb 2020

Please refer to original source for methods of estimation.

a 2015-2016 NFHS

$b$ DHS_HH

${ }^{c}$ DHS_STATcompiler

Data Sources:

1 The world bank: health nutrition and population statistics. Updated 20-Dec-2019. Accessed on February 20 2020. Available at http://data.worldbank.org/data-catalog/ health-nutrition-and-population-statistics

2 United Nations, Department of Economic and Social Affairs, Population Division (2019). World Marriage Data 2019 (POP/DB/Marr/Rev2019). Available at: https ://population. un . org/MarriageData/Index.html\#/home Accessed on February 24, 2020

Table 43: Average number of sexual partners in India

\begin{tabular}{|l|c|c|c|c|c|c|} 
Study & Period of estimate & Year/Period & Birth cohort & $\begin{array}{c}\text { Male } \\
\text { Mean(N) }\end{array}$ & $\begin{array}{c}\text { Female } \\
\text { Mean(N) }\end{array}$ & $\begin{array}{c}\text { Total } \\
\text { Mean(N) }\end{array}$ \\
\hline- & - & - & - & $-(-)$ & $-(-)$ & $-(-)$
\end{tabular}

Data accessed on 8 Aug 2013

Please refer to original source for methods of estimation 
Table 44: Lifetime prevalence of anal intercourse among women in India

\begin{tabular}{l|c|c|c|c|c|c} 
Study & Year/Period & $\begin{array}{c}\text { Birth } \\
\text { cohort }\end{array}$ & N surveyed & N sexual active & $\begin{array}{c}\% \text { among sexually } \\
\text { active }\end{array}$ \\
\hline- & - & - & - & -
\end{tabular}

Data accessed on 8 Aug 2013

Please refer to original source for methods of estimation 


\section{HPV preventive strategies}

It is established that well-organised cervical screening programmes or widespread good quality cytology can reduce cervical cancer incidence and mortality. The introduction of HPV vaccination could also effectively reduce the burden of cervical cancer in the coming decades. This section presents indicators on basic characteristics and performance of cervical cancer screening, status of HPV vaccine licensure and introduction in India.

\subsection{Cervical cancer screening practices}

Screening strategies differ between countries. Some countries have population-based programmes, where in each round of screening women in the target population are individually identified and invited to attend screening. This type of programme can be implemented nationwide or only in specific regions of the country. In opportunistic screening, invitations depend on the individual's decision or on encounters with health-care providers. The most frequent method for cervical cancer screening is cytology, and there are alternative methods such as HPV DNA tests and visual inspection with acetic acid (VIA). VIA is an alternative to cytology-based screening in low-resource settings (the 'see and treat' approach). HPV DNA testing is being introduced into some countries as an adjunct to cytology screening ('co-testing') or as the primary screening test to be followed by a secondary, more specific test, such as cytology.

Table 45: Main characteristics of cervical cancer screening in India

\begin{tabular}{|l|c|c|c|c|} 
Region & $\begin{array}{c}\text { Existence of official } \\
\text { national } \\
\text { recommendations }\end{array}$ & $\begin{array}{c}\text { Starting year of } \\
\text { current } \\
\text { recommendations }\end{array}$ & $\begin{array}{c}\text { Active invitation } \\
\text { to screening }\end{array}$ & $\begin{array}{c}\text { Screening ages (years), } \\
\text { primary screening test used, } \\
\text { and screening interval or } \\
\text { frequency of screenings }\end{array}$ \\
\hline India & Yes & 2016 & No & $30-65$ (VIA, 5 years) \\
\hline
\end{tabular}

\section{Data accessed on 31 Aug 2022}

Data Sources:

Bruni L, Serrano B, Roura E, Alemany L, Cowan M, Herrero R, et al. Cervical cancer screening programmes and age-specific coverage estimates for 202 countries and territories worldwide: a review and synthetic analysis. Lancet Glob Health. 2022;10(8):e1115. 
Figure 70: Estimated coverage* of cervical cancer screening in India

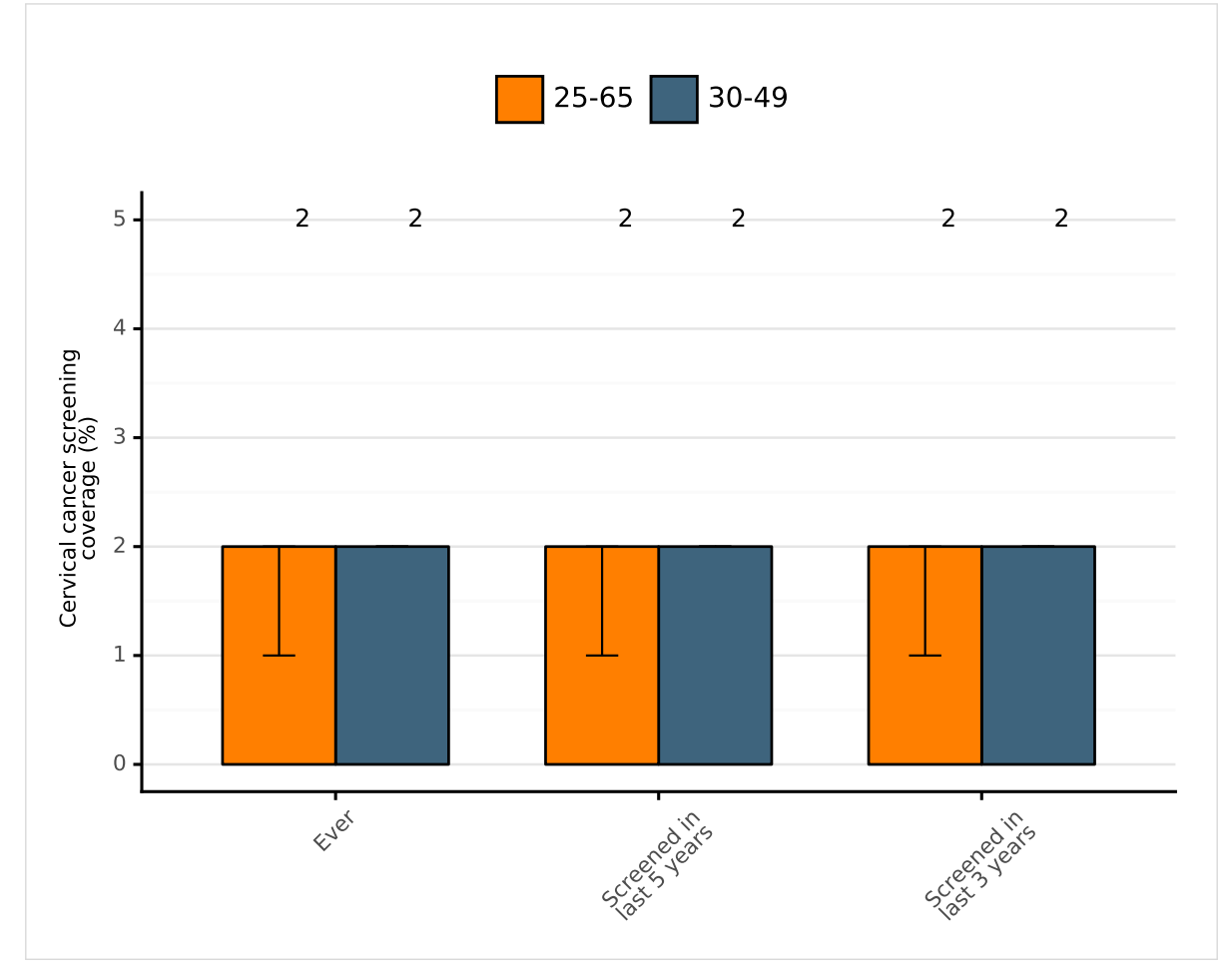

Data accessed on 31 Aug 2022

* Estimated coverage and 95\% confidence interval in 2019

Data Sources:

Bruni L, Serrano B, Roura E, Alemany L, Cowan M, Herrero R, et al. Cervical cancer screening programmes and age-specific coverage estimates for 202 countries and territories worldwide: a review and synthetic analysis. Lancet Glob Health. 2022;10(8):e1115. 


\subsection{HPV vaccination}

Table 46: National HPV Immunization programme in India

\begin{tabular}{|c|c|c|}
\hline & Female & Male \\
\hline HPV vaccination programme & $\begin{array}{l}\text { Not Available/Not } \\
\text { Introduced }\end{array}$ & $\begin{array}{l}\text { Not Available/Not } \\
\text { Introduced }\end{array}$ \\
\hline Year of introduction & - & - \\
\hline Year of estimation of HPV vaccination coverage & - & - \\
\hline HPV coverage - first dose $(\%)$ & - & - \\
\hline HPV coverage - last dose $(\%)$ & - & - \\
\hline
\end{tabular}

\section{Data accessed on 24 Oct 2022}

Data Sources:

Human papillomavirus (HPV) vaccination coverage. World Health Organization. 2022. Available from: https://immunizationdata.who.int/pages/coverage/hpv.html, accessed [24

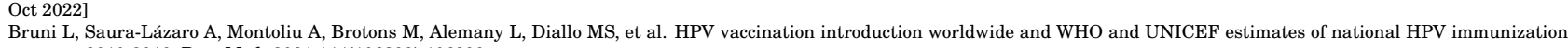
coverage 2010-2019. Prev Med. 2021;144(106399):106399.

Figure 71: HPV vaccination coverage in females by year in India

No data available

Human papillomavirus (HPV) vaccination coverage. World Health Organization. 2022. Available from: https://immunizationdata.who.int/pages/coverage/hpv.html, accessed [24 Oct 2022]

Bruni L, Saura-Lázaro A, Montoliu A, Brotons M, Alemany L, Diallo MS, et al. HPV vaccination introduction worldwide and WHO and UNICEF estimates of national HPV immunization coverage 2010-2019. Prev Med. 2021;144(106399):106399. 
Figure 72: HPV vaccination coverage in males by year in India

No data available

\section{Data accessed on 24 Oct 2022}

Data Sources:

Human papillomavirus (HPV) vaccination coverage. World Health Organization. 2022. Available from: https://immunizationdata.who.int/pages/coverage/hpv.html, accessed [24 Oct 2022]

Bruni L, Saura-Lázaro A, Montoliu A, Brotons M, Alema coverage 2010-2019. Prev Med. 2021;144(106399):106399. 


\section{Protective factors for cervical cancer}

Male circumcision and the use of condoms have shown a significant protective effect against HPV transmission.

Table 47: Prevalence of male circumcision in India

\begin{tabular}{|c|c|c|}
\hline Reference & Prevalence \% (95\% CI) & Methods \\
\hline Drain 2006 & $<20$ & $\begin{array}{c}\text { Data from Demographic and Health } \\
\text { Surveys (DHS) and other publications to } \\
\text { categorize the country-wide prevalence of } \\
\text { male circumcision as }<20 \%, 20-80 \% \text {, or } \\
>80 \% \text {. }\end{array}$ \\
\hline WHO 2007 & $<20$ & $\begin{array}{l}\text { Data from Demographic and Health } \\
\text { Surveys (DHS) and other publications to } \\
\text { categorize the country-wide prevalence of } \\
\text { male circumcision as }<20 \%, 20-80 \% \text {, or } \\
>80 \% .\end{array}$ \\
\hline 2006 DHS & 12.8 & $\begin{array}{c}\text { Data from } 2006 \text { Demographic and Health } \\
\text { Surveys (DHS) }\end{array}$ \\
\hline
\end{tabular}

\section{Data accessed on 31 Aug 2015}

Please refer to country-specific reference(s) for full methodologies.

Data Sources: 2006 Demographic and Health Surveys (DHS) I Drain PK, BMC Infect Dis 2006; 6: 172 I WHO 2007: Male circumcision: Global trends and determinants of prevalence, safety and acceptability

Based on systematic reviews and meta-analysis performed by ICO. The ICO HPV Information Centre has updated data until August 2015. Reference publication: Albero G, Sex Transm Dis. 2012 Feb;39(2):104-13

Table 48: Prevalence of condom use in India

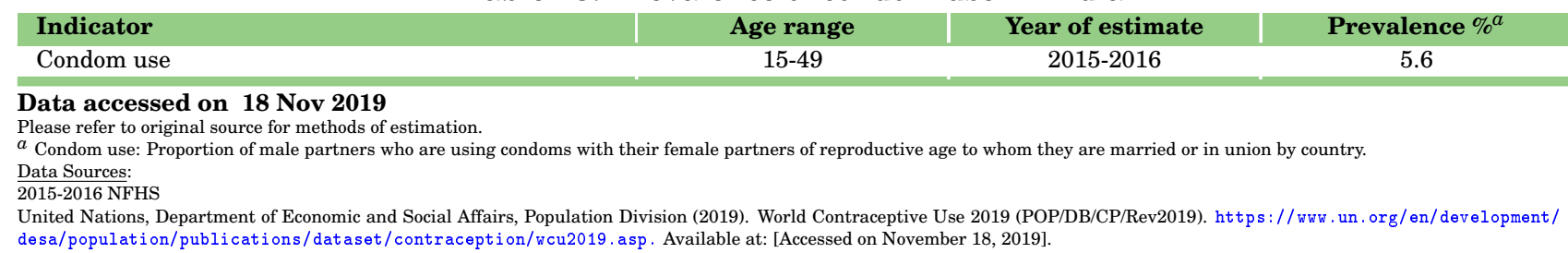




\section{Annex}

\subsection{Incidence}

\subsubsection{Cervical cancer incidence in India across Southern Asia}

Figure 73: Age-standardised incidence rates of cervical cancer of India (estimates for 2020)

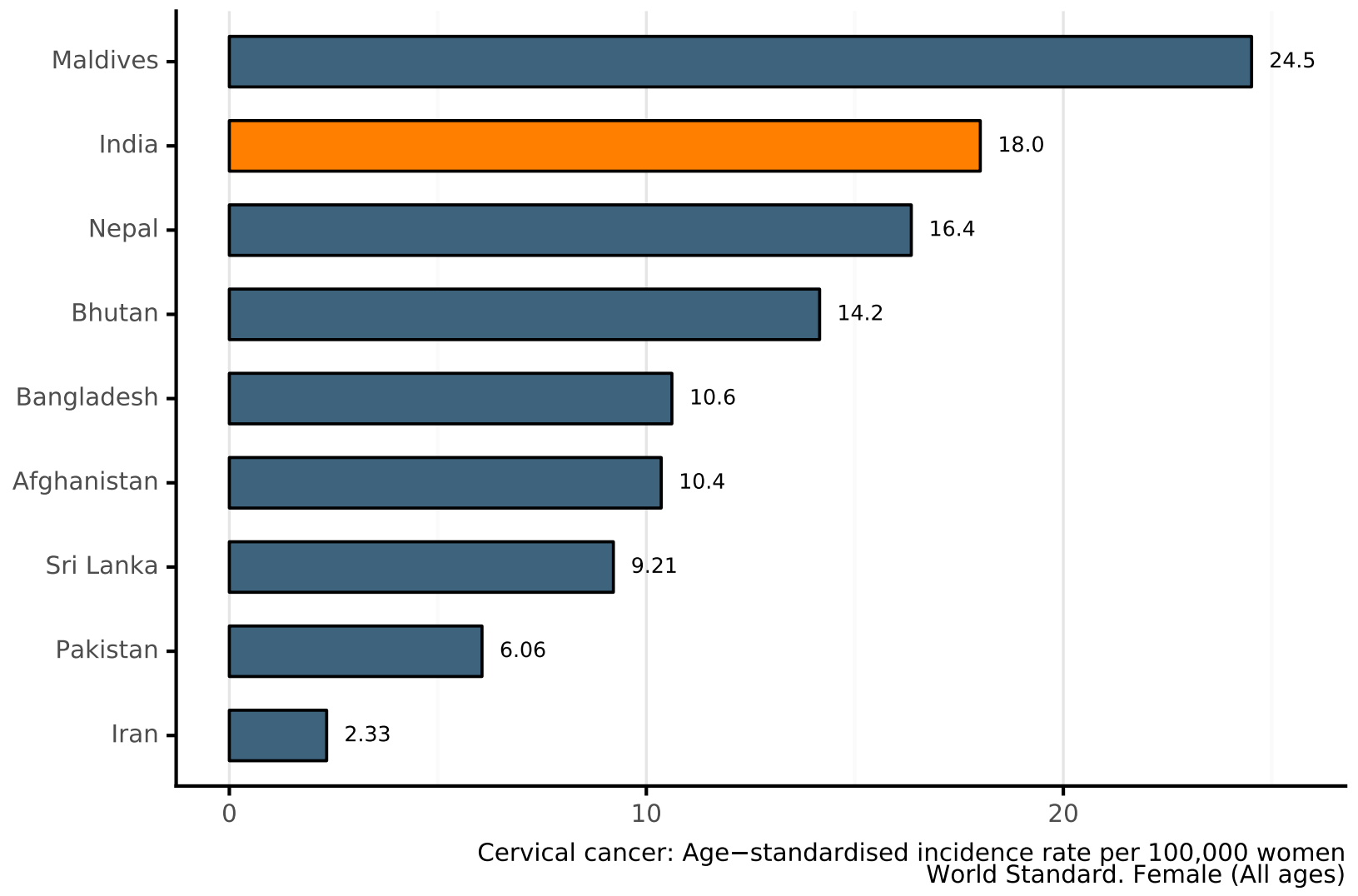

Data accessed on 27 Jan 2021

For more detailed methods of estimation please refer to http://gco.iarc.fr/today/data-sources-methods

For more detailed methods of estimation
Rates per 100,000 women per year.

Data Sources:

Ferlay J, Ervik M, Lam F, Colombet M, Mery L, Piñeros M, Znaor A, Soerjomataram I, Bray F (2020). Global Cancer Observatory: Cancer Today. Lyon, France: International Agency for Research on Cancer. Available from: https://gco.iarc.fr/today, accessed [27 January 2021]. 
Figure 74: Annual number of new cases of cervical cancer by age group in India (estimates for 2020)

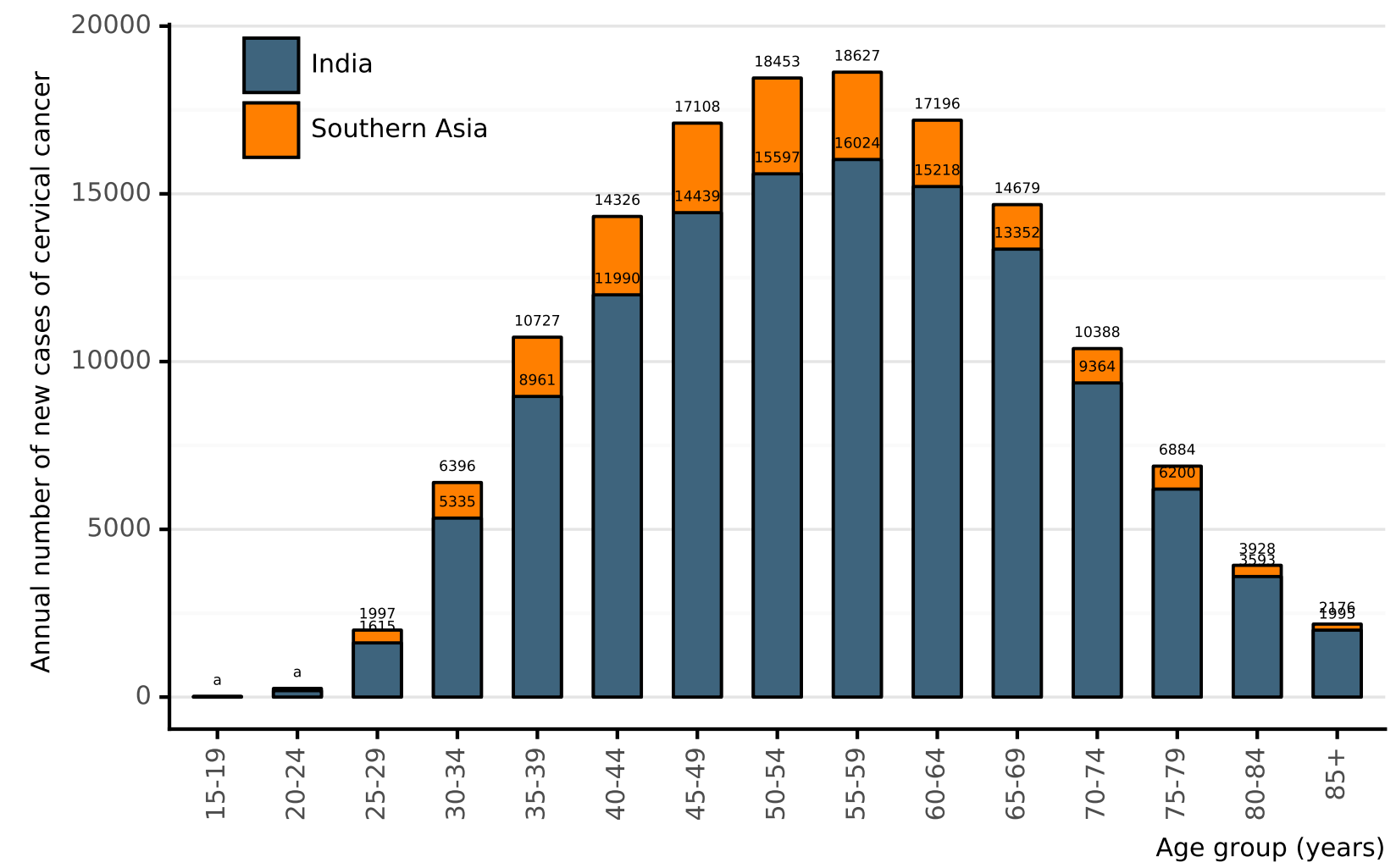

Data accessed on 27 Jan 2021

For more detailed methods of estimation please refer to http://gco.iarc.fr/today/data-sources-methods

${ }^{a} 15$ cases for India and 21 cases for Southern Asia in the 15-19 age group. 191 cases for India and 258 cases for Southern Asia in the 20-24 age group

Ferlay J, Ervik M, Lam F, Colombet M, Mery L, Piñeros M, Znaor A, Soerjomataram I, Bray F (2020). Global Cancer Observatory: Cancer Today. Lyon, France: International Agency for Research on Cancer. Available from: https://gco.iarc.fr/today, accessed [27 January 2021]. 
Figure 75: Comparison of age-specific cervical cancer incidence rates in India, within the region, and the rest of world

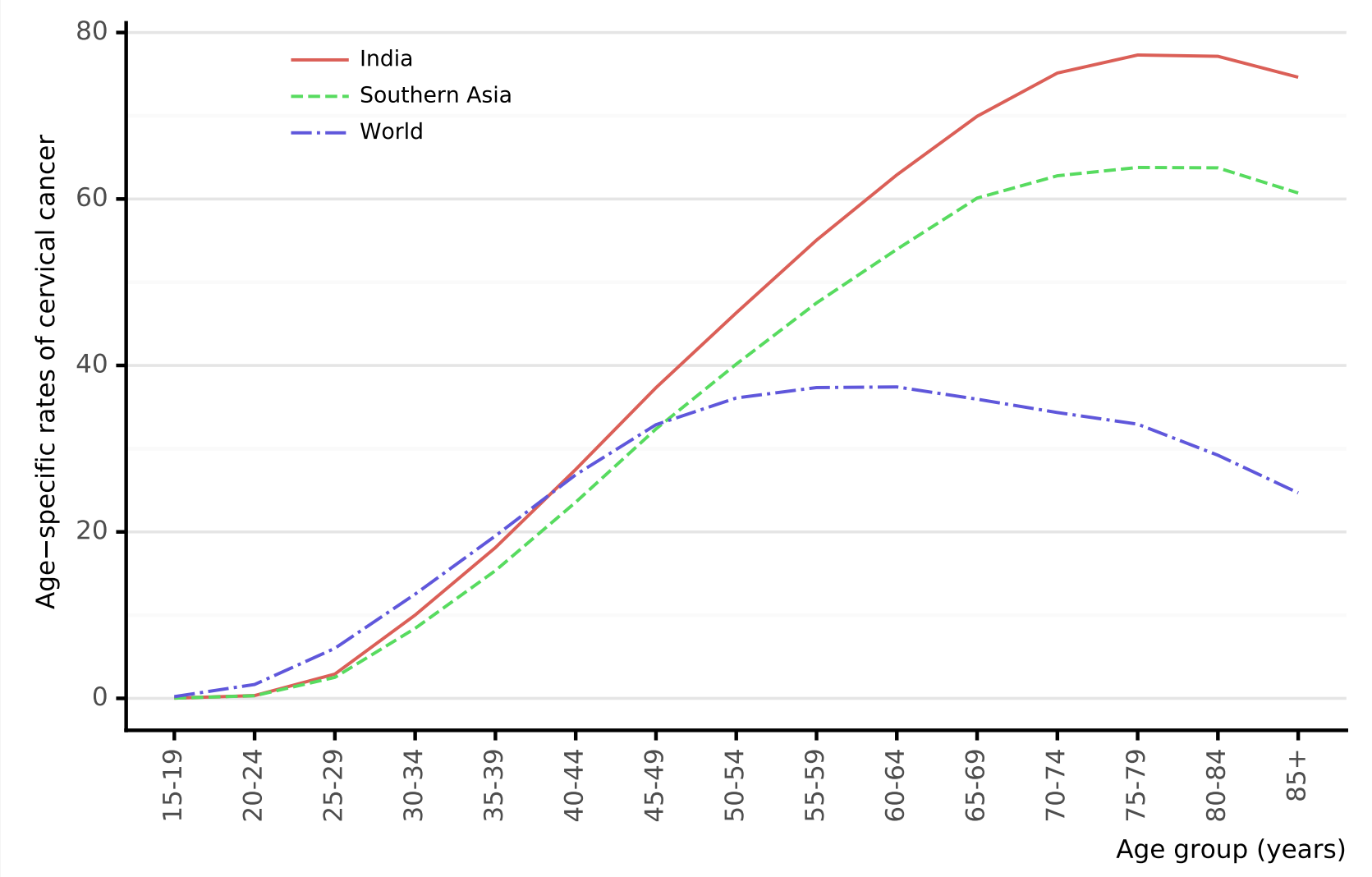

Data accessed on 27 Jan 2021

For more detailed methods of estimation please refer to http://gco.iarc.fr/today/data-sources-methods

$a$ Rates per 100,000 women per year.

Data Sources:

Ferlay J, Ervik M, Lam F, Colombet M, Mery L, Piñeros M, Znaor A, Soerjomataram I, Bray F (2020). Global Cancer Observatory: Cancer Today. Lyon, France: International Agency for Research on Cancer. Available from: https://gco.iarc.fr/today, accessed [27 January 2021]. 


\subsubsection{Anal cancer incidence in India across Southern Asia}

Figure 76: Age-standardised incidence rates of anal cancer of India (estimates for 2020)

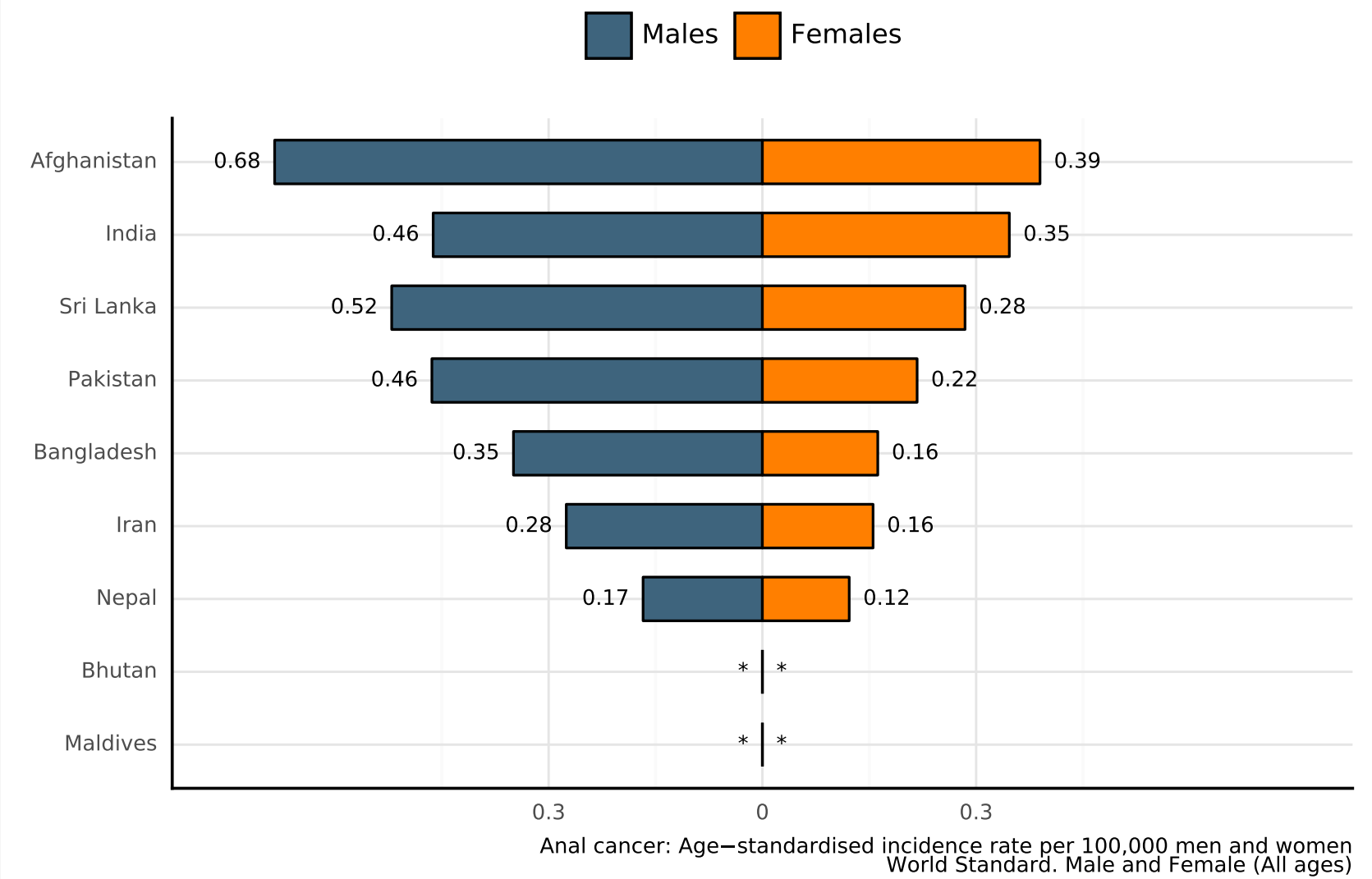

Data accessed on 27 Jan 2021

For more detailed methods of estimation please refer to http://gco.iarc.fr/today/data-sources-methods

${ }^{a}$ Rates per 100,000 men per year.

${ }^{b}$ Rates per 100,000 women per year

* Rates are not available

Data Sources:

Ferlay J, Ervik M, Lam F, Colombet M, Mery L, Piñeros M, Znaor A, Soerjomataram I, Bray F (2020). Global Cancer Observatory: Cancer Today. Lyon, France: International Agency for Research on Cancer. Available from: https://gco.iarc.fr/today, accessed [27 January 2021]. 
Figure 77: Annual number of new cases of anal cancer among men by age group in India (estimates for 2020)

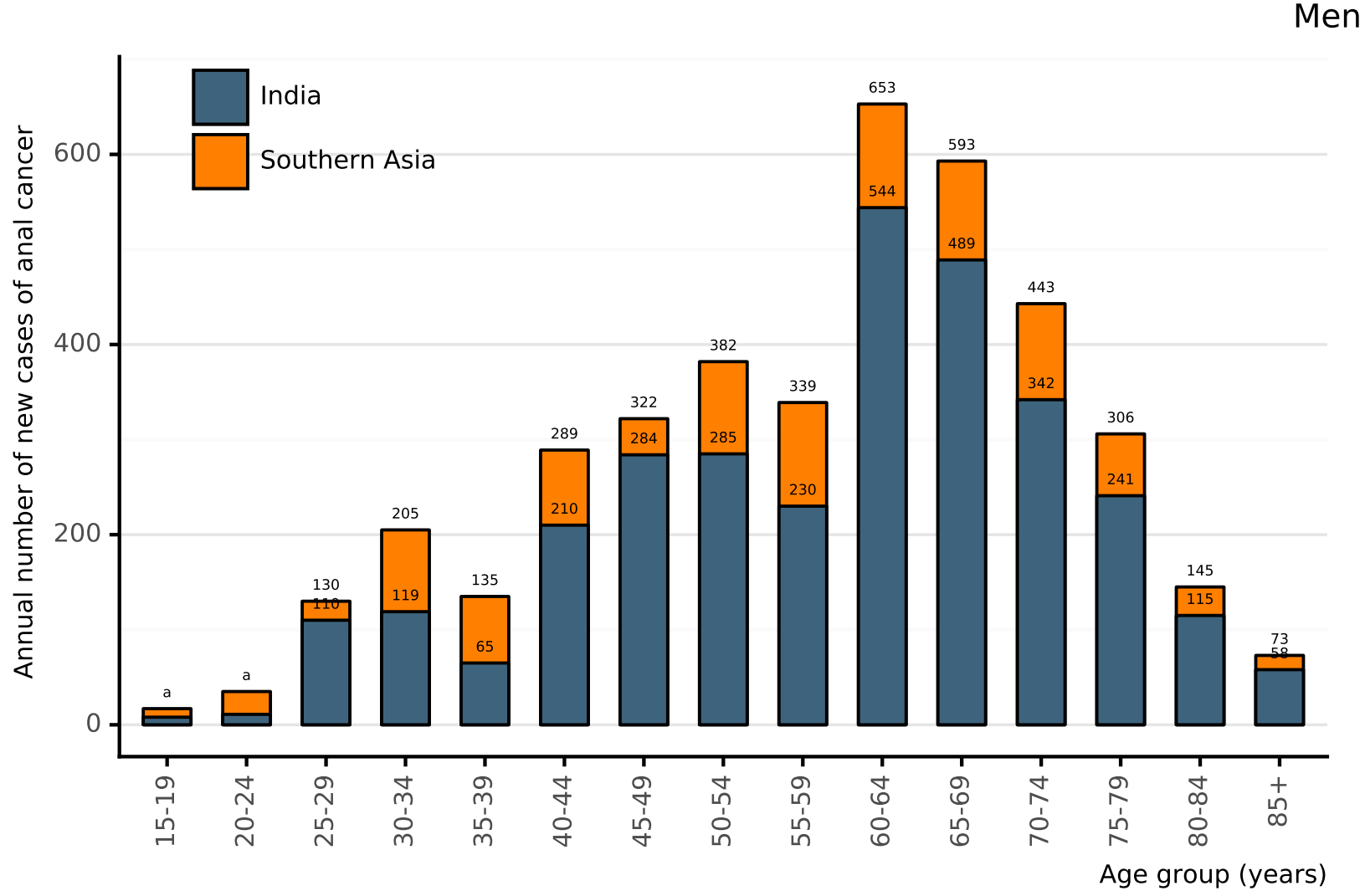

Data accessed on 27 Jan 2021

For more detailed methods of estimation please refer to http://gco.iarc.fr/today/data-sources-methods

$a 8$ cases for India and 17 cases for Southern Asia in the 15-19 age group. 11 cases for India and 35 cases for Southern Asia in the 20-24 age group.

Research on Cancer. Available from: https ://gco.iarc.fr/today, accessed [27 January 2021]. 
Figure 78: Annual number of new cases of anal cancer among women by age group in India (estimates for 2020)

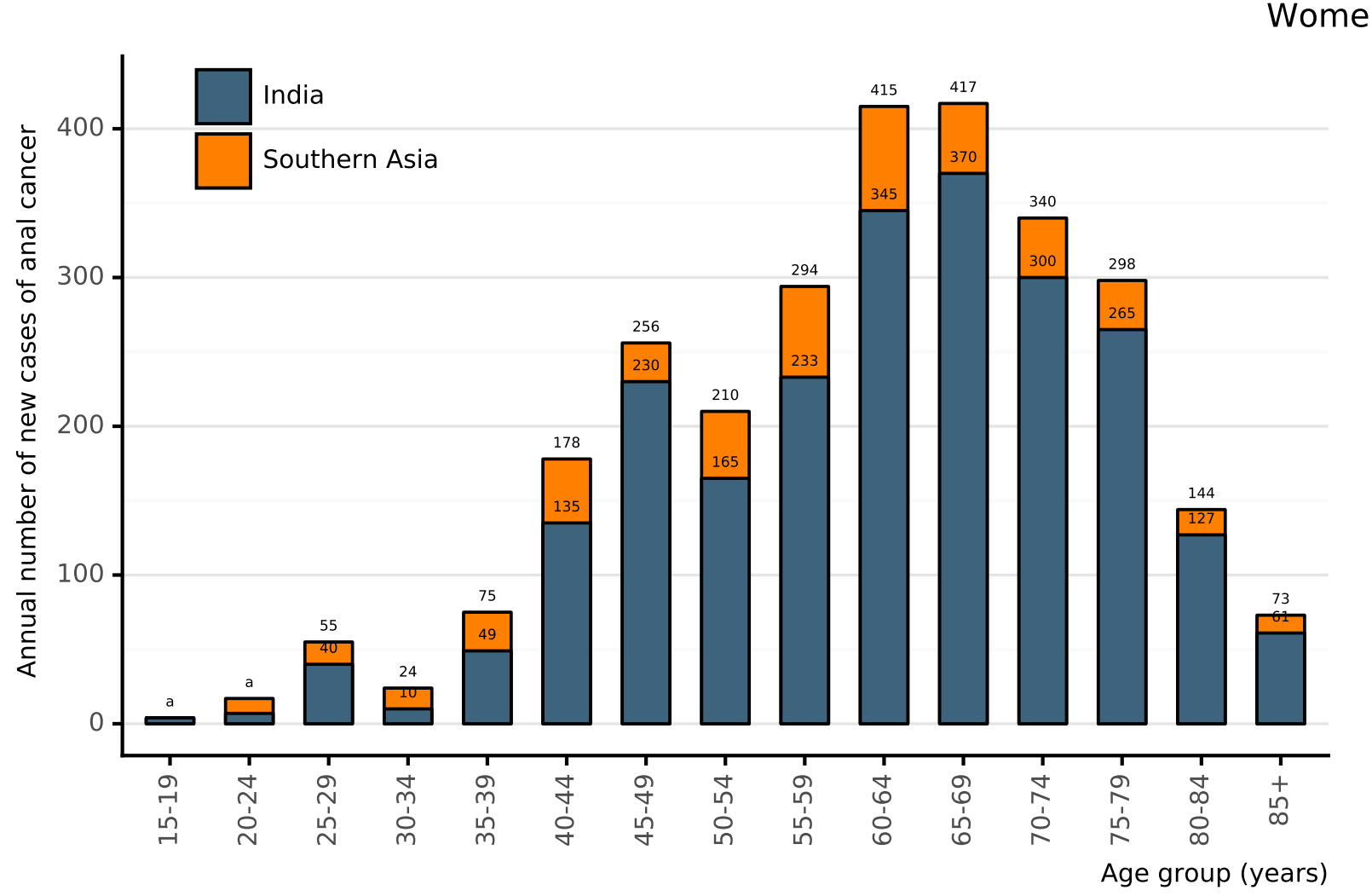

Data accessed on 27 Jan 2021

For more detailed methods of estimation please refer to http://gco.iarc.fr/today/data-sources-methods

${ }^{a} 4$ cases for India and 4 cases for Southern Asia in the 15-19 age group. 7 cases for India and 17 cases for Southern Asia in the 20-24 age group.

Ferlay J, Ervik M, Lam F, Colombet M, Mery L, Piñeros M, Znaor A, Soerjomataram I, Bray F (2020). Global Cancer Observatory: Cancer Today. Lyon, France: International Agency for Research on Cancer. Available from: https ://gco.iarc.fr/today, accessed [27 January 2021]. 
Figure 79: Comparison of age-specific anal cancer incidence rates among men by age in India, within the region, and the rest of world

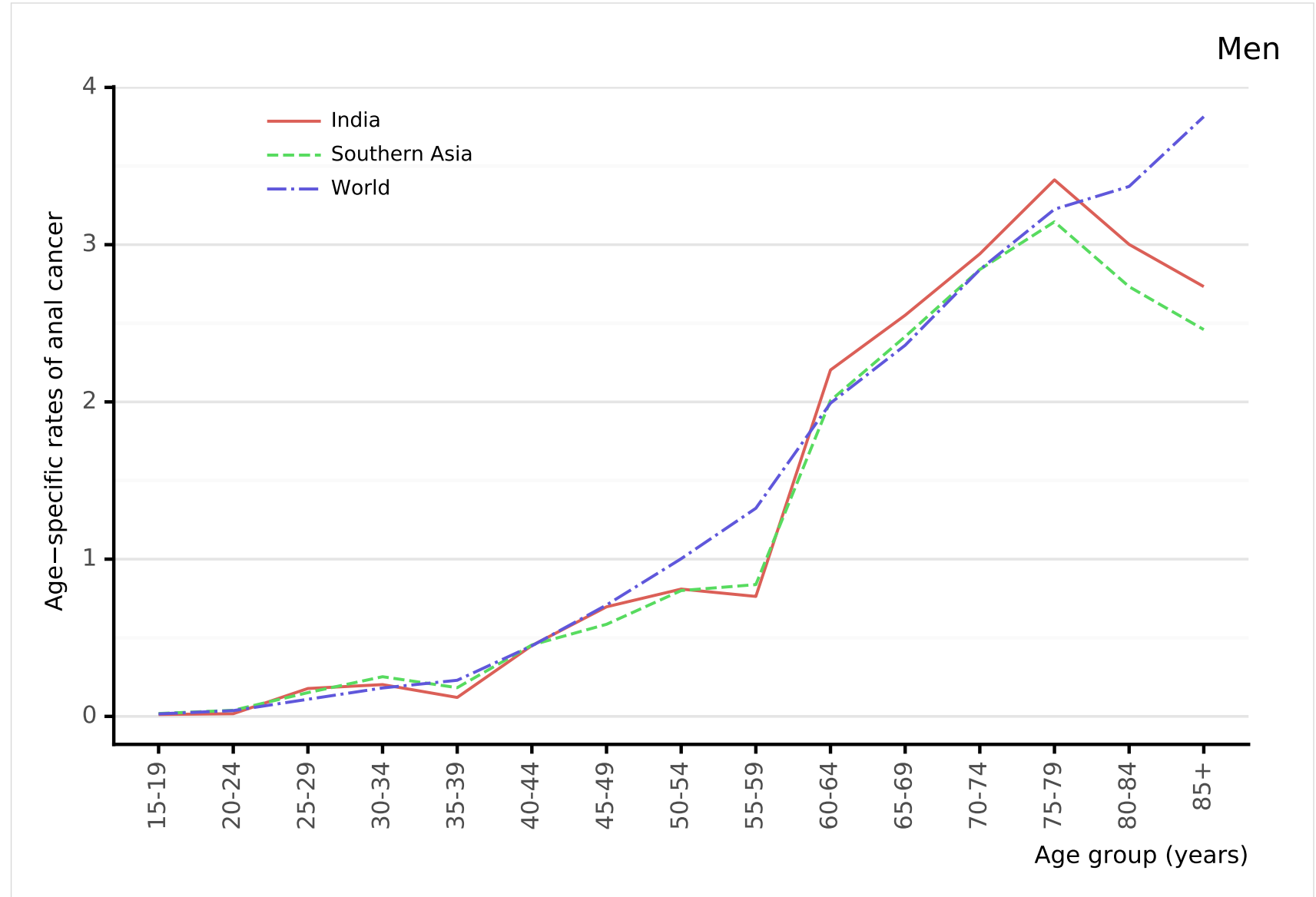

Data accessed on 27 Jan 2021

For more detailed methods of estimation please refer to http://gco.iarc.fr/today/data-sources-methods

${ }^{a}$ Rates per 100,000 men per year.

Ferlay J, Ervik M, Lam F, Colombet M, Mery L, Piñeros M, Znaor A, Soerjomataram I, Bray F (2020). Global Cancer Observatory: Cancer Today. Lyon, France: International Agency for Research on Cancer. Available from: https://gco.iarc.fr/today, accessed [27 January 2021]. 
Figure 80: Comparison of age-specific anal cancer incidence rates among women by age in India, within the region, and the rest of world

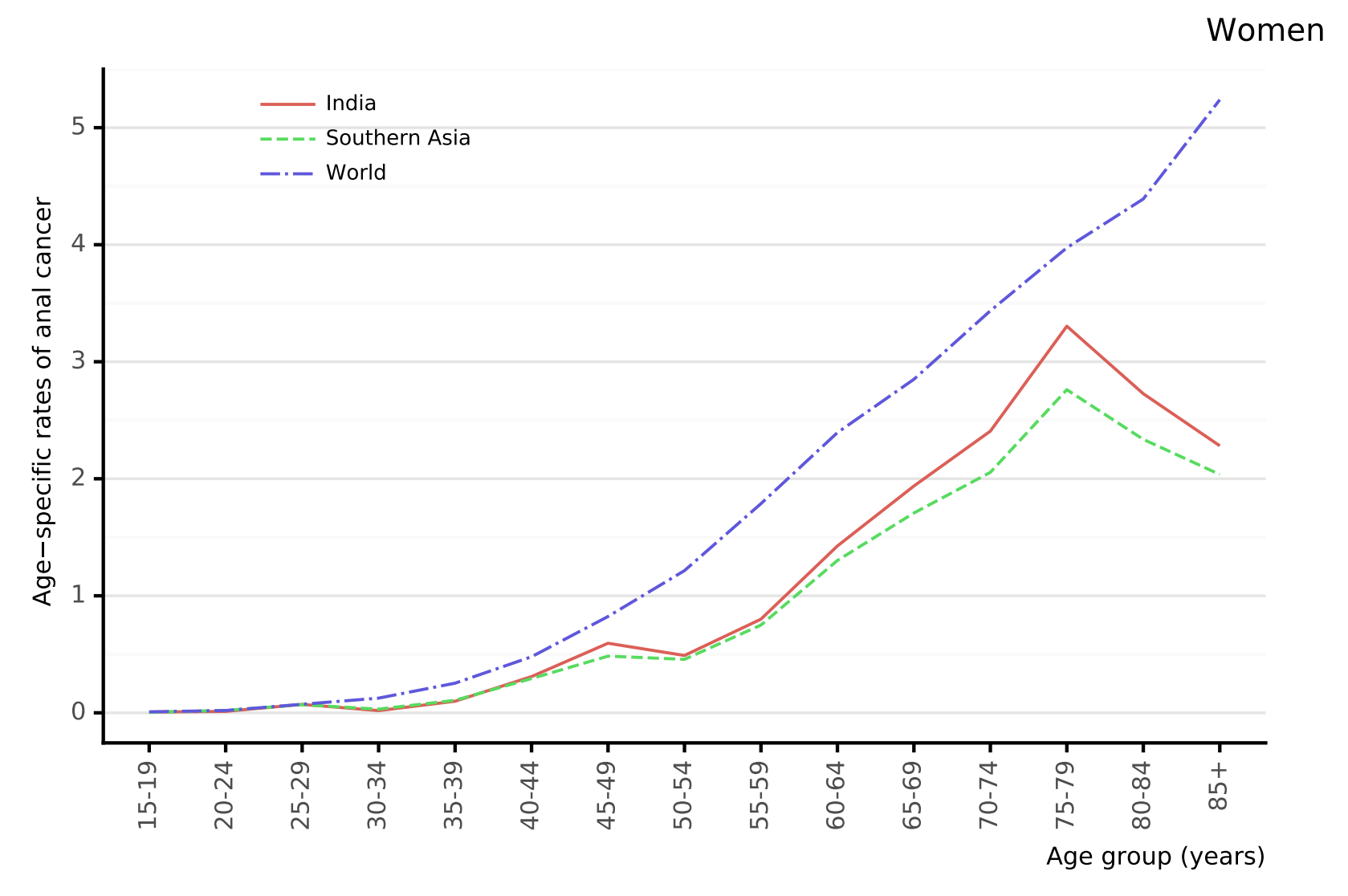

Data accessed on 27 Jan 2021

For more detailed methods of estimation please refer to http://gco.iarc.fr/today/data-sources-methods

${ }^{a}$ Rates per 100,000 women per year.

Ferlay J, Ervik M, Lam F, Colombet M, Mery L, Piñeros M, Znaor A, Soerjomataram I, Bray F (2020). Global Cancer Observatory: Cancer Today. Lyon, France: International Agency for Research on Cancer. Available from: https://gco.iarc.fr/today, accessed [27 January 2021]. 


\subsubsection{Vulva cancer incidence in India across Southern Asia}

Figure 81: Age-standardised incidence rates of vulva cancer of India (estimates for 2020)

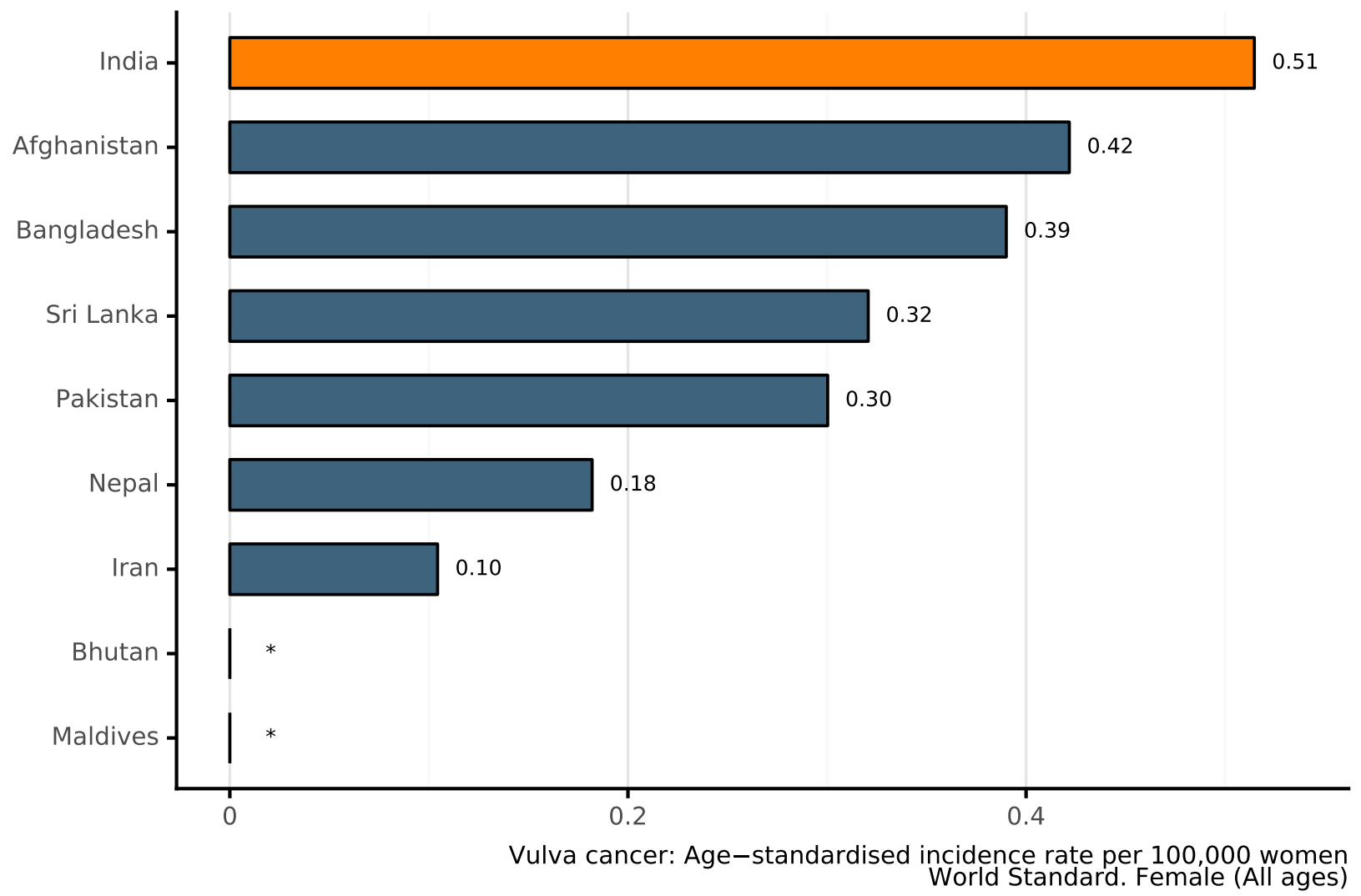

Data accessed on 27 Jan 2021

For more detailed methods of estimation please refer to http://gco.iarc.fr/today/data-sources-methods

${ }^{a}$ Rates per 100,000 women per year.

* Rates are not available

Ferlay J, Ervik M, Lam F Colombet M, Mery L, Piñeros M, Znaor A, Soerjomataram I, Bray F (2020). Global Cancer Observatory: Cancer Today. Lyon, France: International Agency for Research on Cancer. Available from: https ://gco.iarc.fr/today, accessed [27 January 2021]. 
Figure 82: Annual number of new cases of vulva cancer by age group in India (estimates for 2020)

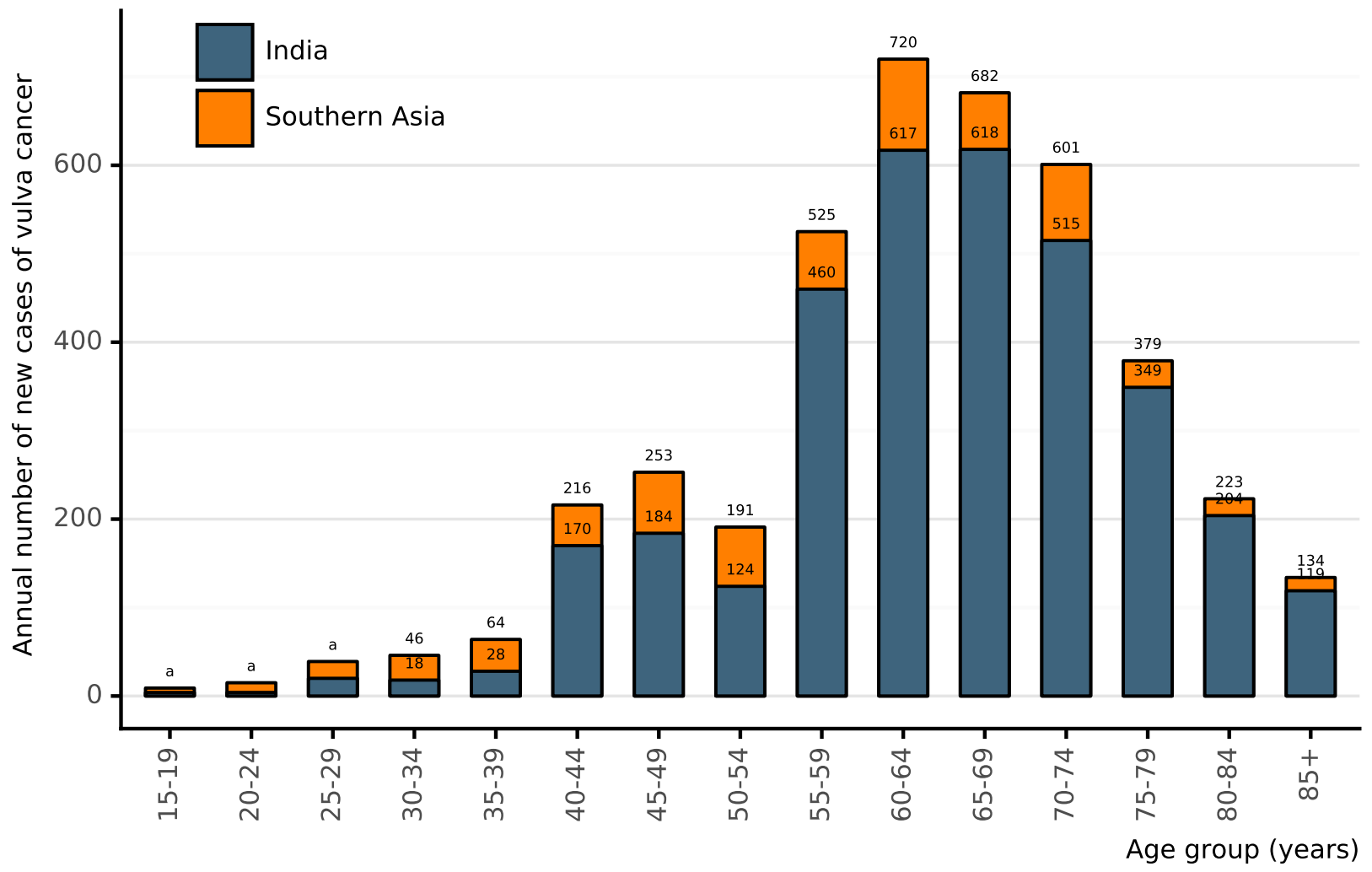

Data accessed on 27 Jan 2021

For more detailed methods of estimation please refer to http://gco.iarc.fr/today/data-sources-methods

$a_{4}$ cases for India and 9 cases for Southern Asia in the 15-19 age group. 4 cases for India and 15 cases for Southern Asia in the 20-24 age group. 20 cases for India and 39 cases for Southern Asia in the 25-29 age group.

Ferlay J, Ervik M, Lam F, Colombet M, Mery L, Piñeros M, Znaor A, Soerjomataram I, Bray F (2020). Global Cancer Observatory: Cancer Today. Lyon, France: International Agency for Research on Cancer. Available from: https://gco.iarc.fr/today, accessed [27 January 2021]. 
Figure 83: Comparison of age-specific vulva cancer incidence rates in India, within the region, and the rest of world

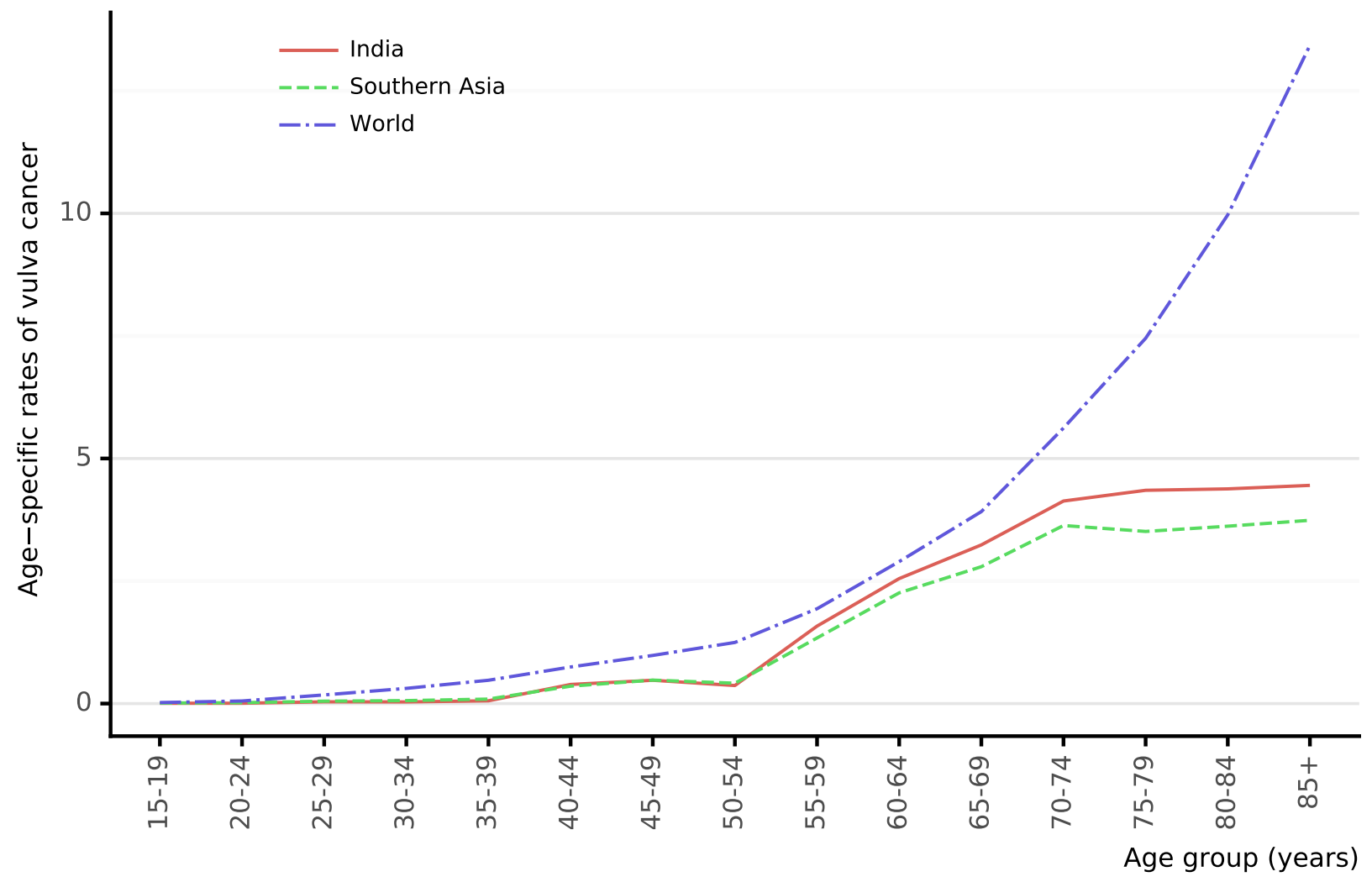

Data accessed on 27 Jan 2021

For more detailed methods of estimation please refer to http://gco.iarc.fr/today/data-sources-methods

${ }^{a}$ Rates per 100,000 women per year.

Data Sources:

Ferlay J, Ervik M, Lam F, Colombet M, Mery L, Piñeros M, Znaor A, Soerjomataram I, Bray F (2020). Global Cancer Observatory: Cancer Today. Lyon, France: International Agency for Research on Cancer. Available from: https://gco.iarc.fr/today, accessed [27 January 2021]. 


\subsubsection{Vaginal cancer incidence in India across Southern Asia}

Figure 84: Age-standardised incidence rates of vaginal cancer of India (estimates for 2020)

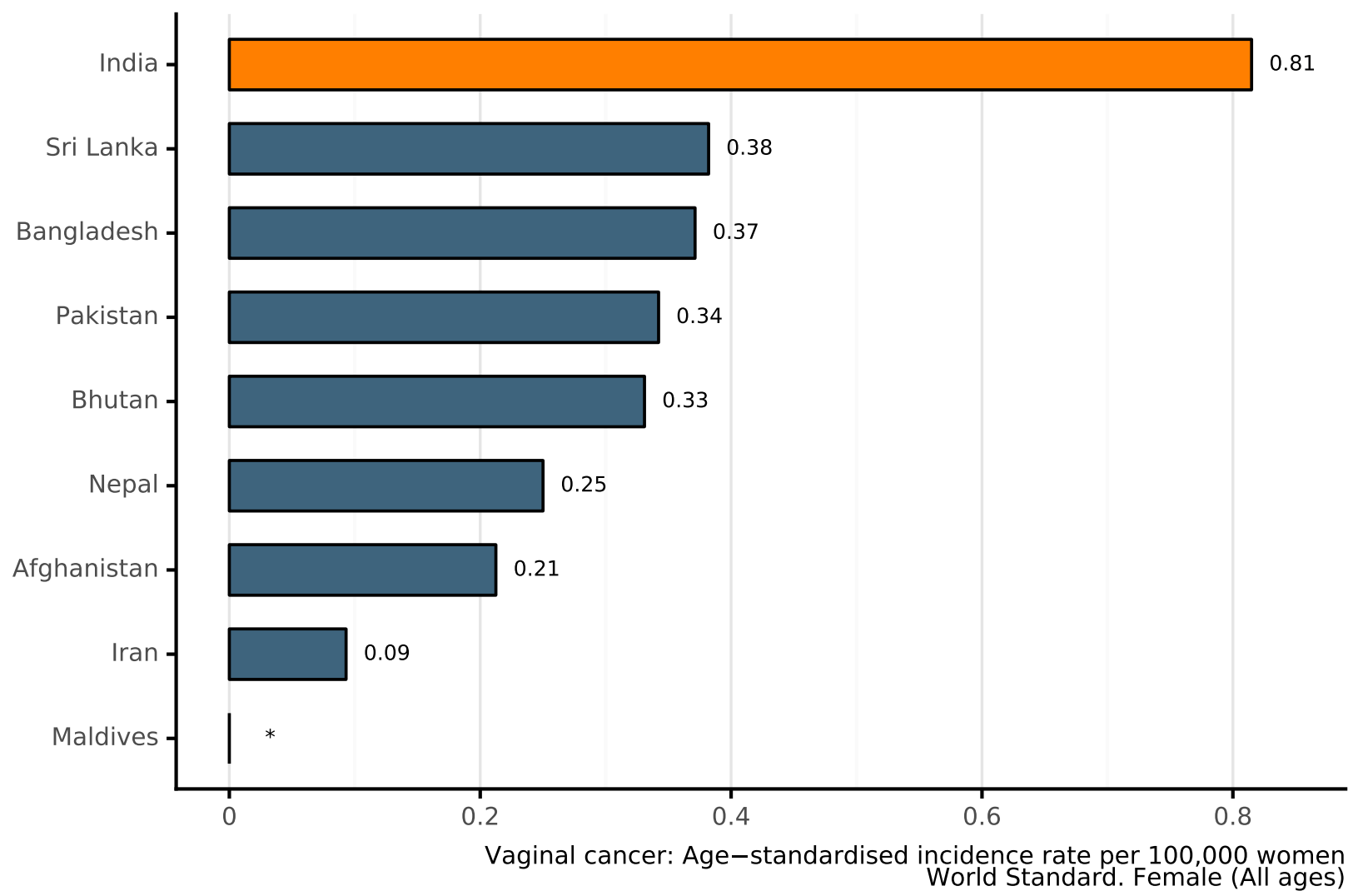

Data accessed on 27 Jan 2021

For more detailed methods of estimation please refer to http://gco.iarc.fr/today/data-sources-methods

${ }^{a}$ Rates per 100,000 women per year.

* Rates are not available

Data Sources:

Ferlay J, Ervik M, Lam F, Colombet M, Mery L, Piñeros M, Znaor A, Soerjomataram I, Bray F (2020). Global Cancer Observatory: Cancer Today. Lyon, France: International Agency for Research on Cancer. Available from: https ://gco.iarc.fr/today, accessed [27 January 2021]. 
Figure 85: Annual number of new cases of cervical cancer by age group in India (estimates for 2020)

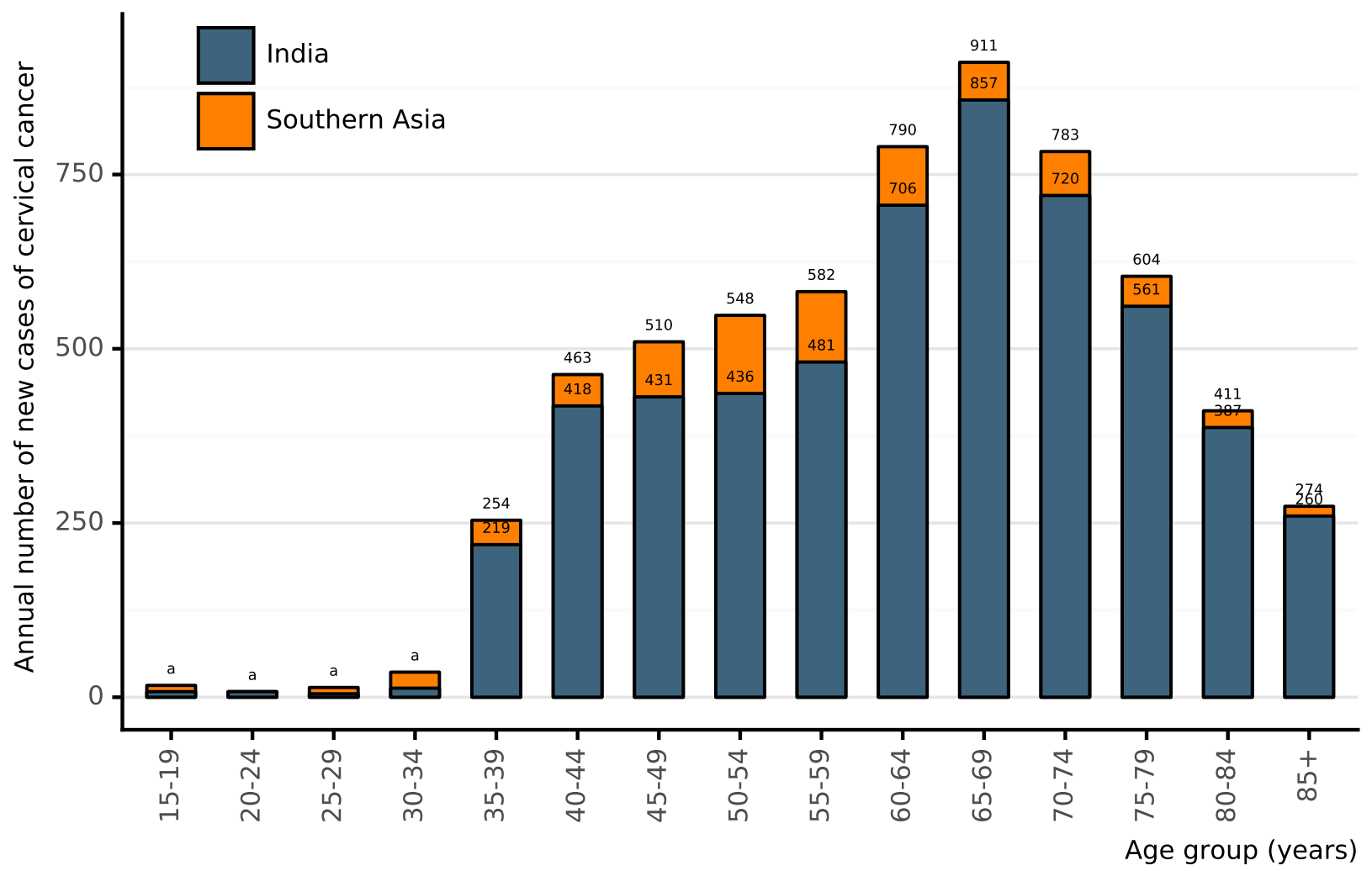

Data accessed on 27 Jan 2021

For more detailed methods of estimation please refer to http://gco.iarc.fr/today/data-sources-methods

$a 8$ cases for India and 17 cases for Southern Asia in the 15-19 age group. 8 cases for India and 8 cases for Southern Asia in the 20-24 age group. 5 cases for India and 14 cases for Southern Asia in the 25-29 age group. 13 cases for India and 36 cases for Southern Asia in the 30-34 age group.

Data Sources:

Ferlay J, Ervik M, Lam F, Colombet M, Mery L, Piñeros M, Znaor A, Soerjomataram I, Bray F (2020). Global Cancer Observatory: Cancer Today. Lyon, France: International Agency for Research on Cancer. Available from: https://gco.iarc.fr/today, accessed [27 January 2021]. 
Figure 86: Comparison of age-specific vaginal cancer incidence rates in India, within the region, and the rest of world

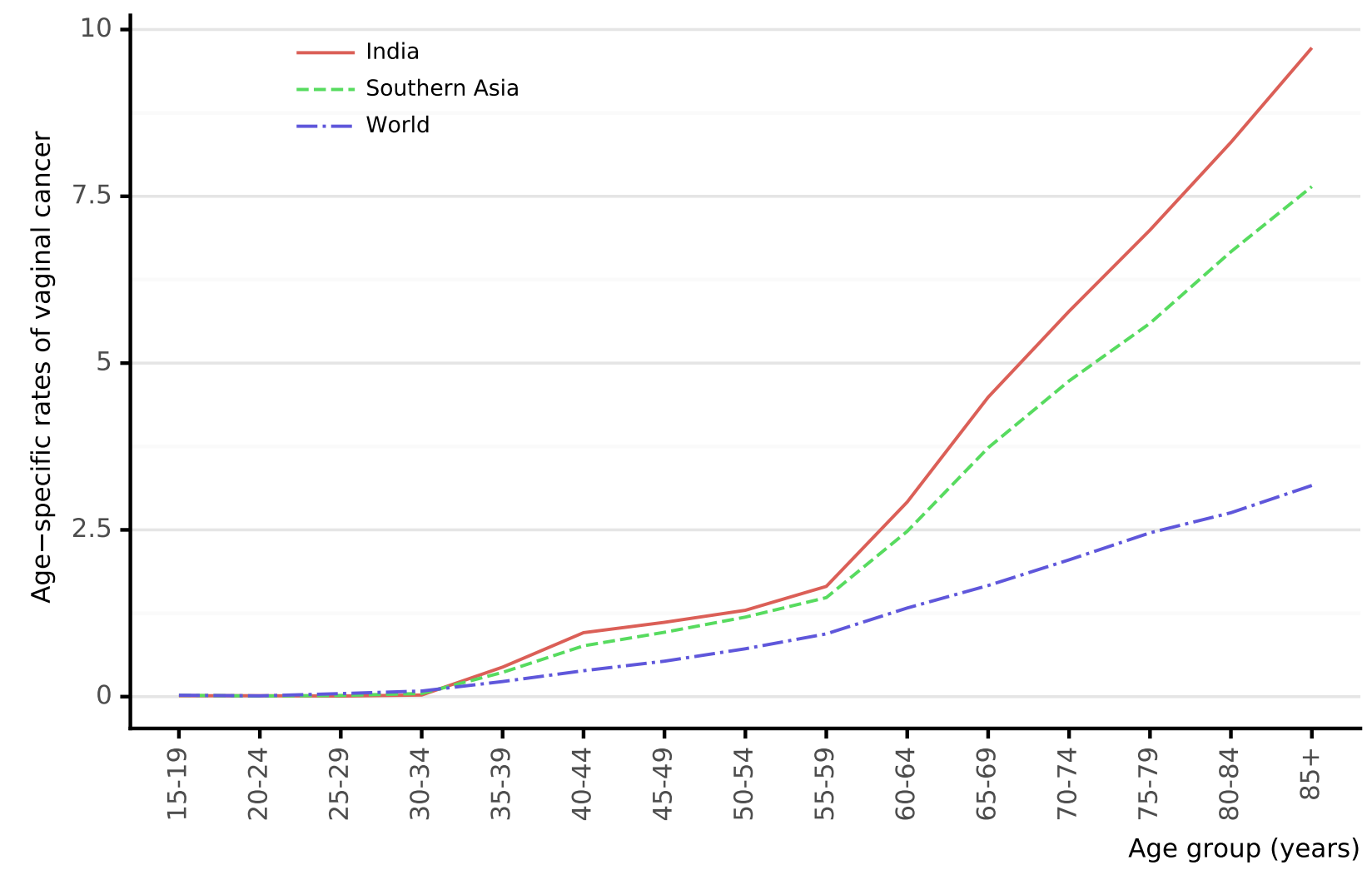

Data accessed on 27 Jan 2021

For more detailed methods of estimation please refer to http://gco.iarc.fr/today/data-sources-methods

${ }^{a}$ Rates per 100,000 women per year.

Ferlay J, Ervik M, Lam F, Colombet M, Mery L, Piñeros M, Znaor A, Soerjomataram I, Bray F (2020). Global Cancer Observatory: Cancer Today. Lyon, France: International Agency for Research on Cancer. Available from: https ://gco.iarc.fr/today, accessed [27 January 2021]. 


\subsubsection{Penile cancer incidence in India across Southern Asia}

Figure 87: Age-standardised incidence rates of penile cancer of India (estimates for 2020)

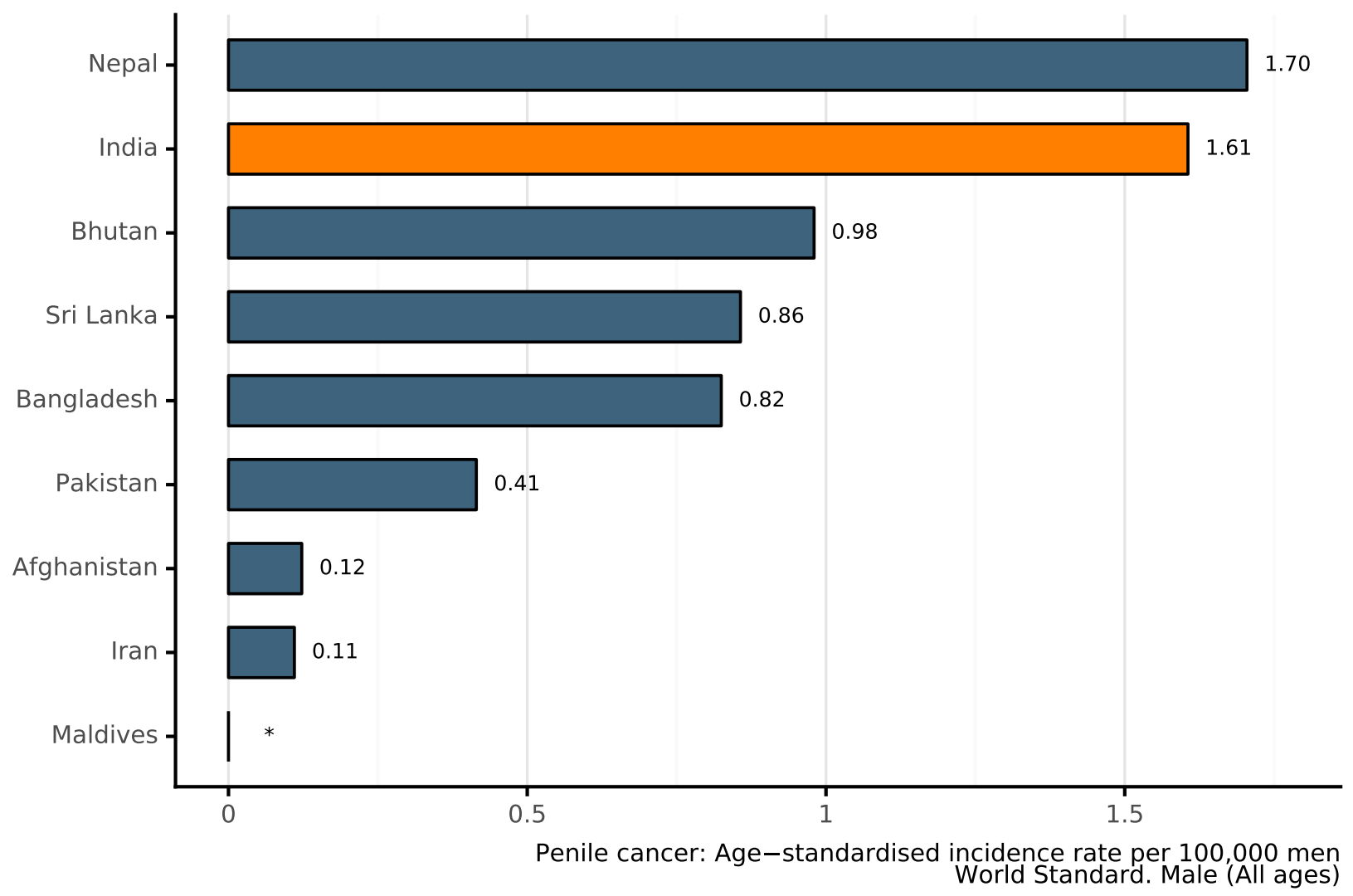

Data accessed on 27 Jan 2021

For more detailed methods of estimation please refer to http://gco.iarc.fr/today/data-sources-methods

${ }^{a}$ Rates per 100,000 men per year.

* Rates are not available

Ferlay J, Ervik M, Lam F Colombet M, Mery L, Piñeros M, Znaor A, Soerjomataram I, Bray F (2020). Global Cancer Observatory: Cancer Today. Lyon, France: International Agency for

Research on Cancer. Available from: https://gco.iarc.fr/today, accessed [27 January 2021]. 
Figure 88: Annual number of new cases of penile cancer by age group in India (estimates for 2020)

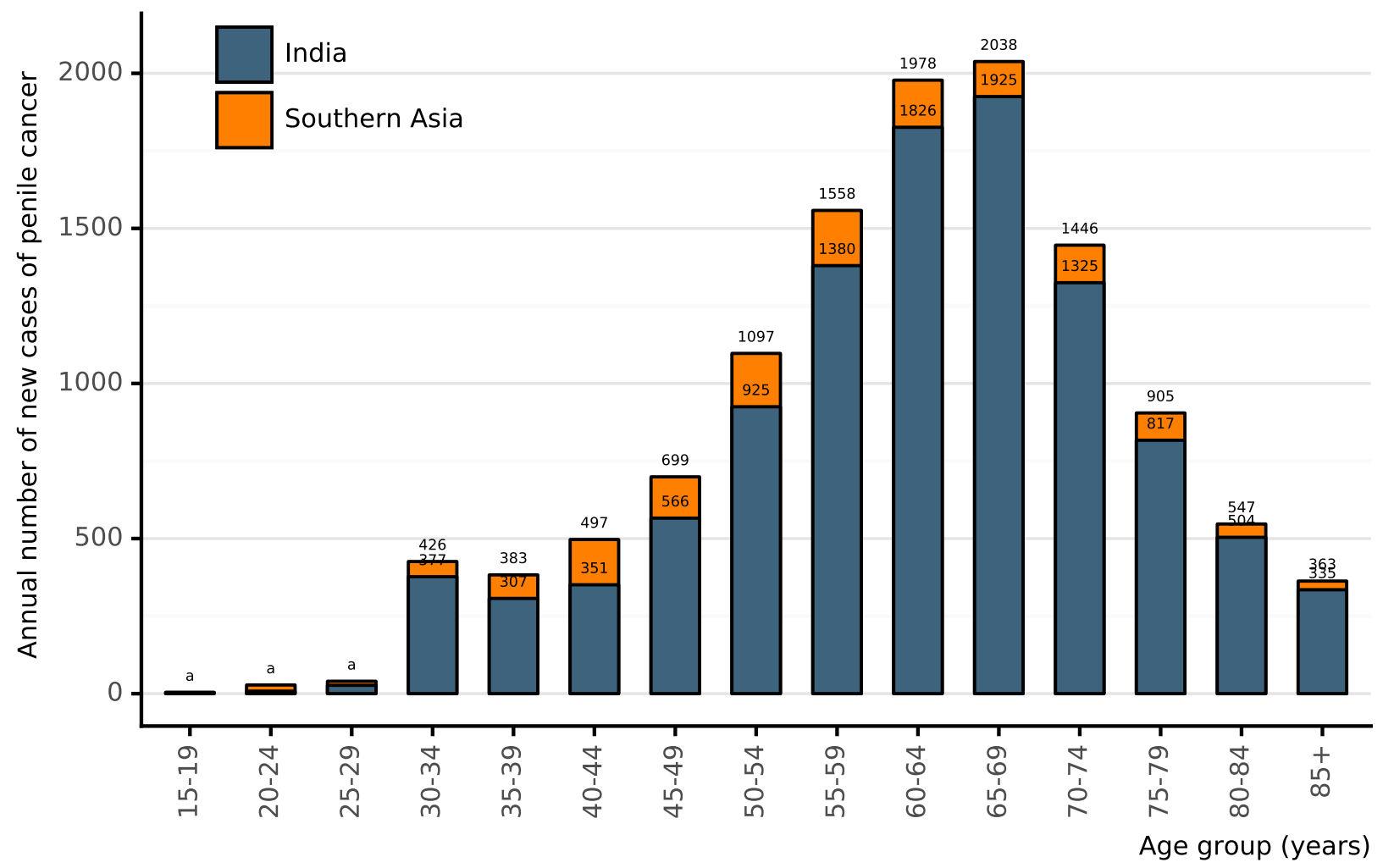

Data accessed on 27 Jan 2021

For more detailed methods of estimation please refer to http://gco.iarc.fr/today/data-sources-methods

$a_{4} 4$ cases for India and 4 cases for Southern Asia in the 15-19 age group. 8 cases for India and 28 cases for Southern Asia in the 20-24 age group. 27 cases for India and 40 cases for Southern Asia in the 25-29 age group.

Data Sources:

Ferlay J, Ervik M, Lam F, Colombet M, Mery L, Piñeros M, Znaor A, Soerjomataram I, Bray F (2020). Global Cancer Observatory: Cancer Today. Lyon, France: International Agency for Research on Cancer. Available from: https ://gco.iarc.fr/today, accessed [27 January 2021]. 
Figure 89: Comparison of age-specific penile cancer incidence rates in India, within the region, and the rest of world

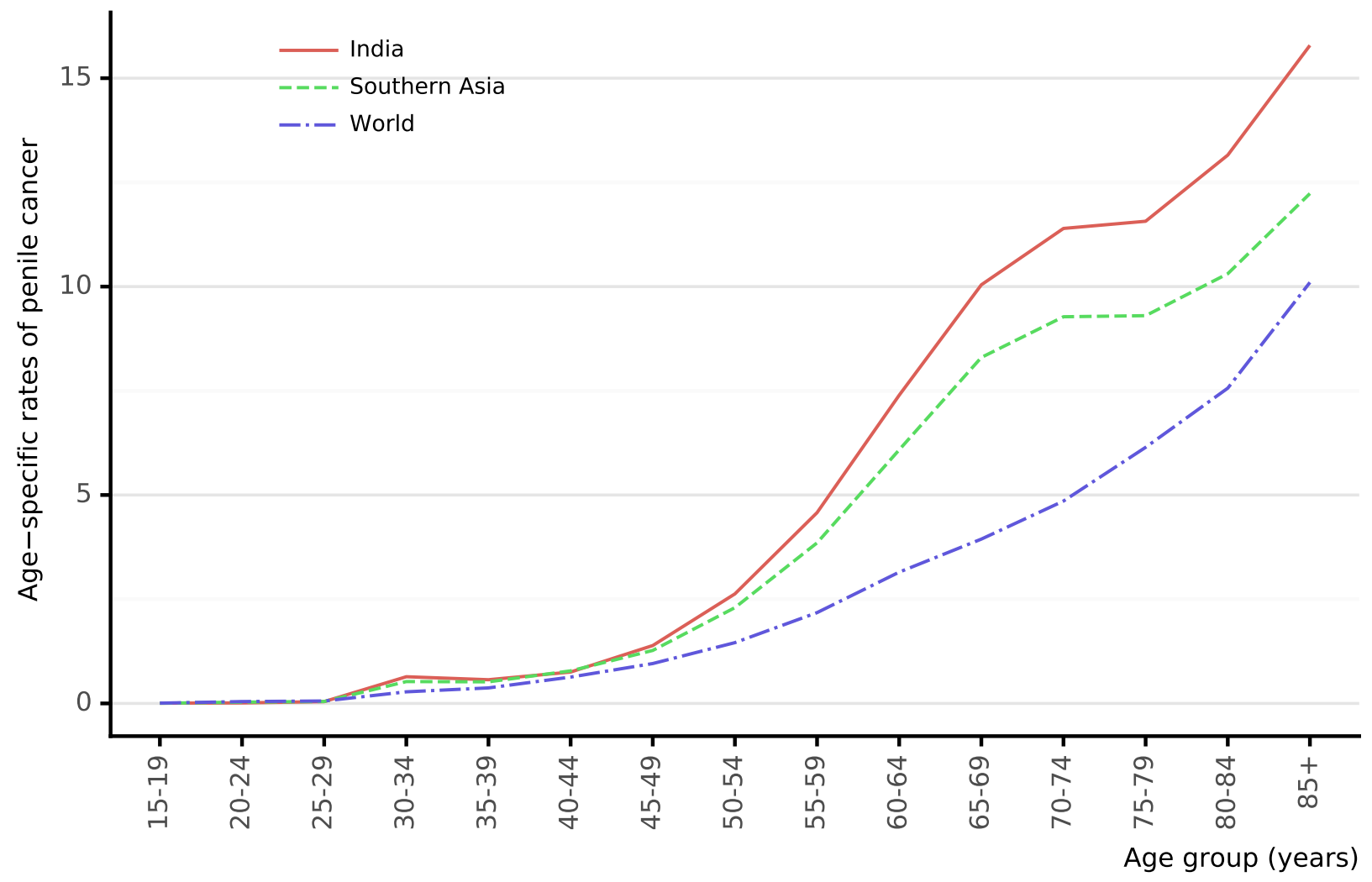

Data accessed on 27 Jan 2021

For more detailed methods of estimation please refer to http://gco.iarc.fr/today/data-sources-methods

${ }^{a}$ Rates per 100,000 men per year.

Data Sources:

Ferlay J, Ervik M, Lam F, Colombet M, Mery L, Piñeros M, Znaor A, Soerjomataram I, Bray F (2020). Global Cancer Observatory: Cancer Today. Lyon, France: International Agency for Research on Cancer. Available from: https://gco.iarc.fr/today, accessed [27 January 2021]. 


\subsubsection{Oropharyngeal cancer incidence in India across Southern Asia}

Figure 90: Age-standardised incidence rates of oropharyngeal cancer of India (estimates for 2020)

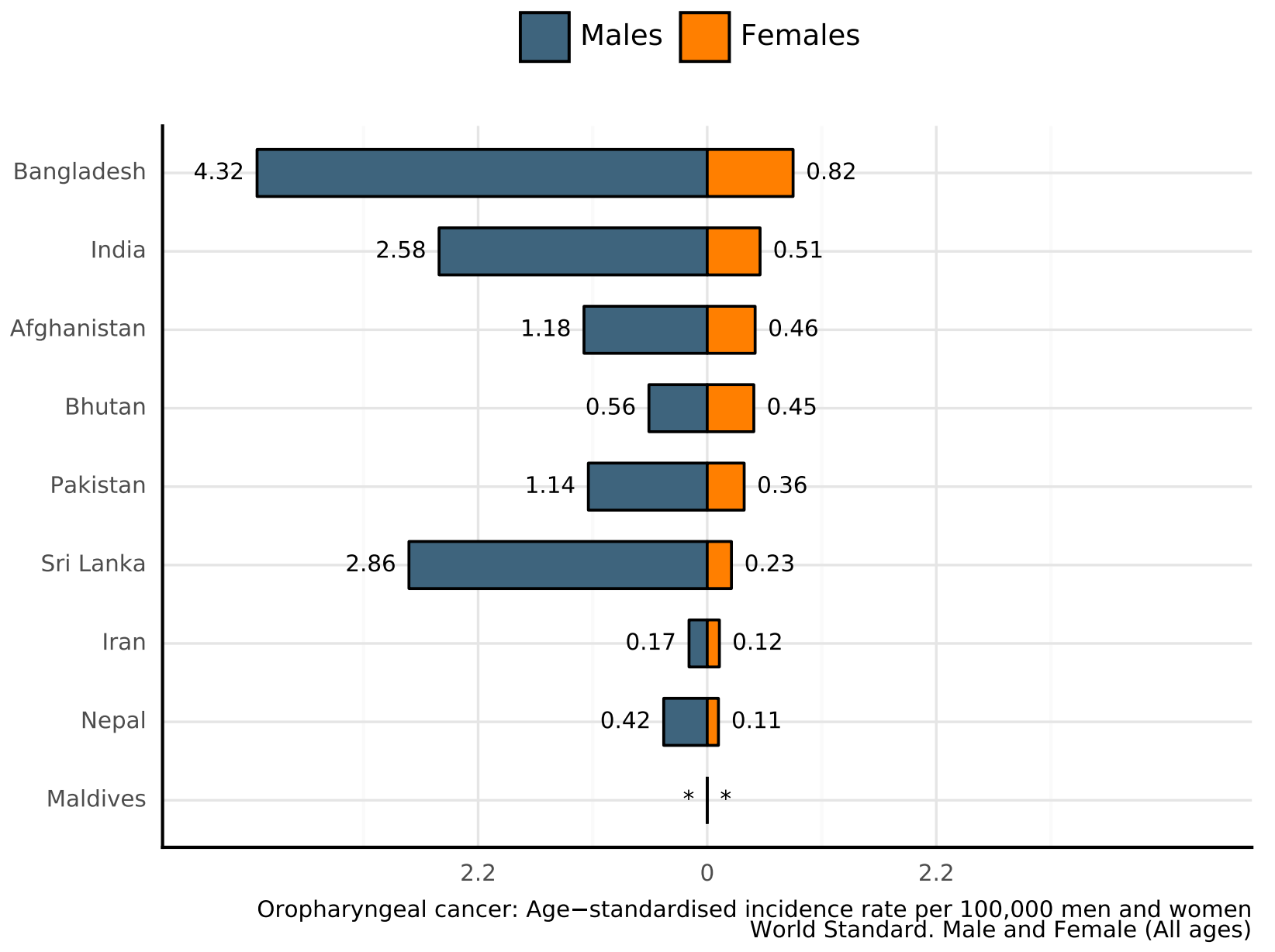

Data accessed on 27 Jan 2021

For more detailed methods of estimation please refer to http://gco.iarc.fr/today/data-sources-methods

${ }^{a}$ Rates per 100,000 men per year.

${ }^{b}$ Rates per 100,000 women per year.

* Rates are not available

Data Sources:

Ferlay J, Ervik M, Lam F, Colombet M, Mery L, Piñeros M, Znaor A, Soerjomataram I, Bray F (2020). Global Cancer Observatory: Cancer Today. Lyon, France: International Agency for Research on Cancer. Available from: https ://gco.iarc.fr/today, accessed [27 January 2021]. 
Figure 91: Annual number of new cases of oropharyngeal cancer among men by age group in India (estimates for 2020)

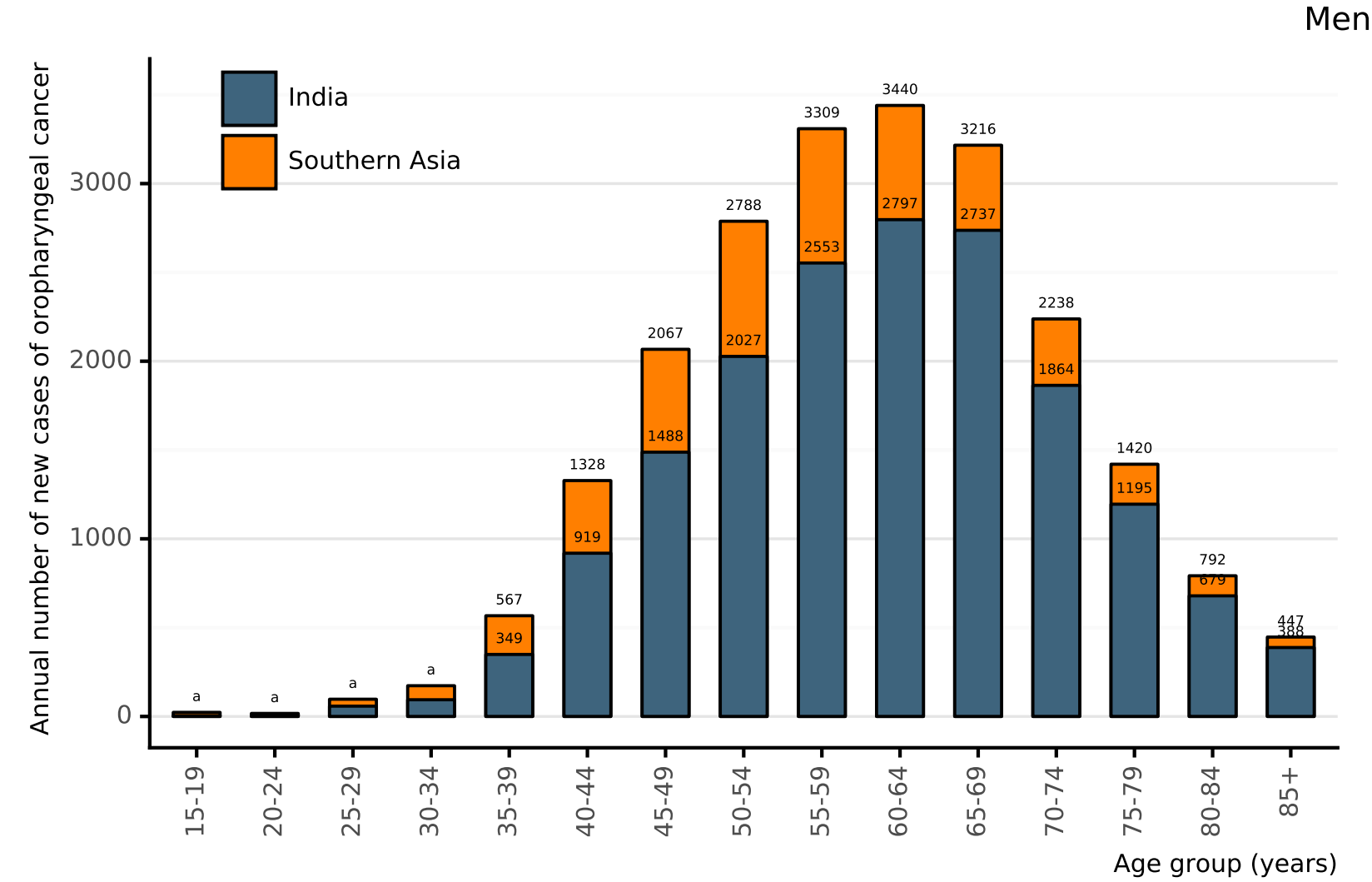

\section{Data accessed on 27 Jan 2021}

For more detailedmetho 27 Jan 2021 .

$a_{4}$ cases for India and 23 cases for Southern Asia in the 15-19 age group. 9 cases for India and 17 cases for Southern Asia in the 20-24 age group. 58 cases for India and 97 cases for Southern Asia in the 25-29 age group. 94 cases for India and 173 cases for Southern Asia in the 30-34 age group.

Ferlay J, Ervik M, Lam F, Colombet M, Mery L, Piñeros M, Znaor A, Soerjomataram I, Bray F (2020). Global Cancer Observatory: Cancer Today. Lyon, France: International Agency for Research on Cancer. Available from: https://gco.iarc.fr/today, accessed [27 January 2021]. 
Figure 92: Annual number of new cases of oropharyngeal cancer among women by age group in India (estimates for 2020)

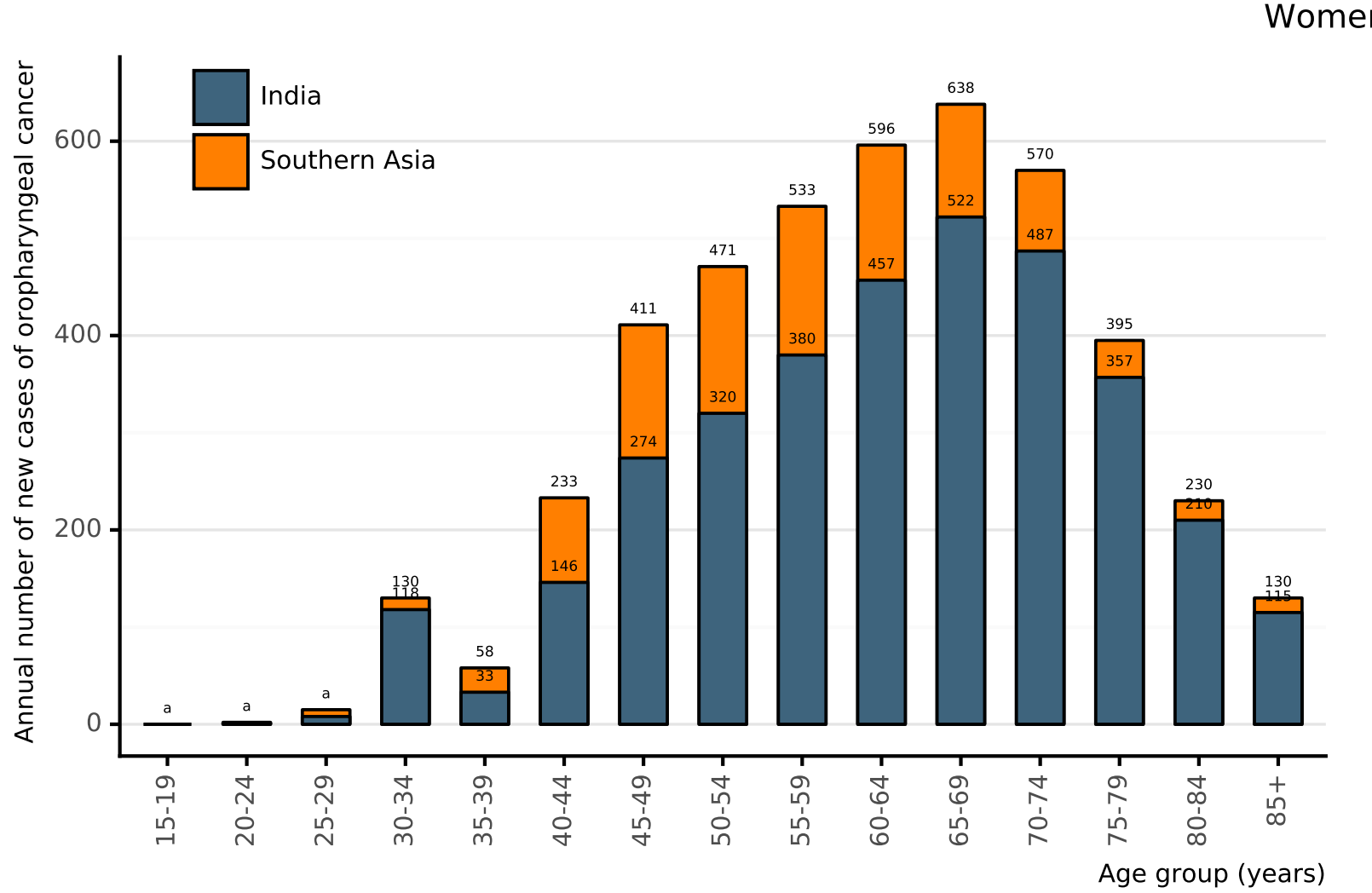

Data accessed on 27 Jan 2021

For more detailed methods of estimation please refer to http://gco.iarc.fr/today/data-sources-methods

${ }^{a} 0$ cases for India and 0 cases for Southern Asia in the 15-19 age group. 1 cases for India and 2 cases for Southern Asia in the 20-24 age group. 8 cases for India and 15 cases for Southern Asia in the 25-29 age group.

Data Sources:

Ferlay J, Ervik M, Lam F, Colombet M, Mery L, Piñeros M, Znaor A, Soerjomataram I, Bray F (2020). Global Cancer Observatory: Cancer Today. Lyon, France: International Agency for Research on Cancer. Available from: https ://gco.iarc.fr/today, accessed [27 January 2021]. 
Figure 93: Comparison of age-specific oropharyngeal cancer incidence rates among men by age in India, within the region, and the rest of world

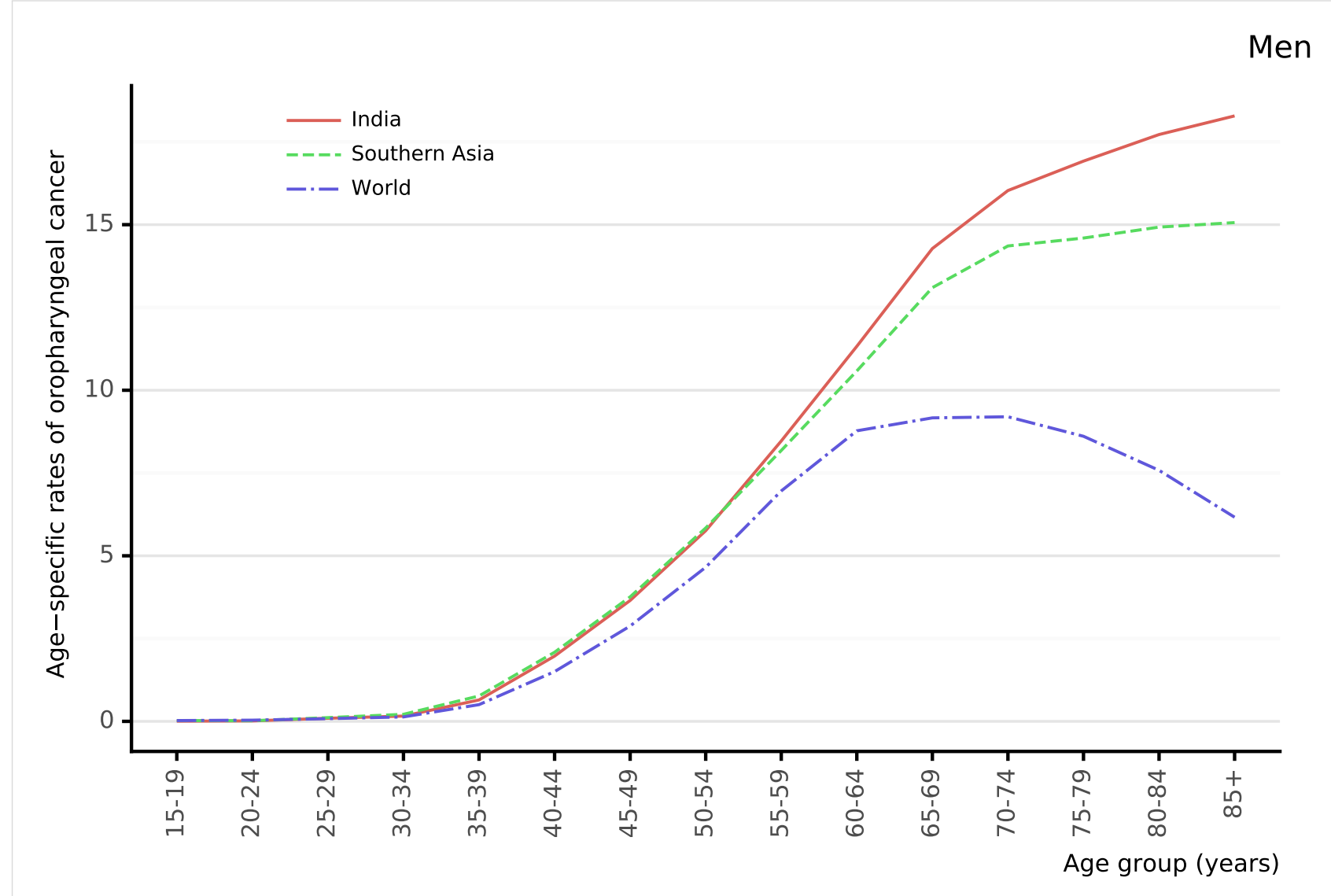

Data accessed on 27 Jan 2021

For more detailed methods of estimation please refer to http://gco.iarc.fr/today/data-sources-methods

${ }^{a}$ Rates per 100,000 men per year.

Ferlay J, Ervik M, Lam F, Colombet M, Mery L, Piñeros M, Znaor A, Soerjomataram I, Bray F (2020). Global Cancer Observatory: Cancer Today. Lyon, France: International Agency for Research on Cancer. Available from: https://gco.iarc.fr/today, accessed [27 January 2021]. 
Figure 94: Comparison of age-specific oropharyngeal cancer incidence rates among women by age in India, within the region, and the rest of world

Women

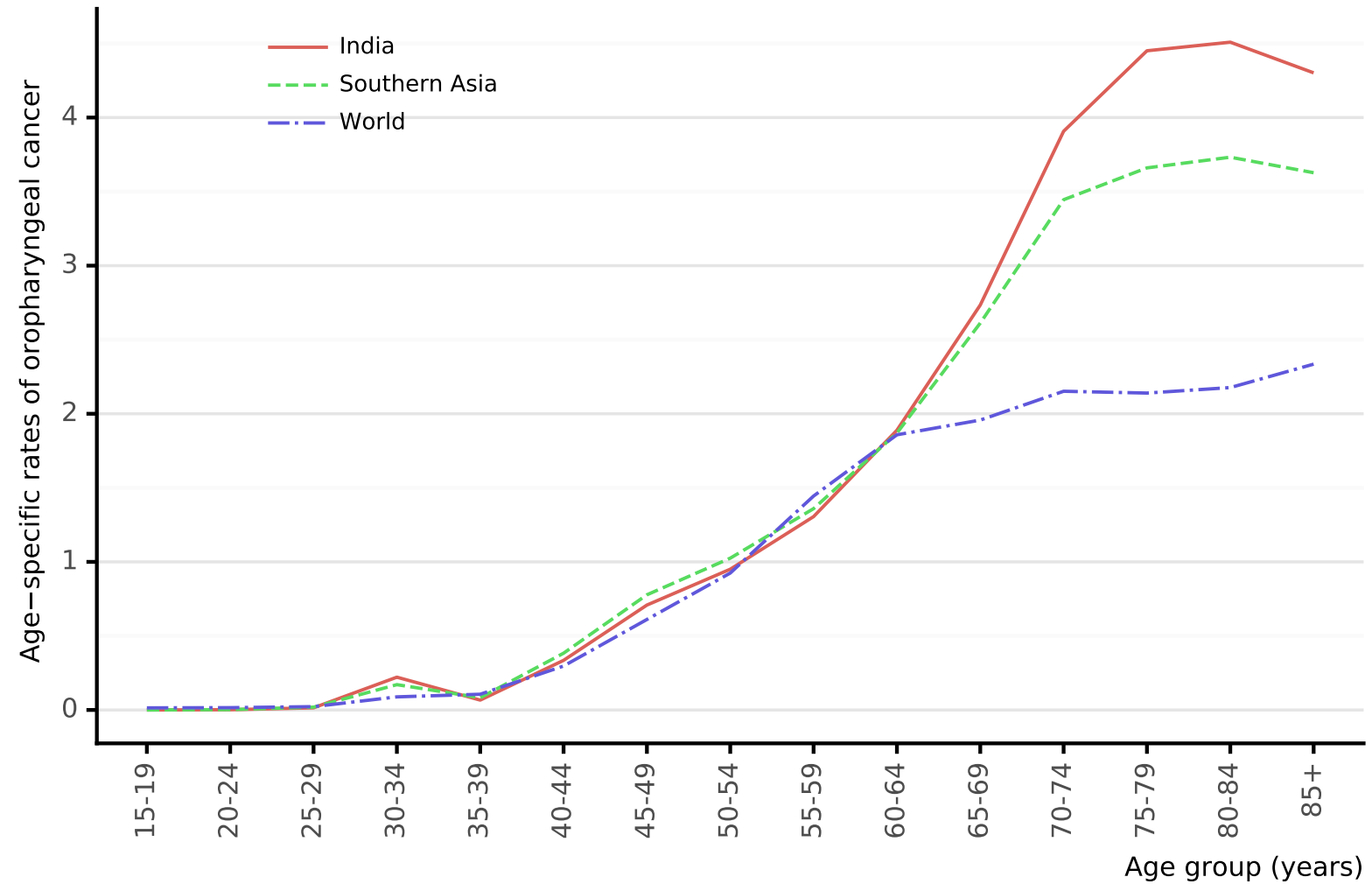

Data accessed on 27 Jan 2021

For more detailed methods of estimation please refer to http://gco.iarc.fr/today/data-sources-methods

${ }^{a}$ Rates per 100,000 women per year.

Ferlay J, Ervik M, Lam F, Colombet M, Mery L, Piñeros M, Znaor A, Soerjomataram I, Bray F (2020). Global Cancer Observatory: Cancer Today. Lyon, France: International Agency for Research on Cancer. Available from: https://gco.iarc.fr/today, accessed [27 January 2021]. 


\subsubsection{Oral cavity cancer incidence in India across Southern Asia}

Figure 95: Age-standardised incidence rates of oral cavity cancer of India (estimates for 2020)

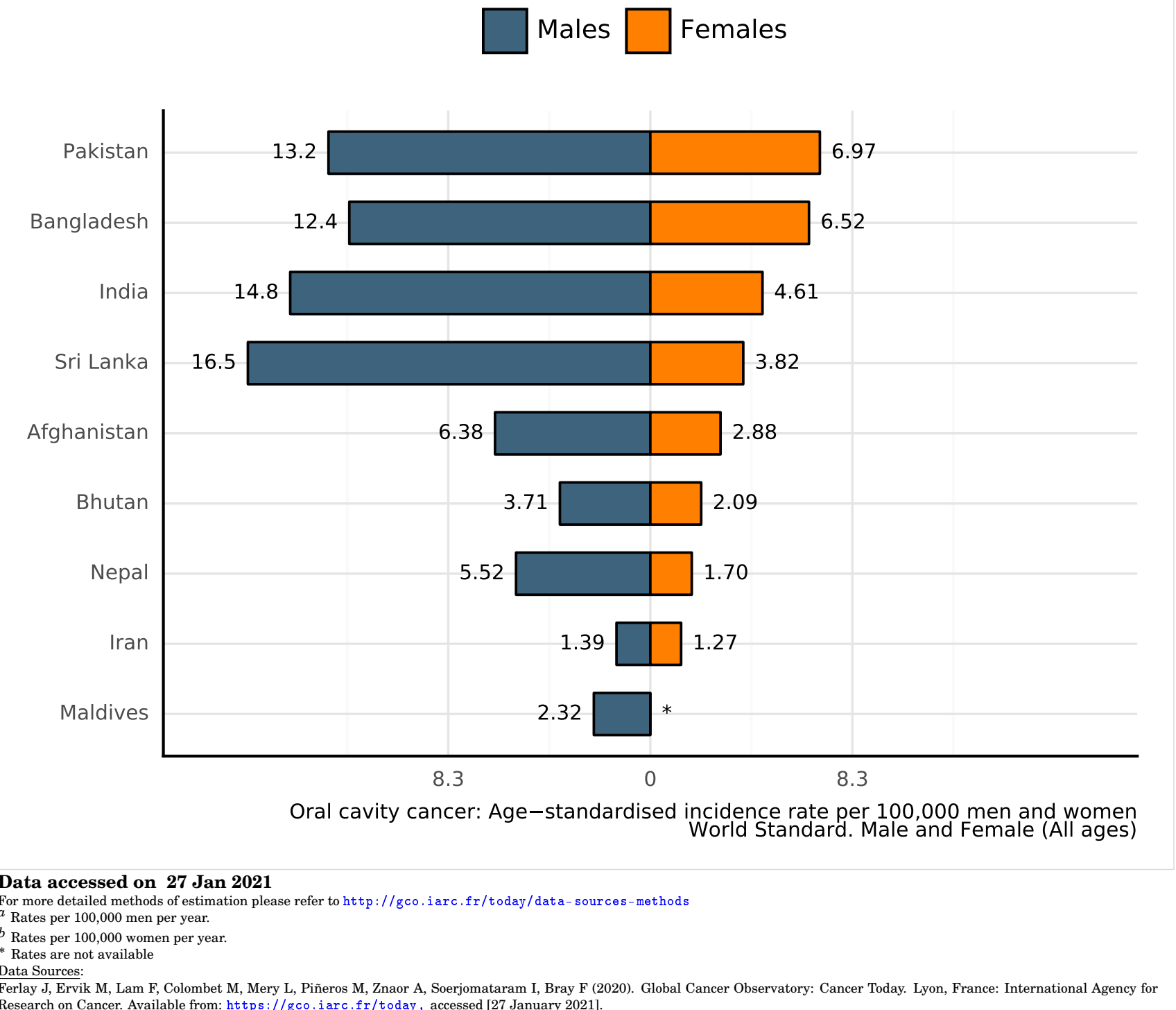


Figure 96: Annual number of new cases of oral cavity cancer among men by age group in India (estimates for 2020)

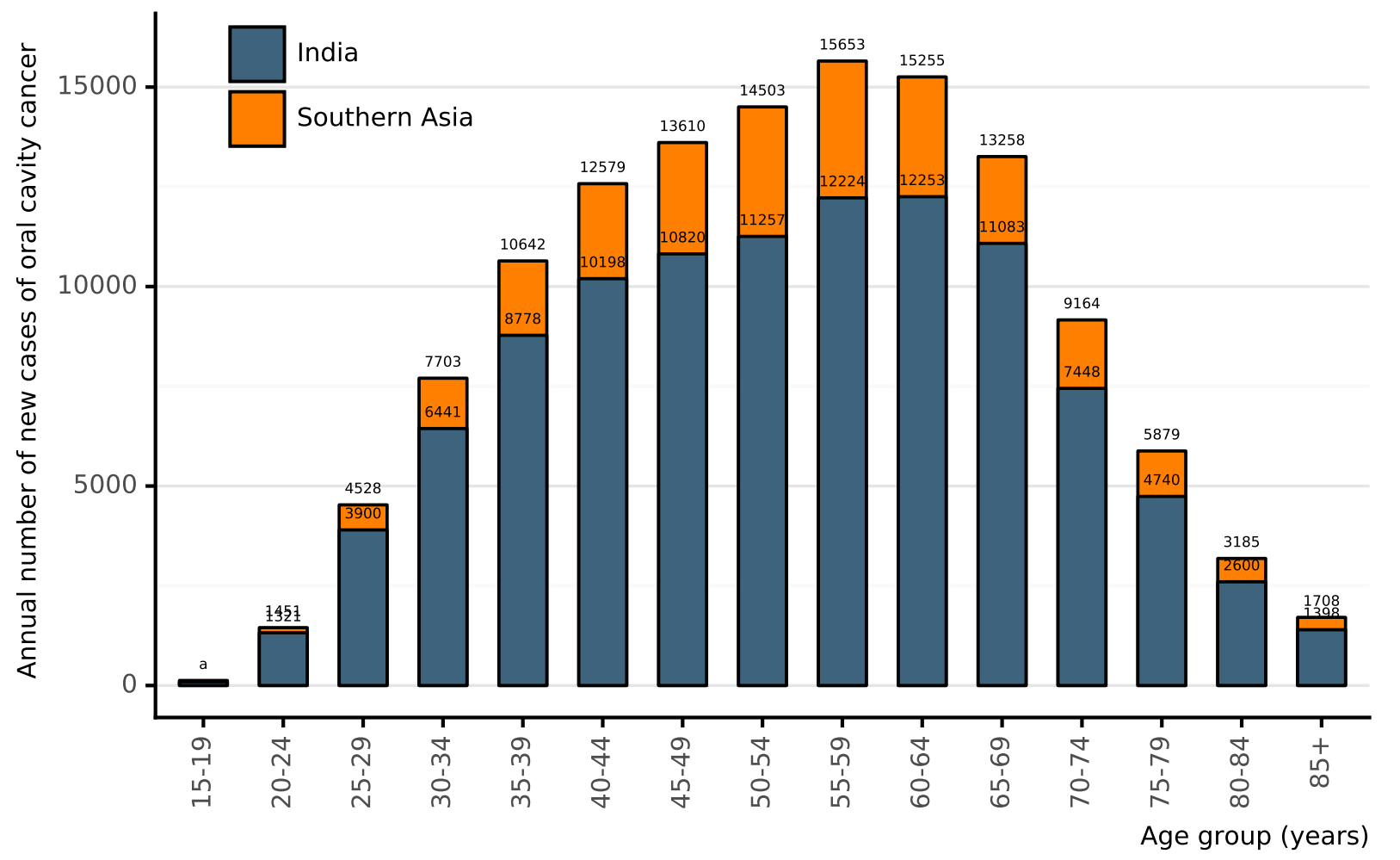

Data accessed on 27 Jan 2021

For more detailed methods of estimation please refer to http://gco.iarc.fr/today/data-sources-methods

a 93 cases for India and 126 cases for Southern Asia in the 15-19 age group.

Data Sources:

Research on Cancer. Available from: https ://gco.iarc.fr/today, accessed [27 January 2021]. 
Figure 97: Annual number of new cases of oral cavity cancer among women by age group in India (estimates for 2020)

Women

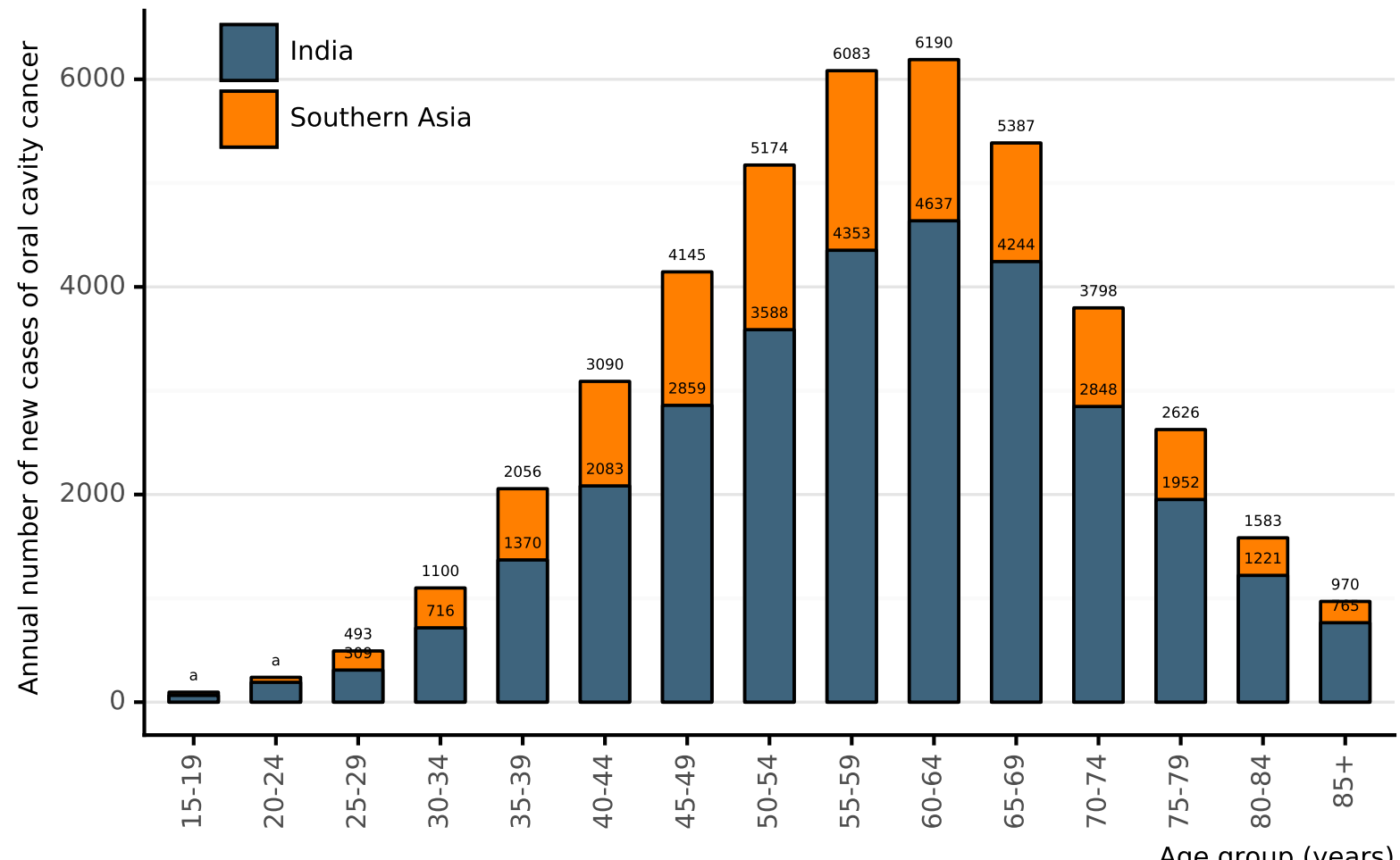

Data accessed on 27 Jan 2021

For more detailed methods of estimation please refer to http://gco.iarc.fr/today/data-sources-methods

${ }^{a} 65$ cases for India and 96 cases for Southern Asia in the 15-19 age group. 191 cases for India and 239 cases for Southern Asia in the 20-24 age group.

Ferlay J, Ervik M, Lam F, Colombet M, Mery L, Piñeros M, Znaor A, Soerjomataram I, Bray F (2020). Global Cancer Observatory: Cancer Today. Lyon, France: International Agency for Research on Cancer. Available from: https ://gco.iarc.fr/today, accessed [27 January 2021]. 
Figure 98: Comparison of age-specific oral cavity cancer incidence rates among men by age in India, within the region, and the rest of world

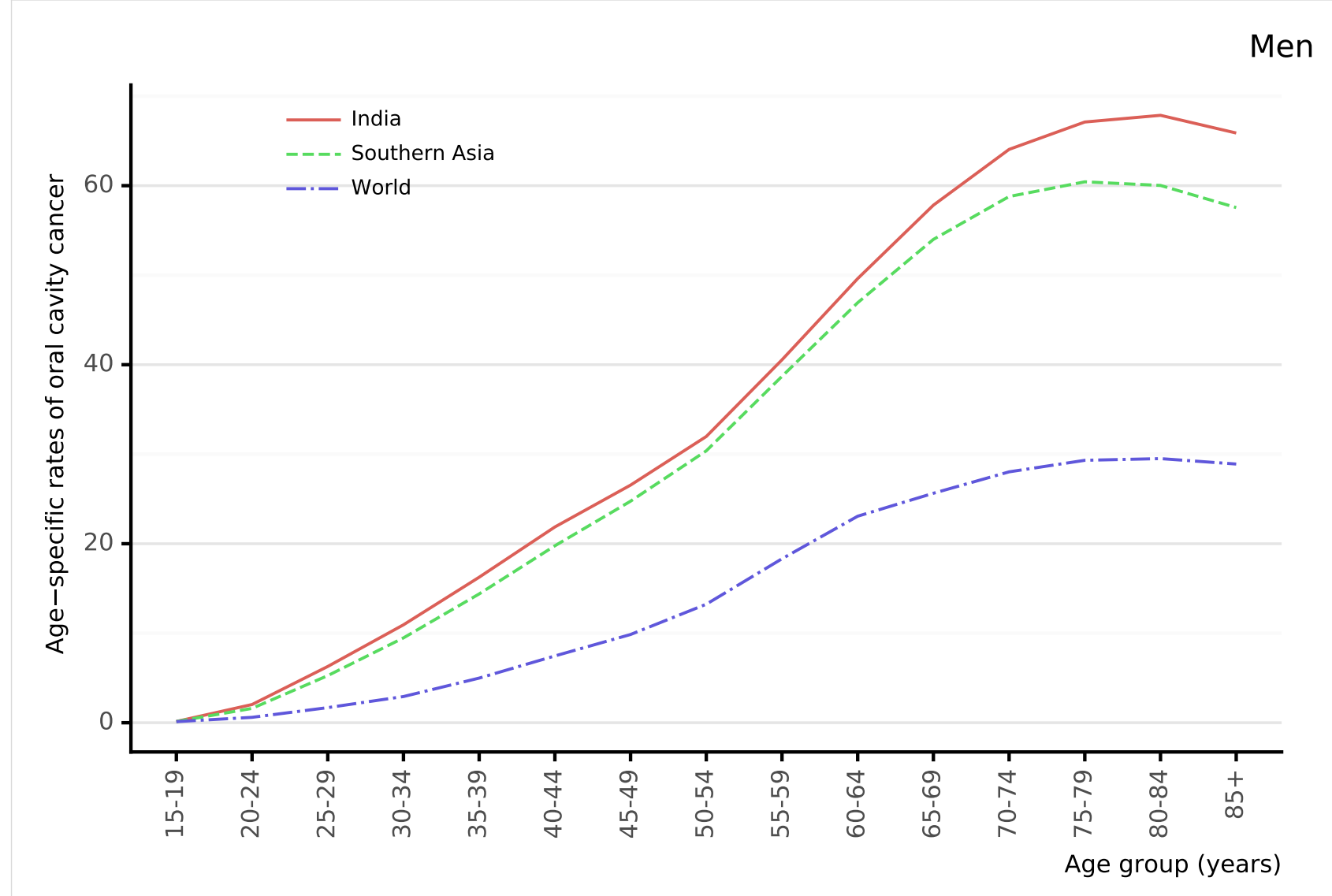

Data accessed on 27 Jan 2021

For more detailed methods of estimation please refer to http://gco.iarc.fr/today/data-sources-methods

${ }^{a}$ Rates per 100,000 men per year.

Ferlay J, Ervik M, Lam F, Colombet M, Mery L, Piñeros M, Znaor A, Soerjomataram I, Bray F (2020). Global Cancer Observatory: Cancer Today. Lyon, France: International Agency for Research on Cancer. Available from: https://gco.iarc.fr/today, accessed [27 January 2021]. 
Figure 99: Comparison of age-specific oral cavity cancer incidence rates among women by age in India, within the region, and the rest of world

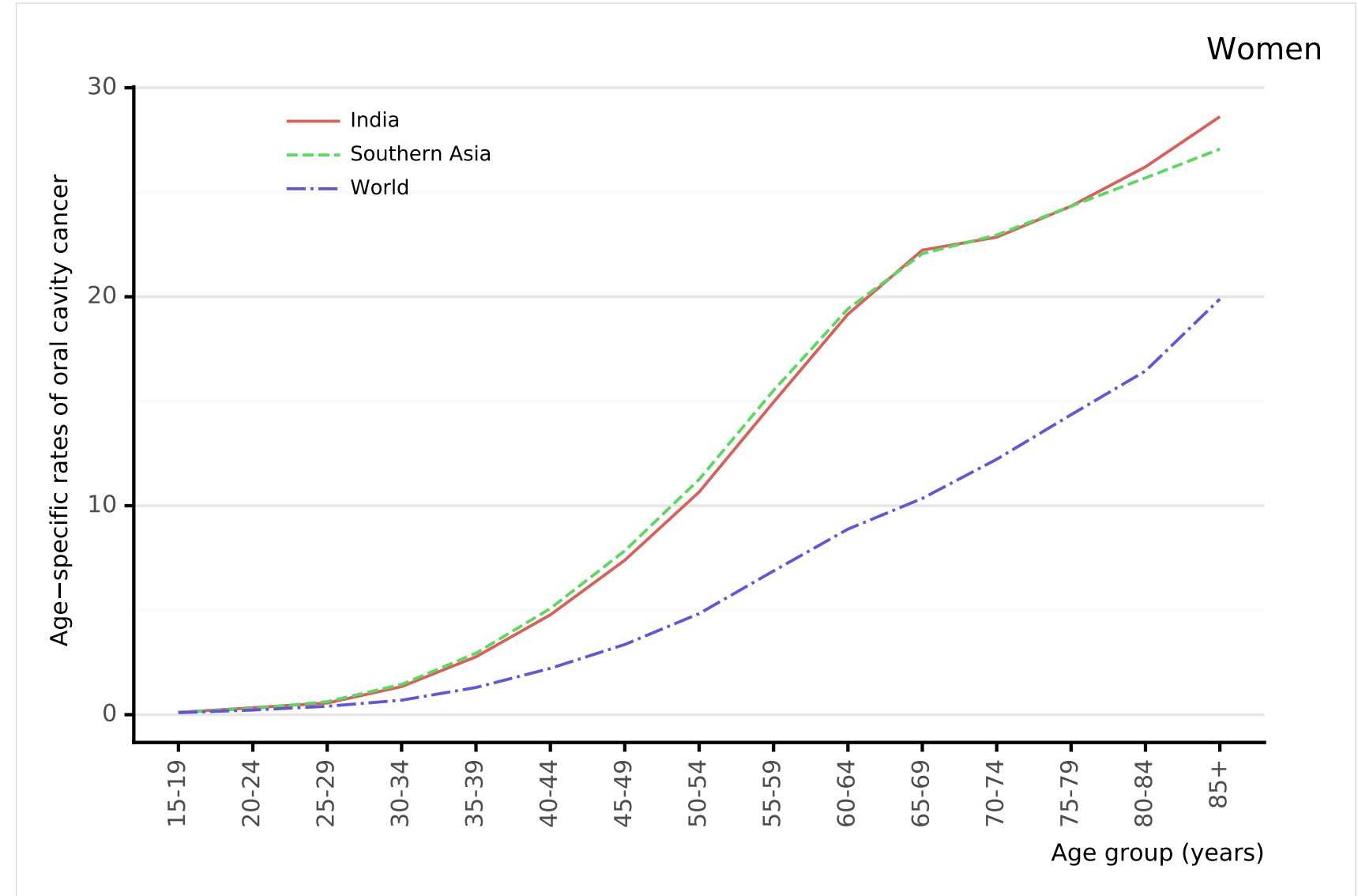

Data accessed on 27 Jan 2021

For more detailed methods of estimation please refer to http://gco.iarc.fr/today/data-sources-methods

${ }^{a}$ Rates per 100,000 women per year.

Derlay J, Ervik M, Lam F, Colombet M, Mery L, Piñeros M, Znaor A, Soerjomataram I, Bray F (2020). Global Cancer Observatory: Cancer Today. Lyon, France: International Agency for Research on Cancer. Available from: https ://gco.iarc.fr/today, accessed [27 January 2021]. 


\subsubsection{Laryngeal cancer incidence in India across Southern Asia}

Figure 100: Age-standardised incidence rates of laryngeal cancer of India (estimates for 2020)

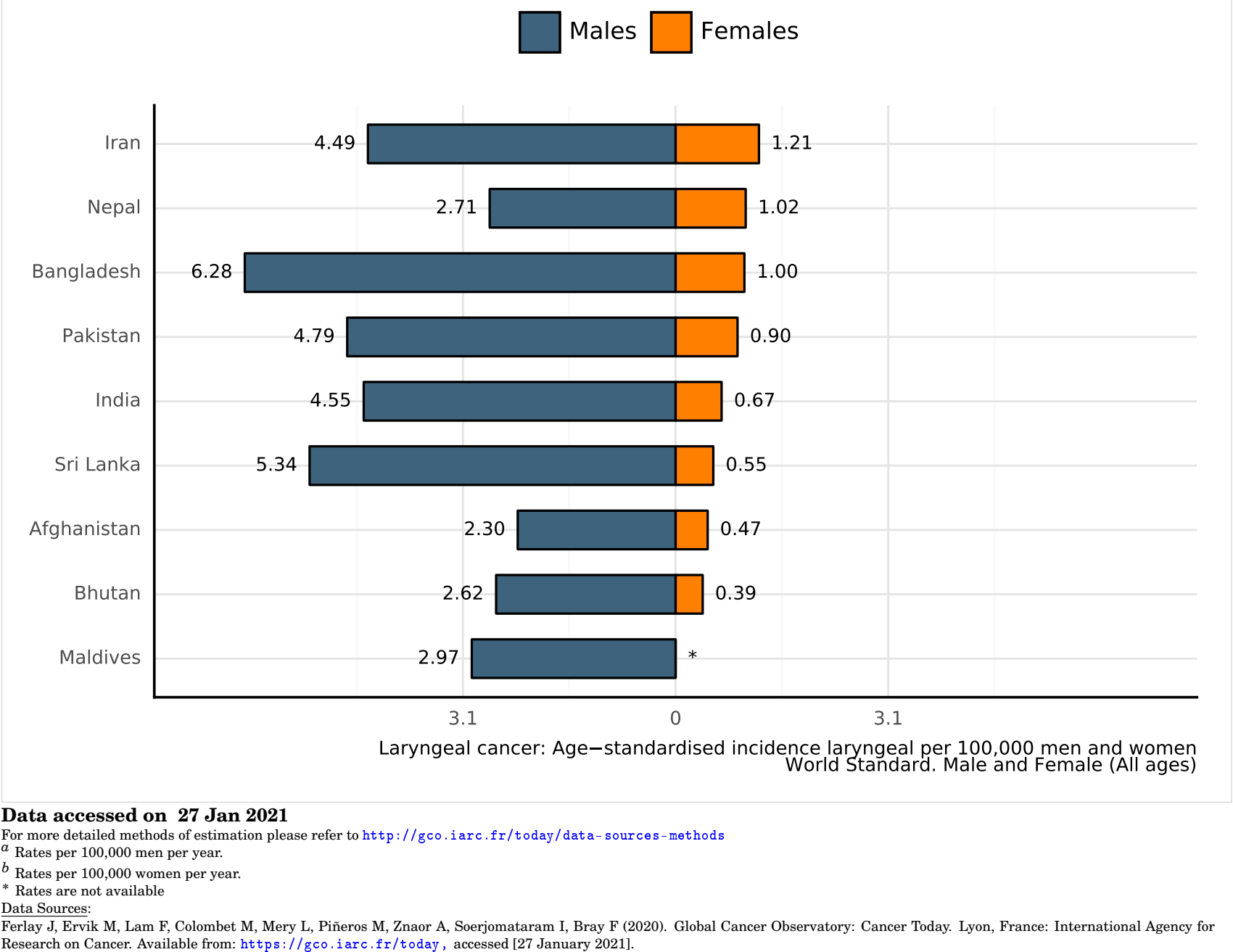


Figure 101: Annual number of new cases of laryngeal cancer among men by age group in India (estimates for 2020)

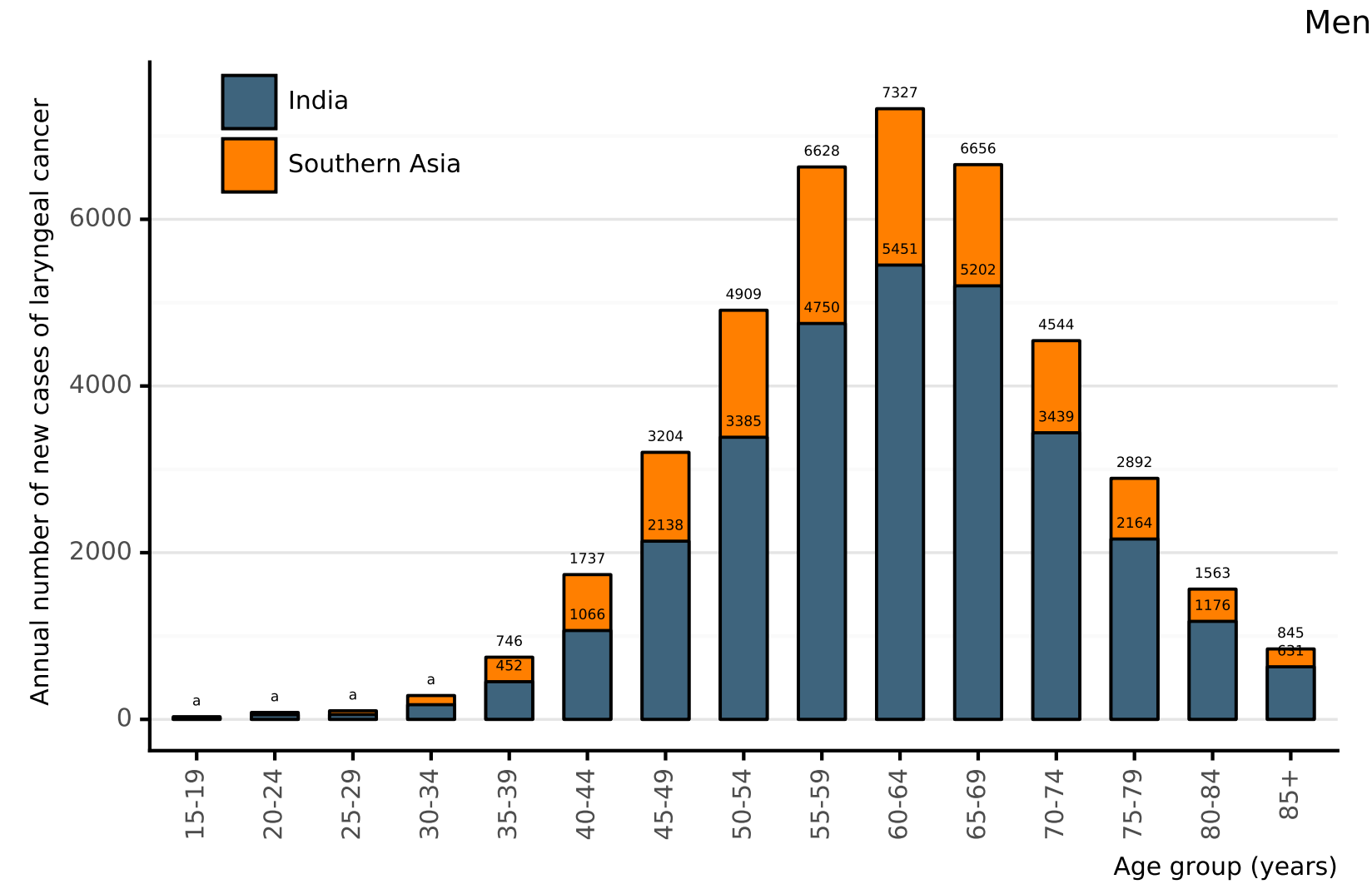

\section{Data accessed on 27 Jan 2021}

For more detailed methods of estimation please rer to

${ }^{a} 19$ cases for India and 32 cases for Southern Asia in the 15-19 age group. 55 cases for India and 83 cases for Southern Asia in the 20-24 age group. 58 cases for India and 103 cases for Southern Asia in the 25-29 age group. 176 cases for India and 286 cases for Southern Asia in the 30-34 age group.

Ferlay J, Ervik M, Lam F, Colombet M, Mery L, Piñeros M, Znaor A, Soerjomataram I, Bray F (2020). Global Cancer Observatory: Cancer Today. Lyon, France: International Agency for Research on Cancer. Available from: https://gco.iarc.fr/today, accessed [27 January 2021]. 
Figure 102: Annual number of new cases of laryngeal cancer among women by age group in India (estimates for 2020)

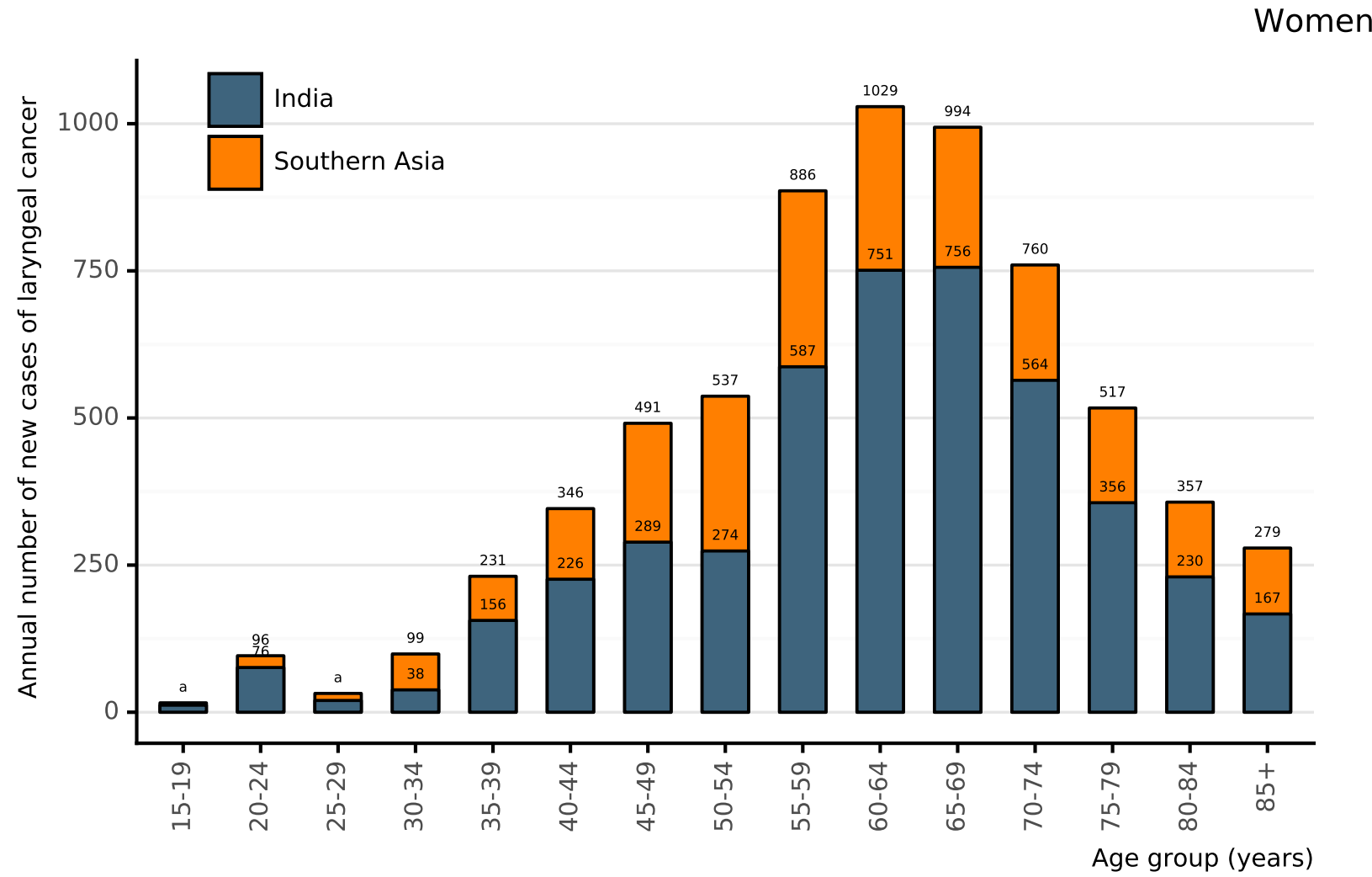

Data accessed on 27 Jan 2021

For more detailed methods of estimation please refer to http://gco.iarc.fr/today/data-sources-methods

$a_{12}$ cases for India and 16 cases for Southern Asia in the 15-19 age group. 20 cases for India and 32 cases for Southern Asia in the 25-29 age group.

Ferlay J, Ervik M, Lam F, Colombet M, Mery L, Piñeros M, Znaor A, Soerjomataram I, Bray F (2020). Global Cancer Observatory: Cancer Today. Lyon, France: International Agency for Research on Cancer. Available from: https://gco.iarc.fr/today, accessed [27 January 2021]. 
Figure 103: Comparison of age-specific laryngeal cancer incidence rates among men by age in India, within the region, and the rest of world

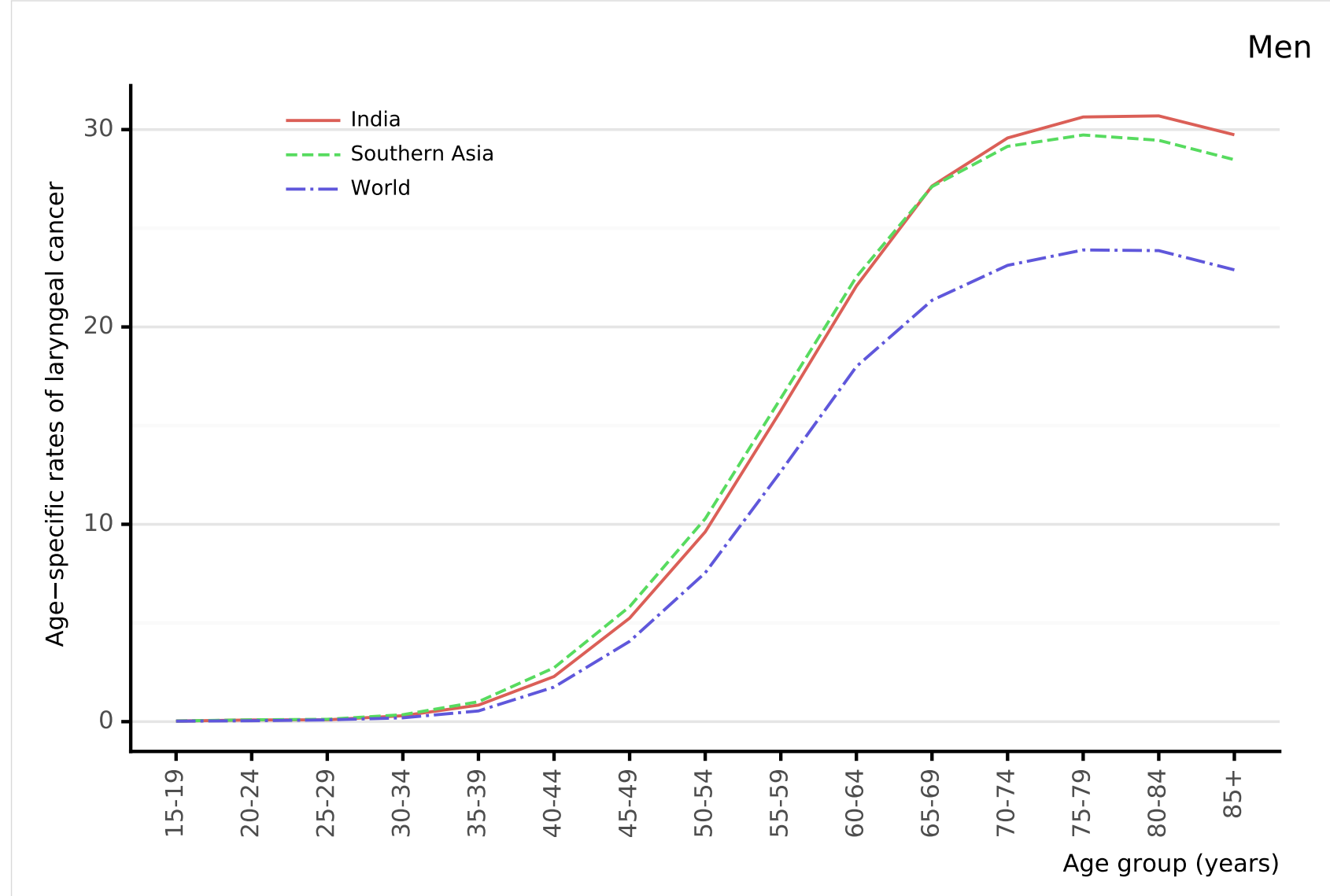

Data accessed on 27 Jan 2021

For more detailed methods of estimation please refer to http://gco.iarc.fr/today/data-sources-methods

${ }^{a}$ Rates per 100,000 men per year.

Ferlay J, Ervik M, Lam F, Colombet M, Mery L, Piñeros M, Znaor A, Soerjomataram I, Bray F (2020). Global Cancer Observatory: Cancer Today. Lyon, France: International Agency for Research on Cancer. Available from: https://gco.iarc.fr/today, accessed [27 January 2021]. 
Figure 104: Comparison of age-specific laryngeal cancer incidence rates among women by age in India, within the region, and the rest of world

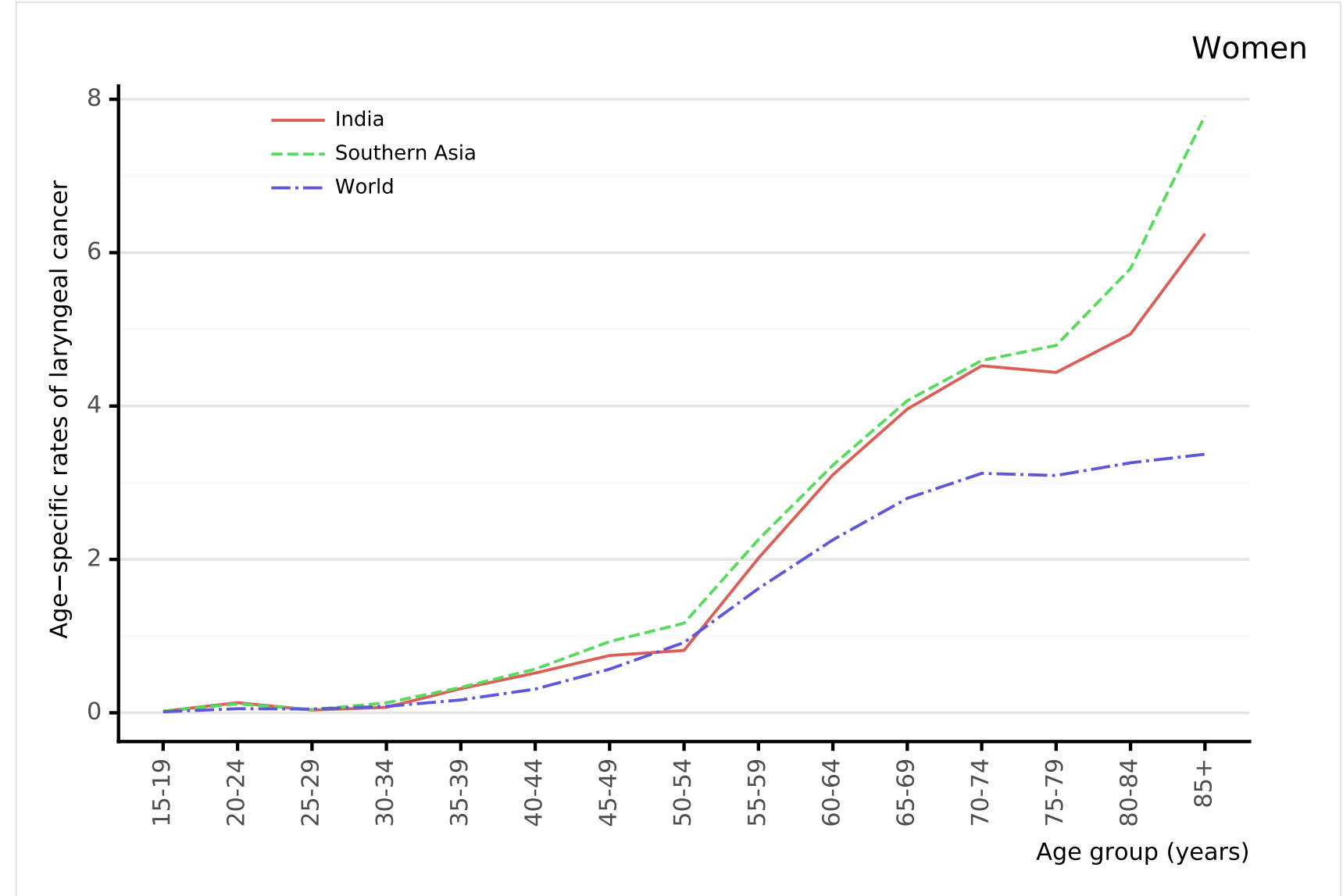

Data accessed on 27 Jan 2021

For more detailed methods of estimation please refer to http://gco.iarc.fr/today/data-sources-methods

${ }^{a}$ Rates per 100,000 women per year.

Ferlay J, Ervik M, Lam F, Colombet M, Mery L, Piñeros M, Znaor A, Soerjomataram I, Bray F (2020). Global Cancer Observatory: Cancer Today. Lyon, France: International Agency for Research on Cancer. Available from: https://gco.iarc.fr/today, accessed [27 January 2021]. 


\subsection{Mortality}

\subsubsection{Cervical cancer mortality in India across Southern Asia}

Figure 105: Age-standardised mortality rates of cervical cancer of India (estimates for 2020)

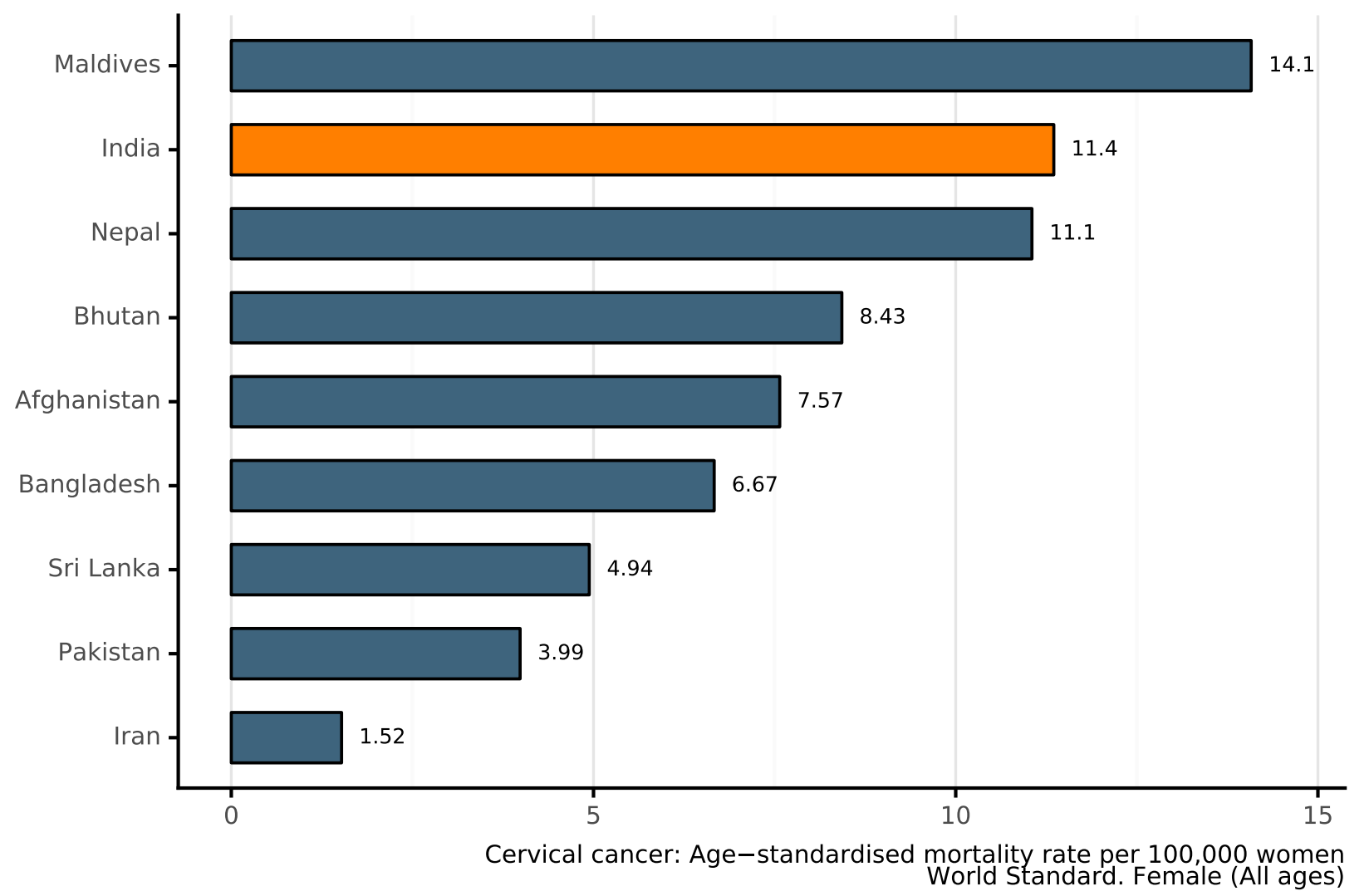

Data accessed on 27 Jan 2021

For more detailed methods of estimation please refer to http://gco.iarc.fr/today/data-sources-methods

${ }^{a}$ Rates per 100,000 women per year.

Ferlay J, Ervik M, Lam F, Colombet M, Mery L, Piñeros M, Znaor A, Soerjomataram I, Bray F (2020). Global Cancer Observatory: Cancer Today. Lyon, France: International Agency for Research on Cancer. Available from: https://gco.iarc.fr/today, accessed [27 January 2021]. 
Figure 106: Annual number of deaths of cervical cancer by age group in India (estimates for 2020)

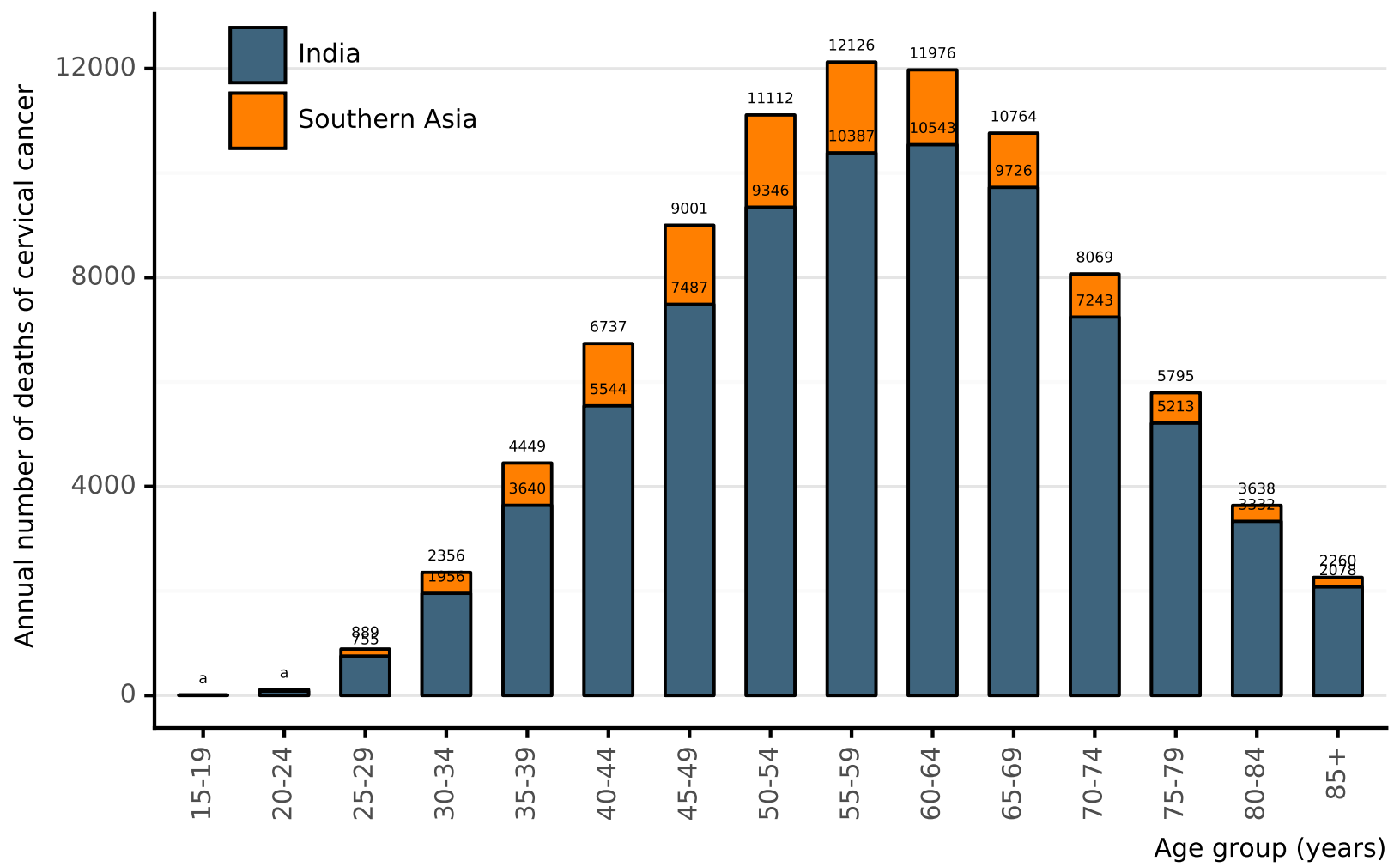

Data accessed on 27 Jan 2021

For more detailed methods of estimation please refer to http://gco.iarc.fr/today/data-sources-methods

${ }^{a} 7$ cases for India and 10 cases for Southern Asia in the 15-19 age group. 83 cases for India and 116 cases for Southern Asia in the 20-24 age group.

Ferlay J, Ervik M, Lam F, Colombet M, Mery L, Piñeros M, Znaor A, Soerjomataram I, Bray F (2020). Global Cancer Observatory: Cancer Today. Lyon, France: International Agency for Research on Cancer. Available from: https://gco.iarc.fr/today, accessed [27 January 2021]. 
Figure 107: Comparison of age-specific cervical cancer mortality rates in India, within the region, and the rest of world

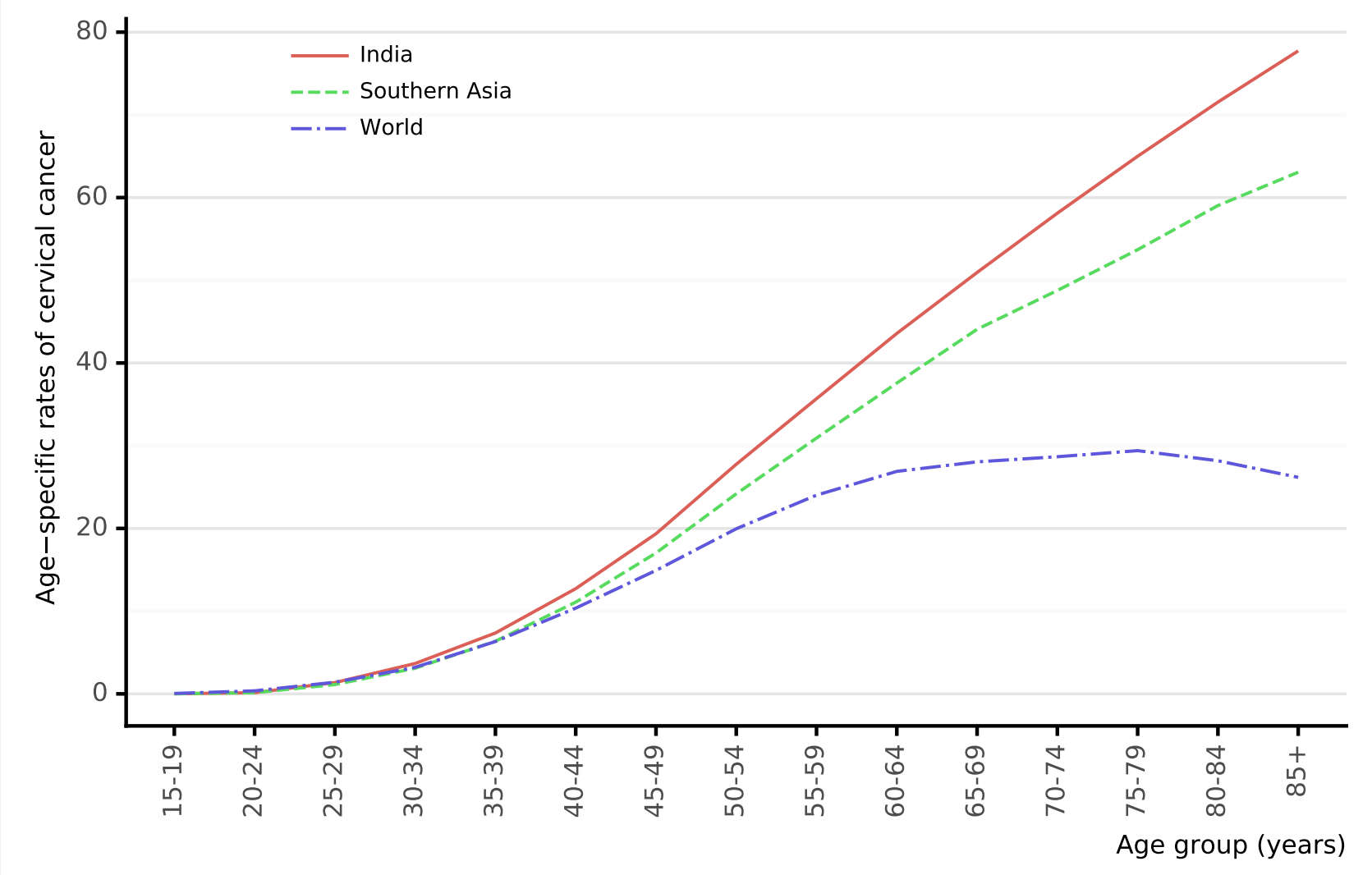

Data accessed on 27 Jan 2021

For more detailed methods of estimation please refer to http://gco.iarc.fr/today/data-sources-methods

Data Sources:

Ferlay J, Ervik M, Lam F, Colombet M, Mery L, Piñeros M, Znaor A, Soerjomataram I, Bray F (2020). Global Cancer Observatory: Cancer Today. Lyon, France: International Agency for Research on Cancer. Available from: https://gco.iarc.fr/today, accessed [27 January 2021]. 


\subsubsection{Anal cancer mortality in India across Southern Asia}

Figure 108: Age-standardised mortality rates of anal cancer of India (estimates for 2020)

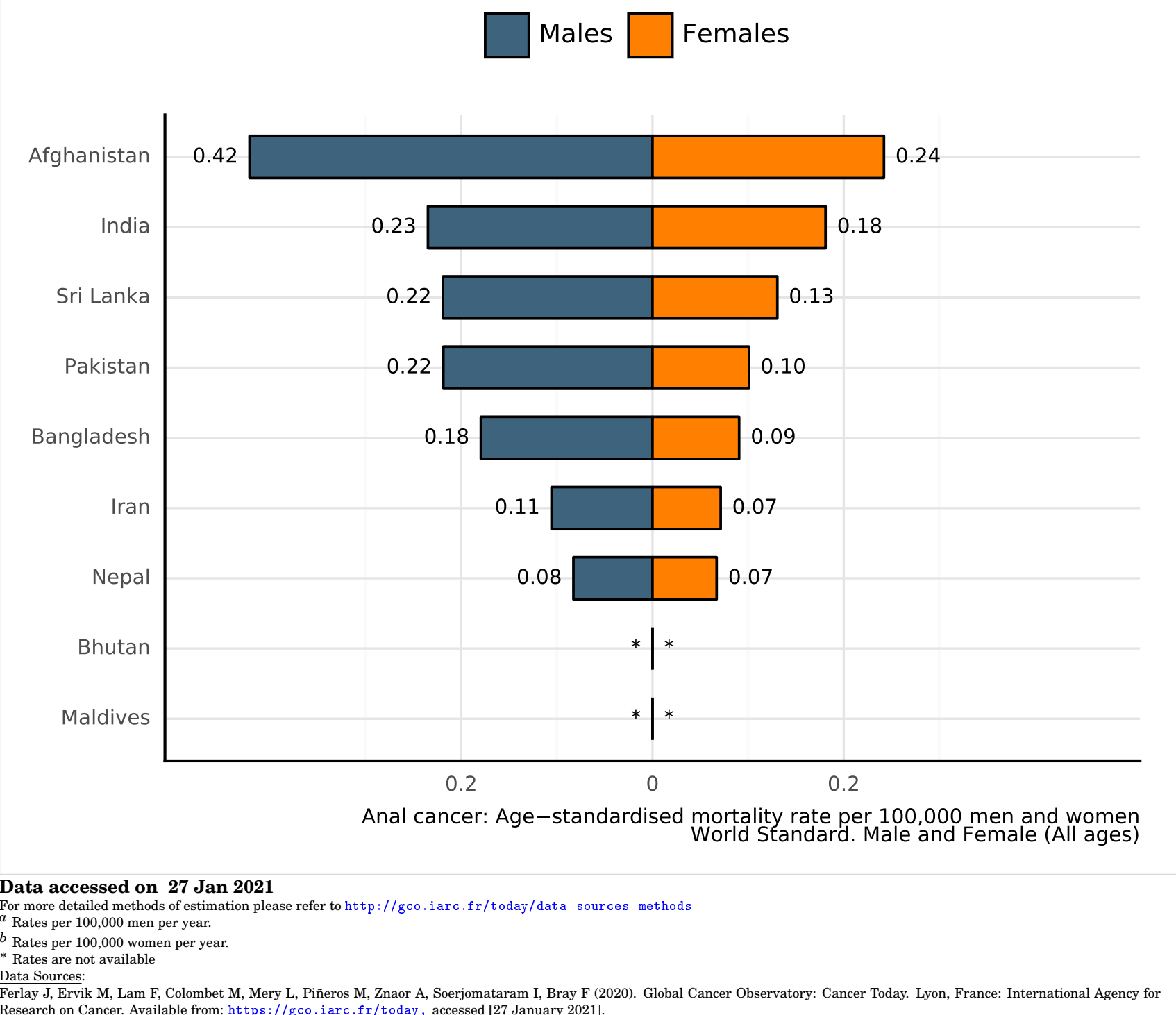


Figure 109: Annual number of deaths of anal cancer among men by age group in India (estimates for 2020)

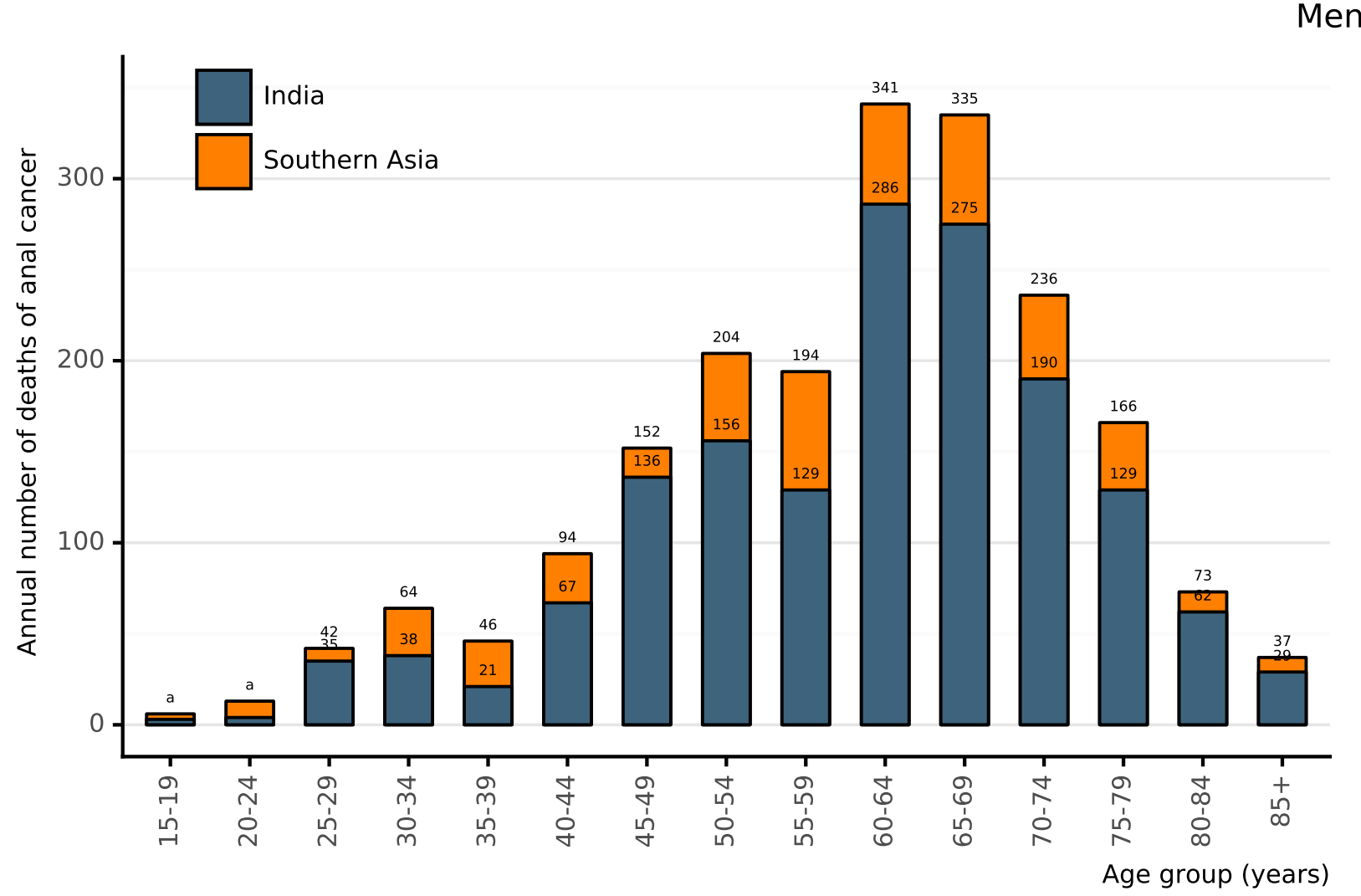

Data accessed on 27 Jan 2021

For more detailed methods of estimation please refer to http://gco.iarc.fr/today/data-sources-methods

${ }^{a} 3$ cases for India and 6 cases for Southern Asia in the 15-19 age group. 4 cases for India and 13 cases for Southern Asia in the 20-24 age group.

Data Sources:

Ferlay J, Ervik M, Lam F, Colombet M, Mery L, Piñeros M, Znaor A, Soerjomataram I, Bray F (2020). Global Cancer Observatory: Cancer Today. Lyon, France: International Agency for Research on Cancer. Available from: https ://gco.iarc.fr/today, accessed [27 January 2021]. 
Figure 110: Annual number of deaths of anal cancer among women by age group in India (estimates for 2020)

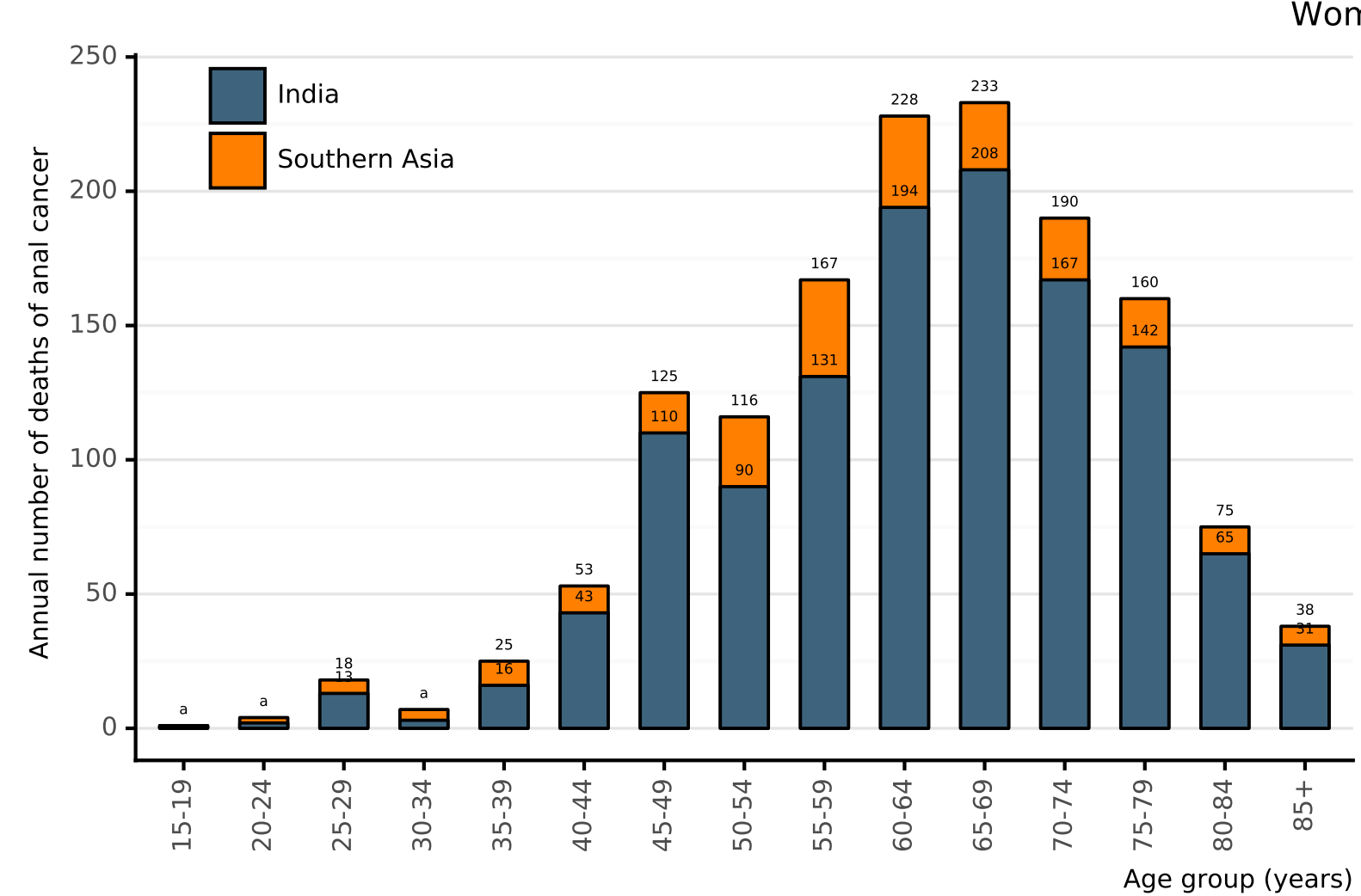

Data accessed on 27 Jan 2021

For more detailed methods of estimation please refer to http://gco.iarc.fr/today/data-sources-methods

${ }^{a} 1$ cases for India and 1 cases for Southern Asia in the 15-19 age group. 2 cases for India and 4 cases for Southern Asia in the 20-24 age group. 3 cases for India and 7 cases for Southern Asia in the 30-34 age group.

Ferlay J, Ervik M, Lam F, Colombet M, Mery L, Piñeros M, Znaor A, Soerjomataram I, Bray F (2020). Global Cancer Observatory: Cancer Today. Lyon, France: International Agency for Research on Cancer. Available from: https ://gco.iarc.fr/today, accessed [27 January 2021]. 
Figure 111: Comparison of age-specific anal cancer mortality rates among men by age in India, within the region, and the rest of world

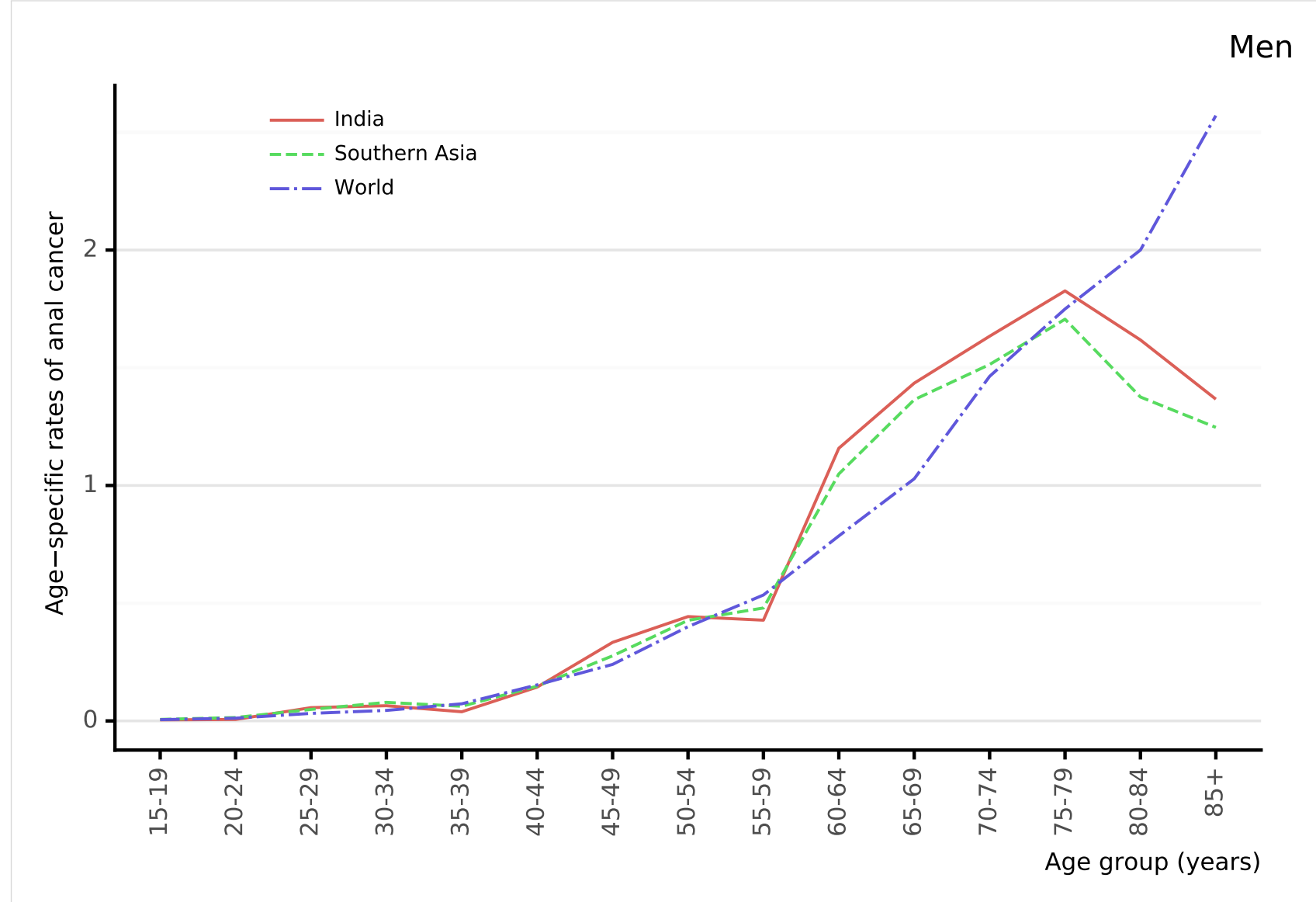

Data accessed on 27 Jan 2021

For more detailed methods of estimation please refer to http://gco.iarc.fr/today/data-sources-methods

${ }^{a}$ Rates per 100,000 men per year.

Ferlay J, Ervik M, Lam F, Colombet M, Mery L, Piñeros M, Znaor A, Soerjomataram I, Bray F (2020). Global Cancer Observatory: Cancer Today. Lyon, France: International Agency for Research on Cancer. Available from: https://gco.iarc.fr/today, accessed [27 January 2021]. 
Figure 112: Comparison of age-specific anal cancer mortality rates among women by age in India, within the region, and the rest of world

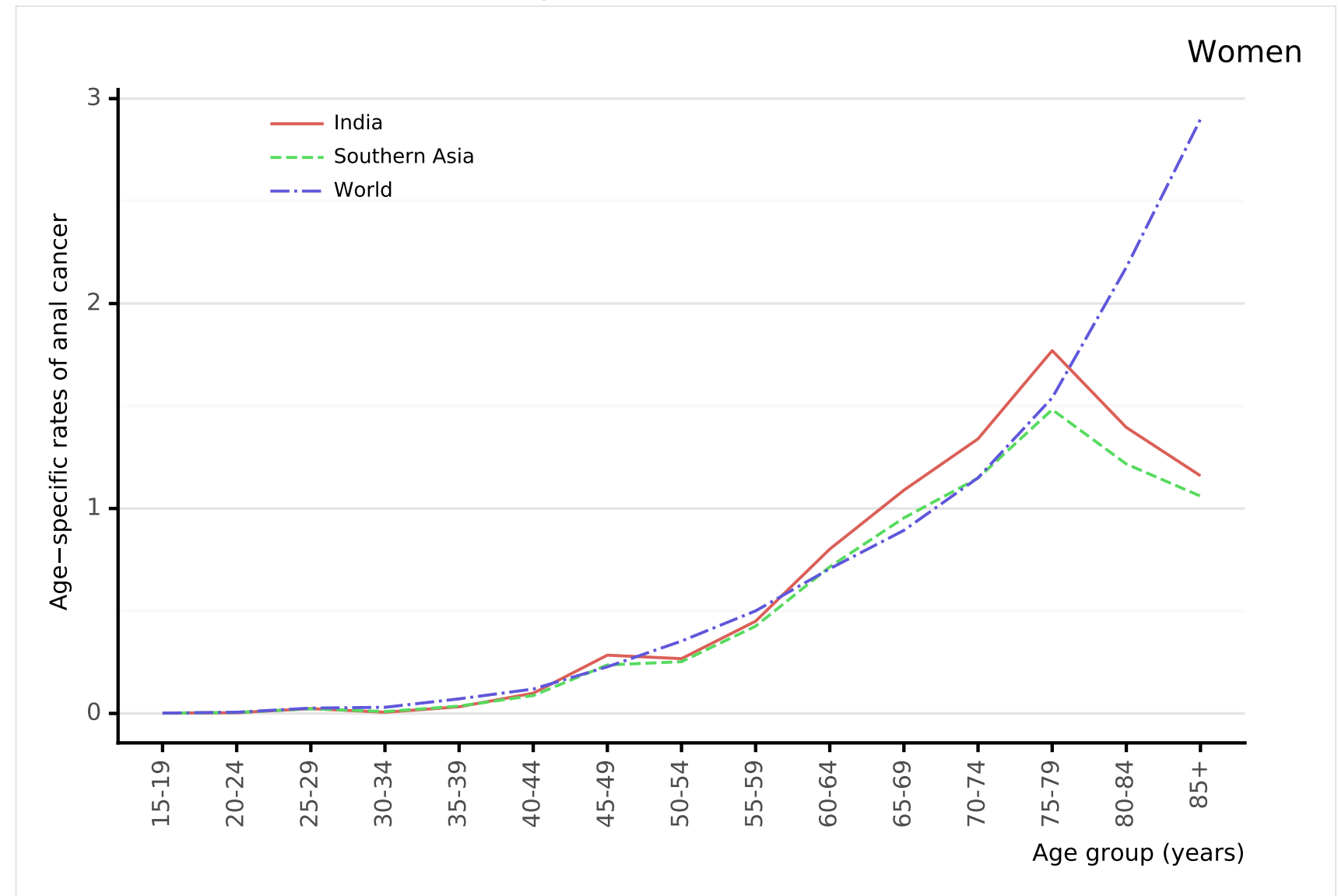

Data accessed on 27 Jan 2021

For more detailed methods of estimation please refer to http://gco.iarc.fr/today/data-sources-methods

${ }^{a}$ Rates per 100,000 women per year.

Ferlay J, Ervik M, Lam F, Colombet M, Mery L, Piñeros M, Znaor A, Soerjomataram I, Bray F (2020). Global Cancer Observatory: Cancer Today. Lyon, France: International Agency for Research on Cancer. Available from: https://gco.iarc.fr/today, accessed [27 January 2021]. 


\subsubsection{Vulva cancer mortality in India across Southern Asia}

Figure 113: Age-standardised mortality rates of vulva cancer of India (estimates for 2020)

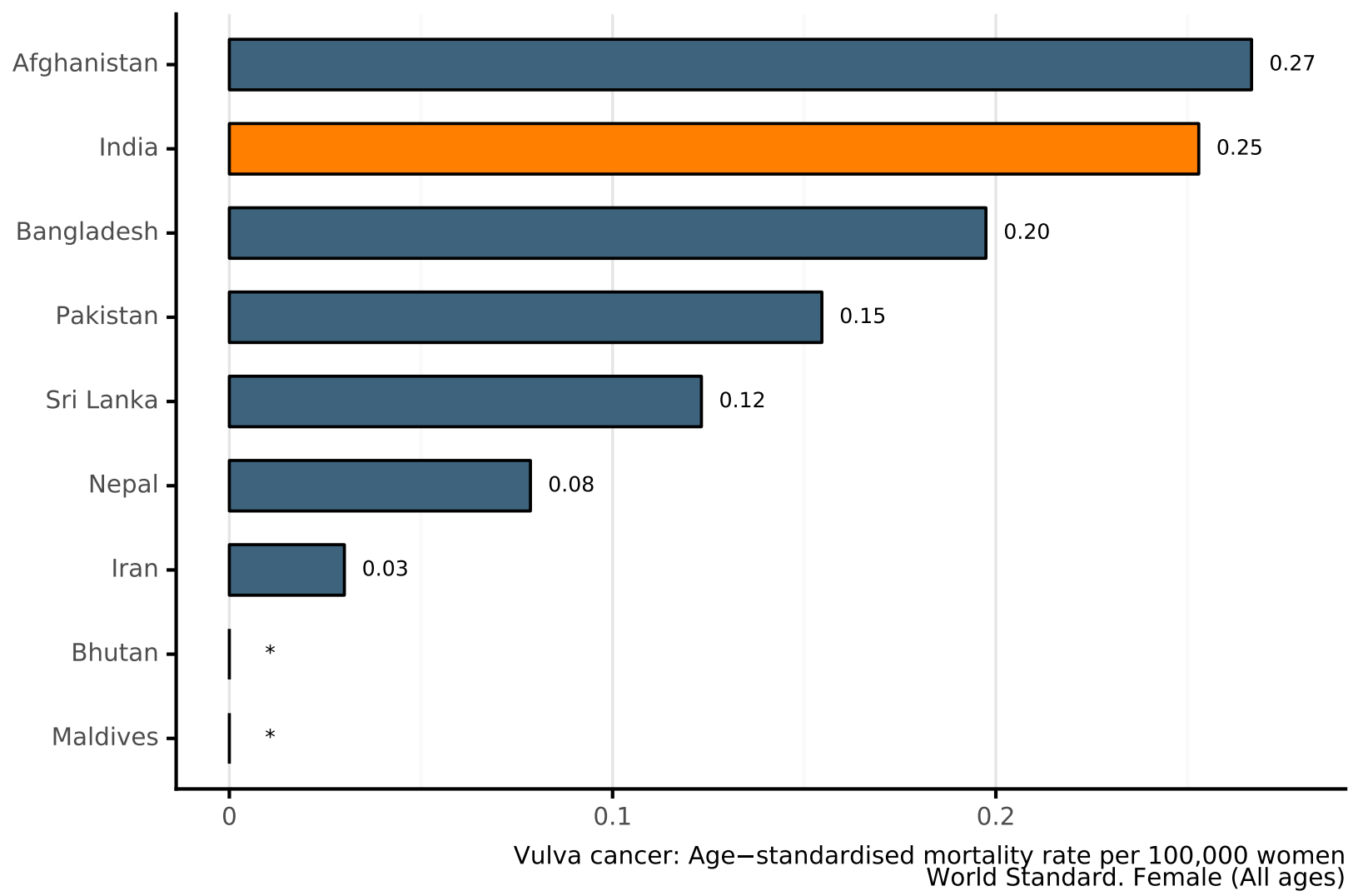

Data accessed on 27 Jan 2021

For more detailed methods of estimation please refer to http://gco.iarc.fr/today/data-sources-methods

${ }^{a}$ Rates per 100,000 women per year.

* Rates are not available

Data Sources:

Ferlay J, Ervik M, Lam F, Colombet M, Mery L, Piñeros M, Znaor A, Soerjomataram I, Bray F (2020). Global Cancer Observatory: Cancer Today. Lyon, France: International Agency for Research on Cancer. Available from: https ://gco.iarc.fr/today, accessed [27 January 2021]. 
Figure 114: Annual number of deaths of vulva cancer by age group in India (estimates for 2020)

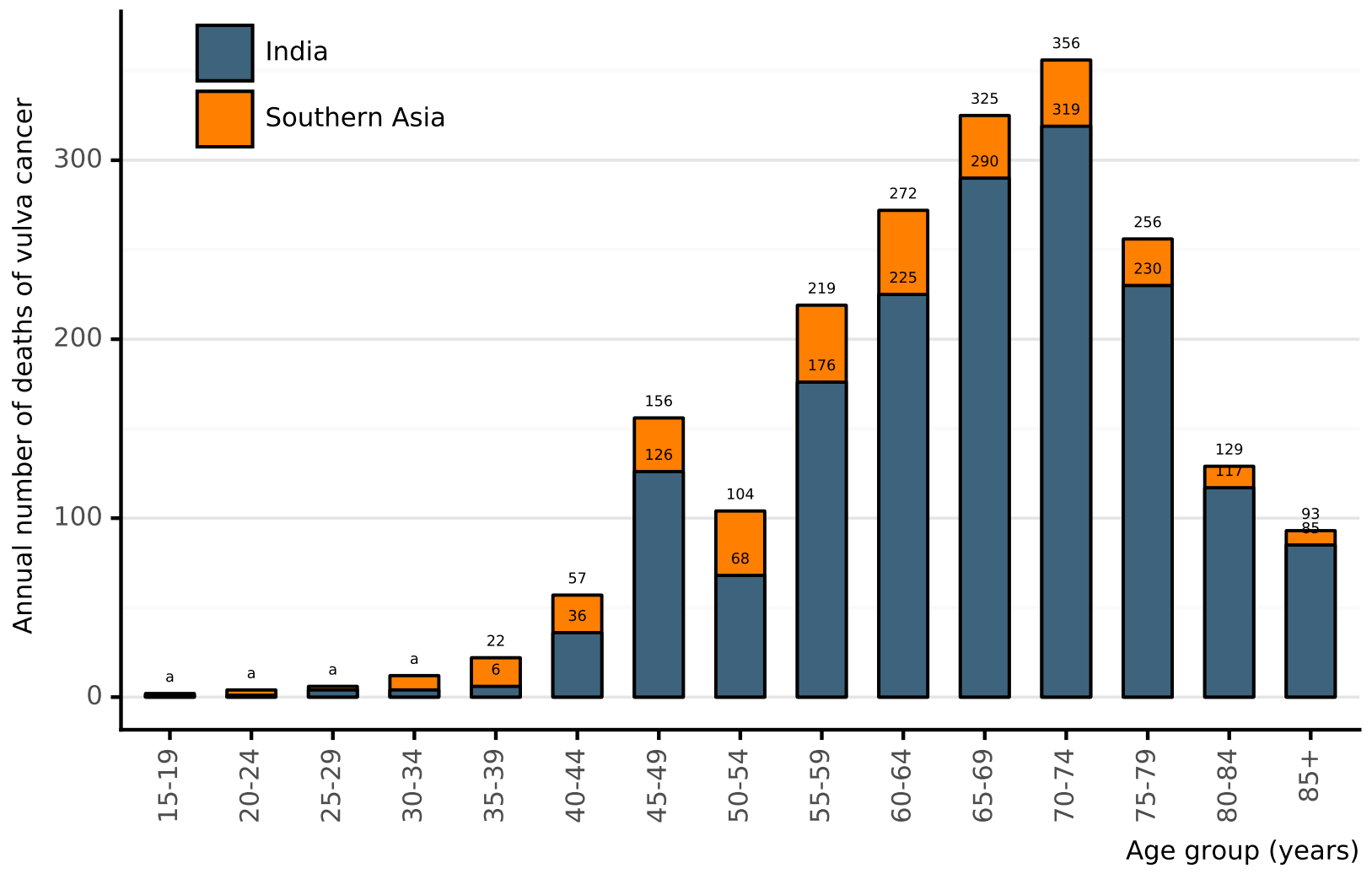

Data accessed on 27 Jan 2021

For more detailed methods of estimation please refer to http://gco.iarc.fr/today/data-sources-methods

$a_{1} 1$ cases for India and 2 cases for Southern Asia in the 15-19 age group. 1 cases for India and 4 cases for Southern Asia in the 20-24 age group. 4 cases for India and 6 cases for Southern Asia in the 25-29 age group. 4 cases for India and 12 cases for Southern Asia in the 30-34 age group.

Data Sources:

Ferlay J, Ervik M, Lam F, Colombet M, Mery L, Piñeros M, Znaor A, Soerjomataram I, Bray F (2020). Global Cancer Observatory: Cancer Today. Lyon, France: International Agency for Research on Cancer. Available from: https ://gco.iarc.fr/today, accessed [27 January 2021]. 
Figure 115: Comparison of age-specific vulva cancer mortality rates in India, within the region, and the rest of world

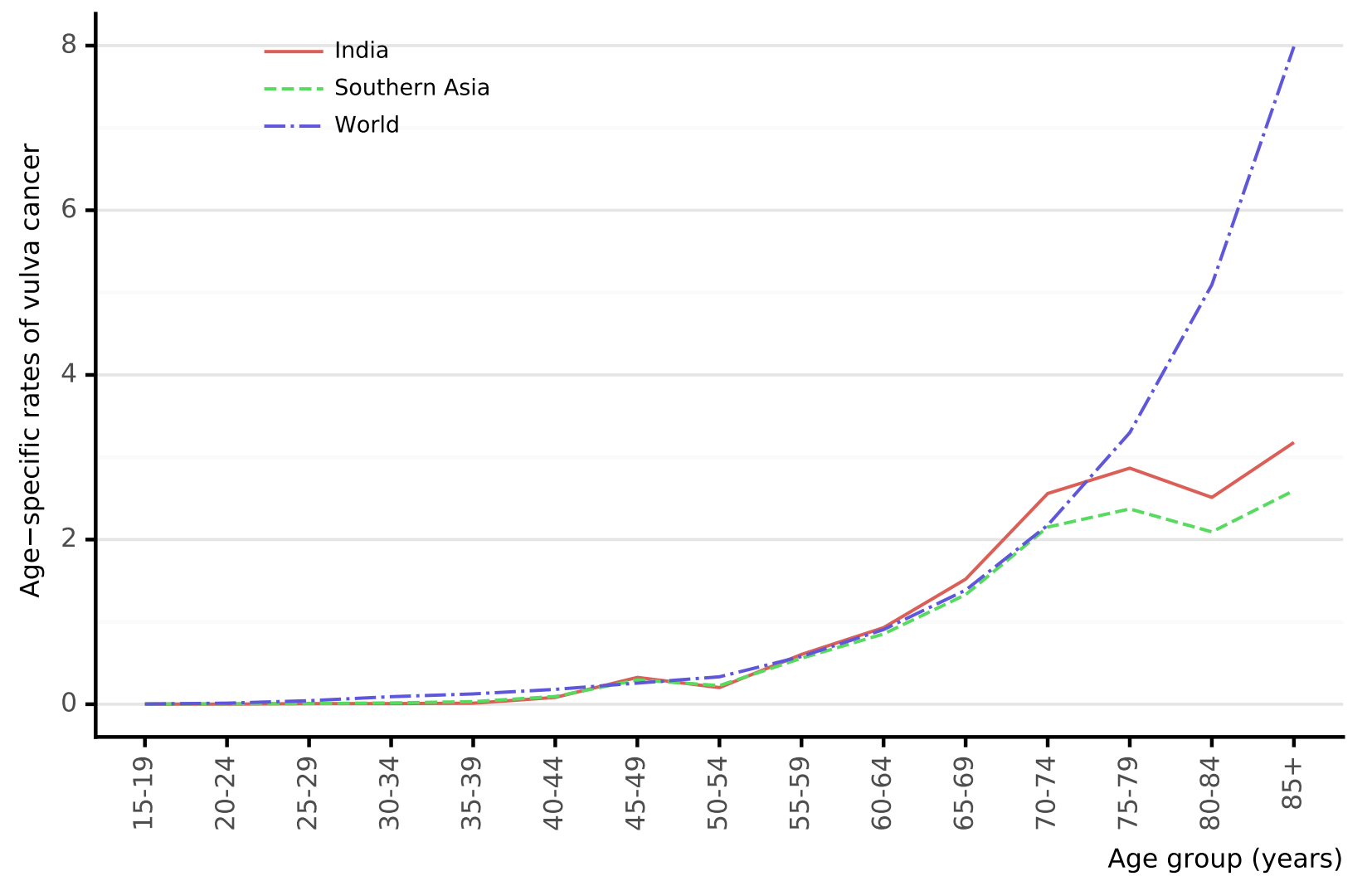

Data accessed on 27 Jan 2021

For more detailed methods of estimation please refer to http://gco.iarc.fr/today/data-sources-methods

For more detailed methods of estimation
Rates per 100,000 women per year.

Data Sources:

Ferlay J, Ervik M, Lam F, Colombet M, Mery L, Piñeros M, Znaor A, Soerjomataram I, Bray F (2020). Global Cancer Observatory: Cancer Today. Lyon, France: International Agency for Research on Cancer. Available from: https ://gco.iarc.fr/today, accessed [27 January 2021]. 


\subsubsection{Vaginal cancer mortality in India across Southern Asia}

Figure 116: Age-standardised mortality rates of vaginal cancer of India (estimates for 2020)

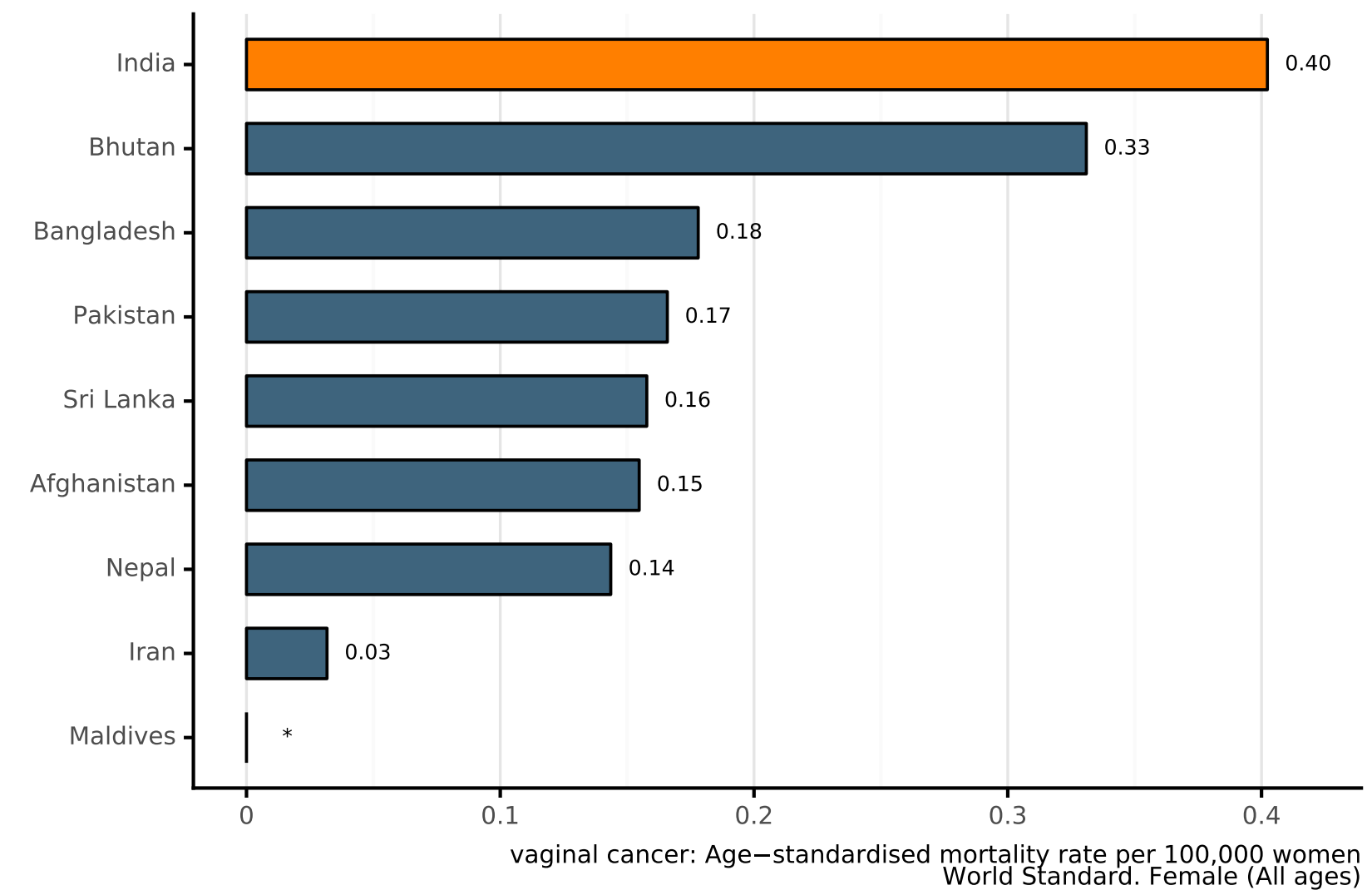

Data accessed on 27 Jan 2021

For more detailed methods of estimation please refer to http://gco.iarc.fr/today/data-sources-methods

$a^{a}$ Rates per 100,000 women per year.

* Rates are not available

Data Sources:

Ferlay J, Ervik M, Lam F, Colombet M, Mery L, Piñeros M, Znaor A, Soerjomataram I, Bray F (2020). Global Cancer Observatory: Cancer Today. Lyon, France: International Agency for Research on Cancer. Available from: https://gco.iarc.fr/today, accessed [27 January 2021]. 
Figure 117: Annual number of deaths of cervical cancer by age group in India (estimates for 2020)

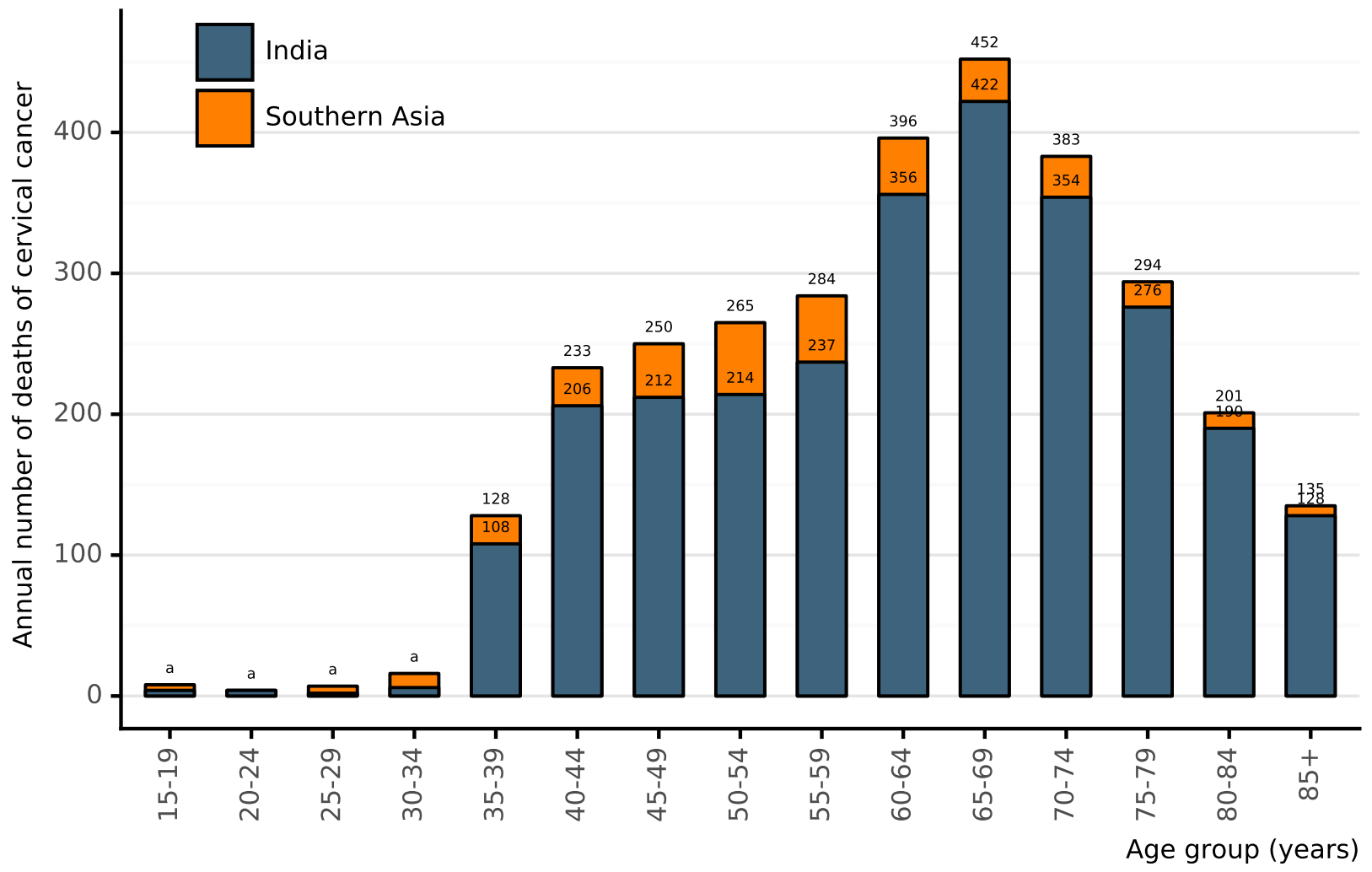

Data accessed on 27 Jan 2021

For more detailed methods of estimation please refer to http://gco.iarc.fr/today/data-sources-methods

$a_{4}$ cases for India and 8 cases for Southern Asia in the 15-19 age group. 4 cases for India and 4 cases for Southern Asia in the 20-24 age group. 2 cases for India and 7 cases for Southern Asia in the 25-29 age group. 6 cases for India and 16 cases for Southern Asia in the 30-34 age group.

Ferlay J, Ervik M, Lam F, Colombet M, Mery L, Piñeros M, Znaor A, Soerjomataram I, Bray F (2020). Global Cancer Observatory: Cancer Today. Lyon, France: International Agency for Research on Cancer. Available from: https ://gco.iarc.fr/today, accessed [27 January 2021]. 
Figure 118: Comparison of age-specific vaginal cancer mortality rates in India, within the region, and the rest of world

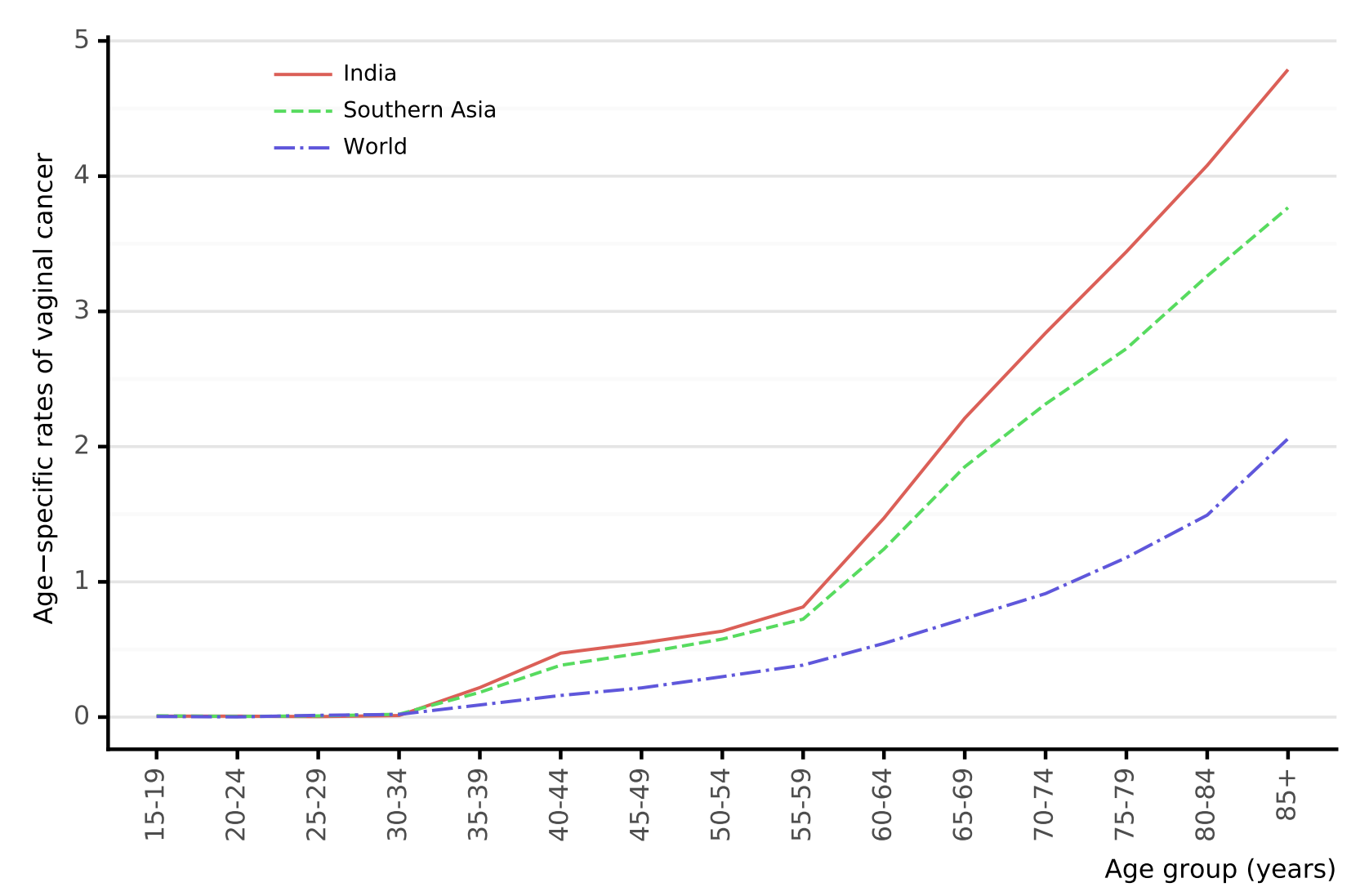

Data accessed on 27 Jan 2021

For more detailed methods of estimation please refer to http://gco.iarc.fr/today/data-sources-methods

$a$ Rates per 100,000 women per year.

Data Sources:

Ferlay J, Ervik M, Lam F, Colombet M, Mery L, Piñeros M, Znaor A, Soerjomataram I, Bray F (2020). Global Cancer Observatory: Cancer Today. Lyon, France: International Agency for Research on Cancer. Available from: https ://gco.iarc.fr/today, accessed [27 January 2021]. 


\subsubsection{Penile cancer mortality in India across Southern Asia}

Figure 119: Age-standardised mortality rates of penile cancer of India (estimates for 2020)

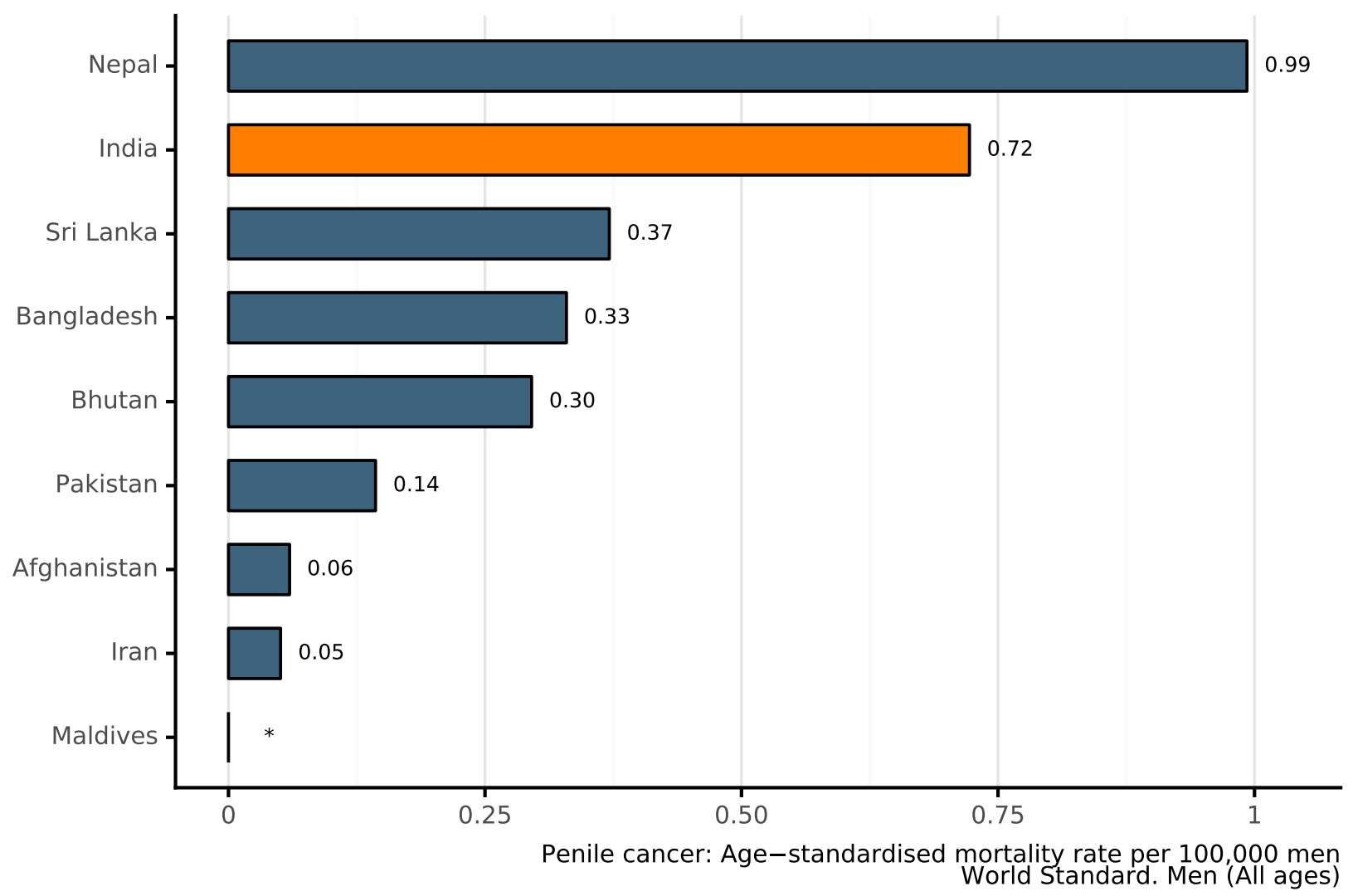

Data accessed on 27 Jan 2021

For more detailed methods of estimation please refer to http://gco.iarc.fr/today/data-sources-methods

${ }^{a}$ Rates per 100,000 men per year.

* Rates are not available

Data Sources:

Ferlay J, Ervik M, Lam F, Colombet M, Mery L, Piñeros M, Znaor A, Soerjomataram I, Bray F (2020). Global Cancer Observatory: Cancer Today. Lyon, France: International Agency for Research on Cancer. Available from: https://gco.iarc.fr/today, accessed [27 January 2021]. 
Figure 120: Annual number of new deaths of penile cancer by age group in India (estimates for 2020)

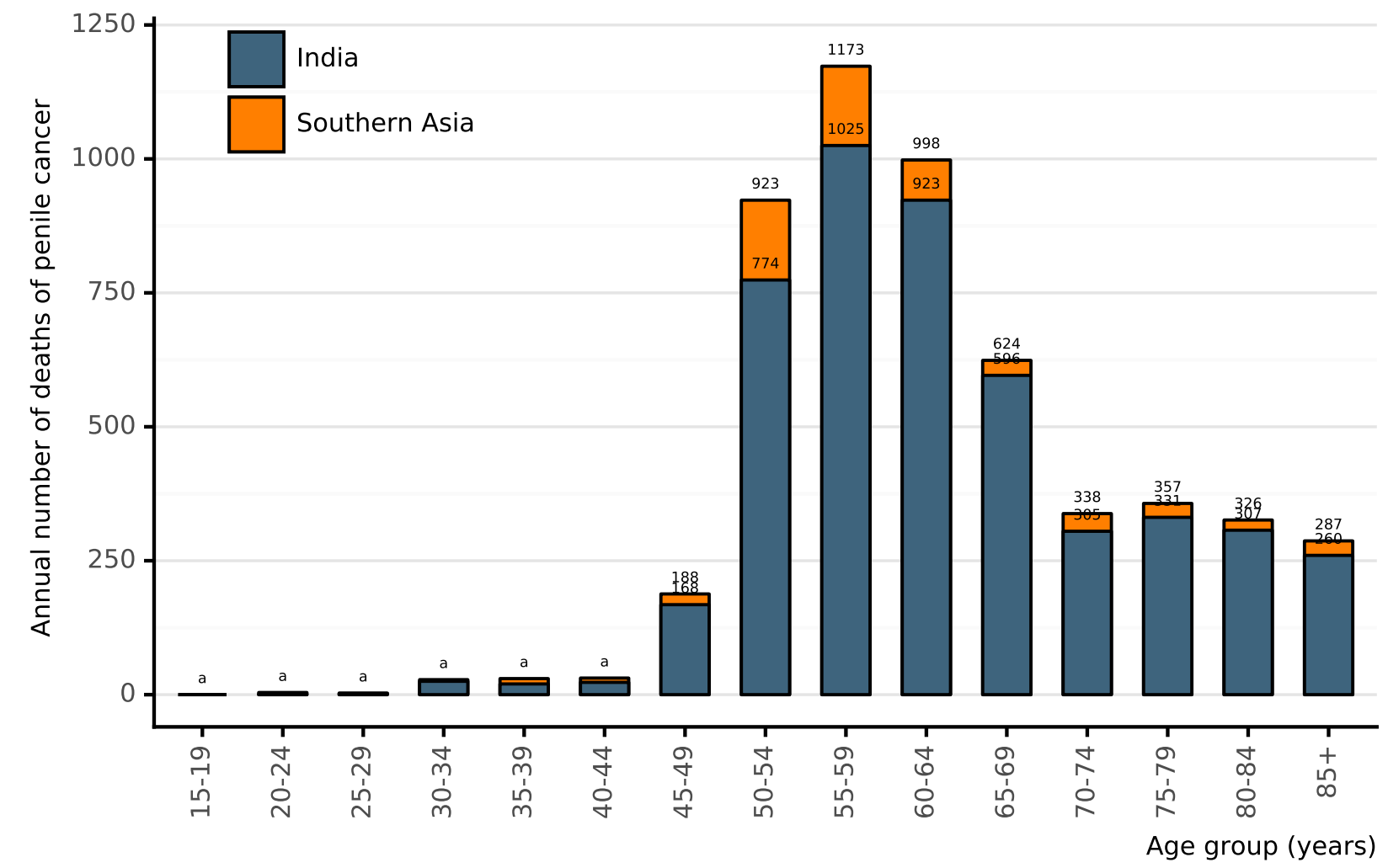

Data accessed on 27 Jan 2021

For more detailed methods of estimation please refer to http://gco.iarc.fr/today/data-sources-methods

$a_{0}$ cases for India and 0 cases for Southern Asia in the 15-19 age group. 1 cases for India and 4 cases for Southern Asia in the 20-24 age group. 2 cases for India and 3 cases for Southern Asia in the 25-29 age group. 25 cases for India and 28 cases for Southern Asia in the 30-34 age group. 20 cases for India and 30 cases for Southern Asia in the 35-39 age group. 23 cases for India and 31 cases for Southern Asia in the 40-44 age group.

Data Sources: Research on Cancer. Available from: https ://gco.iarc.fr/today, accessed [27 January 2021]. 
Figure 121: Comparison of age-specific penile cancer mortality rates in India, within the region, and the rest of world

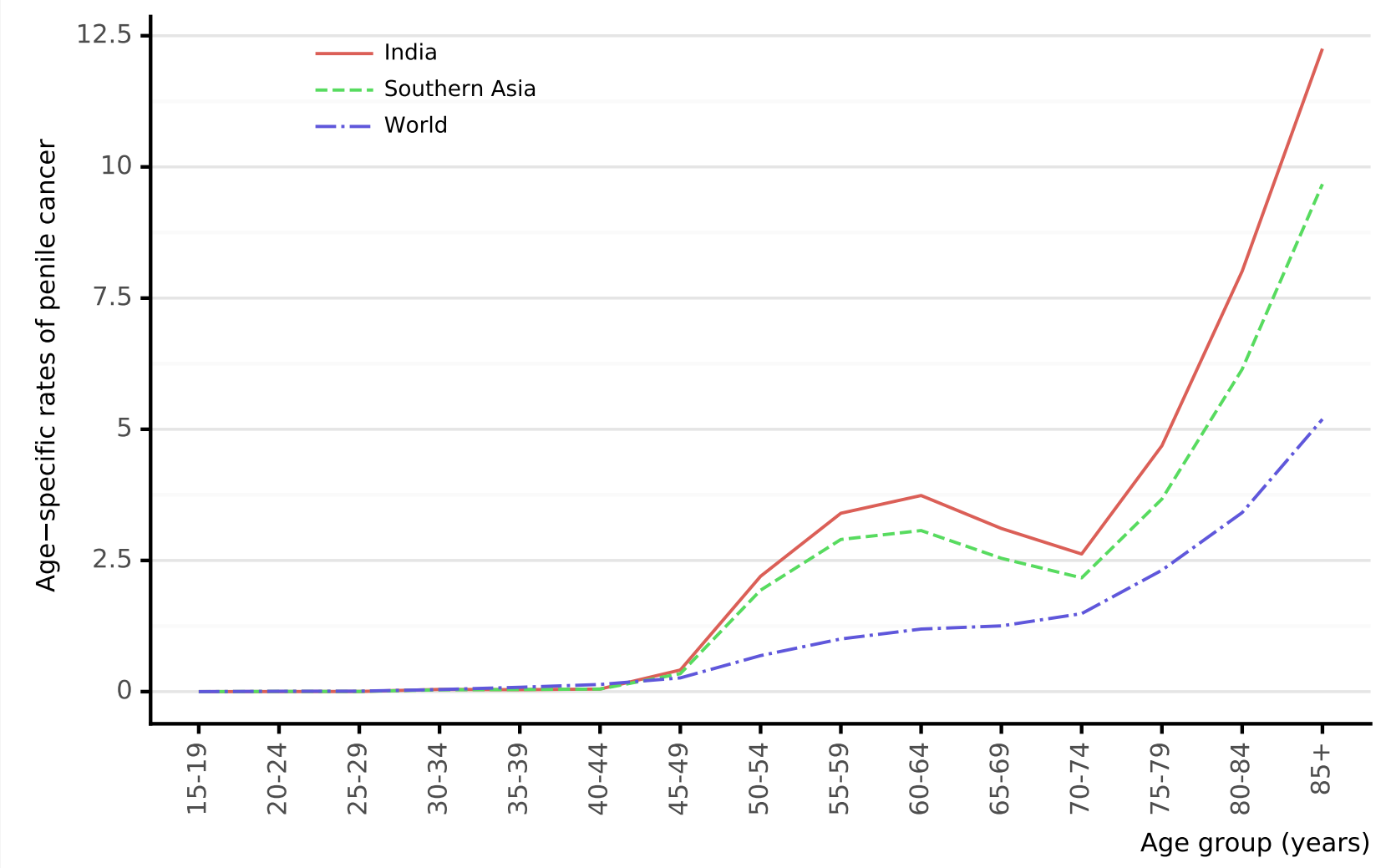

Data accessed on 27 Jan 2021

For more detailed methods of estimation please refer to http://gco.iarc.fr/today/data-sources-methods

${ }^{a}$ Rates per 100,000 men per year.

Ferlay J, Ervik M, Lam F, Colombet M, Mery L, Piñeros M, Znaor A, Soerjomataram I, Bray F (2020). Global Cancer Observatory: Cancer Today. Lyon, France: International Agency for Research on Cancer. Available from: https://gco.iarc.fr/today, accessed [27 January 2021]. 


\subsubsection{Oropharyngeal cancer mortality in India across Southern Asia}

Figure 122: Age-standardised mortality rates of oropharyngeal cancer of India (estimates for 2020)

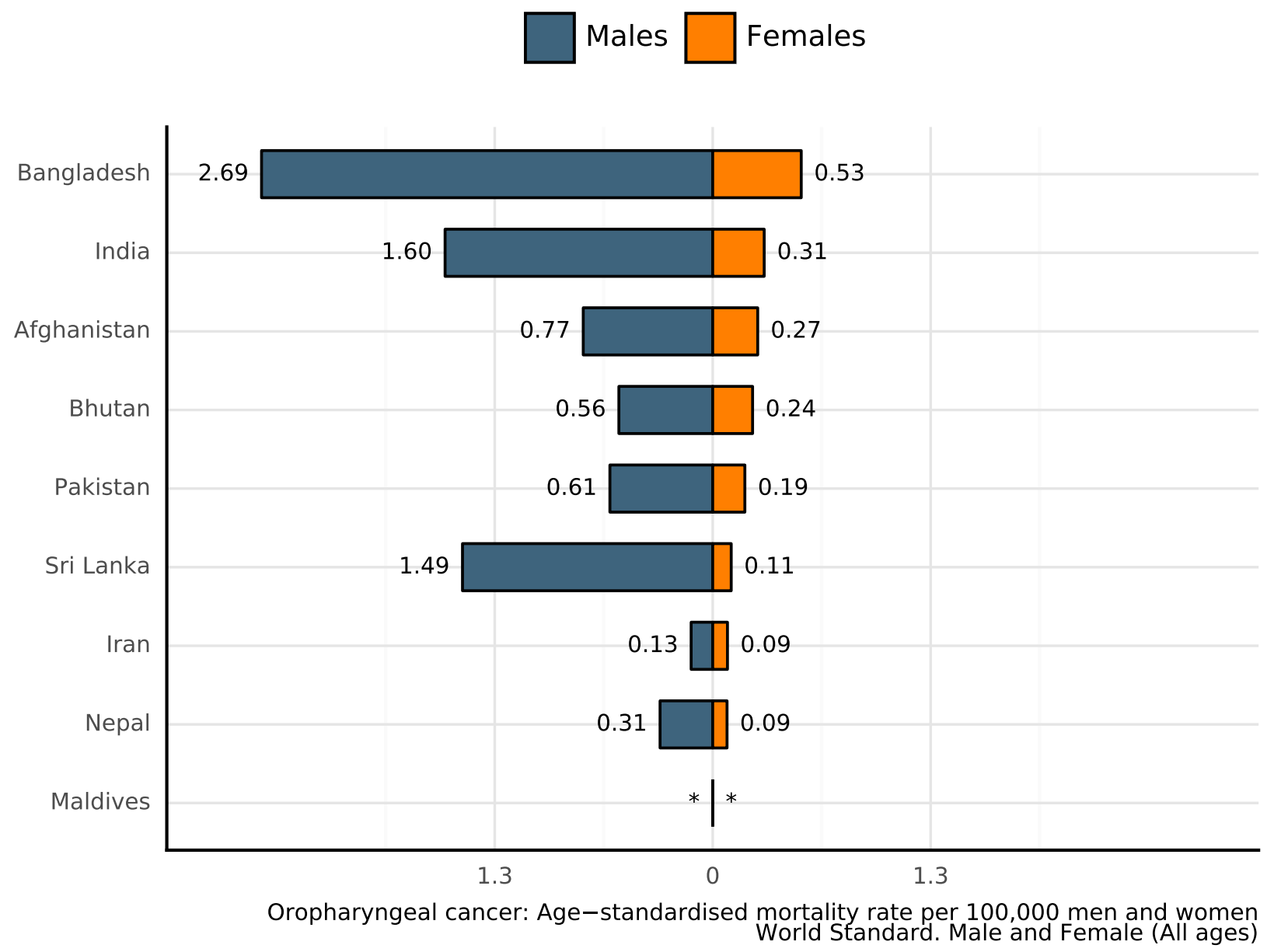

Data accessed on 27 Jan 2021

For more detailed methods of estimation please refer to http://gco.iarc.fr/today/data-sources-methods

${ }^{a}$ Rates per 100,000 men per year.

${ }^{b}$ Rates per 100,000 women per year.

* Rates are not available

Data Sources:

Ferlay J, Ervik M, Lam F, Colombet M, Mery L, Piñeros M, Znaor A, Soerjomataram I, Bray F (2020). Global Cancer Observatory: Cancer Today. Lyon, France: International Agency for Research on Cancer. Available from: https ://gco.iarc.fr/today, accessed [27 January 2021]. 
Figure 123: Annual number of deaths of oropharyngeal cancer among men by age group in India (estimates for 2020)

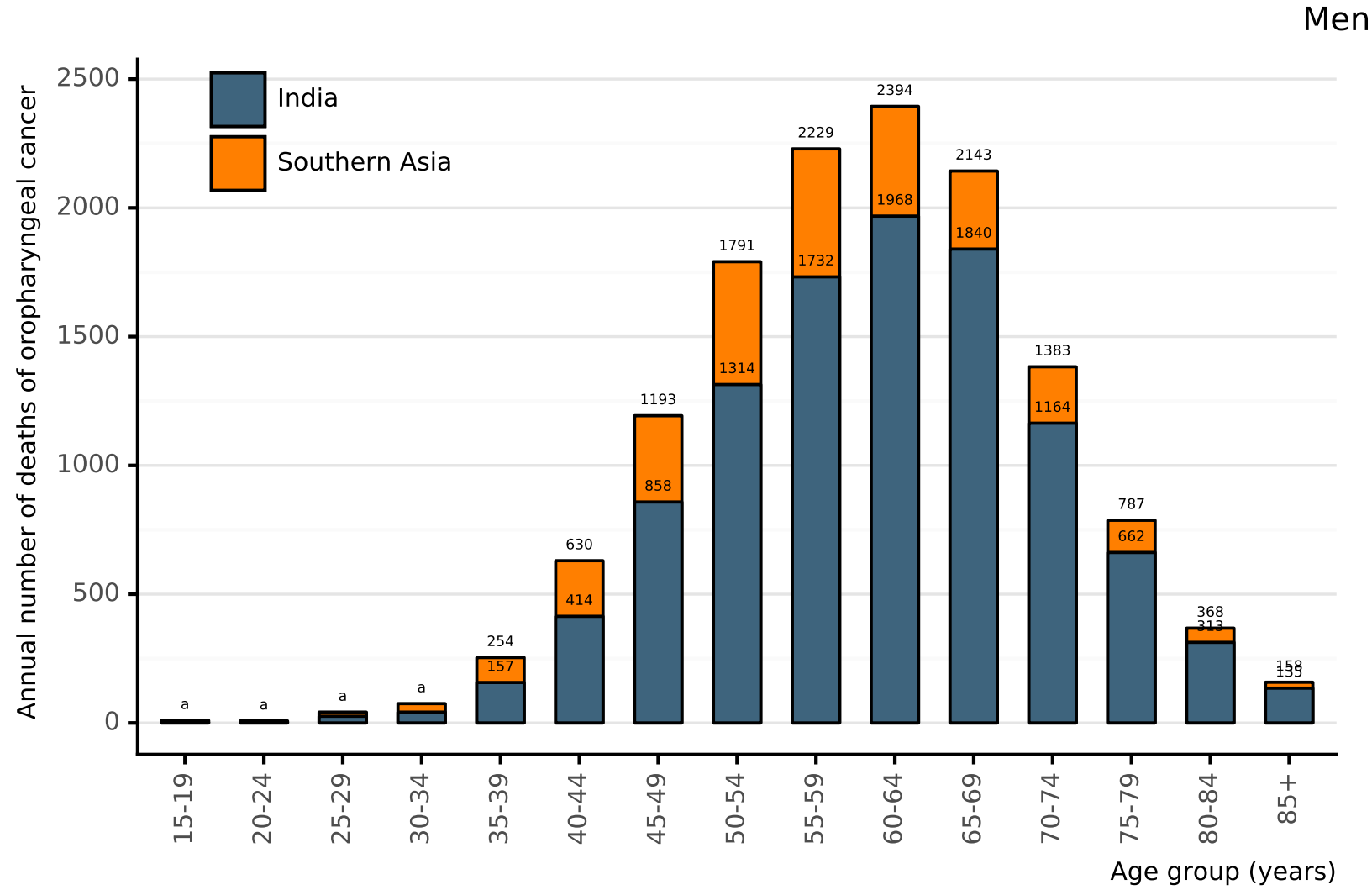

\section{Data accessed on 27 Jan 2021}

For more detailed methods of estimation please refer to http://gco.iarc.fr/today/data-sources-methods

${ }^{a} 2$ cases for India and 10 cases for Southern Asia in the 15-19 age group. 4 cases for India and 8 cases for Southern Asia in the 20-24 age group. 26 cases for India and 42 cases for Southern Asia in the 25-29 age group. 42 cases for India and 75 cases for Southern Asia in the 30-34 age group.

Ferlay J, Ervik M, Lam F, Colombet M, Mery L, Piñeros M, Znaor A, Soerjomataram I, Bray F (2020). Global Cancer Observatory: Cancer Today. Lyon, France: International Agency for Research on Cancer. Available from: https ://gco.iarc.fr/today, accessed [27 January 2021]. 
Figure 124: Annual number of deaths of oropharyngeal cancer among women by age group in India (estimates for 2020)

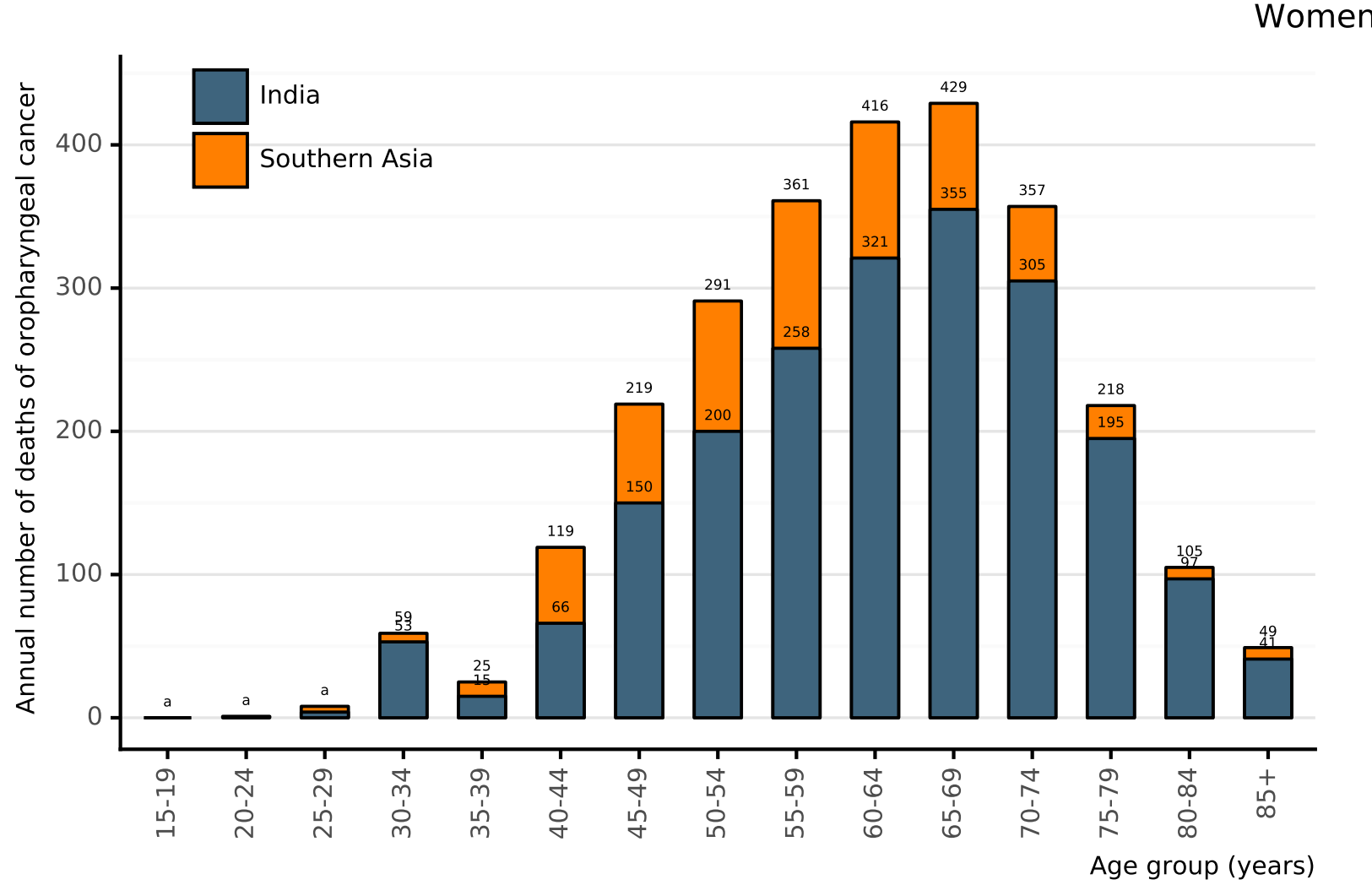

Data accessed on 27 Jan 2021

For more detailed methods of estimation please refer to http://gco.iarc.fr/today/data-sources-methods

${ }^{a} 0$ cases for India and 0 cases for Southern Asia in the 15-19 age group. 0 cases for India and 1 cases for Southern Asia in the 20-24 age group. 4 cases for India and 8 cases for Southern Asia in the 25-29 age group.

Data Sources:

Ferlay J, Ervik M, Lam F, Colombet M, Mery L, Piñeros M, Znaor A, Soerjomataram I, Bray F (2020). Global Cancer Observatory: Cancer Today. Lyon, France: International Agency for Research on Cancer. Available from: https ://gco.iarc.fr/today, accessed [27 January 2021]. 
Figure 125: Comparison of age-specific oropharyngeal cancer mortality rates among men by age in India, within the region, and the rest of world

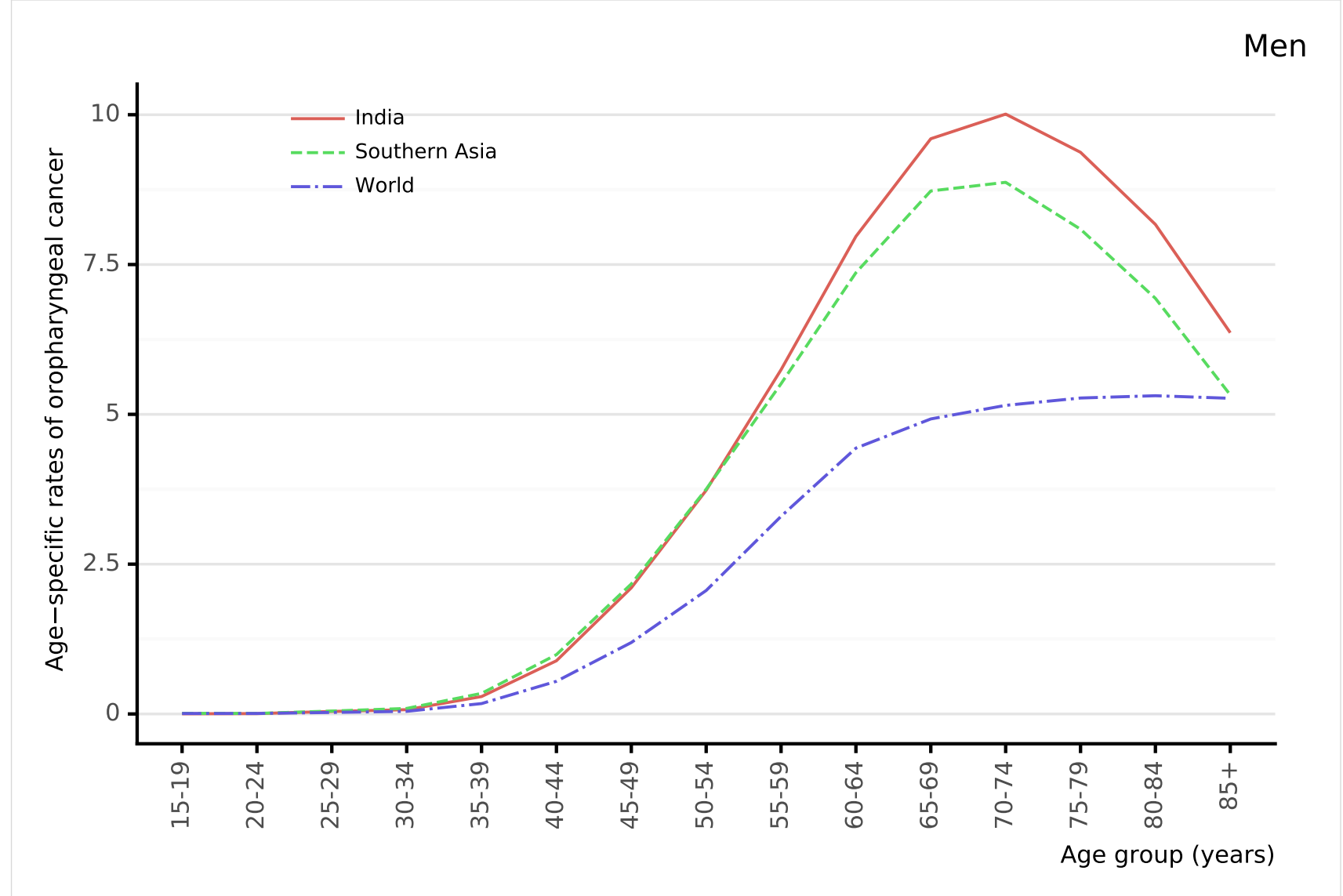

Data accessed on 27 Jan 2021

For more detailed methods of estimation please refer to http://gco.iarc.fr/today/data-sources-methods

$a$ Rer 100,000 men per year.

Data Sources:

Ferlay J, Ervik M, Lam F, Colombet M, Mery L, Piñeros M, Znaor A, Soerjomataram I, Bray F (2020). Global Cancer Observatory: Cancer Today. Lyon, France: International Agency for Research on Cancer. Available from: https://gco.iarc.fr/today, accessed [27 January 2021]. 
Figure 126: Comparison of age-specific oropharyngeal cancer mortality rates among women by age in India, within the region, and the rest of world

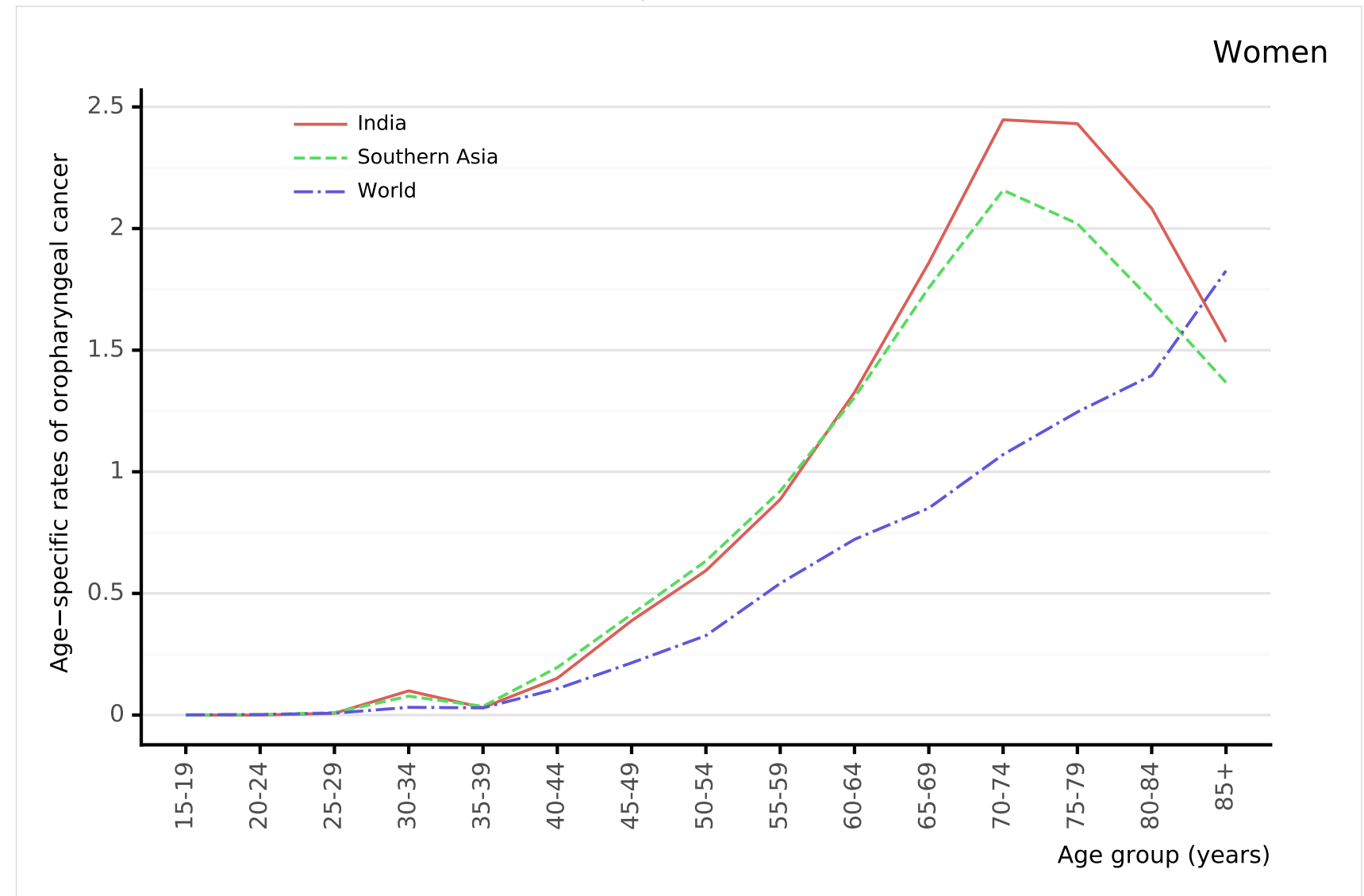

Data accessed on 27 Jan 2021

For more detailed methods of estimation please refer to http://gco.iarc.fr/today/data-sources-methods

${ }^{a}$ Rates per 100,000 women per year.

Data Sources:

Ferlay J, Ervik M, Lam F, Colombet M, Mery L, Piñeros M, Znaor A, Soerjomataram I, Bray F (2020). Global Cancer Observatory: Cancer Today. Lyon, France: International Agency for Research on Cancer. Available from: https ://gco.iarc.fr/today, accessed [27 January 2021]. 


\subsubsection{Oral cavity cancer mortality in India across Southern Asia}

Figure 127: Age-standardised mortality rates of oral cavity cancer of India (estimates for 2020)

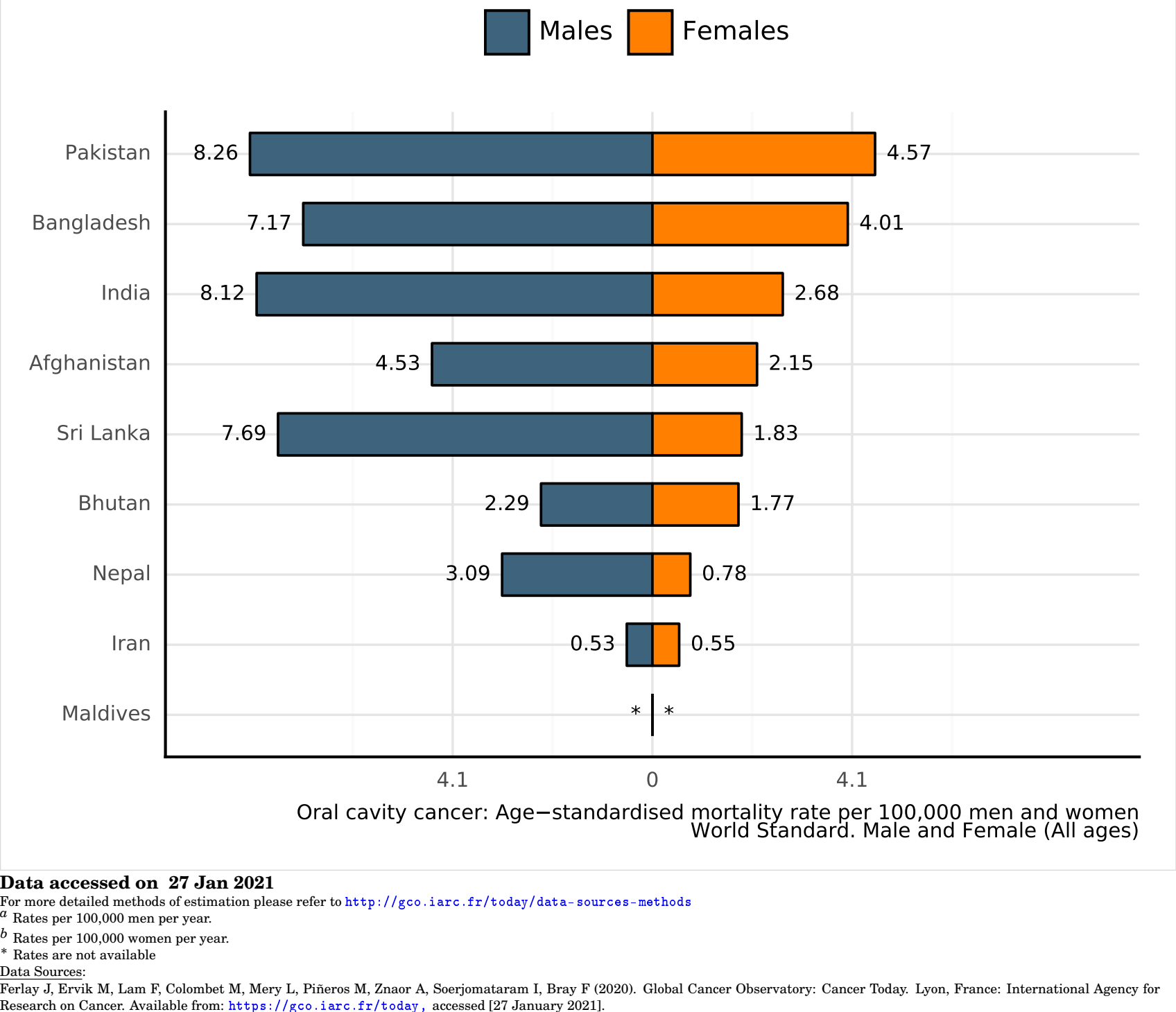


Figure 128: Annual number of deaths of oral cavity cancer among men by age group in India (estimates for 2020)

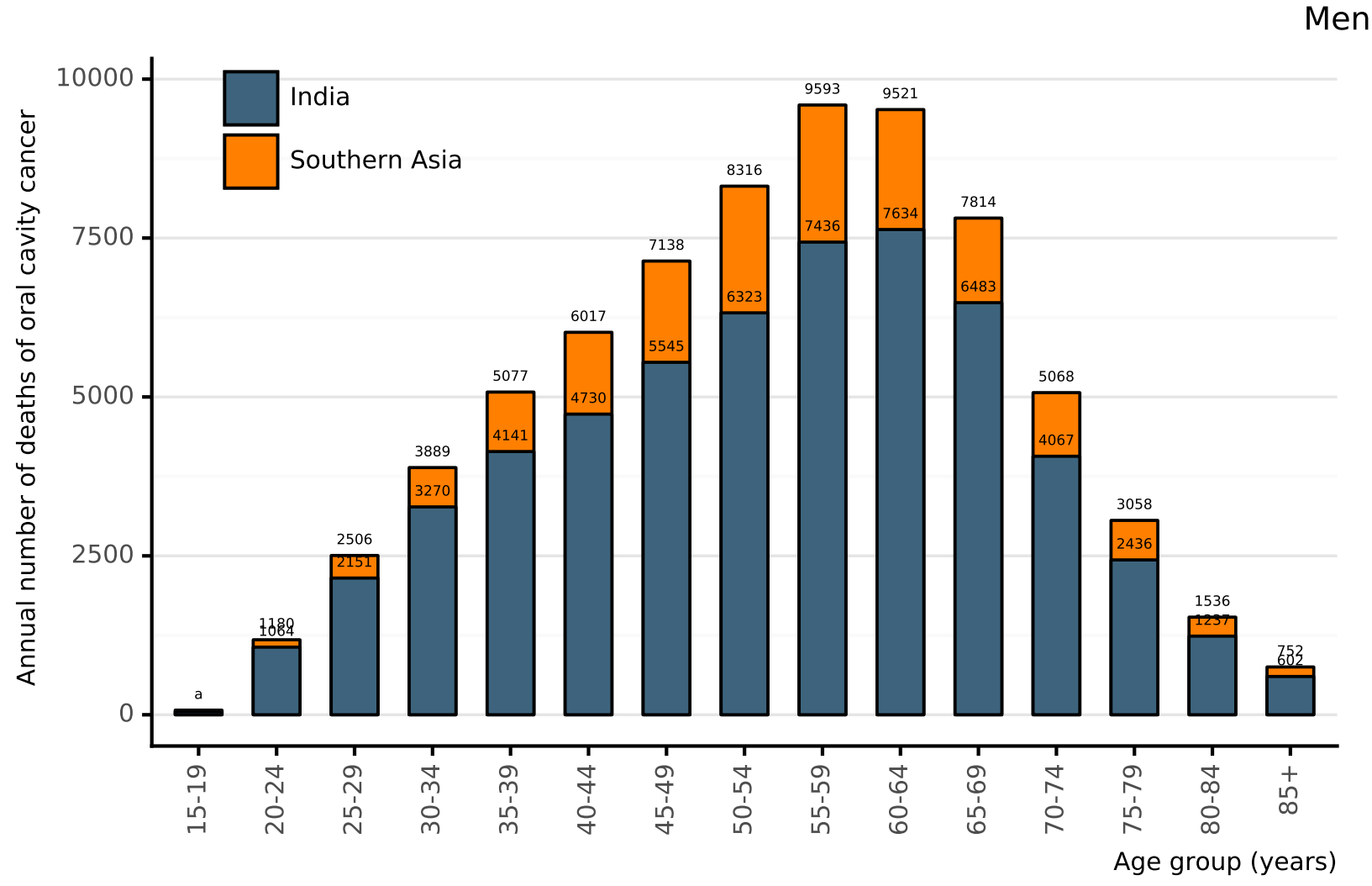

Data accessed on 27 Jan 2021

For more detailed methods of estimation please refer to http://gco.iarc.fr/today/data-sources-methods

${ }^{a} 52$ cases for India and 73 cases for Southern Asia in the 15-19 age group.

Data Sources:

Research on Cancer. Available from: https ://gco.iarc.fr/today, accessed [27 January 2021]. 
Figure 129: Annual number of deaths of oral cavity cancer among women by age group in India (estimates for 2020)

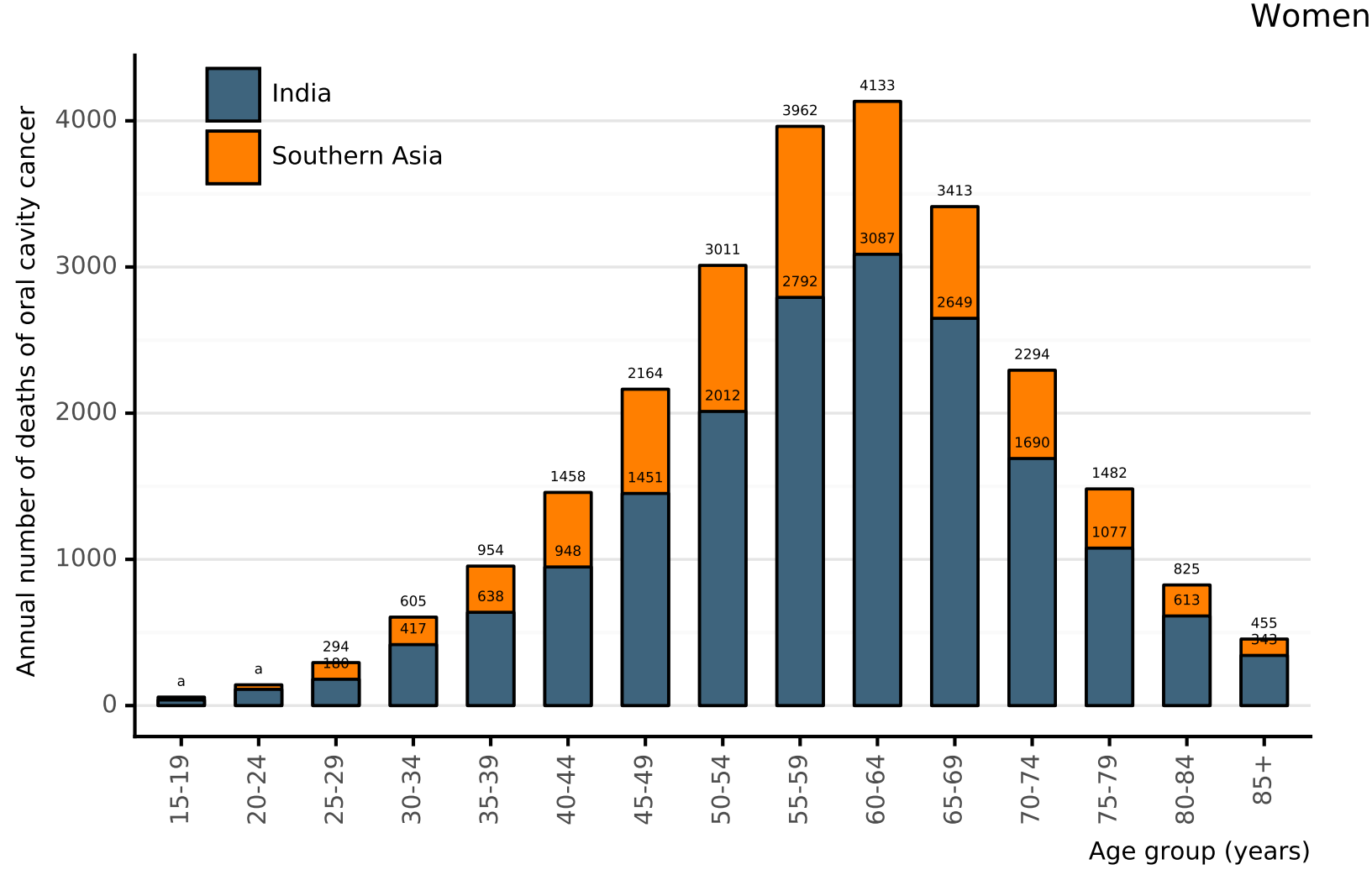

Data accessed on 27 Jan 2021

For more detailed methods of estimation please refer to http://gco.iarc.fr/today/data-sources-methods

${ }^{3} 38$ cases for India and 58 cases for Southern Asia in the 15-19 age group. 111 cases for India and 142 cases for Southern Asia in the 20-24 age group.

Ferlay J, Ervik M, Lam F, Colombet M, Mery L, Piñeros M, Znaor A, Soerjomataram I, Bray F (2020). Global Cancer Observatory: Cancer Today. Lyon, France: International Agency for Research on Cancer. Available from: https://gco.iarc.fr/today, accessed [27 January 2021]. 
Figure 130: Comparison of age-specific oral cavity cancer mortality rates among men by age in India, within the region, and the rest of world

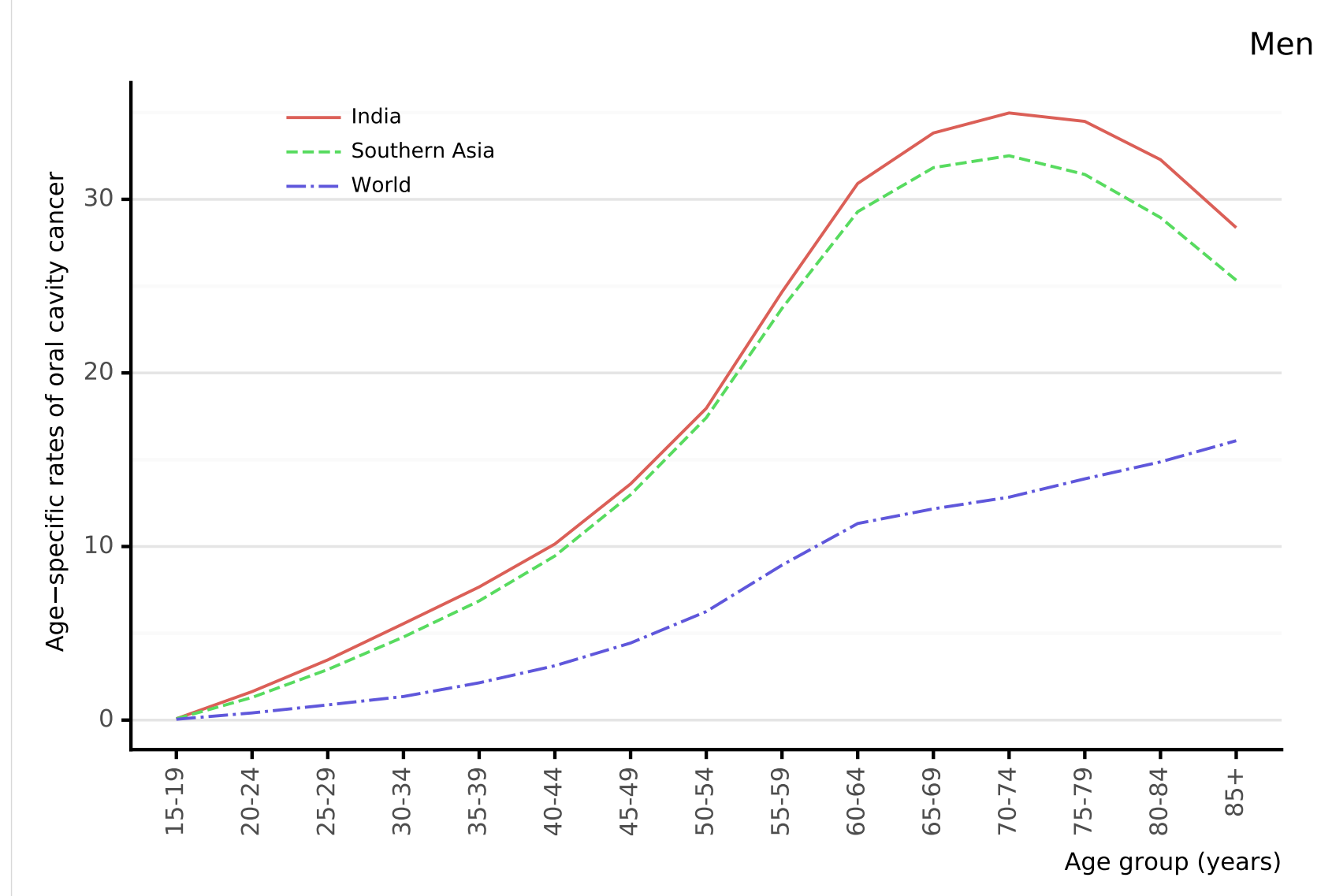

Data accessed on 27 Jan 2021

For more detailed methods of estimation please refer to http://gco.iarc.fr/today/data-sources-methods

${ }^{a}$ Rates per 100,000 men per year.

Ferlay J, Ervik M, Lam F, Colombet M, Mery L, Piñeros M, Znaor A, Soerjomataram I, Bray F (2020). Global Cancer Observatory: Cancer Today. Lyon, France: International Agency for Research on Cancer. Available from: https ://gco.iarc.fr/today, accessed [27 January 2021]. 
Figure 131: Comparison of age-specific oral cavity cancer mortality rates among women by age in India, within the region, and the rest of world

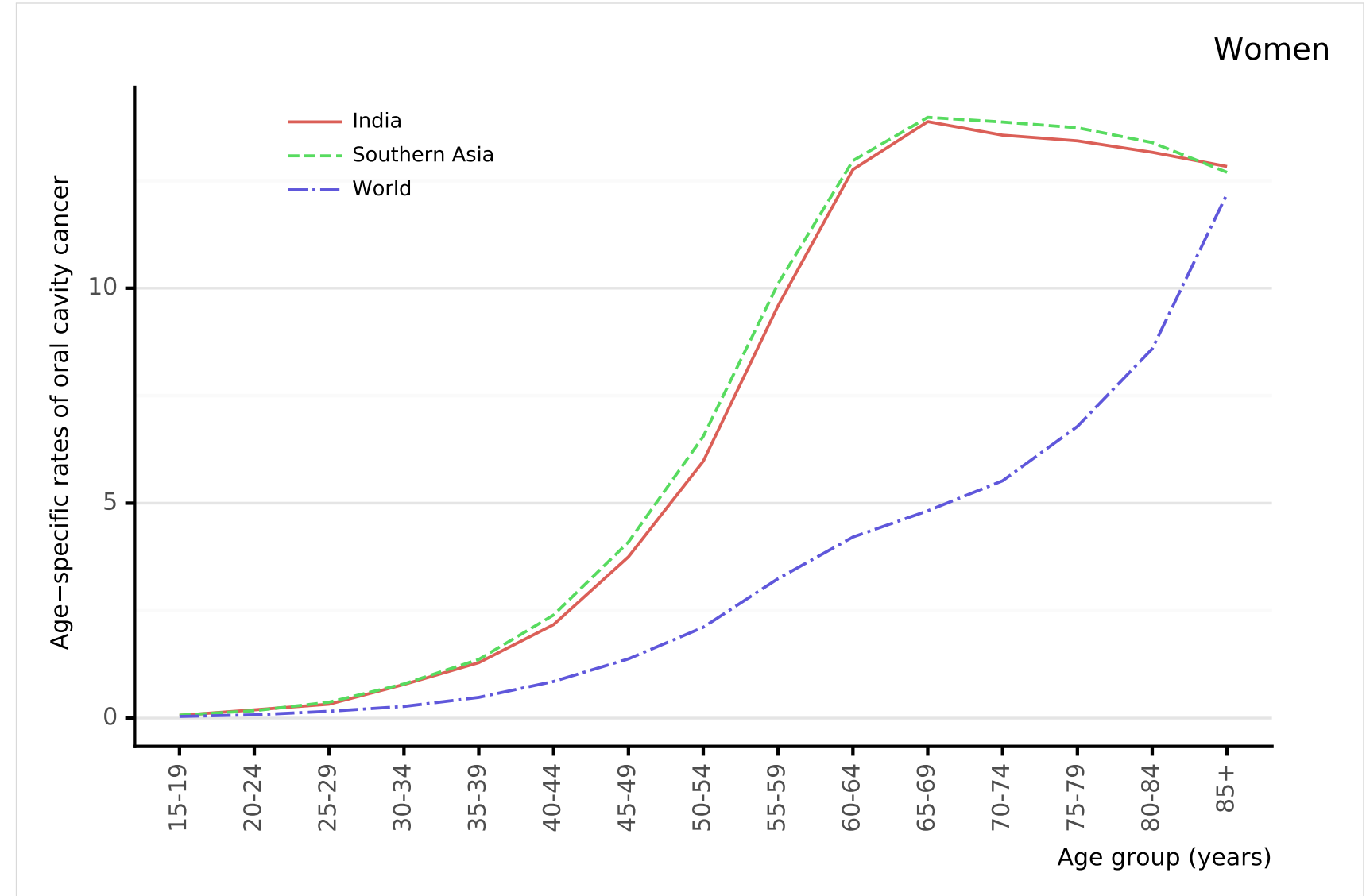

Data accessed on 27 Jan 2021

For more detailed methods of estimation please refer to http://gco.iarc.fr/today/data-sources-methods

${ }^{a}$ Rates per 100,000 women per year.

Ferlay J, Ervik M, Lam F, Colombet M, Mery L, Piñeros M, Znaor A, Soerjomataram I, Bray F (2020). Global Cancer Observatory: Cancer Today. Lyon, France: International Agency for Research on Cancer. Available from: https ://gco.iarc.fr/today, accessed [27 January 2021]. 


\subsubsection{Laryngeal cancer mortality in India across Southern Asia}

Figure 132: Age-standardised mortality rates of laryngeal cancer of India (estimates for 2020)

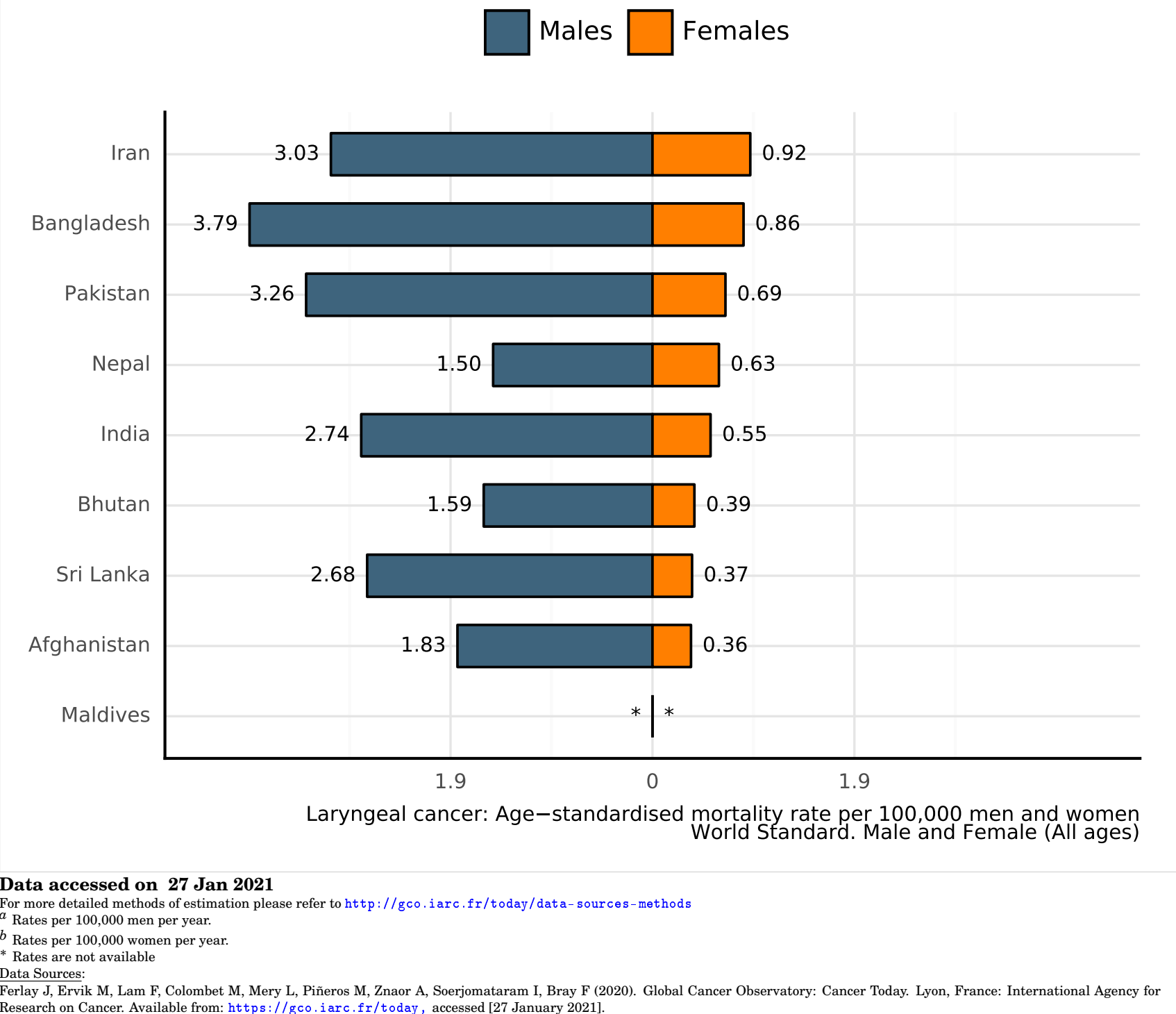


Figure 133: Annual number of deaths of laryngeal cancer among men by age group in India (estimates for 2020)

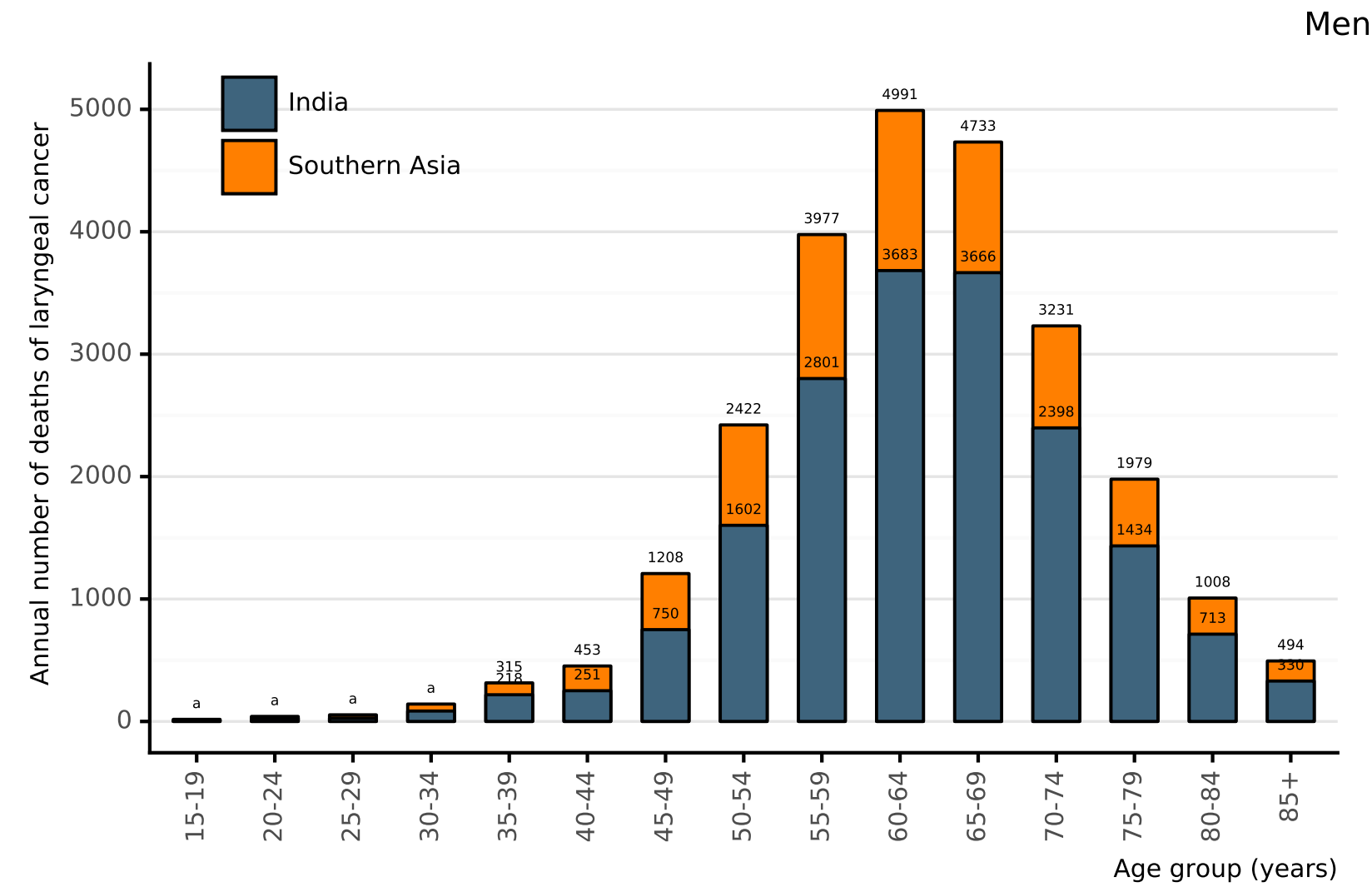

\section{Data accessed on 27 Jan 2021}

For more detailed method of estimation 2021

$a 9$ cases for India and 17 cases for Southern Asia in the 15-19 age group. 26 cases for India and 41 cases for Southern Asia in the 20-24 age group. 28 cases for India and 54 cases for Southern Asia in the 25-29 age group. 85 cases for India and 142 cases for Southern Asia in the 30-34 age group.

Ferlay J, Ervik M, Lam F, Colombet M, Mery L, Piñeros M, Znaor A, Soerjomataram I, Bray F (2020). Global Cancer Observatory: Cancer Today. Lyon, France: International Agency for Research on Cancer. Available from: https://gco.iarc.fr/today, accessed [27 January 2021]. 
Figure 134: Annual number of deaths of laryngeal cancer among women by age group in India (estimates for 2020)

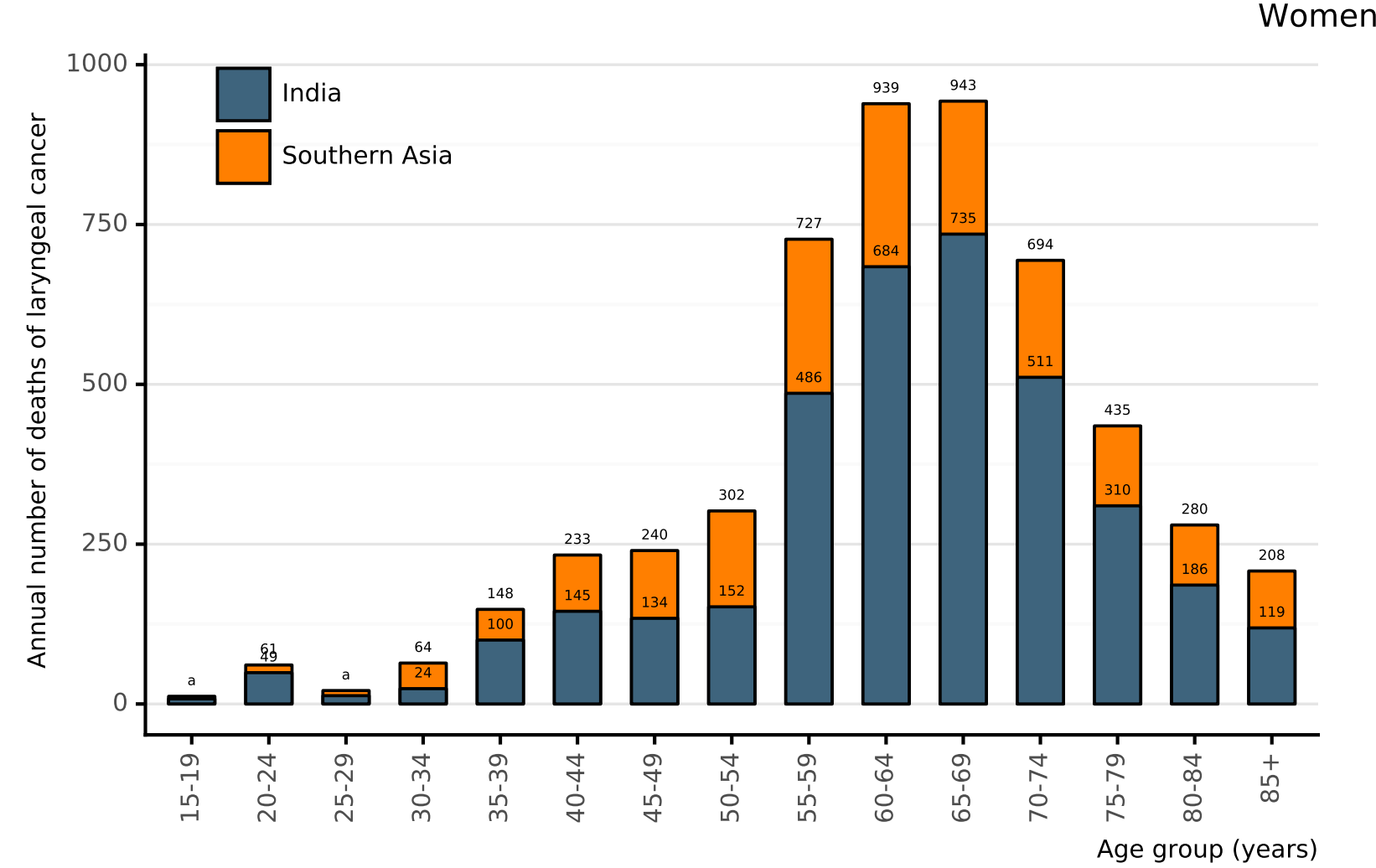

Data accessed on 27 Jan 2021

For more detailed methods of estimation please refer to http://gco.iarc.fr/today/data-sources-methods

a 8 cases for India and 12 cases for Southern Asia in the 15-19 age group. 13 cases for India and 21 cases for Southern Asia in the 25-29 age group.

Ferlay J, Ervik M, Lam F, Colombet M, Mery L, Piñeros M, Znaor A, Soerjomataram I, Bray F (2020). Global Cancer Observatory: Cancer Today. Lyon, France: International Agency for Research on Cancer. Available from: https://gco.iarc.fr/today, accessed [27 January 2021]. 
Figure 135: Comparison of age-specific laryngeal cancer mortality rates among men by age in India, within the region, and the rest of world

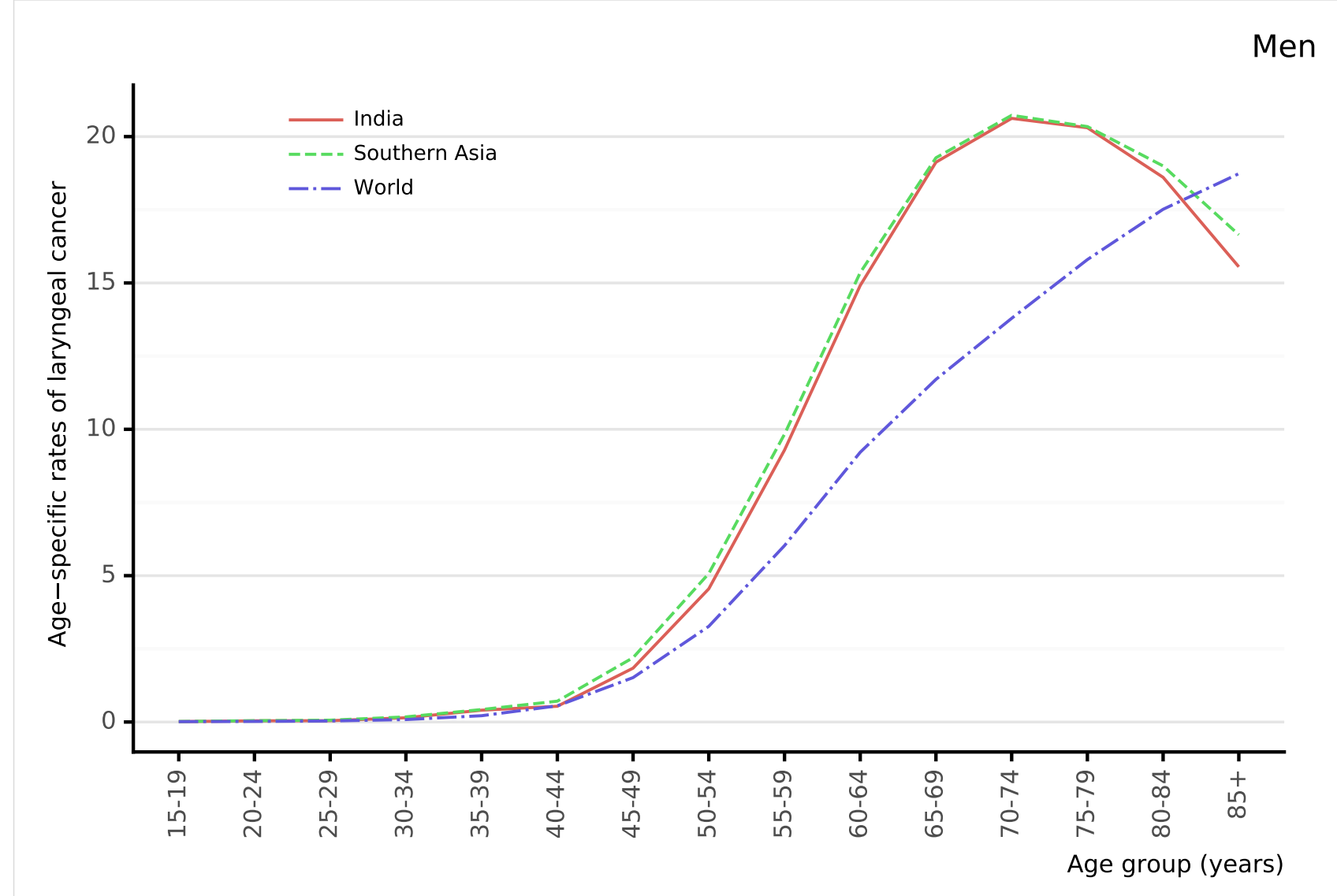

Data accessed on 27 Jan 2021

For more detailed methods of estimation please refer to http://gco.iarc.fr/today/data-sources-methods

${ }^{a}$ Rates per 100,000 men per year.

Data Sources:

Ferlay J, Ervik M, Lam F, Colombet M, Mery L, Piñeros M, Znaor A, Soerjomataram I, Bray F (2020). Global Cancer Observatory: Cancer Today. Lyon, France: International Agency for Research on Cancer. Available from: https://gco.iarc.fr/today, accessed [27 January 2021]. 
Figure 136: Comparison of age-specific laryngeal cancer mortality rates among women by age in India, within the region, and the rest of world

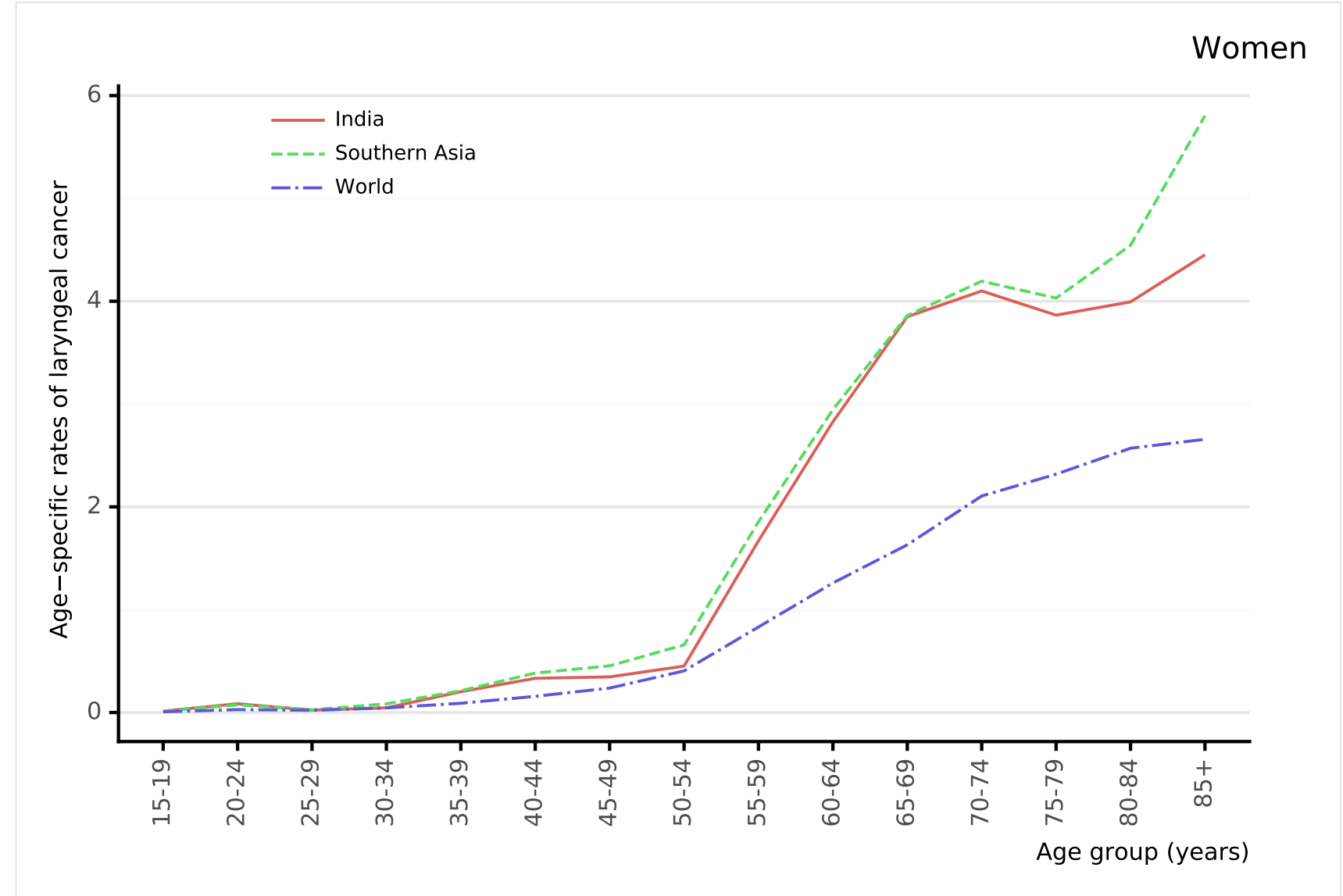

Data accessed on 27 Jan 2021

For more detailed methods of estimation please refer to http://gco.iarc.fr/today/data-sources-methods

${ }^{a}$ Rates per 100,000 women per year.

Ferlay J, Ervik M, Lam F, Colombet M, Mery L, Piñeros M, Znaor A, Soerjomataram I, Bray F (2020). Global Cancer Observatory: Cancer Today. Lyon, France: International Agency for Research on Cancer. Available from: https://gco.iarc.fr/today, accessed [27 January 2021]. 


\section{Glossary}

Table 49: Glossary

$\begin{array}{ll}\text { Term } & \text { Definition } \\ \text { Incidence is the number of new cases arising in a given period in a speci- } \\ \text { fied population. This information is collected routinely by cancer registries. } \\ \text { It can be expressed as an absolute number of cases per year or as a rate } \\ \text { per 100,000 persons per year (see Crude rate and ASR below). The rate } \\ \text { provides an approximation of the average risk of developing a cancer. } \\ \text { Mortality is the number of deaths occurring in a given period in a specified } \\ \text { population. It can be expressed as an absolute number of deaths per year } \\ \text { or as a rate per 100,000 persons per year. } \\ \text { The prevalence of a particular cancer can be defined as the number of per- } \\ \text { sons in a defined population who have been diagnosed with that type of } \\ \text { cancer, and who are still alive at the end of a given year, the survivors. Com- } \\ \text { plete prevalence represents the number of persons alive at certain point in } \\ \text { time who previously had a diagnosis of the disease, regardless of how long } \\ \text { ago the diagnosis was, or if the patient is still under treatment or is con- } \\ \text { sidered cured. Partial prevalence, which limits the number of patients to } \\ \text { those diagnosed during a fixed time in the past, is a particularly useful } \\ \text { measure of cancer burden. Prevalence of cancers based on cases diagnosed } \\ \text { within one, three and five are presented as they are likely to be of rele- } \\ \text { vance to the different stages of cancer therapy, namely, initial treatment } \\ \text { (one year), clinical follow-up (three years) and cure (five years). Patients } \\ \text { who are still alive five years after diagnosis are usually considered cured } \\ \text { since the death rates of such patients are similar to those in the general } \\ \text { population. There are exceptions, particularly breast cancer. Prevalence is } \\ \text { presented for the adult population only (ages } 15 \text { and over), and is available } \\ \text { both as numbers and as proportions per 100,000 persons. } \\ \text { Prevalence }\end{array}$

Data on incidence or mortality are often presented as rates. For a specific tumour and population, a crude rate is calculated simply by dividing the

Crude rate number of new cancers or cancer deaths observed during a given time period by the corresponding number of person years in the population at risk. For cancer, the result is usually expressed as an annual rate per 100,000 persons at risk.

An age-standardised rate (ASR) is a summary measure of the rate that a population would have if it had a standard age structure. Standardization is necessary when comparing several populations that differ with respect to age because age has a powerful influence on the risk of cancer. The ASR is a weighted mean of the age-specific rates; the weights are taken from population distribution of the standard population. The most frequently

ASR (age-standardised rate) used standard population is the World Standard Population. The calculated incidence or mortality rate is then called age-standardised incidence or mortality rate (world). It is also expressed per 100,000. The world standard population used in GLOBOCAN is as proposed by Segi [1] and modified by Doll and al. [2]. The age-standardised rate is calculated using 10 age-groups. The result may be slightly different from that computed using the same data categorised using the traditional 5 year age bands. 
Table 49 - continued from previous page

\begin{tabular}{l|l} 
Term & Definition \\
& Cumulative incidence/mortality is the probability or risk of individuals get- \\
ting/dying from the disease during a specified period. For cancer, it is ex- & pressed as the number of new born children (out of 100, or 1000) who would \\
be expected to develop/die from a particular cancer before the age of 75 if \\
they had the rates of cancer observed in the period in the absence of com- \\
peting causes.
\end{tabular}
women

Cervical Intraepithelial Neoplasia (CIN) / Squamous Intraepithelial Lesions (SIL)

Low-grade cervical lesions (LSIL/CIN-1)

High-grade cervical lesions (HSIL / CIN-2 / CIN-3 / CIS)
SIL and CIN are two commonly used terms to describe precancerous lesions or the abnormal growth of squamous cells observed in the cervix. SIL is an abnormal result derived from cervical cytological screening or Pap smear testing. CIN is a histological diagnosis made upon analysis of cervical tissue obtained by biopsy or surgical excision. The condition is graded as CIN 1,2 or 3 , according to the thickness of the abnormal epithelium $(1 / 3,2 / 3$ or the entire thickness).

Low-grade cervical lesions are defined by early changes in size, shape, and number of ab-normal cells formed on the surface of the cervix and may be referred to as mild dysplasia, LSIL, or CIN-1.

High-grade cervical lesions are defined by a large number of precancerous cells on the sur-face of the cervix that are distinctly different from normal cells. They have the potential to become cancerous cells and invade deeper tissues of the cervix. These lesions may be referred to as moderate or severe dysplasia, HSIL, CIN-2, CIN-3 or cervical carcinoma in situ (CIS).

Carcinoma in situ Preinvasive malignancy limited to the epithelium without invasion of the (CIS) basement membrane. CIN 3 encompasses the squamous carcinoma in situ.

Invasive cervical can- If the high-grade precancerous cells invade the basement membrane is cer (ICC) / Cervical called ICC. ICC stages range from stage I (cancer is in the cervix or uterus cancer only) to stage IV (the cancer has spread to distant organs, such as the liver).

Adenocarcinoma Invasive tumour with glandular and squamous elements intermingled 


\section{Acknowledgments}

This report has been developed by the Unit of Infections and Cancer, Cancer Epidemiology Research Program, at the Institut Català d'Oncologia (ICO, Catalan Institute of Oncology). This report was supported by a grant from the Instituto de Salud Carlos III (Spanish Government) through the projects PI18/01137, PI21/00982, PI22/00219 and CIBERESP CB06/02/0073, and the Secretariat for Universities and Research of the Department of Business and knowledge of the Government of Catalonia grants to support the activities of research groups (SGR 2017-2021) (Grant number 2017SRG1718 and 2021SGR01029). The report has also received funding from the European Union's Horizon 2020 research and innovation program under grant agreement No. 847845. We thank the CERCA Program / Generalitat de Catalunya for institutional support. The HPV Information Centre is being developed by the ICO. The Centre was originally launched by ICO with the collaboration of WHO's Immunisation, Vaccines and Biologicals (IVB) department and support from the Bill and Melinda Gates Foundation.

\section{Cancer Epidemiology Research Program, Catalan Institute of Oncology (ICO), Institut d'Investigació Biomèdica de Bellvitge (IDIBELL), in alphabetic order}

Albero G, Amarilla S, Bosch FX, Bruni L, Collado JJ, de Sanjosé S, Gómez D, Mena M, Muñoz J, Ruiz FJ, Serrano B.

International Agency for Research on Cancer (IARC)

\section{Note to the reader}

Anyone who is aware of relevant published data that may not have been included in the present report is encouraged to contact the HPV Information Centre for potential contributions.

Although efforts have been made by the HPV Information Centre to prepare and include as accurately as possible the data presented, mistakes may occur. Readers are requested to communicate any errors to the HPV Information Centre, so that corrections can be made in future volumes.

\section{Disclaimer}

The information in this database is provided as a service to our users. Any digital or printed publication of the information provided in the web site should be accompanied by an acknowledgment of HPV Information Centre as the source. Systematic retrieval of data to create, directly or indirectly, a scientific publication, collection, database, directory or website requires a permission from HPV Information Centre.

The responsibility for the interpretation and use of the material contained in the HPV Information Centre lies on the user. In no event shall the HPV Information Centre be liable for any damages arising from the use of the information.

\section{Licensed Logo Use}

Use, reproduction, copying, or redistribution of HPV Information Centre logo is strictly prohibited without written explicit permission from the HPV Information Centre.

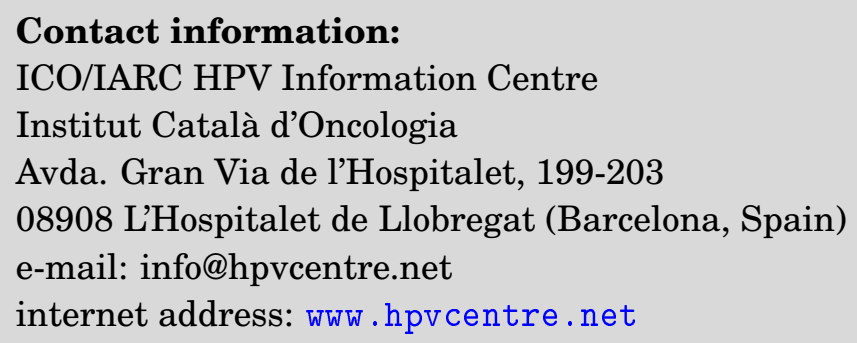

